\title{
QC
}

B351i

1892

Mieroseopes.

AeeEssORIES.
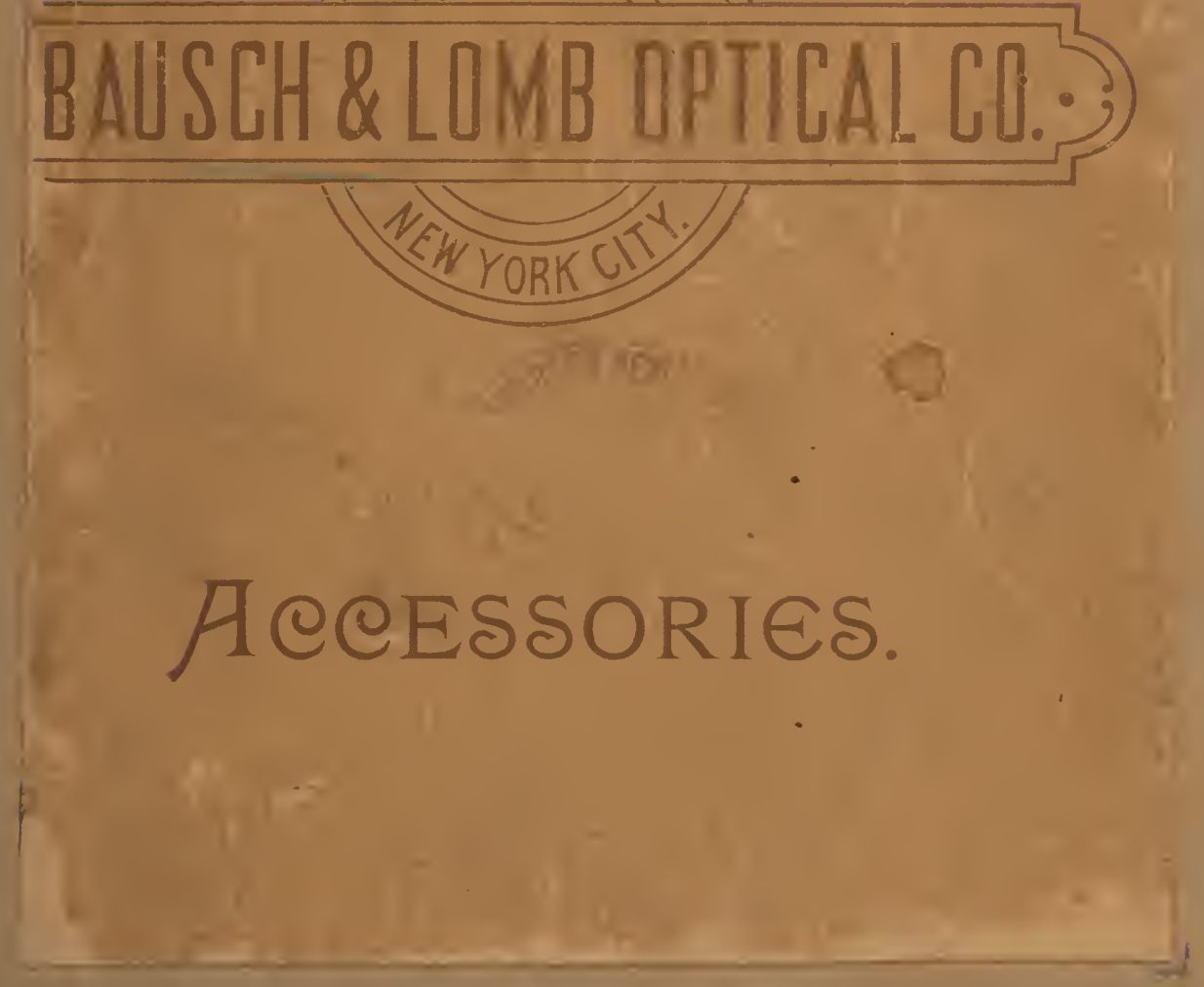


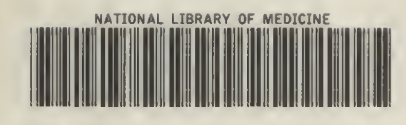

NLM 00097486 9

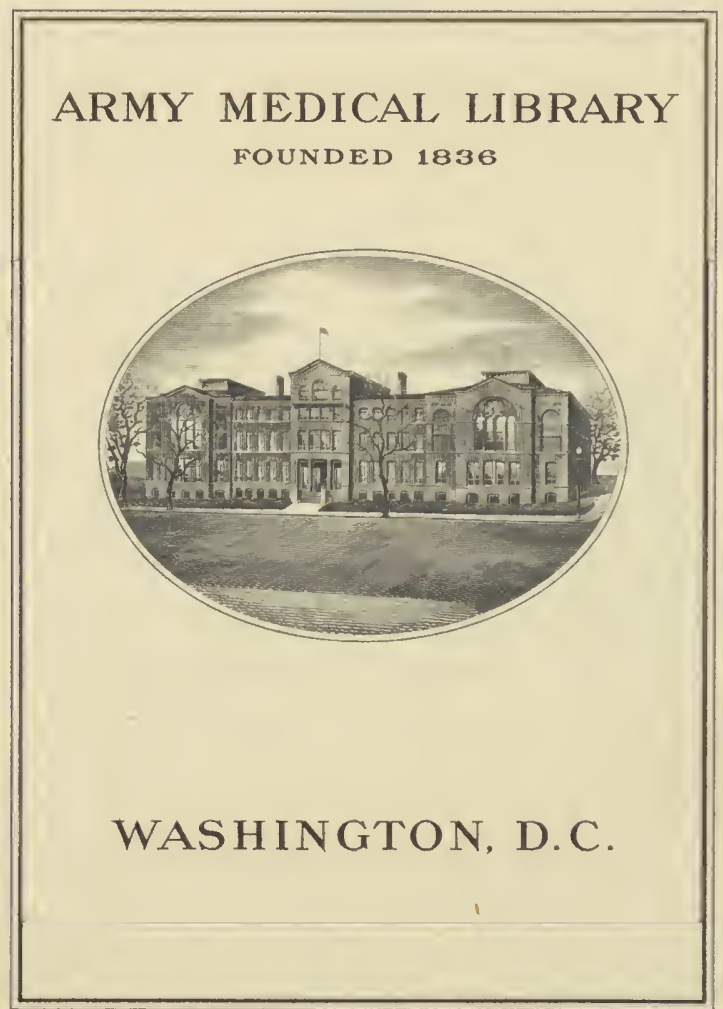






\section{ILLUSTRATED CATALOGUE}

\section{Mieroseopes, OBJEeTIVES}

. AND .

\section{ACeESSORIES,}

MANUFACTURED BY

Đausch \& Lomb Đptical Co.

FACTORY AND OFFICE :

515-543 N. ST. PAUL STREET, ROCHESTER, N. Y.

P. O. DRAWER 1033.
BRANCH OFFICE :

48 AND 5O MAIDEN LANE,

NEW YORK CITY.

P. O. BOX 13:. 
$-3251$

$183 E$

PRESS OF A. J. WEGMAN, ROCHESTER, M. Y 


\section{TERMS.}

Goods should be ordered under their respective letters and numbers.

Our terms are cash at catalogue prices.

Parties unknown to us, when ordering, should give satisfactory reference; otherwise remittance should accompany the order. Remit by Post-office or Express Order, or New York Draft, made payable to us. Expense of collecting, if any, must be defrayed by the purchaser. Money in letters is at the risk of sender.

Goods will be sent by Express C. O. D., expense of collection to be borne by purchaser. One-fourth of total amount should accompany order.

We malie 110 churge for preking.

We assume responsibility for all goods shipped by Express uring transportation and rectify any alluges which may (०) 111$)$

Freight should never be used forwany of our goods. Shipmeuts so ordered are at the rist: of the purchaser.

Goods sent by mail are likewise at purchaser's risk.

Correspondents are requested to give exact Post-office address, and state distinctly by what Express line goods are to be shipped.

When goods are returned for exchange, repair or otherwise, a tag bearing sender's name and address should be attached; this is very essential and will avoid delays.

Our book, "Manipulation of the Microscope" (second edition, bound in cloth, price 75 cents), is furnished free to every purchaser of one of our instruments. In case it is desired to study the subject before making a selection, the book should be paid for, but we give credit for the amount when an instrument is purchased at its full price. It gives all necessary information on the principles and leads to the intelligent use of the microscope in plain and concise language. It is spoken of in high terms by those most conversant with the subject of microscopy. 


\section{PREFACE.}

After years of indefatigable and unceasing efforts to reduce the cost of production of microscopes, so as to bring them within the means of the practitioner and student, to offer such patterns as will meet the variety of tastes and requirements, to raise the standard of excellence of the optical and mechanical perfection, we have reached the gratifying state, which may be aptly called the first era of this portion of our business. With the issue of this edition of our catalogue we have

\section{MADE AND SOLD 10,000 MICROSCOPES,}

not including the thousands of dissecting microscopes.

There are few colleges or other educational institutions with well equipped microscopical laboratories which have not our instruments in constant use. They are used by our Government in its various departments. The most eminent individual microscopists and practitioners throughout this country use and recommend our products.

This result is not alone due to the worth of our products, but in a large measure to the kindly and patriotic desire of our scientists to use American - microscopes, and to see their production successfully carried on within our borders. That they possess unusual merit is evinced by the fact that a demand has arisen for them in European countries.

This issue is entirely revised and provided almost throughout with new illustrations, showing new apparatus, as well as giving exact representations of instruments which have undergone changes to meet modern requirements and improvements in structure.

BAUSCH \& LOMB OPTICAL CO.

June 1892. 


\section{IMPORTANT FACTS.}

Buly American. Microscopes.-The development of our instruments is the result of suggestions from the most eminent American scientists, and they are therefore particularly well adapted to American wants. The practical advantages are that they may be obtained in short time, and with the absolute assurance that they are the best of their kind, and that any repairs which may be required are quickly and cheaply done, and bring an instrument up to its original excellence.

We gurrantee cull our moducts.-In doing this we are fully cognizant of the responsibility and adequately in position to accomplish it. Whenever it is possible, we apply special machinery, which we devise and build, and there is probably no optical establishment in the world which possesses such a quantity of precise and delicate tools. As adjunct to these we have in our employ a class of mechanics of superior accomplishments. All work is under our personal supervision, and none is sent out until after a painstaking personal scrutiny.

We offer a larger variety of instruments than any manufrreturer in the world.-This variety does not exist for the sake of variety, but is retained to meet the difference of tastes and requirements. Eacli instrument offers advantages either in price, size or utility.

All approvetus enumeruted is produced entipoly rt our fuctory and umler our constunt personal suprrision.-It is almost impossible for faulty work to pass unnoticed. In a business so extensive as ours, however, this may occasionally occur, but when so, we are thankful to have our attention drawn to the same and cheerfully remedy any defects.

We livep a stork of all cpprerretus on hrun.-While this is of ten difficult on account of the constantly increasing demand for our products, we bend all our efforts to keep pace, and ordinarily are in condition to supply any demand promptly. In this connection we may state that we supplied the United States Government with 300 microscopes for the inspection of pork, which were delivered within $t \boldsymbol{m}$ months from date of order.

We guarantee the safe arrival of our instruments uhen shipped by Expless.-A purchaser may therefore rely upon receiving an instrument in perfect condition. If any accident should occur, we remedy the defect. 
We malie exchrnges in owr morlucts.-This is important, as purchasers often find that certain apparatus is unsuitable for the work intended. We make the condition, however, that articles to be exchanged correspond with our current catalogue, and that we be remunerated for putting articles in salable condition.

Our Arar-tubes are cll gradurted with the exception of a few inexpensive forms. Besides this, they are all arranged to be used for the short and long standards, which have been established by the American Society of Microscopists.

It is with pleasure that we announce to the scientific world that by an agreement with the well-known firm of

\section{CARL ZEISS OF JENA,}

we are made the sole manufacturers under license of the American patents of their photographic lenses, which we have this year introduced into the American market. Without desiring to enlarge on this subject, it is gratifying to us, as no doubt it is to our patrons, to show the good feeling existing between the two firms, and the esteem in which they hold one another.

Our photographic catalogue, containing a list of different series of ZeissAnastigmat, Rapid Universal and Alvan G. Clark Lenses, as well as Diaphragm Shutter, will be sent to any address.

BAUSCH \& LOMB OPTICAL CO. 


\section{Gortinental Mligroseopes.}

Following out the principle of giving the public whatever there may be a demand for, we are now making a Series of these microscopes which correspond with the principal types of the instruments supplied by the best European Continental makers.

IVe have endeavored to combine the best features of the various patterns in our instruments, and have made some modifications at the suggestion of eminent gentlemen who favor this type, such as larger stages and broader bases, so that for solidity and comfort of working, we believe that ours possess advantages.

The working parts are made to work with the greatest smoothness, and the finish as well as perfection of the optical adjuncts, are of the highest order.

The demand for these instruments has been especially from educational institutions, and it is our object to supply them for this purpose at prices which meet those of European productions, when imported duty free. 


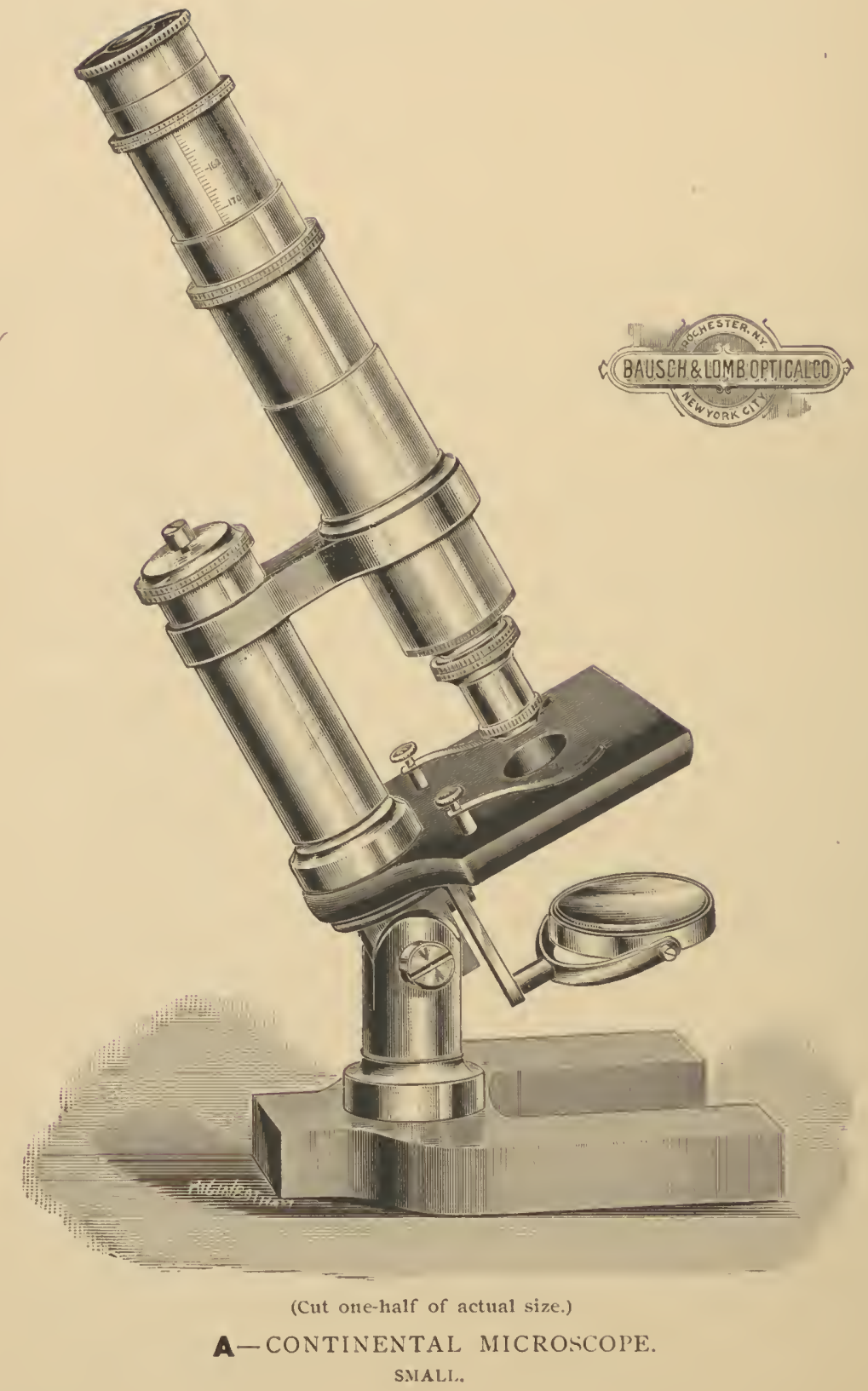




\section{A GonTINenTAL MICROSCOPE.}

The base of this stand has the horseshoe form, and is of japanned iron. Pillar is of brass; the stage is square and has spring clips which are readily removable; a revolving diaphragm is attached to the under side of the stage having four different size apertures. The mirror-bar is secured to the arm and can be swung to any obliquity below the stage; the mirrors are plane and concave. Coarse adjustment is by sliding tube, and fine adjustment by micrometer screw acting on triangular bearing of the arm. Nain tube is provided with drawtube, which will allow extension of tubes to the lut andard.

The instrument is made in two forms:

A, with solid pillar and arm;

AA, with joint for inclination.

Eyepieces are the Continental, objectives of Series

Upright polished case with receptacles for eyepieces and objectives accompanies the outfit.

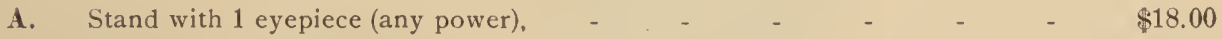

A1. Stand with 1 eyepiece and $\frac{2}{3}$ in. objective, $\quad$ - $\quad$ - $\quad \ldots \quad$ - 25.00

A2. Stand with 1 eyepiece and $\frac{2}{8}$ in. and $\frac{1}{6}$ in. objectives, _ $\quad$ - 40.00

43. Stand with 2 eyepieces and $\frac{2}{3}$ in. and $\frac{1}{6}$ in. objectives, - _ $\quad$ - $\quad 43.00$

A4. Stand with 2 eyepieces and 2 in., 3 in. and $\frac{1}{6}$ in. ohjectives, _ $\quad$ - 49.00

AA. Stand with 1 eyepiece (any power), $\quad$ - $\quad$ - $\quad$ - $\quad$ - $\quad$ - $\quad$ - 20.00

AA1. Stand with 1 eyepiece and $\frac{2}{3}$ in. objective, - _ _ _ _ $\quad$ - 27.00

AA2. Stand with 1 eyepiece and $\frac{2}{3}$ in. and $\frac{1}{6}$ in, objectives, - _ _ $\quad 42.00$

A A3. Stand with 1 eyepiece and 2 in., $\frac{2}{3}$ in. and $\frac{1}{6}$ in. objectives, _ $\quad 48.00$

AA4. Stand with 2 eyepieces and $\frac{2}{3}$ in. and $\frac{1}{6}$ in. objectives, - _ _ $\quad 45.00$

AA5. Stand with 2 eyepieces and 2 in., $\frac{2}{3}$ in. and $\frac{1}{6}$ in. objectives, $\quad$ - $\quad 51.00$

Double nosepiece, brass finish extra, $\quad$ - $\quad$ - $\quad$ - $\quad$ - $\quad$ - 5.00

For table of magnifying powers, refer to page $4 \bar{i}$. 


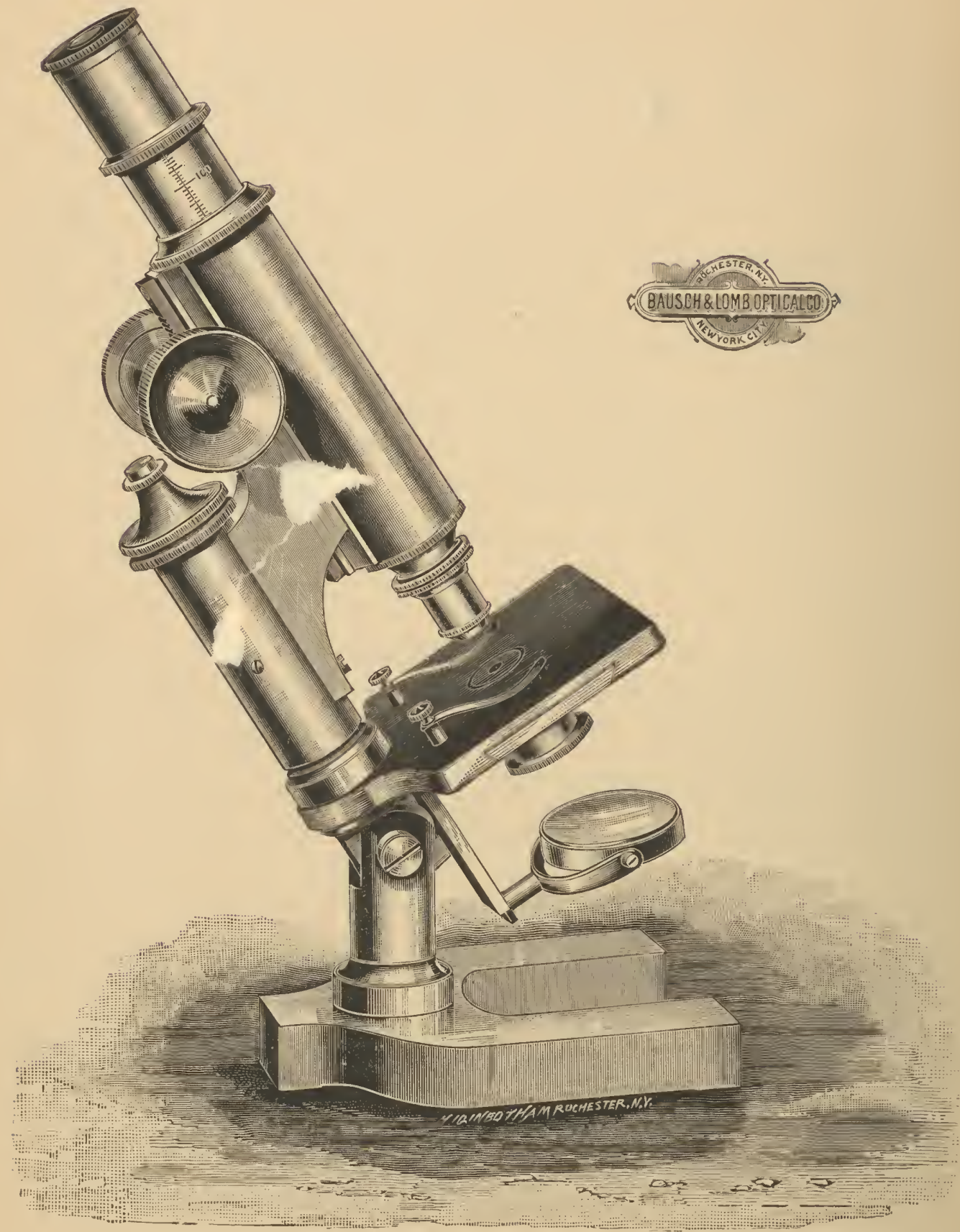

(Cut one-half of actual size.)

BB-CONTINENTAL MiCROSCOPE. MEDIUM. 


\section{В-CONTINENTAL MICROSCOPE.}

(MEDIUN.)

This microscope is made of brass throughout, highly polished and lacquered. The base is of larger dimensions than any of the foreign instruments, and therefore more firm, particularly when the body is inclined. The stage is also of large size, thus allowing the use of culture slides without the danger of tilting; a groove is provided on its lower surface for the slide with cylinder diaphragms, for convenience called slide A. This slide may be replaced by another (slide B), carrying standard size sub-stage, arranged to be centered, provided with our dome diaphragm. To this may also be fitted any of our regular sub-stage accessories, particularly the series of sub-stage condensers. Fine adjustment is by large micrometer screw and works on the triangular bearing of the arm. The main tube has a draw-tube, which, when contracted, gives short standard of tube length with double nosepiece. The draw-tube may be extended and is graduated in millimeters.

The instrument is made in two forms:

B, with joint for inclination and sliding tube for coarse adjustment.

BB, with joint for inclination, and rack and pinion for coarse adjustment

Eyepieces are the Continental, objectives of Series I

Upright polished case, with receptacles for eyepieces and objectives, accompanies the outfit.

B. Stand with 1 eyepiece (any power), $\quad$ - $\quad \ldots \quad \ldots \quad \ldots \quad$ - $\quad$ - $\quad \$ 25.00$

B1. Stand with 1 eyepiece and $\frac{2}{3}$ in. and $\frac{1}{b}$ in, objectives, $\quad$ - $\quad$ - $\quad 47.00$

B2. Stand with 1 eyepiece and 2 in., $\frac{2}{3}$ in. and $\frac{1}{6}$ in. objectives, _ $\quad 53.00$

B:3. Stand with 2 eyepieces and $\frac{2}{3}$ in. and $\frac{1}{6}$ in. objectives, _ _ _ $\quad 50.00$

B4. Stand with 2 eyepieces and 2 in., $\frac{2}{3}$ in. and $\frac{1}{6} \mathrm{in}$. objectives, - 56.00

B.5. Stand with 2 eyepieces and $\frac{2}{3}$ in., $\frac{1}{6}$ in. and $\frac{1}{12}$ in, oil immersion, objectives, $\quad 9.5 .00$

B6. Stand with 2 eyepieces and 2 in., $\frac{2}{3}$ in., $\frac{1}{6}$ in. and $\frac{1}{12}$ in. oil immersion, objectives, 101.00

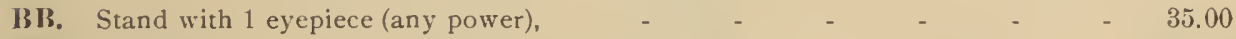

B B1. Stand with 1 evepiece and $\frac{2}{3}$ in, and $\frac{1}{6}$ in, objectives, $\quad$ - $\quad$ - 5 i.00

B Bะ. Stand with 1 eyepiece and 2 in., $\frac{2}{3}$ in, and $\frac{1}{6}$ in. objectives, $\quad-\quad 63.00$

B B3. Stand with 2 eyepieces and $\frac{2}{3}$ in, and $\frac{1}{6}$ in. objectives, $\quad$ - $\quad$ - $\quad 60.00$

B B4. Stand with 2 eyepieces and 2 in., $\frac{2}{3}$ in. and $\frac{1}{6}$ in. objectives, $\quad-\quad-\quad 66.00$

B B. Stand with 2 eyepieces and $\frac{2}{3}$ in., $\frac{1}{6}$ in. and $\frac{1}{12}$ in. oil immersion, objectives, 105.00

B B6. Stand with 2 eyepieces and 2 in., $\frac{2}{3}$ in., $\frac{1}{6}$ in. and $\frac{1}{12}$ in. oil immersion, objectives, 111.00 Slide B, carrying standard sub-stage ring, with dome diaphragm, extra, - $\quad 4.00$ Abbe condenser, 1.20 N. A., in mounting, No. 1678, - _ _ - 14.00 Abbe condenser, $1.42 \mathrm{~N}$. A., in mounting, No. 1678, $\quad$ - $\quad 16.00$ Double nosepiece, brass finish, extra, - $\quad$ - $\quad$ - $\quad$ - $\quad$ - 5.00

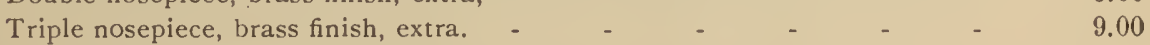

For table of magnifying powers refer to page 47 . 


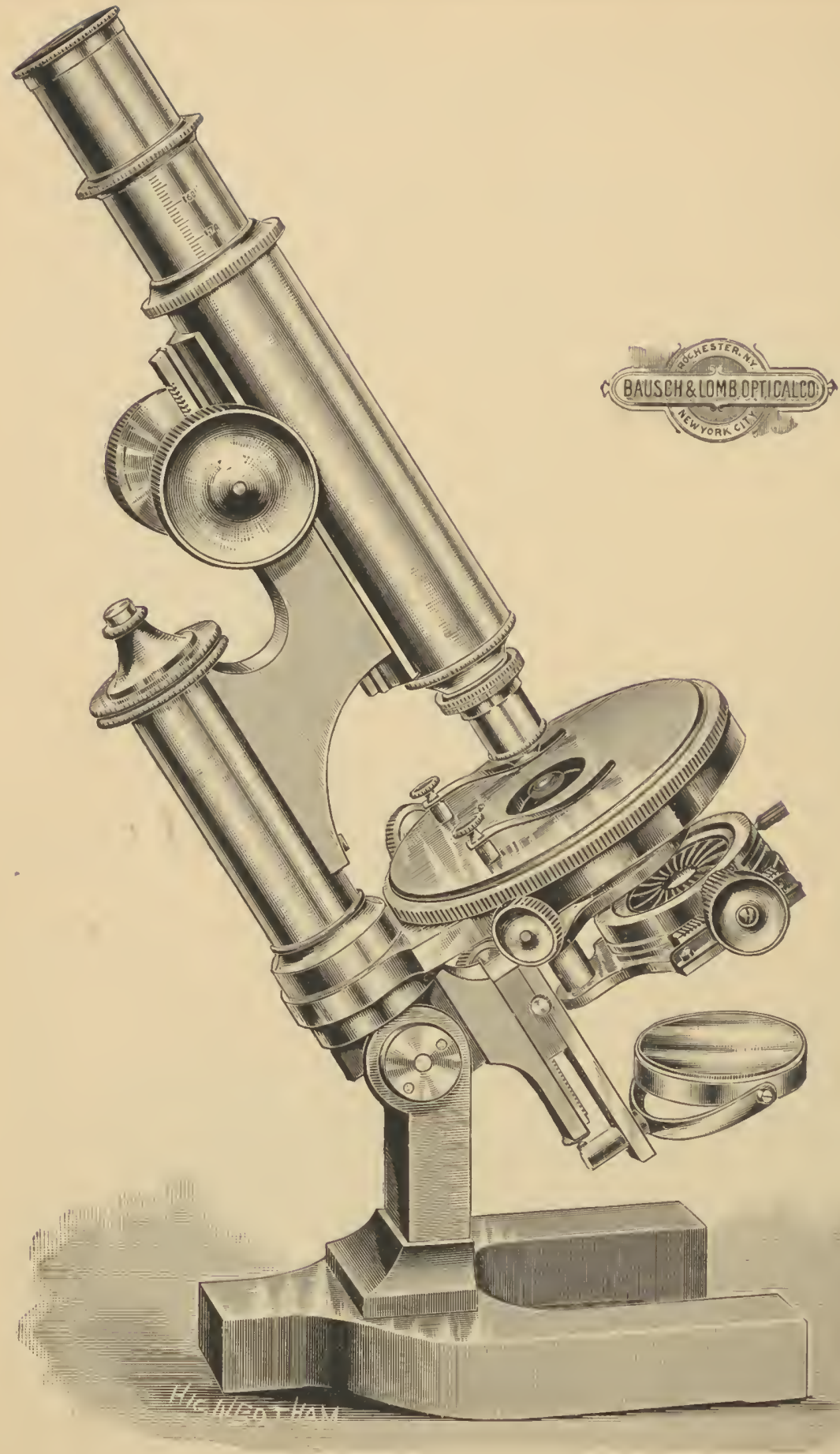

(Cut one-half of actual size.)

CC-CONTINENTAL MiCROSCOFE. 


\section{C-Continental microscope.}

(L.ARGE.)

This instrument is made entirely of brass; the base is of large dimensions and heavy, to secure extreme steadiness under manipulation in an inclined, upright or horizontal position; coarse adjustment is by rack and pinion; fine adjustment by large micrometer screw working on the triangular bearing of the arm; the head of the micrometer screw is graduated to 100 parts, an index point is provided. The main tube has a draw-tube which is graduated. When contracted, the tubes give short standard tube length with clouble nosepiece.

This instrument is made up in five forms :

c. Plain square stage with groove, fitted with slide and cylinder diaphragms. Swinging mirror-bar with adjustable plane and concave mirrors.

C.. Plain square stage as in C; sub-stage attachment, complete, No. 1684.

CB. Revolving stage with centering arrangement; swinging mirror-bar with adjustable plane and concave mirrors.

CC. (As in cut.) Revolving stage with centering arrangement; sub-stage attachment, complete, No. $168+$.

(1). Mechanical stage, revolving, with graduations and vernier; rectangular morements with graduations; centering arrangement; sub-stage attachment, complete, No. 1684.

Eyepieces are the Continental, objectives of Series I. Upright polished case, with receptacles for eyepieces and objectives, accompanies the outfit.

C. Stand with 1 eyepiece (any power),

C1. Stand with 1 eyepiece and $\frac{2}{3}$ in. and $\frac{1}{6}$ in. objectives,

$\$ 5.5 .00$

( 2 . Stand with 2 eyepieces and $\frac{2}{3}$ in. and $\frac{1}{6}$ in. objectives,

77.00

80.00

C. Stand with 1 eyepiece (any power).

C. 1 Stand with 1 eyepiece and $\frac{2}{3}$ in. and $\frac{1}{6}$ in. objectives,

80.00

102.00

CA. Stand with 2 eyepieces and $\frac{2}{3}$ in and $\frac{1}{6}$ in. objectives

105.00

(A:). Stand with 2 eyepieces and 2 in., 2 in. and $\frac{1}{6}$ in. objectives,

111.00

( 1 . Stand with 2 eyejieces and $\frac{2}{8} \mathrm{in}$., $\frac{1}{6}$ in. and $\frac{1}{12}$ in. oil immersion, objectives, $\quad 150.00$

CA.). Stand with 2 eyepieces and 2 in., $\frac{2}{3}$ in., $\frac{1}{6} \mathrm{in}$. and $\frac{1}{12}$ in. oil immersion, objectives,

156.00

C13. Stand with 1 eyepiece (any power), _ _ _ _ $\quad \ldots \quad \ldots$

(131. Stand with 1 eycpiece and $\frac{2}{3}$ in. and $\frac{1}{6}$ in. objectives, $\quad$ - _ _ $\quad 87.00$

(132. Stand with 2 eyepieces and $\frac{2}{3}$ in, and $\frac{1}{6}$ in. objectives, $\quad-\quad$ - $\quad-90.00$

C B3. Stand with 2 eyepieces and 2 in., $\frac{2}{3}$ in. and $\frac{1}{6}$ in objectives, $\quad 96.00$

C B1. Stand with 2 eyepieces and $\frac{2}{3}$ in., $\frac{1}{6}$ in and $\frac{1}{12}$ in. oil immersion, objectives, -135.00

C 13.5. Stand with 2 eyepieces and 2 in , $\frac{2}{3}$ in., $\frac{1}{6}$ in. and $\frac{1}{12}$ in. oil immersion, objectives,

14100

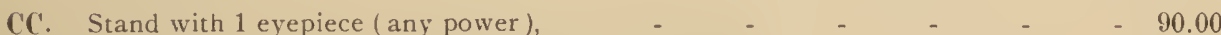

CC1. Stand with 1 eyepiece and $\frac{2}{3}$ in. and $\frac{1}{6}$ in objectives. $\quad$ - $\quad$ - $\quad 112.00$

CC. Stand with 2 eyepieces and $\frac{2}{3}$ in. and 1 in. objectives,

115.00

121.00

C'(3). Stand with 2 eyepieces and 2 in., $\frac{2}{3}$ in. and $\frac{1}{6}$ in. objectives,

(C). Stand with 2 eyepieces and 2 in., $\frac{2}{3}$ in., $\frac{1}{6}$ in. and $\frac{1}{12}$ in. oil immersion,

160.00 objectives,

166.00

Cl). Stand with 1 eyepiece ( any power),

130.00

152.00

C1). Stand with 1 eyepiece and $\frac{2}{3}$ in. and $\frac{1}{6}$ in. objectives,

(1). Stand with 2 eyepieces and $\frac{2}{3}$ in. and $\frac{1}{6}$ in. objectives,

CI03. Stand with 2 eyepieces and 2 in., $\frac{2}{3}$ in. and $\frac{1}{6}$ in. objectives,

155.00

161.00

Cl14. Stand with 2 eyepieces and $\frac{2}{3}$ in., $\frac{1}{6}$ in, and $\frac{1}{12} \mathrm{in}$, oil immersion, objectives,

Cl.5. Stand with 2 eyepieces and 2 in., $\frac{2}{3}$ in., $\frac{1}{6}$ in. and $\frac{1}{12}$ in. oil immersion,

200.00 objectives,

206.00

For table of magnifying powers refer to page 47 . 



\section{A menigan Joype.}

This class of microscopes is almost generally preferred for individual use, and will always remain favorites because they possess features which are specifically the outcome of American ingenuity. The designs and finish are made pleasing to the eye as well as being effective for the purpose. Many of the parts are for convenience of manipulation, while others are for obtaining the best results with the least expenditure of time, and also for lasting qualities. Many of the important features have originated with us and are only produced by our firm. 


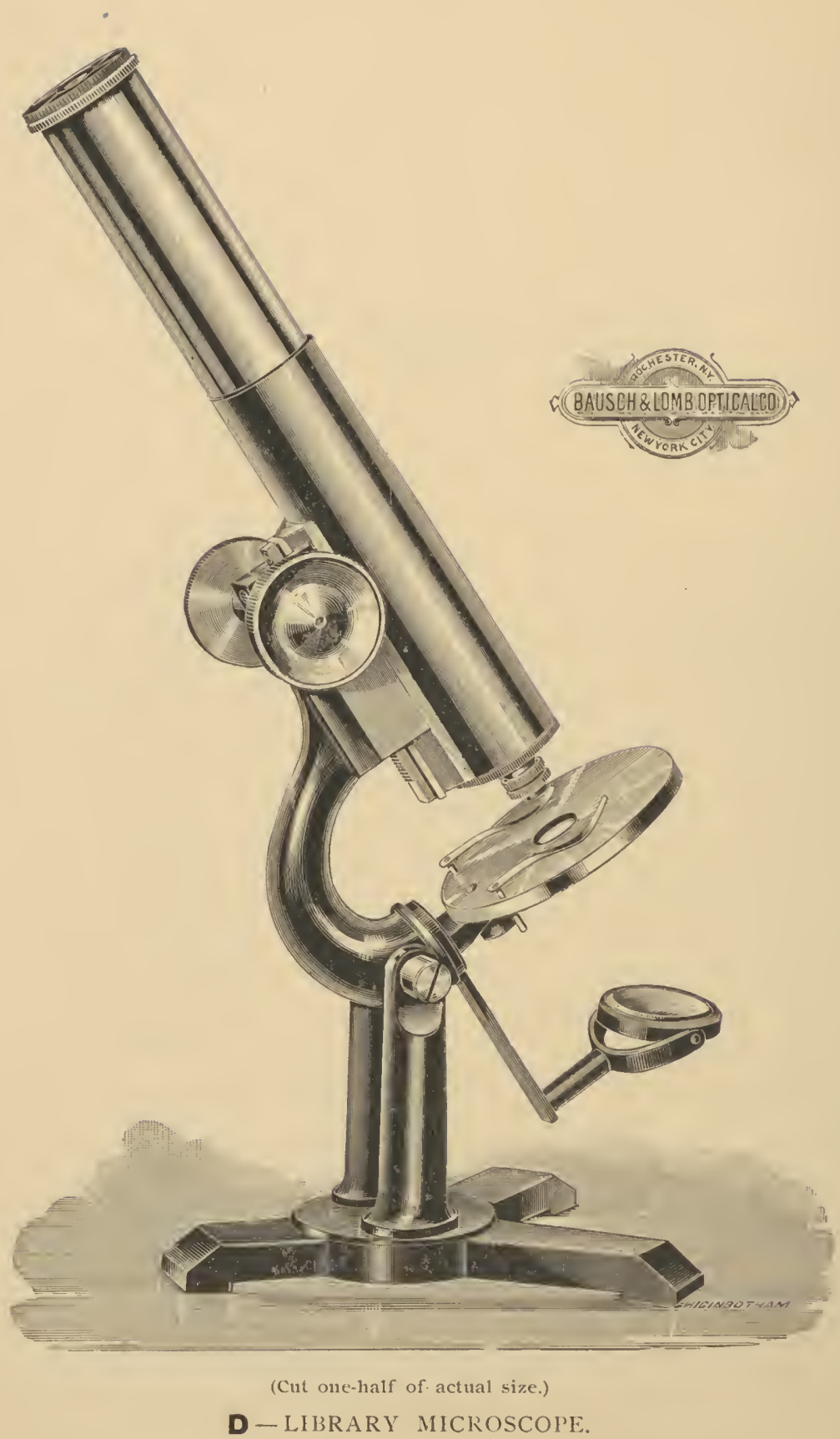




\section{D-LIBRARY MICROSCOPE.}

'This microscope is intended mainly for young beginners. It is well made and thoroughly reliable.

It has japanned foot and arm with joint for inclination. The adjustment is by rack and pinion of such delicacy that it is readily serviceable with a high power objective. The body is provided with draw-tube and society screw. The eyepieces are of the Continental pattern; the mirror is concave, swinging so as to give oblique illumination, and capable of being brought above the stage for illumination of opaque objects. The stage is provided with spring clips.

We make two forms of this instrument:

I). As described above.

1). The same, but with the addition of an adjustable stage plate, provided with micrometer screw, which, while limited in its motion, forms a serviceable fine adjustment.

Objectives are Series II, unless otherwise stated.

In upright case with handle.

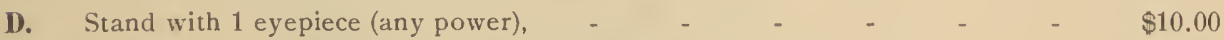

D1. Stand with 1 eyepiece and 1 in. objective, $\quad$ - $\quad$ - $\quad$ - $\quad$ - $\quad$ - 16.00

102. Stand with 1 eyepiece and 1 in. and $\frac{1}{4}$ in. objectives, $\quad$ - $\quad$ - $\quad 30.00$

I83. Stand with 1 eyepiece and non-achromatic doublet objective ; no society screw, $\quad 10.00$

D4. Stand with 1 eyepiece and achromatic doublet objective ; no society screw, $\quad 12.00$

D1). Stand with 1 eyepiece (any power), $\quad$ - $\quad$ - $\quad$ - $\quad$ - $\quad$ - 13.00

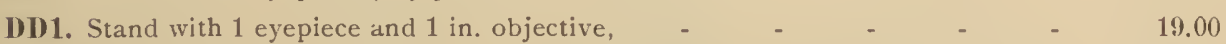

D1)2. Stand with 1 eyepiece and $1 \mathrm{in}$. and $\frac{1}{4}$ in. objectives, _ _ _ $\quad$ - $\quad 333.00$

For table of magnifying powers, refer to page 47 . 


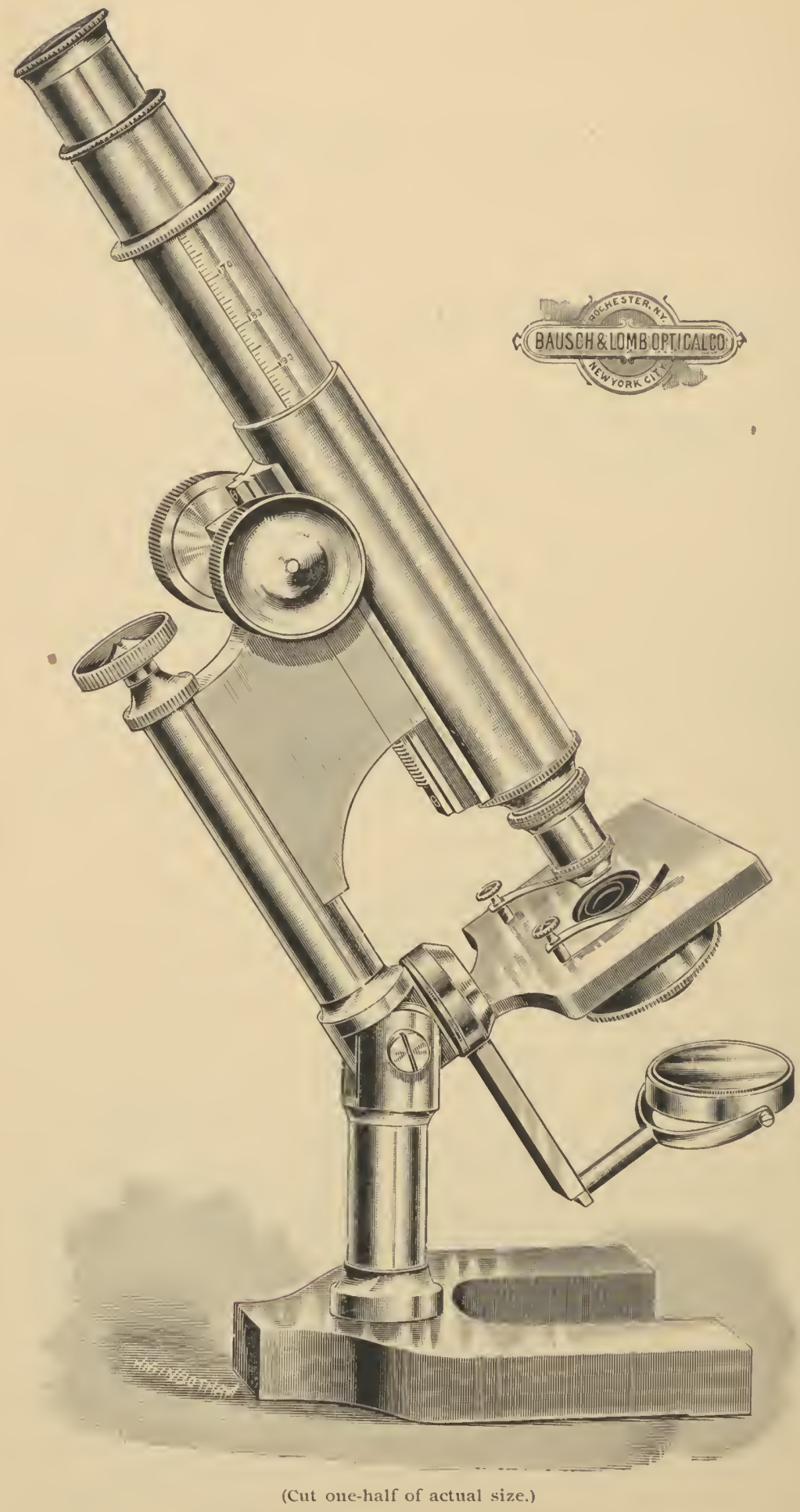

EE - HARVARD MICROSCOPE. 


\section{F-HARVARD MICROSCOPE.}

The stand is made entirely of brass, with bronze pillar and arm. Although compact so as to allow its convenient use in an upright position on an ordinary table, it still gives sufficient range of adjustment for all ordinary work. The base is of the horseshoe form, with a projection at the back to give it steadiness when the body is inclined. Coarse adjustment is by a sliding tube in a clothlined sleeve, which gives an exceedingly smooth and firm movement; fine adjustment is by micrometer screw, with milled head of more than ordinary size, acting on our patent movement. The main tube also has a cloth lining and is provided with a draw-tube graduated in millimeters, and with a mark indicating standard length. The stage is large and provided with spring clips; our dome diaphragm is attached to its lower surface by a sub-stage. The mirrors are plane and concave, of large size, and swing with the mirror-bar to any obliquity below the stage, and above it for the illumination of opaque objects ; they also have adjustment on the mirror-bar.

E. Is arranged with joint for inclination of the body.

EE. Is provided with rack and pinion for coarse adjustment, as well as with joint for inclination of the body.

Eyepieces are the Huyghenian, objectives of Series II, unless otherwise stated.

Polished case, with receptacle for eyepieces and objectives, with handle and lock, accompanies the outfit.

With every complete outfit (stand and objectives) we supply eyepiece micrometer No. 1734 free, this cannot be used on powers less than $\mathrm{C}$ or 1 in.

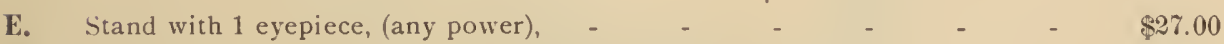

E1. Stand with 1 eyepiece and ${ }_{4}^{3}$ in. and $\frac{1}{5}$ in. objectives, - _ _ $\quad 50.00$

E2. Stand with 1 eyepiece and 2 in., $\frac{3}{4}$ in. and $\frac{1}{5}$ in. objectives, _ _ $\quad$ - $\quad 56.00$

E3. Stand with 2 eyepitces and $\frac{3}{4}$ in. and $\frac{1}{5}$ in. objectives, - _ _ _ 54.00

E4. Stand with 2 eyepieces and 2 in., 3 in. and $\frac{1}{5}$ in. objectives, - - $\quad 60.00$

E.5. Stand with 2 eyepieces and ${ }_{4}^{8}$ in., $\frac{1}{5}$ in. and $\frac{1}{12}$ in. oil immersion, (Series III.)

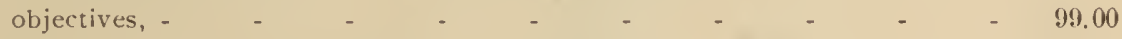

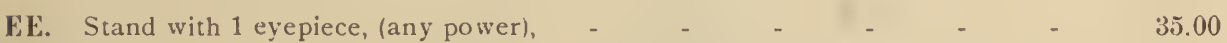

EE1. Stand with 1 eyepiece and $\frac{3}{4}$ in and $\frac{1}{5}$ in. objectives, _ _ $\quad$ - $\quad 58.00$

ElE. Stand with 1 eyepiece and 2 in.. $\frac{3}{4}$ in. and $\frac{1}{5}$ in. objectives, - _ _ 64.00

EE3. Stand with ? eyt pieces and $\frac{3}{4}$ in and $\frac{1}{5}$ in. objectives, _ _ _ $\quad$ - 62.00

EEt Stand with 2 eyepieces and 2 in., $\frac{3}{4}$ in. and $\frac{1}{5}$ in. objectives, $\quad$ - 68.00

EE.). Stand with 2 eyepieces and $\frac{3}{4}$ in., $\frac{1}{3}$ in. and ${ }_{12}^{1}$ in, oil immersion, (Series III) objectives.

$10 \% .00$

EE6. Stand with 2 eyepieces and 2 in., $\frac{3}{4}$ in., $\frac{1}{5}$ in. and $\frac{1}{1}$ in. oil immersion, (Series II I) objectives,

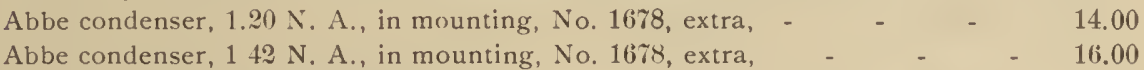

Double nosepiece, brass finish, extra, _ $\quad$ _ $\quad \ldots \quad \ldots \quad \ldots 00$

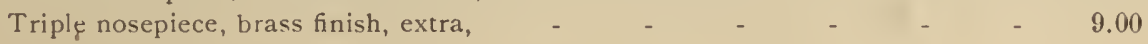

For table of magnifying powers, refer to page +7 . 


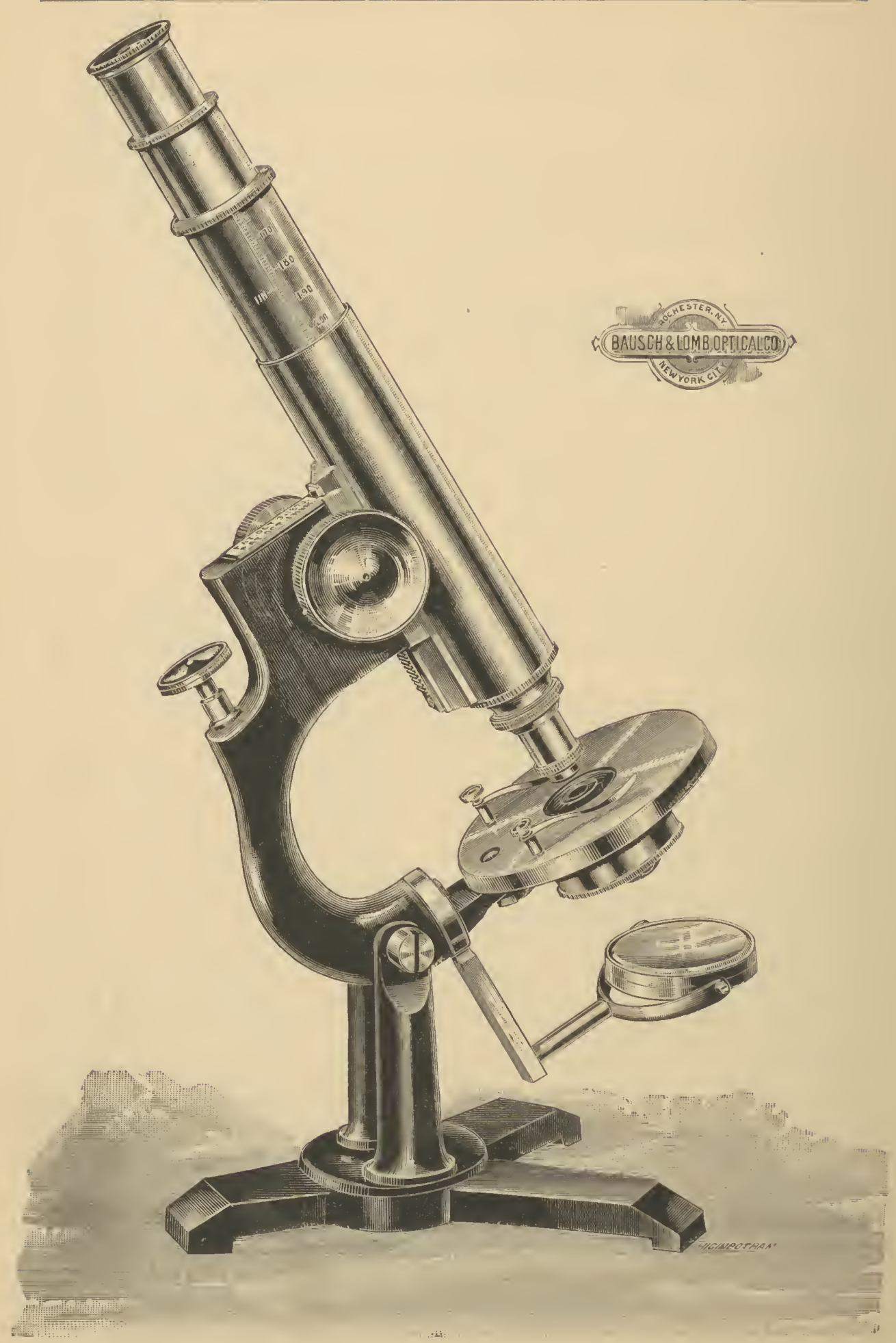

. Cut one-half of actual size).

F-MOdEL MICROSCOPE. 


\section{F-MODEL MICROSCOPE.}

The tripod base, pillars and arm, are neatly japanned; the axis is arranged with strong bearings to allow inclination of the body to any angle. Coarse adjustment is by perfect rack and pinion, provided with tightening screws; fine adjustment by a delicate micrometer screw, acting on our patent movement.

The stage is of brass, circular in form, thin to allow great obliquity, but of sufficient strength to be firm under manipulation. Attached to its lower side is a sub-stage ring and dome diaphragm, both of which may be removed.

The main tube is arranged with cloth lining in which the graduated drawtube is fitted ; it is provided with the society screw. Plane and concave mirrors are of large size, adjustable on the mirror-bar; the mirror-bar swings on a bearing (the axis of which lies in the plane of the stage) to any obliquity below and above the stage, the latter for the illumination of opaque objects.

Eyepieces are the Huyghenian, objectives of Series II, unless otherwise stated.

Upright polished case with drawer for accessories and receptacles for eyepieces and objectives, with handle and lock, accompanies the outfit.

With every complete outfit (stand and objectives) we supply eyepiece micrometer No. 1734 free, this cannot be used on powers less than C or 1 in.

F. Stand with 1 eyepiece (any power), _ _ _ _ _ _ _ _ _ $\quad \$ 25.00$

F1. Stand with 1 eyepiece and $\frac{8}{4}$ in, and $\frac{1}{5}$ in. objectives, _ _ _ - - 48.00

F\%. Stand with 1 eyepiece and 2 in., $\frac{3}{4}$ in. and $\frac{1}{5}$ in. objectives, _ _ _ $\quad 54.00$

F3. Stand with 2 eyepieces and $\frac{3}{4}$ in and $\frac{1}{5}$ in. objectịves, - _ _ _ $\quad$ - 52.00

F4. Stand with 2 eyepieces and 2 in., $\frac{3}{4}$ in. and $\frac{1}{5}$ in. objectives, _ _ _ 58.00

F5. Stand with 2 eyepieces and $\frac{3}{4}$ in. $\frac{1}{5}$ in., and $\frac{1}{12}$ in. oil immersion, (Series III)

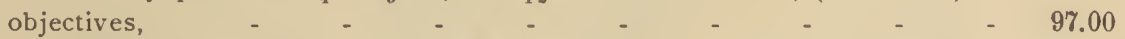

F6. Stand with 2 eyepieces and 2 in., $\frac{3}{4}$ in., $\frac{1}{5}$ in and $\frac{1}{12}$ in. oil immersion, (Series

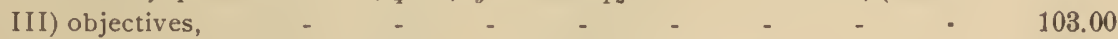

Revolving stage, with removable spring clips, extra, _ _ _ _ . $\quad 5.00$

Glass stage with slide carrier, which slips over either plain or revolving stages, extra, $\quad 5.00$

Graduated mirror bar, with mirror and sub-stage (both adjustable), same as used on

Investigator, in place of one accompanying stand, extra, - _ $\quad 5.00$

Abbe condenser, $1.20 \mathrm{~N}$. A., in mounting, No. 1678, extra, - $\quad$ - $\quad-14.00$

Abbe condenser, 1.42 N. A., in mounting, No. 1678, extra, _ _ _ $\quad$ - 16.00

Mechanical stage No. 1728, in place of the regular, extra, _ _ _ $\quad$ - 18.00

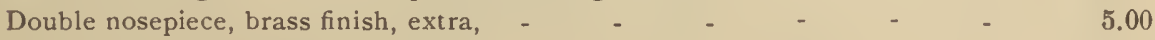

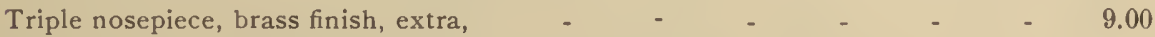

For table of magnifying powers, refer to page 47 . 


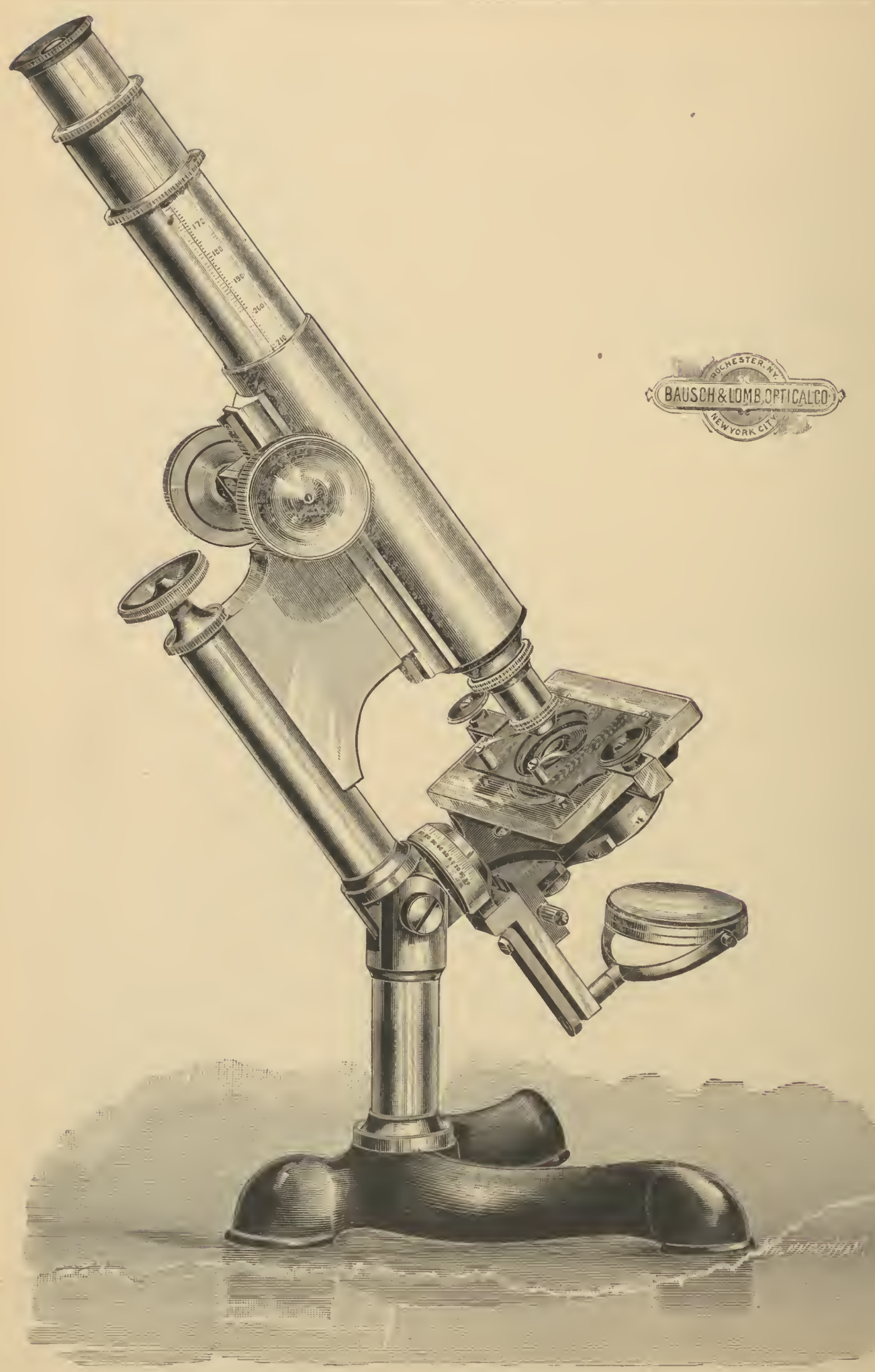

(Cut one-half of actual_size.)

G-PHysicin MiCroscope. 


\section{G-PHYSICIAN MICROSCOPE.}

The base is japanned iron. Pillar and arm are of bronze, connected by a joint for inclination of the body. Coarse adjustment is by rack and pinion, giving a long range; fine adjustment by micrometer screw, acting on our patent movement; main tube has cloth lining and is provided with graduated draw-tube. The stage consists of our square glass stage and slide-carrier attached to a firm projecting stage plate. The mirror-bar is provided with adjustable sub-stage, carrying dome diaphraghm, and plane and concave mirrors. It swings on its axis in plane of the stage to any obliquity below or above the stage.

Eyepieces are the Huyghenian, objectives of Series II, unless otherwise stated.

Upright polished case with drawer for accessories and receptacles for eyepieces and objectives, with handle and lock, accompanies the outfit.

With every complete outfit (stand and objectives), we supply eyepiece micrometer No. 17:34 free, this cannot be used on powers less than $\mathrm{C}$ or 1 in.

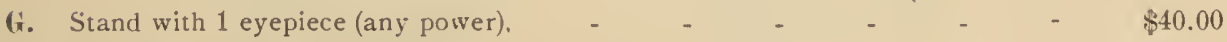

(11. Stand with 1 eyepiece and $\frac{3}{4}$ in. and $\frac{1}{5}$ in. objectives, $\quad$ - $\quad$ - $\quad 63.00$

G2. Stand with 1 eyepiece and 2 in., $\frac{3}{4}$ in. and $\frac{1}{5}$ in, objectives, _ _ _ $\quad 69.00$

G3. Stand with 2 eyepieces and $\frac{3}{4}$ in. and $\frac{1}{6}$ in. objectives, _ _ $\quad-67.00$

(44. Stand with 2 eyepieces and 2 in., $\frac{8}{4}$ in. and $\frac{1}{5}$ in. objectives, _ _ $\quad$ - $\quad 73.00$

(45. Stand with 2 eyepieces and $\frac{3}{4}$ in., $\frac{1}{5}$ in. and $\frac{1}{12}$ in. oil immersion, (Series III)

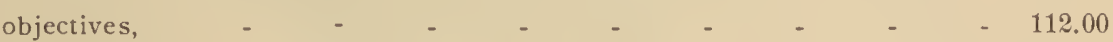

G6. Stand with 2 eyepieces and 2 in., $\frac{3}{4}$ in., $\frac{1}{5}$ in, and $\frac{1}{12}$ in. oil immersion, (Series

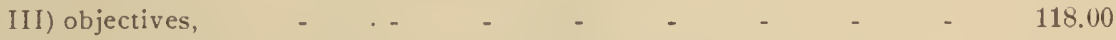

Investigator base in place of japanned iron base, with suitable case, extra, $\quad-\quad 2.50$

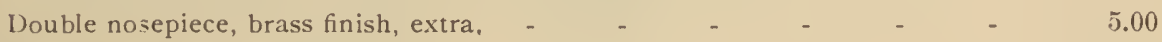

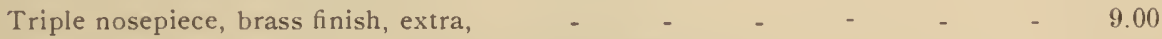

Abbe condenser, $1.20 \mathrm{~N}$. A., in mounting, No. $16 \tau 8$, extra, - $\quad$ - $\quad 14.00$

Abbe condenser, 1.42 N. A., in mounting, No. 16r8, extra, _ _ $\quad$ - 16.00

For table of magnifying powers refer to page $4 \pi$. 


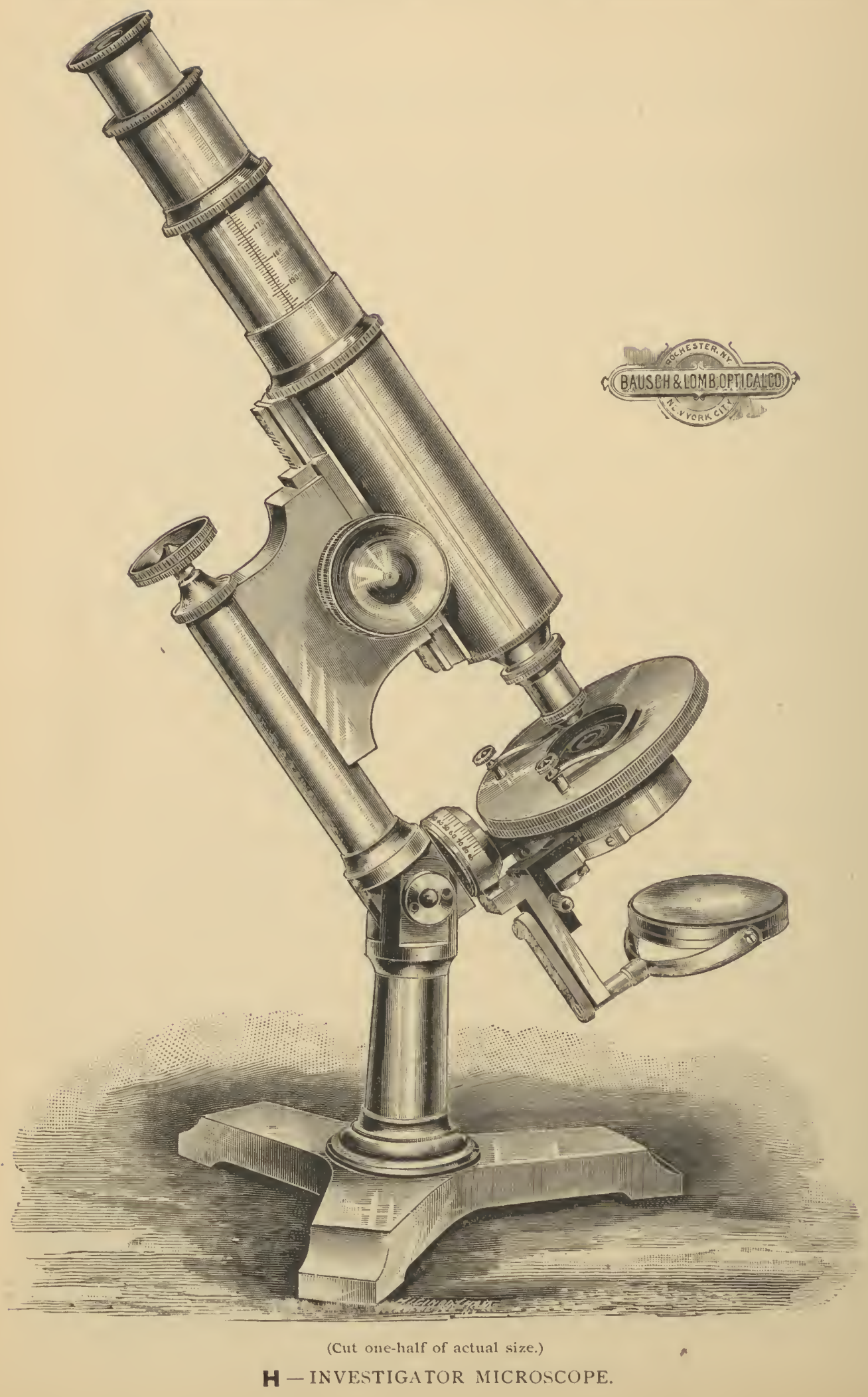




\section{王-INVESTIGATOR MICROSCOPE.}

The base is of brass and has the tripod form; pillar and arm of bronze, connected by a solid joint for inclination of body; rack and pinion for coarse adjustment, fine adjustment by our patent frictionless motion; main tube with two draw-tubes, one of which is graduated in millimeters, arranged with cloth lining. The stage lies in the same plane as center of movement for mirror, is of bronze and has concentric, revolving motion with removable clips.

The mirror-bar swings upon its bearing to any obliquity below and above the stage. It is provided with a sliding arrangement, whereby the mirror may be moved to and from the object. The mirrors are plane and concave and adjustable. The sub-stage is adjustable and provided with dome diaphragm. Steel pin for centering stage and sub-stage is provided.

Eyepieces are the Hughenian, objectives of Series II, unless otherwise stated.

Upright polished case with drawer for accessories and receptacles for eyepieces and objectives, with handle and lock, accompanies the outfit.

With every complete outfit (stand and objectives), we supply eyepiece micrometer No. $1734 \mathrm{free}$, this cannot be used on powers less than $\mathrm{C}$ or 1 in.

H. Stand with 1 eyepiece (any power), $\quad$ - $\quad$ - $\quad \ldots \quad \ldots$

H1. Stand with 1 eyepiece and $\frac{3}{4}$ in. and $\frac{1}{5}$ in. objectives, _ _ _ $\quad$ - $\quad 68.00$

H2. Stand with 1 eyepiece and 2 in., $\frac{3}{4}$ in. and $\frac{1}{5}$ in. objectives, _ _ _ $\quad 74.00$

H3. Stand with 2 eyepieces, and ${ }_{4}^{3}$ in. and $\frac{1}{5}$ in. objectives, _ _ _ _ $\quad$ - 72.00

H4. Stand with 2 eyepieces, and 2 in., $\frac{3}{4}$ in. and $\frac{1}{5}$ in. objectives, - $\quad$ - $\quad 78.00$

H5. Stand with 2 eyepieces, and $\frac{8}{4}$ in., $\frac{1}{5}$ in. and $\frac{1}{12}$ in. oil immersion, (Series III)

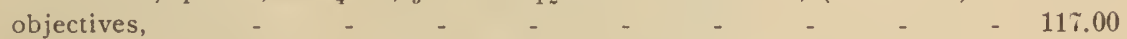

H6. Stand with 2 eyepieces, and 2 in., $\frac{3}{4}$ in., $\frac{1}{3}$ in. and $\frac{1}{12}$ oil immersion, (Series III)

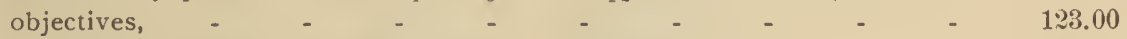

Glass stage and slide-carrier which slips over brass stage, extra, - $\quad$ - $\quad 5.00$

Mechanical stage No. 1728, in place of the regular, extra, _ _ _ _ $\quad-17.00$

Double nosepiece, brass finish, extra, $\quad$ - $\quad$ - $\quad$ - $\quad$ - $\quad$ - $\quad$ - 5.00

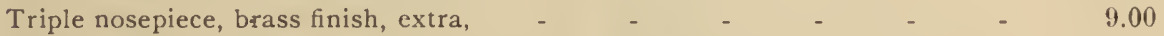

Abbe condenser, $1.20 \mathrm{~N}$. A., in mounting No. 1678, extra, _ _ - $\quad$ - 14.00

Abbe condenser, 1.42 N. A., in mounting No. 16ið, extra, _ _ $\quad$ - 16.00

For table of magnifying powers refer to page 47 . 

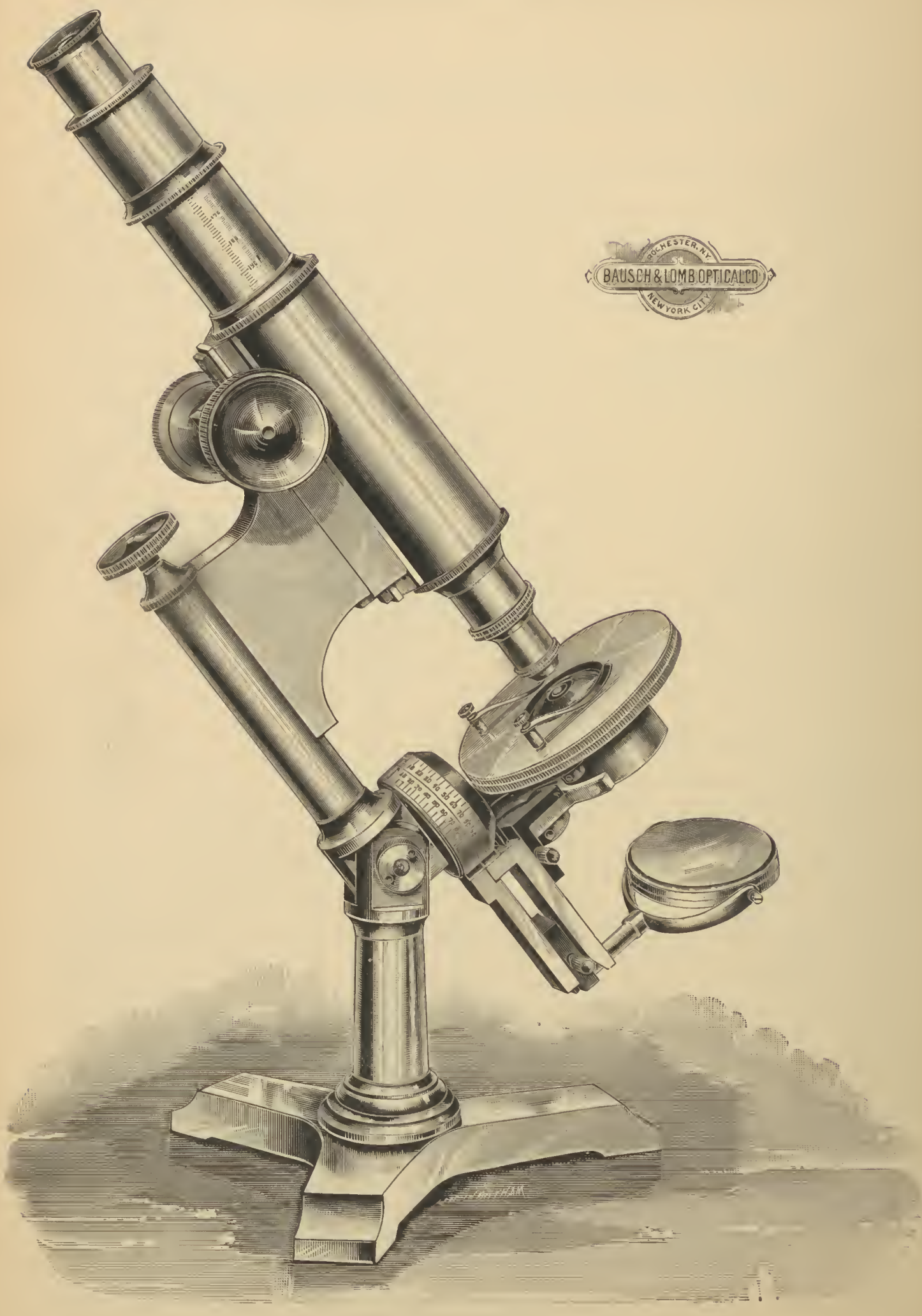

(Cut one-half of actual size.)

J - UNIVERSAL MICROSCOPE. 


\section{J-UNIVERSAL MICROSCOPE.}

The base is of the tripod form and made of brass. The bronze pillar is large, and connected by joint for inclination of the arm. A heavy thumbscrew permits the instrument to be fastened in any position on the base. The coarse adjustment is by rack and pinion of long range; the fine adjustment is by micrometer screw acting on our patent frictionless motion. The main tube has two draw-tubes, one being graduated, provided with cloth-lining. The stage has concentric, revolving motion with removable spring clips. The mirrors are plane and concave and of large size, and both these and the sub-stage, carrying dome diaphragm, are adjustable on their respective bars; the circular bearings of these are large and are graduated to degrees and silvered. The mirror and sub-stage bars have their axis in the plane of the stage and move independent of one another or together to any obliquity below or above the stage. A steel pin for centering stage and sub-stage accompanies the instrument.

Eyepieces are the Huyghenian, objectives of Series II, unless otherwise stated.

Upright polished case with drawer for accessories and receptacles for eyepieces and objectives, with handle and lock, accompanies the outfit.

With every complete outfit (stand and objectives) we supply eyepiece micrometer No. 1734 free, this cannot be used on powers less than C or 1 in.

J. Stand with 1 eyepiece (any power).

$\$ 55.00$

78.00

J1. Stand with 1 eyepiece and $\frac{3}{4}$ in. and $\frac{1}{5}$ in. objectives,

J3. Stand with 2 eyepieces and $\frac{3}{4}$ in. and $\frac{1}{5}$ in. objectives, $\quad$ _ $\quad$ _ $\quad 82.00$

J4. Stand with 2 eyepieces and 2 in., $\frac{3}{4}$ in. and $\frac{1}{3}$ in. objectives, _ _ $\quad$ - 88.00

J5. Stand with 2 eyepieces and $\frac{3}{4}$ in., $\frac{1}{5}$ in. and $\frac{1}{12}$ in. oil immersion (Series III) objectives,

J6. Stand with 2 eyepieces and 2 in., $\frac{3}{4}$ in., $\frac{1}{5}$ in. and $\frac{1}{12}$ in. oil immersion (Series III) objectives,

Glass stage and slide-carrier which slips over brass stage, extra, _ _ _ $\quad$ - 5.00

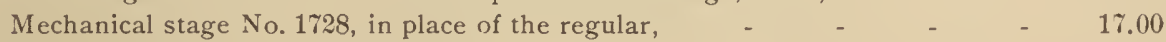

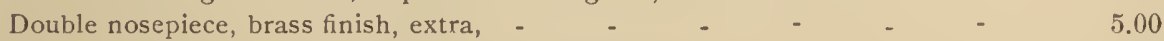

Triple nosepiece, brass finish, extra, $\quad$ - $\quad$ - $\quad$ - $\quad$ - $\quad$ - $\quad$ - 9.00

Abbe condenser, $1.20 \mathrm{~N}$. A. in mounting No. 1678 , extra, _ _ _ $\quad$ - 14.00

Abbe condenser, $1.42 \mathrm{~N}$. A. in mounting No. 1678 , extra, _ $\quad$ - $\quad$ - 16.00

Rack and pinion adjustment to the sub-stage, extra, - $\quad$ - $\quad$ - $\quad$ - $\quad 15.00$

Centering adjustments by micrometer screw to either stage or sub-stage, extra,

for each,

For table of magnifying powers, refer to page 47 . 

. 


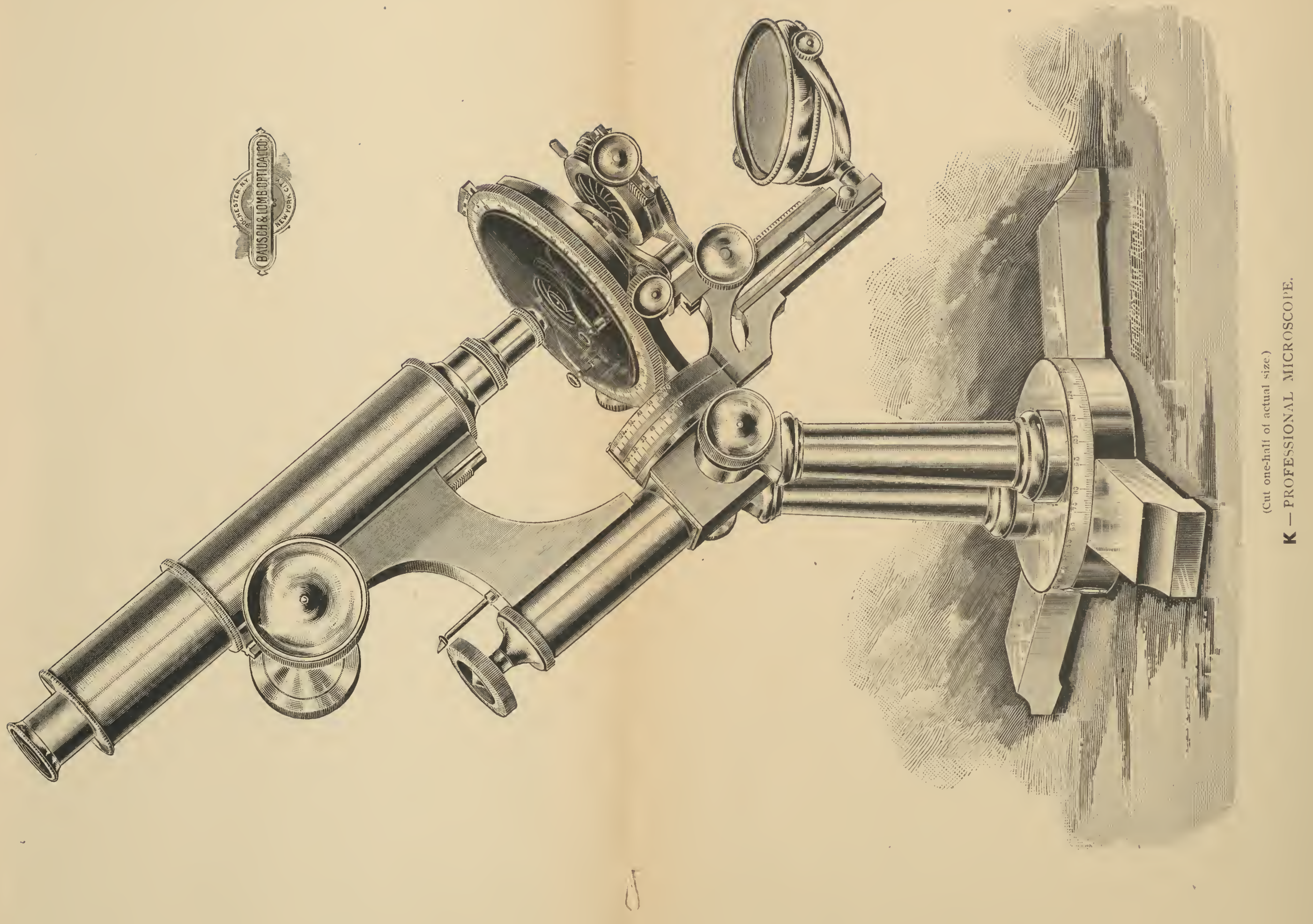




\section{KK-PROFESSIONAL MICROSCOPE.}

This instrument may be considered as the highest attainment in microscopical construction, in design, solidity and practical utility of the various parts. It is entirely constructed of brass and bronze. The base is unusually large and heavy. To its upper surface is fastened a revolvable plate graduated and provided with index, to which is attached two pillars. The arm is fitted to pillars by joint for inclination with steel axis. Coarse adjustment is by rack and pinion with large milled heads. The micrometer screw acting on fine adjustment is graduated to hundred parts and provided with index finger. Main tube has draw-tube working in cloth lining. Tubes when contracted are of the long standard. Mirror and sub-stage bars are separate and have independent movements working on an axis in the plane of the stage; both are graduated to degrees. Mirrors are plane and concave, of unusual large size and adjustable on mirror-bar. The sub-stage consists of the entire attachment No. 1684, and has a long adjustment by rack and pinion. The stage is revolving, graduated to degrees and provided with vernier. It has spring clips and centering adjustment. Graduations are all silvered.

Eyepieces are the Huyghenian, objectives of Series II, unless otherwise stated.

Upright polished case, with handle, lock and key, drawer for accessories and receptacles for eyepieces and objectives, accompanies the outfit.

With every complete outfit (stand and objectives) we supply eyepiece micrometer No. $173+$ free, this cannot be used on powers less than $\mathrm{C}$ or $1 \mathrm{in}$.

K. Stand with 2 eyepieces, -

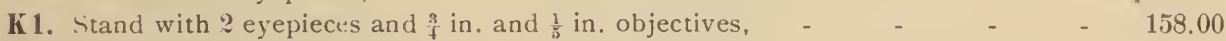

K2. Stand with 2 eyepieces and 2 in., $\frac{3}{4}$ in. and $\frac{1}{5}$ in. objectives, _ _ $\quad 164.00$

K:3. Stand with 2 eyepieces and 2 in., $\frac{3}{4}$ in.. $\frac{1}{5}$ in. and $1 / 8$ in. obj stives, _ $\quad 182.00$

K4. Stand with 3 eyepieces and $\frac{8}{4}$ in and $\frac{1}{3}$ in objectives, $\quad$ - $\quad$ - 162.00

K.j. Stand with 3 eyepieces and 2 in., $\frac{3}{4}$ in. and $\frac{1}{5}$ in. objectives, $\quad$ - $\quad-168.00$

K 6. Stand with 3 eyepieces and 2 in., $\frac{3}{4}$ in., $\frac{1}{5}$ in. and $1 / 8$ in. objectives, $\quad 186.00$

K. . Stand with 2 eyepieces and $\frac{3}{4}$ in., $\frac{1}{3}$ in. and $1^{\frac{1}{2}}$ in. oil immersion, (Series III) objectives,

KS. Stand with 3 eyepieces and $\frac{3}{4}$ in., $\frac{1}{5}$ in. and $\frac{1}{12}$ in. oil immersion, (Series III) objectives,

K9. Stand with 4 eyepieces and 2 in., $\frac{3}{4}$ in., $\frac{1}{5}$ in. and $\frac{1}{12}$ in. oil immersion, (Series III) objectives,

Double nosepiece, brass finish, extra,

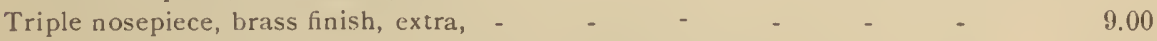

Abbe cundenser, 1.20 N A. in mounting, No. 1678, extra, _ _ _ $\quad$ - 14.00

Abbe condenser, 1.42 N. A. in mounting, No. 1678, extra, - _ - - $\quad 16.00$

Mechanical Stage No. 1732, in place of one accompanying stand, extra, _ $\quad 30.00$

For table of magnifying powers refer to page 47 . 


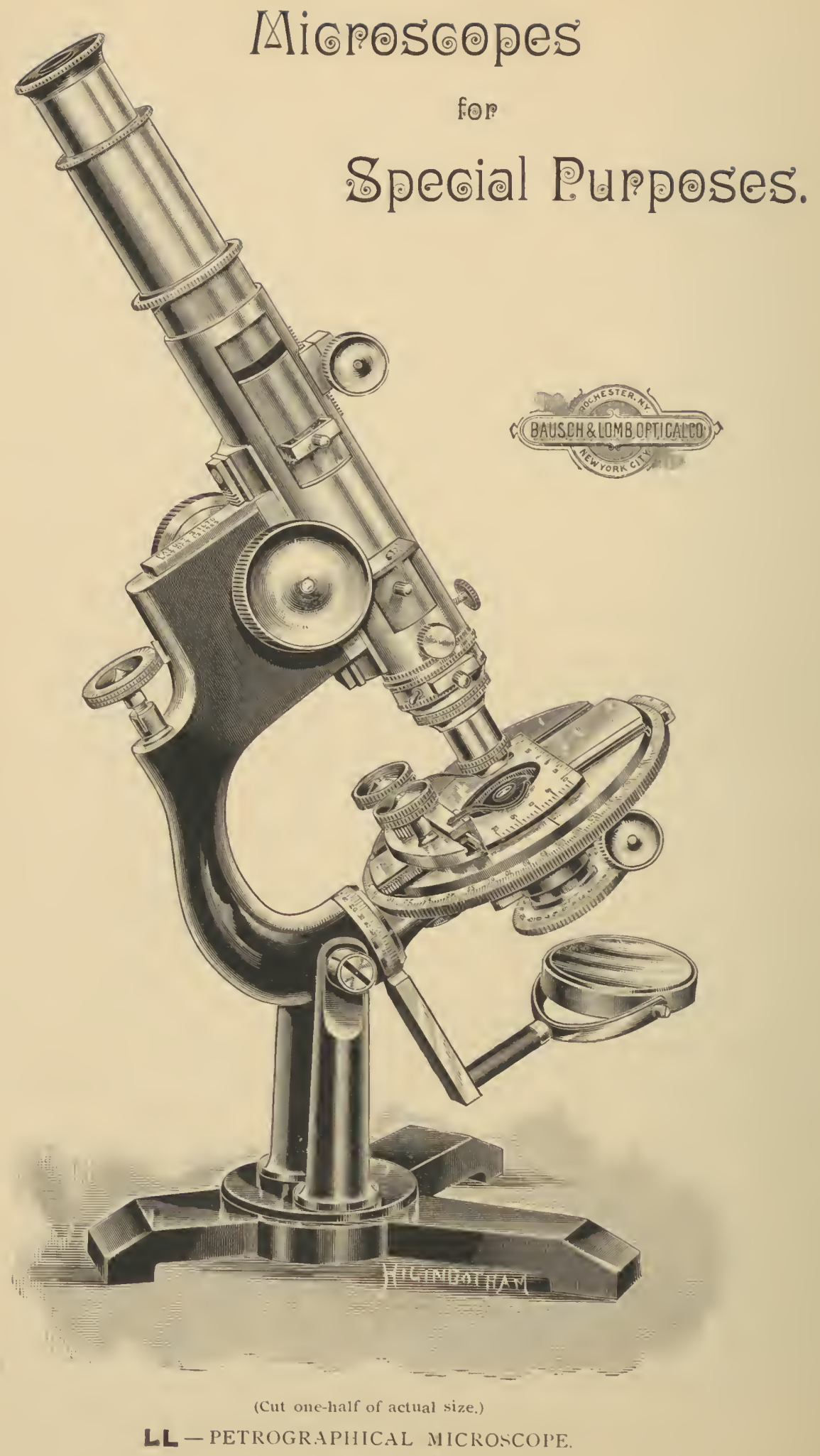




\section{I-PETROGRAPHICAL MICROSCOPE.}

'The base, upright pillars and arm of this instrument are of japanned iron ; the stage will be made in two ways, first, plain revolving, having silvered graduations at right angles and second, our mechanical stage, No. 1728, with silvered graduations on the edge, with vernier and graduations for the rectangular movements; mirror-bar is adjustable and graduated, mirror of large size, plane and concave; coarse adjustment is by rack and pinion, fine adjustment by micrometer screw, with graduated head into hundred parts; pitch of screw, 72. The nosepiece has centering adjustment and opening for the use of the various accessories, also ring to exclude light when not in use. The double chambered box in the main tube carries in the one opening the upper nicol or analyzer, the second being vacant and which may be slid in or out at will, without at any time leaving an opening through which dust may enter. The eyepiece tube is moved in the main tube by rack and pinion and has two openings to receive accessories; the lower nicol in polarizer is mounted in cylindrical box beneath the stage, to which it is held by a swinging arm, so that it may be thrown instantly to one side if clesired. The polarizer may be vertically raised or depressed by a rack and pınion movement, and is capable of an axial revolution upon a graduated and silvered circle with index. It is provided with a compound lens for securing converged polarized light, which may be removed at will; the point at which both nicols are crossed, giving total extinction of light, is registered by a pronounced click, provided in the polarizer mounting. Eyepieces have projecting studs which fit into slits in eyepiece tube securing central position and allowing movement to 4.5 degrees either way. The following accessories are a part of the stand: a) Bertrand's lens for magnifying the interference figure; $b$ ) a quarter undulation mica plate ; c) a quartz wedge; d) a gypsum plate, red of the first order.

Eyepieces are the Huyghenian, objectives of Series II.

A polished case with handle, lock and key, drawer for accessories and receptacles for eyepieces and objectives, accompanies the outfit.

I. Stand with plain revolving stage and 1 eyepiece, provided with cross hairs, $\$ 125.0$ n

1. Stand with plain revolving stage and 1 eyepiece, and $\frac{3}{4}$ in and $\frac{1}{5}$ in. objectives, 148.00

I.2. Stand with plain revolving stage and 2 eyepieces (one provided with cross hairs), and $\frac{3}{4} \mathrm{in}$. and $\frac{1}{5} \mathrm{in}$. objectives,

LI. Stand with mechanical stage No. 1728, and 1 eyepiece provided with cross hairs, 142.00

LL1. Stand with mechanical stage No. 1728, and 1 eyepiece, and $\frac{3}{4}$ in. and $\frac{1}{5}$ in. objectives,

165.00

LL2. Stand with mechanical stage No. 1728, and 2 eyepieces (one provided with cross hairs), and $\frac{3}{4}$ in. and $\frac{1}{5}$ in. objectives,

L. 43 . Stand with mechanical stage No. $1 \% 28$, and 2 eyepieces (one provided with cross hairs), and 2 in., $\frac{3}{4}$ in. and $\frac{1}{5}$ in. objectives,

LL4. Stand with mechanical stage No. 1728 , and 2 eyepieces (one provided with cross

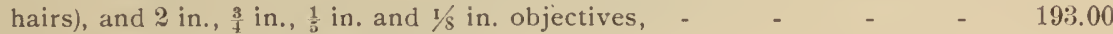

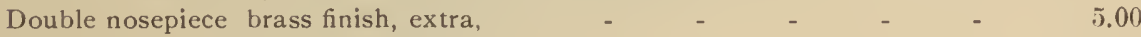

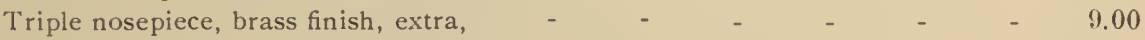

Bertrand's quadrant eyepiece with revolving prism, extra, _ _ _ $\quad$ 16.50

Prices of separate petrographical accessories will be found on another page. For table of magnifying powers refer to page 47 . 

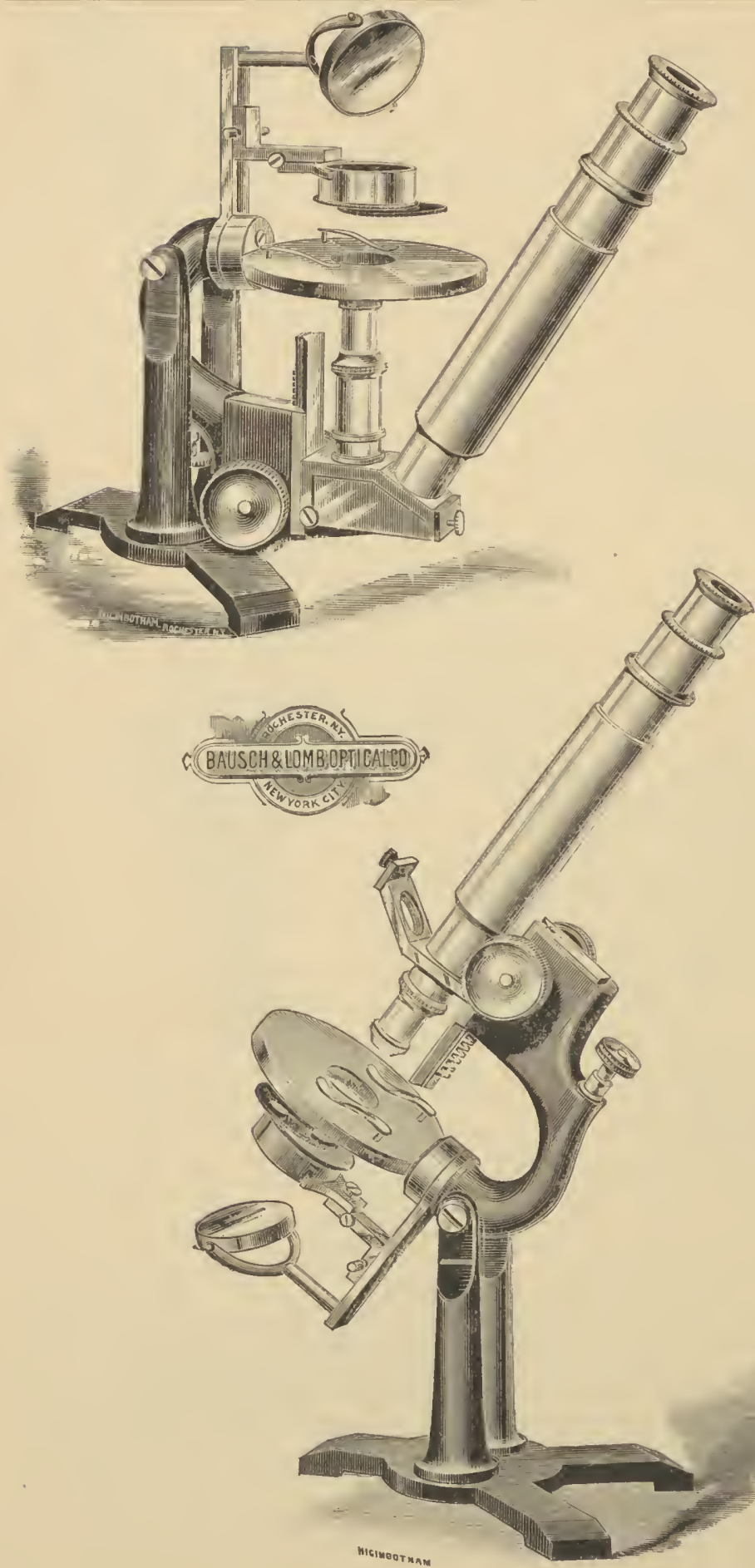

(Cut one-third of actual size.)

M-LABORATORY MICROSCOPE. 


\section{Combined Invented and Ventigal Æigrescopes.}

The principles involved in the microscopes described on this and the following pages, are to the best of our knowledge entirely new. Although the Inverted microscope has been used for some time, it does not seem to have occured to any one to combine this, which is used for special work, with the ordinary vertical instrument. There is no question that the fact, that the Inverted could only be used as such and that it was but incomplete at the best, has precluded its more general use, and we have no doubt, that offering them as we do now, by combining two instruments in one and supplying each with such complete adjustments as modern requirements demand, they will be found to fill a necessity in certain branches and prove a great. convenience in others.

In the Inverted microscope, the usual conditions are reversed. The mirror is above the stage, while the objective is below it, and the object is therefore viewed from the lower side instead of from the upper one. After the rays have passed through the objective, they must be given an upward direction, so that the image which they form may be viewed; and in order to accomplish this, we make use of a four-sicled prism, of which we give a sectional cut, its angles being respectively $57^{\circ}, 150^{\circ}, 48^{\circ}, 105^{\circ}$. The prism is large and its surfaces accurately made, so that there is no noticeable depreciation in lighi and none at all in definition.

This form of instrument is particularly adapted for chemical investigations, diatomacee and other objects in water.

For examinations with low powers, the ordinary slide may be used, but for high powers, a cover glass of proper dimensions may be substituted.

We make these instruments in two styles. 


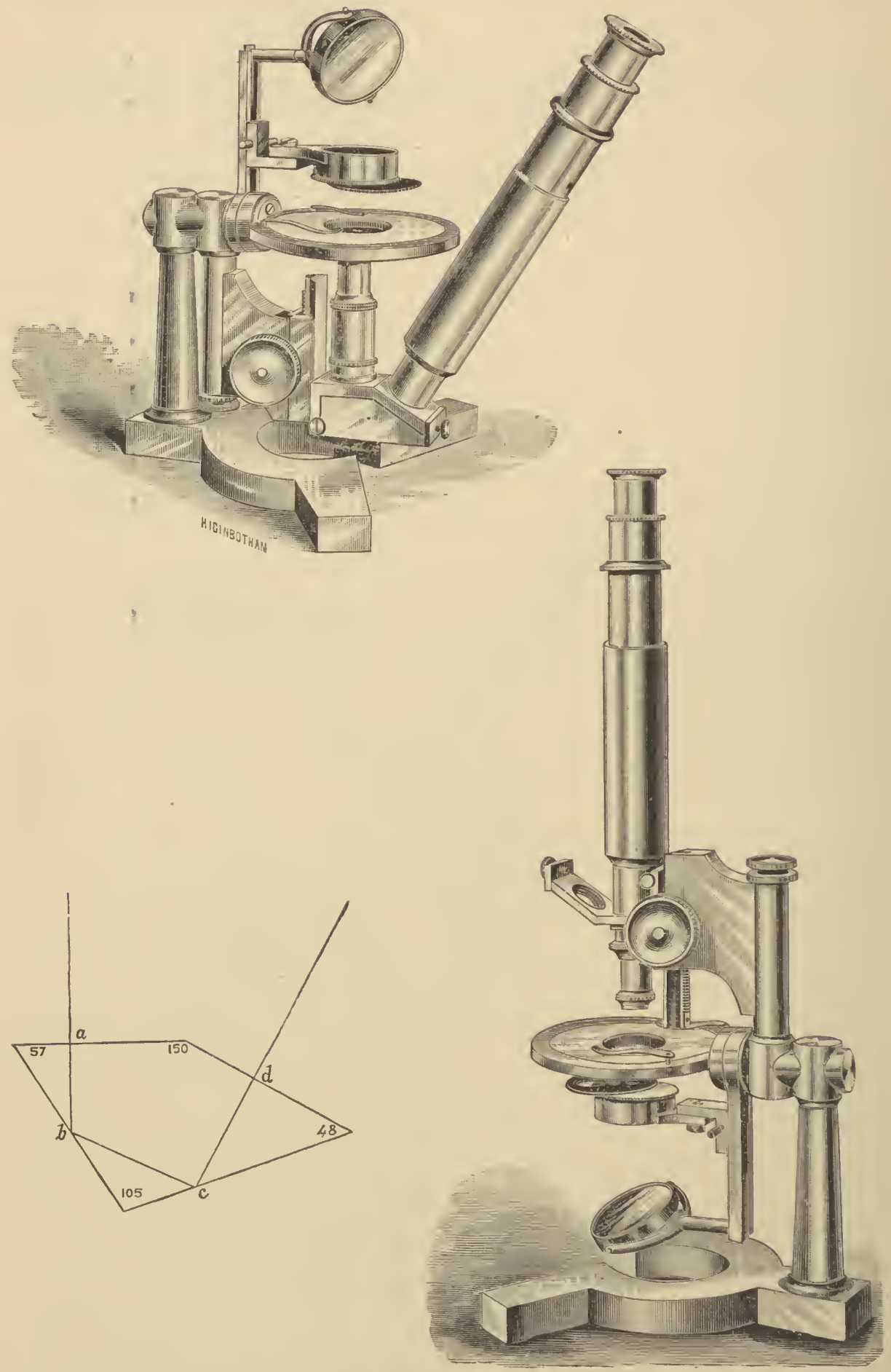

(Cut one-third of actual size.)

N-University microscote. 


\section{M-LABORATORY MICROSCOPE.}

In this microscope the pillar and arm are japanned. The stage is of solid metal and provided with spring clips. The mirror-bar swings on an axis in the plane of the stage, to any point above or below it. 'The mirrors are plane and concave and adjustable on the mirror-bar, as is also the sub-stage. This carries a revolving diaphragm, and is fixed on a pivot so that it will swing in or out of the optical axis. The coarse adjustment is by rack and pinion; the fine adjustment by micrometer screw acting on our patent movement. Attached to the slide is the arm, to the lower side of which is fastened the prism-box; on the upper horizontal surface is the nosepiece, with an extra adapter for high powers; in the oblique surface is a screw socket, to which the tube attaches; this is provided with cloth lining and has draw-tube.

To transform the instrument into an ordinary microscope, the tube is unscrewed, the milled head at the front of the arm loosened, which releases the prism-box, and the arm is swung on its axis from between the pillars into an upright position. The tube is now attached to the opposite side of the nosepiece and, after the clips are reversed, it is ready for work.

II. Stand with 1 Huyghenian eyepiece (any power) in polished case with handle, lock and key,

$\$+5.00$

\section{N-UNIVERSITY MICROSCOPE.}

This instrument is in its general construction similar to the Laboratory. It is, however, made entirely of brass, with the exception of the stage, which consists of a heavy glass plate, mounted in a solid brass ring. The base is of the tripod form, of graceful construction. One solid pillar supports the instrument. In transforming this into an ordinary instrument, the tube and prismbox are removed as in the preceding, and the instrument is swung on its axis, which is the same as that of the mirror bar, into an upright position. The instrument may be used in an upright or inclined position.

N. Stand with 1 Huyghenian eyepiece (any power) in polished case with handle, lock and key, 

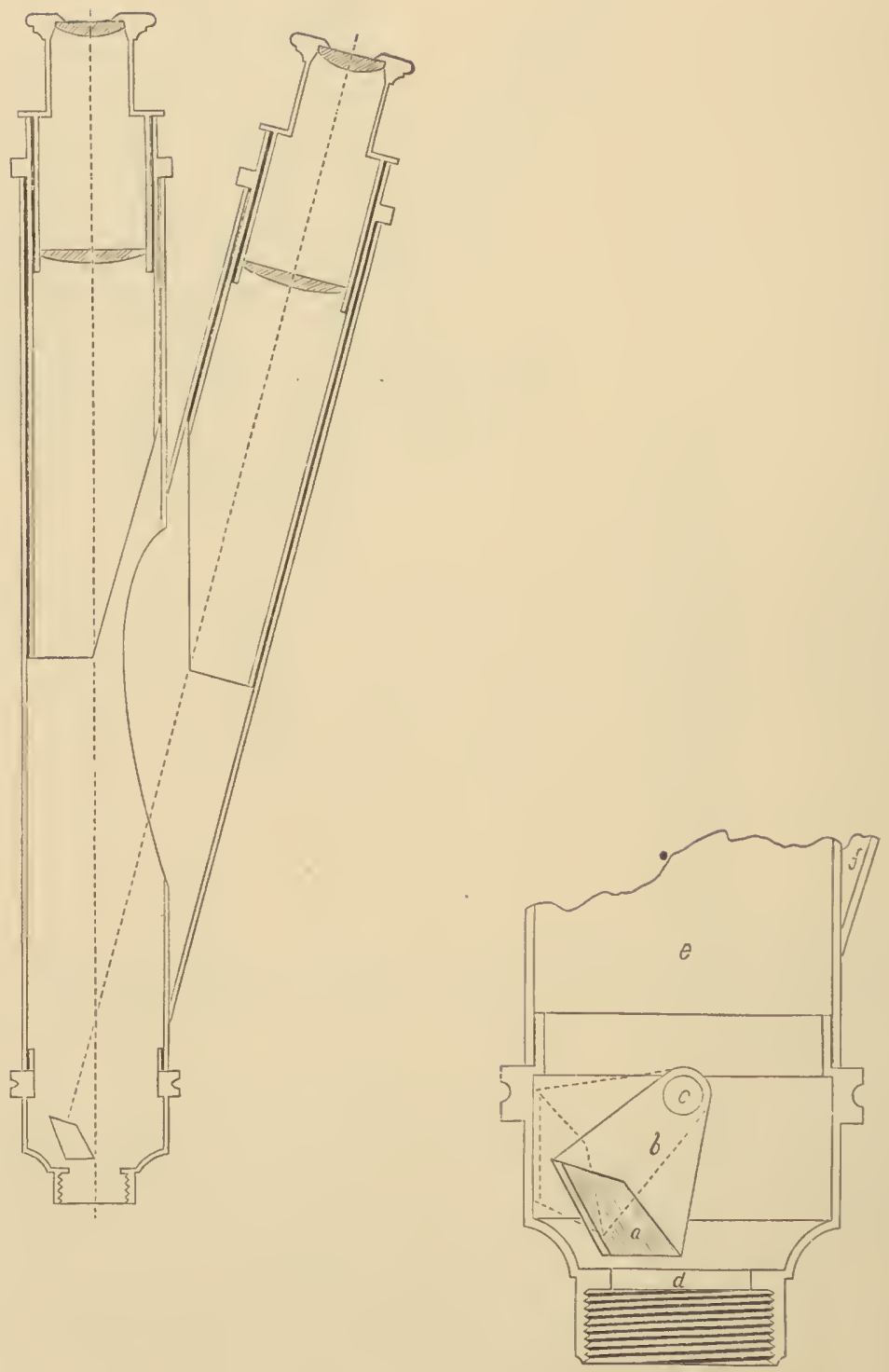

BINOCULAR TUBE AND NOSEPIECE WITH PRISM ATTACHMENT. 


\section{BINOCULAR MICROSCOPES.}

(Patented Feb. 12, 1884.)

The purpose of the Binocular microscope is to give a stereoscopic vision of objects, whereby their form, relative distance and position of the various parts are most plainly seen. We use the plan devised by Mr. Wenham, but with the modification that the prism is held by a swinging carrier instead of being in a sliding box. This plan admits no dust and leaves the tube unobstructed when the monocular tube only is used.

Eyepieces are the Huyghenian, objectives of Series II.

Polished case with receptacles for eyepieces and objectives accompanies the outfit.

F Binocular. Model stand with binocular body, 1 pair of eyepieces, - - $\quad \$ 45,00$

F Binocular 1. Model stand with 1 pair of eyepieces and $\frac{8}{4}$ in and $\frac{1}{5}$ in objectives, $\quad 68.00$

F Binocular 2. Model stand with 1 pair of eyepieces and $2 \mathrm{in.}, \frac{3}{4}$ in. and $\frac{1}{5}$ in.

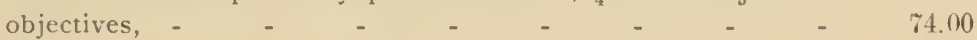

G Binocular. Physician stand with binocular body, 1 pair of eyepieces, $\quad 60.00$

G Binocular 1. Physician stand with 1 pair of eyepieces and $\frac{3}{4}$ in. and $\frac{1}{6}$ in. objectives, 83.00

G Binocular 2. Physician stand with 1 pair of eyepieces and 2 in., $\frac{3}{4} \mathrm{in}$. and $\frac{1}{5}$ in.

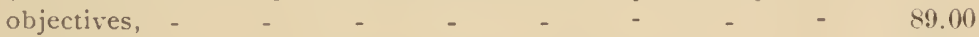

H Binocular. Investigator stand with binocular body, 1 pair of eyepieces, - $\quad 65.00$

H Binocular 1. Investigator stand with 1 pair of eyepieces and $\frac{3}{4}$ in. and $\frac{1}{5}$ in. objectives, - $\quad$ - $\quad$ - $\quad$ - $\quad$ - $\quad$ - $\quad$ - $\quad$ - 8800

H Binocular 2. Investigator stand with 1 pair of eyepieces and 2 in., $\frac{3}{4}$ in. and $\frac{1}{5}$ in.

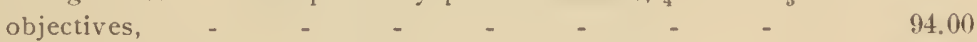

J Binocular. Universal stand with binocular body, 1 pair of eyepieces, $\quad$ - $\quad \mathbf{5} .00$

J Binocular 1. Universal stand with 1 pair of eyepieces and $\frac{3}{4}$ in. and $\frac{1}{3}$ in. objectives, $\quad 98.00$

J Binocular 2. Universal stand with 1 pair of eyepieces and 2. in., $\frac{3}{4}$ in. and $\frac{1}{5}$ in. objectives,

All of the above have arrangement for pupillary distance by a sliding adjustment.

K Binocular. Professional stand with binocular body, adjustment for pupillary distance by rack and pinion, 1 pair of eyepieces, - -

K Binocular 1. Professional stand with 1 pair of eyepieces and $\frac{3}{4}$ in. and $\frac{1}{5}$ in. objectives,

198.00

K Binocular 2. Professional stand with 1 pair of eyepieces and 2 in., $\frac{3}{4}$ in. and $\frac{1}{5}$ in. objectives,

K Binocular 3. Professional stand with 2 pair of eyepieces and $\frac{3}{4}$ in. and $\frac{1}{5}$ in. objectives,

K Binocular 4. Professional stand with 2 pair of eyepieces and 2 in., $\frac{3}{4}$ in, and $\frac{1}{5}$ in. objectives,

Binocular body with sliding adjustment for pupillary distance, fitted to rack of any of our monocular microscopes, with 1 pair of eyepieces, extra, (When so ordered, stand must in every case be sent on for adaptation.) 


\section{Simple Iligrescopes.}

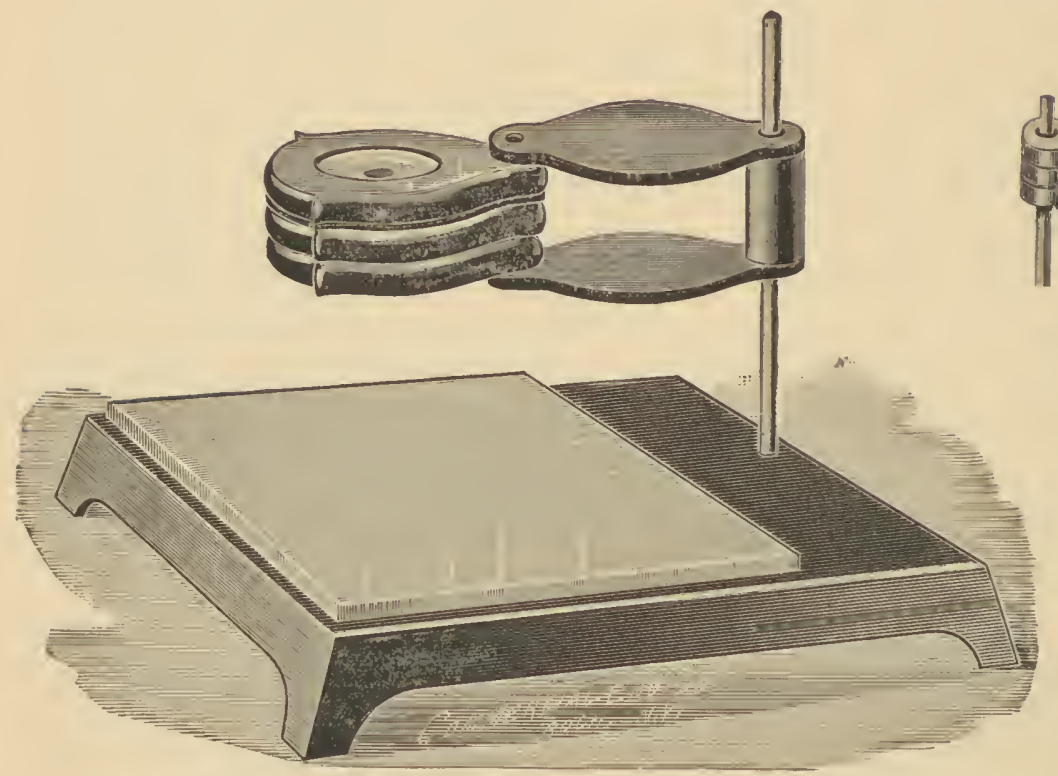

(Cut full size.)

R-HANDY DISSECTING MICROSCOPE.

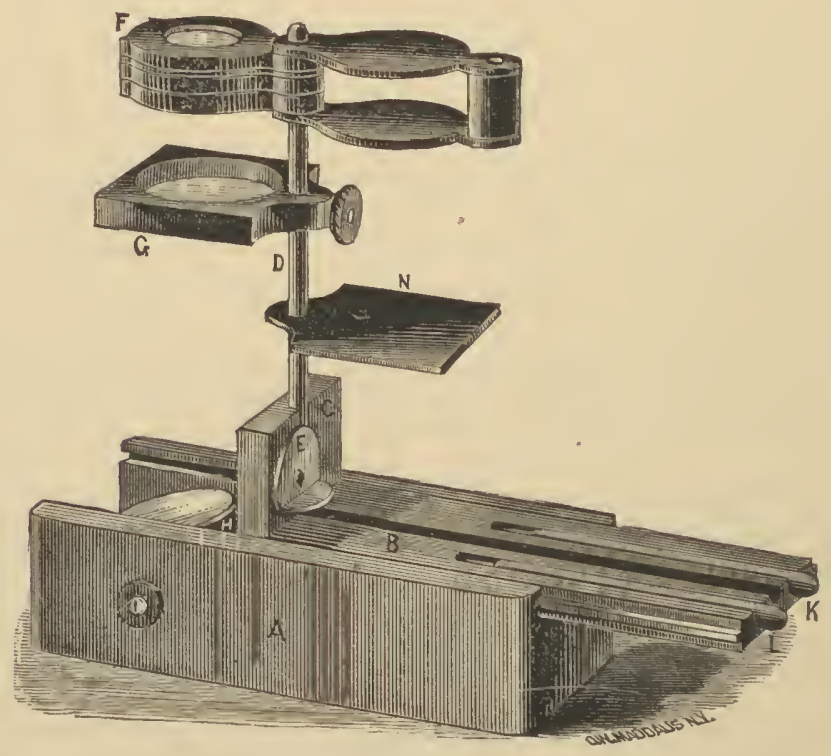

(Cut two-thirds of actual size.)

S-EXCELSIOR POCKET AND DISSECTING MICROSCOPE. 


\section{R-HANDY DISSECTING MICROSCOPE.}

The dissecting microscopes represented on the previous page are very efficient and convenient for examination of minerals, insects, flowers. etc.

They consist of an iron base with glass plate inlaid, forming a white back ground. A steel stem is screwed into the base plate, to which the magnifier is fitted and arranged to slide. The magnifiers are furnished with one, two or three lenses, which give a power of from 5 to 25 diameters. Those with two or three lenses are provided with a diaphragm which secures distinctness of definition.

The stem can be easily unscrewed, and the whole packed in a small box. Nickel plated pliers are furnished with the instruments.

R1, with one lens,

R2, with two lenses,

R3, with three lenses,

$\mathbf{R} 4$, with three lenses, magnifier not in folding case, as shown,

\section{S-EXCELSIOR POCKET AND DISSECTING MICROSCOPE.}

This instrument consists of a small wooden case, to one end of the lid is attached one of the ends of the box, which, when reversed, forms a stand for the lenses and stage. These are supported by a steel rod, D, the lower end of which is hinged to the lid so that it may be turned down and lie in a groove. The glass stage, G, and magnifier are adjustable, and the former may be fixed by the set-screw. An adjustable mirror, $\mathrm{H}$, is fitted into the case, by means of which light may be reflected on the objects; when these are opaque, all transmitted light may be shut off by the stop, N. Dissecting needles, $\mathrm{K}$ and L., with neat handles, fit into appropriate grooves.

As a dissecting microscope for botanical and entomological work, this instrument is very efficient. The glass plate in the stage forms a cell for holding water, so that aquatic animals may be examined. The lenses and stage may be packed in the case, which readily admits of its being carried in the vest pocket.

The lenses may be used either singly or together; are well made, and are provided with a proper diaphragm which secures distinctness of definition. They give a range of power of from five to twenty-five diameters. Under good management they show the individual corpuscles in the blood of the frog, and will exhibit very clearly the circulation in the foot of this animal.

S1, with two lenses,

S3, set of three hard rubber slides, with opening of different kinds, to serve as linen 


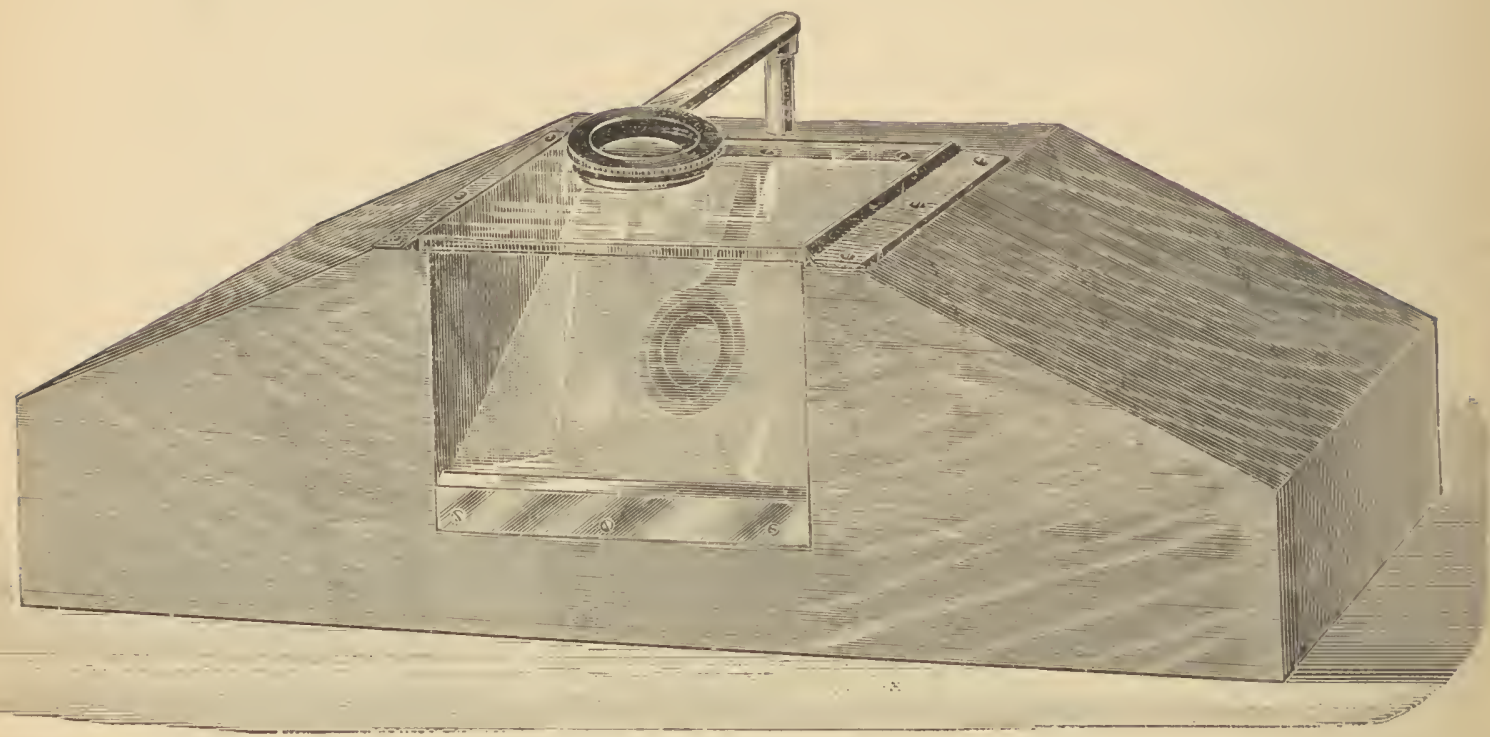

(Cut one-half of actual size.)

T-PRIMARY DISSECTING MICROSCOPE.

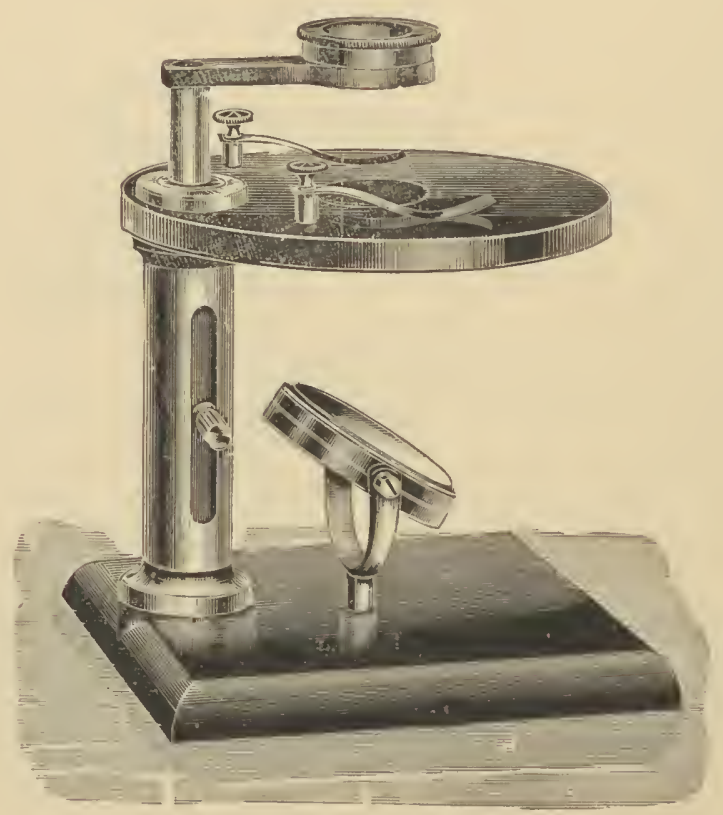

(Cut one-half of actual size.)

$\mathbf{U}$ - EDUCATIONAL DISSECTING MICROSCOPE, 


\section{T-PRIMARY DISSECTING MICROSCOPE.}

This represents a most effective and low priced dissecting instrument. The body is a solid block of wood so shaped that the sides serve the purpose of hand rests : mirror and movable glass stage plate are provided for in a simple manner. The lens holder slides in a brass tube driven into a hole in the block. The lens is of $1 \mathrm{in}$. focus and mounted in hard rubber.

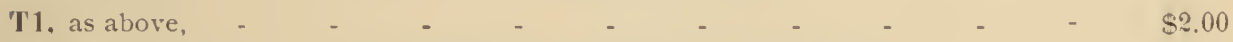

T2. with 2 mounted lenses of $?$ in. and 1 in. focus. $\quad$ - $\quad$ - $\quad$ - $\quad$ - $\quad$ - 3.00

Single lenses, mounted of $\frac{3}{4}$ in., $\frac{1}{2}$ in., or $\frac{1}{4}$ in, focus, extra, each, - - 1.00

\section{U-EDUCATIONAL DISSECTING MICROSCOPE.}

This instrument has been specially designed for class and laboratory use, and is of the utmost simplicity, nothing, however, having been sacrificed of its thorough efficiency. The base is of japanned iron; the pillar is of finished brass, and contained therein is the sliding rod, provided with projecting pin ; the arm is partly adjustable in the rod; the stage is of bronzed brass provided with spring clips. The mirror is concave, and on the opposite side has a white opaque surface." The instrument is supplied in cherry case with handle.

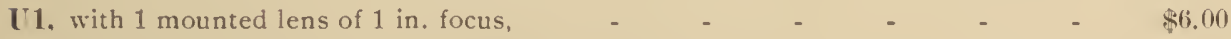

U2. with 2 mounted lenses of 2 in. and 1 in. focus, $\quad$ - $\quad$ - $\quad$ - $\quad$ - $\quad$ \%.00

Arm for lenses, with joint in place of single arm, extra, _ $\quad$ - $\quad$ - $\quad 1.00$

Single lenses mounted of $\frac{3}{4}$ in., $\frac{1}{2}$ in. or $\frac{1}{4}$ in focus, extra, each, - - $\quad-1.00$ 


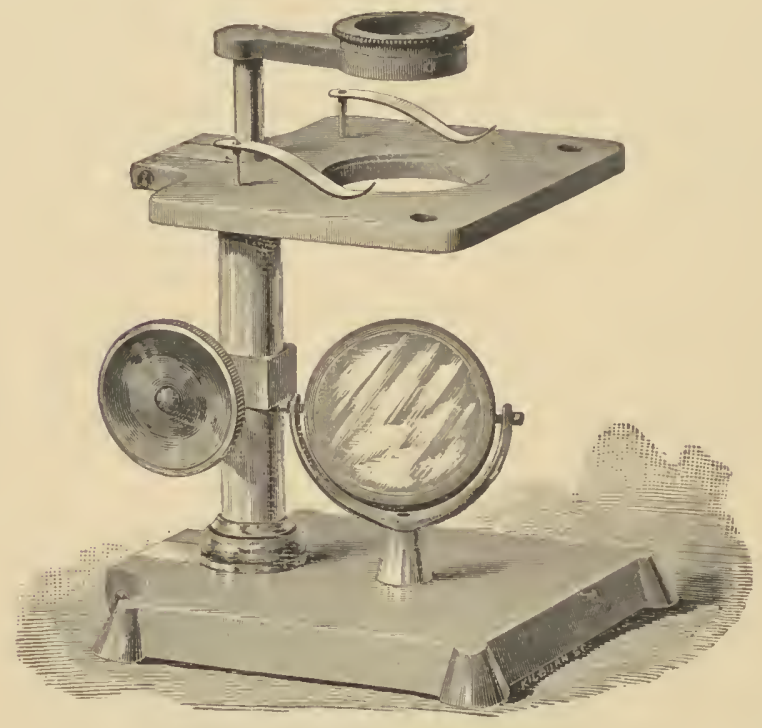

(Cut one-third of actual size.)

V-FOLDING DISSECTINC MICROSCOPE. 


\section{$\checkmark$-FOLDING DISSECTING MICROSCOPE.}

(Pat. Aug. 3, 1880.)

This instrument is compact, portable and efficient. It has all the elements of the ordinary dissecting microscopes, and besides these the important feature that, when folded, it is brought into a very small compass.

The base is japanned iron. The stage is of brass, blackened, has spring clips, and in its center contains a removable glass disc. It is of convenient height, so that any amount of work may be done without any fatigue to the arms or hands. The arm holding the lenses is adjustable in a triangular rack-rod, and is arranged with society screw, thus permitting the use of lowpower objectives. The rack and pinion give a perfectly smooth adjustment. The mirror is detachable from the base, and can be readily attached to the stage for oblique light or illumination of opaque objects. The brass work is all highly finished and lacquered. In folding, the rack is brought down and arm detached, the stage swings backwards on the pillar and the base on the stage, so that the space occupied is merely the size of the base, and thickness of this, stage and arm.

Mounted lenses, of 2 and 1 in. focus, and nickel-plated pliers accompany the instrument, and are so arranged that they may be used singly or in conjunction. The whole packed in a neat case. Grooves are provided on lower surface of stage to receive brass hand-rests.

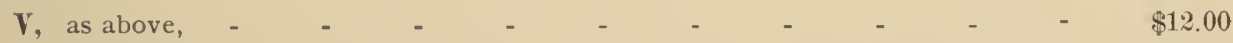

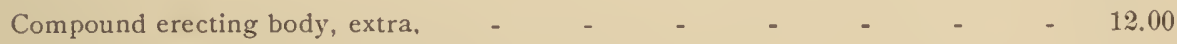

Hand-rests as shown in cut, per pair, $\quad$ - $\quad$ - $\quad$ - $\quad$ - $\quad$ - $\quad-\quad 2.00$

Arm for lenses, with joint in place of single arm, extra, - _ _ _ $\quad$ - 1.00

Single lenses, mounted, of $\frac{3}{4}$ in., $\frac{1}{2}$ in. or $\frac{1}{4}$ in. focus, extra, each, _ $\quad-\quad 1.00$

Coddington magnifiers, $1 \mathrm{in}, \frac{3}{4} \mathrm{in}$. or $\frac{1}{2} \mathrm{in}$. focus, extra, each, - $\quad$ - $\quad 2.50$

Achromatic Triplets, giving large flat field with beautiful definition, $1 \mathrm{in} ., \frac{3}{4} \mathrm{in}$.

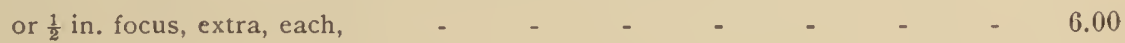





\section{Objegtives.}

Our list of objectives has been added to from time to time, and now embraces a variety from which a suitable selection may be made for every field of investigation. Our objectives are all carefully computed for the utmost freedom of color, largest amount of light, greatest working distance, and extreme flatness of field for their respective angular apertures and magnifying powers. The process of production is carried out on a system which was developed after constant efforts to reach the highest results, and eliminates every possibility of chance, so common' to optical work generally. A faulty objective never leares our hands, and every opportunity for improvement is utilized. The glass employed is of the celebrated Jena production, but only such is used, which after years of constant use has proven itself to be not liable to the least deterioration. The many thousands of objectives which are in constant use, and the constantly increasing demand, fully attest their comparative merits as well as moderate prices.

Our objectives are all classified according to their numerical aperture and divided into series. We draw particular attention to the fact that all of our objectives have our name in full, "Bausch \& I.omb Optical Co.," cut upon them. We deem this necessary, as we often learn that unscrupulous parties palm off worthless productions as ours which are similar in appearance. 111 objectives have the stanclard society screw and are furnished in neatly finished brass boxes.

All non-adjustable objectives are corrected for a cover thickness of $0.16 \mathrm{~mm}$. (about 0.006 in.), and the medium point of adjustment in all adjustable objectives is for the same thickness. This thickness is about the average in the No. 2 cover glass, but there is a wide difference between the two extremes. While a variation in thickness of the cover glass is admissible in the low powers, it disturbs the correction in medium powers and very consiclerably so in high powers, and, as a consequence, objectives fail proportionately to give good results. Cover glasses should therefore either be measured, for which purpose our Cover Glass Gauge is admirably adapted, and to which we call particular attention, or where means will permit, adjustable objectives should be selected. With these it is possible to obtain the highest degree of their performance under any condition, and where correct thickness is used, they may be left at the medium point of adjustment. 
NUMERICAL APERTURE TABLE.

(Reprint from "The Jourual of the Royal Microscopical society.)

\begin{tabular}{|c|c|c|c|c|c|c|c|c|}
\hline \multirow{2}{*}{$\begin{array}{l}\text { NUYERICAL } \\
\text { APERTURE. } \\
\text { ( } n \sin u=a \text {.) }\end{array}$} & \multicolumn{3}{|c|}{ Corresponding Angle ( $2 u$ ) for } & \multicolumn{3}{|c|}{ Limit of Resolving Power, in Lines to an Inch. } & \multirow[b]{2}{*}{$\begin{array}{c}\text { Illuminating } \\
\text { Power. } \\
\left(\begin{array}{l}\text { a 2.) } \\
\end{array}\right.\end{array}$} & \multirow{2}{*}{$\begin{array}{c}\text { Pene- } \\
\text { trating } \\
\text { Power } \\
\left(\frac{1}{a}\right)\end{array}$} \\
\hline & $\begin{array}{c}\text { Air } \\
(n=1 . \infty .)\end{array}$ & $\begin{array}{c}\text { Water } \\
(n=\mathrm{I} 33 .)\end{array}$ & $\begin{array}{c}\text { Homogencons } \\
\text { Immersion } \\
(n=152 .)\end{array}$ & $\begin{array}{c}\text { White light. } \\
(\lambda=0.5269 \mu \text {, } \\
\text { Line E })\end{array}$ & $\begin{array}{c}\text { Monochromatic } \\
\text { (13lue) Light } \\
(\lambda-0.48611 \mu, \\
\text { Line F.) }\end{array}$ & \begin{tabular}{|} 
Photography \\
$(\lambda=0.4000 \mu$ \\
Near Line $h)$.
\end{tabular} & & \\
\hline 1.52 & $\cdots$ & $\cdots$ & $180^{\circ} 0^{\prime}$ & 146,543 & 158,845 & $193,03 \pi$ & 2.310 & .6 .58 \\
\hline 1.51 & . & .. & $166^{\circ} 51^{\prime}$ & 145,579 & 157.800 & 191.767 & 2.280 & .662 \\
\hline 1.50 & . & . & $161^{\circ} 23^{\prime}$ & 144,615 & $156.75 \pi$ & 190,497 & 2.250 & .667 \\
\hline 1.49 & .. & . & $157^{\circ} 12^{\prime}$ & $143,6.51$ & $15 \%, \pi 10$ & 189.227 & 2.220 & $.6 \div 1$ \\
\hline 1.45 & .. & . & $153^{\circ} 39^{\prime}$ & $142,6 \times \%$ & $154,66.5$ & $18 \%, 9.57$ & 2.190 & $.6 \div 6$ \\
\hline 1.47 & . & . & $150^{-} 32^{\prime}$ & 141,723 & $15: 3,620$ & 186,687 & 2.161 & .680 \\
\hline 1.46 & . & . & $147^{\circ} 42^{\prime}$ & 140,759 & 152,575 & $18 \pi, 417$ & 2.132 & .685 \\
\hline 1.45 & .. & $\ldots$ & 145 6 & 139,795 & 151,530 & 184,147 & 2.103 & .690 \\
\hline $1 .+4$ & .. & . & $142 \cdot 39$ & 138,830 & $150,48 i \bar{j}$ & $182,87 \%$ & 2.074 & .694 \\
\hline $1.4: 3$ & .. & . & $140 \quad 22$ & 137,866 & 149.440 & 181,607 & 2.045 & 699 \\
\hline 1.42 & .. & . & $138^{\circ} 12^{\prime}$ & 136.902 & 148.39 .5 & 180,337 & 2.016 & .704 \\
\hline 1.41 & . & . & $136^{\circ} \quad 8^{\prime}$ & 135,938 & $14 \tau$ & $179,0+i 7$ & $1.9<8$ & .709 \\
\hline 1.40 & .. & . & $134 \quad 10^{\prime}$ & 134.974 & $146,30 \%$ & 177.797 & 1.960 &.$\tilde{\pi} 14$ \\
\hline 1.399 & .. & . & $13216^{\prime}$ & 134.010 & 145,260 & 176.527 & 1.932 & .719 \\
\hline 1.35 & . & . & $130^{\circ} 26^{\circ}$ & $13: 3.046$ & 144.215 & 175.257 & 1.904 & .725 \\
\hline 1.37 & . & . & $128^{\circ} 40^{\prime}$ & 132,082 & $143.1 \div 0$ & $173,98 \tau$ & 1.877 & .729 \\
\hline 136 & . & . & $126^{\circ} 58^{\prime}$ & 131.118 & 142,125 & $1 \% 2,71 \%$ & 1.8 .50 & .735 \\
\hline 1.35 & .. & . & $125^{\circ} 18^{\prime}$ & 130.154 & 141,080 & $1 \pi 1,44 \pi$ & 1.823 & .741 \\
\hline 1.34 & .. & & $123^{\prime} 40^{\prime}$ & 129,189 & 140.03 .5 & $170.17 \%$ & 1.796 & .746 \\
\hline 1.333 & .. & $180 \quad 0^{\prime}$ & $122^{\circ} \quad 6$ & 128,225 & 138,989 & 168,907 & 1.769 & .752 \\
\hline 1.30 & .. & 16556 & $120^{\circ} 33^{\prime}$ & $12 \tau, 261$ & $13 \% .944$ & $16 \%, 63 \%$ & 1.742 & .758 \\
\hline 1.330 & .. & $155^{\circ} 38^{\prime}$ & $117^{\circ} 35^{\prime}$ & $12,5,33: 3$ & 135.85 & $165,09 \tau$ & 1.690 & .769 \\
\hline 1.25 & .. & $148+2$ & $114 \quad 44^{\prime}$ & 123,405 & 133,764 & $162,55 \%$ & 1.638 & .781 \\
\hline 1.26 & $\ldots$ & $14239^{\prime}$ & $111^{\circ} 59^{\prime}$ & 121,477 & $131.6 \pi 4$ & $160,01 \%$ & 1.588 & .794 \\
\hline 1.24 & . & $137^{\circ} 36^{\prime}$ & $109^{\circ} 20^{\prime}$ & 119,548 & 129,584 & 157,477 & 1.538 & .806 \\
\hline 1.22 & .. & $133 \quad 4^{\prime}$ & $106^{\circ} 45^{\prime}$ & 117.620 & $12 \tau, 494$ & 154,937 & 1.488 & .820 \\
\hline 1.20 & . & $128^{\circ} 55^{\prime}$ & 10415 & 115,692 & $12 \bar{j}, 404$ & 152.3997 & 1.440 & .8333 \\
\hline 1.18 & . & $125 \quad 3^{\prime}$ & $101^{\circ} 50^{\prime}$ & 113.764 & 123.314 & $149.85 \%$ & 1.392 & $.84 i$ \\
\hline 1.16 & .. & $121^{\circ} 26$ & $99 \quad 29^{\prime}$ & 111,835 & 121,224 & $147,31 \%$ & 1.346 & .862 \\
\hline 1.14 & . & $118^{\circ} 0^{\prime}$ & $97^{\circ} 11^{\prime}$ & $109.90 \tau$ & 119,134 & $144, \pi 7 \%$ & 1.300 & $.87 \tau$ \\
\hline 1.12 & .. & $114^{\circ} 44^{\prime}$ & $94^{\circ} 55^{\prime}$ & 107,979 & 117044 & $14: 237$ & 1.254 & .893 \\
\hline 1.10 & . & $111^{\circ} 36^{\prime}$ & $92^{\circ} 43^{\prime}$ & 106,051 & 114,954 & 139.698 & 1.210 & .909 \\
\hline $1.0 \mathrm{~S}$ & . & $108^{\circ} 36^{\prime}$ & $90 \quad 34$ & 104,123 & 112,564 & 137.158 & 1.166 & .926 \\
\hline 1.06 & .. & $105^{\circ} 42^{\prime}$ & $88^{\circ} 27^{\prime}$ & 102,195 & 110,714 & 134,618 & 1.124 & .943 \\
\hline 1.04 & .. & $102^{\circ} 53^{\prime}$ & $86^{\circ} 21^{\circ}$ & 100,266 & 108,684 & $132,0 \div 8$ & 1.082 & .962 \\
\hline 1.02 & & $100^{\circ} 10^{\prime}$ & $84^{\circ} 18^{\prime}$ & 98,338 & 106,593 & $129 . \overline{3} 38$ & 1.040 & .980 \\
\hline 1.00 & $180^{\circ} \quad 0^{\prime}$ & $97^{\circ} 31^{\prime}$ & $82 \quad 17^{\prime}$ & 96,410 & 104.503 & 126,998 & 1.000 & 1.000 \\
\hline 0.95 & $157^{\circ} 2^{\prime}$ & $94^{\circ} 56^{\prime}$ & $80 \quad 1 \%$ & 94,482 & 102,413 & 124,458 & .960 & 1.020 \\
\hline 0.96 & $147^{\circ} 29^{\prime}$ & $92^{2} 24$ & $\begin{array}{lll}78^{\circ} & 20^{\prime}\end{array}$ & 92,554 & 100,323 & 121,918 & .922 & 1.042 \\
\hline 0.94 & $140^{\circ} \quad 6^{\prime}$ & $89^{\circ} 56^{\prime}$ & $76^{\circ} 24$ & 90,625 & 98,233 & 119.378 & .884 & 1.064 \\
\hline 0.92 & $133^{\circ} \mathrm{51}$ & $87^{\circ} 32^{\prime}$ & ' it $30^{\prime}$ & 88,697 & 96,143 & 116.838 & .846 & $1.08 \%$ \\
\hline 0.90 & $128^{\circ} 19^{\prime}$ & $85^{\circ} 10^{\prime}$ & 7236 & $86, \pi 69$ & $94,0.3$ & 114.298 & .810 & 1.111 \\
\hline 0.85 & $123^{\circ} 1 \gamma^{\prime}$ & 82 51' & $70^{\circ} 44^{\prime}$ & 84841 & 91,963 & 111,758 & .774 & 1.136 \\
\hline 0.86 & $118^{\circ} 38^{\prime}$ & $80^{\prime} 34^{\prime}$ & $68^{\circ} 54$ & 82,913 & $89.8 \% 3$ & 109,218 & .740 & 1.163 \\
\hline 0.84 & $114^{\circ} 17^{\prime}$ & $78^{\circ} 20^{\prime}$ & $67^{\circ} \quad 6$ & 80,984 & $8 \%, 78: 3$ & 106.678 & .706 & 1.190 \\
\hline 0.82 & $110^{\prime} 10^{\prime}$ & $76^{\circ} 8^{\prime}$ & $65 \quad 18$ & $\tau 9,056$ & 85,693 & 104,138 & $.6 \pi 2$ & 1. 220 \\
\hline 0.80 & $106^{\circ} 16^{\prime}$ & $73^{\circ} 58^{\prime}$ & 6331 & $\tau \%, 128$ & 83,$1 ; 03$ & 101,j91 & .640 & 1.250 \\
\hline 0.75 & $102^{\circ} 31^{\prime}$ & $71^{\circ} 49^{\prime}$ & $61^{\circ} 45$ & $\tau 5,200$ & $81,51: 3$ & 99,058 & .608 & 1.282 \\
\hline 0.76 & $98^{\circ} 56^{\prime}$ & 6942 & $\begin{array}{lll}60 & 0^{\prime}\end{array}$ & 73,272 & 79,423 & 96.518 & .578 & 1.316 \\
\hline 0.74 & $9)^{\circ} 28^{\prime}$ & $67^{\circ} 37^{\prime}$ & $58 \quad 16$ & 71,343 & $\tau 2,3333$ & 93,979 & .548 & 1.351 \\
\hline 0.70 & $92^{\circ} 06^{\prime}$ & $65^{\circ} 32^{\prime}$ & $56^{\circ} 32$ & $69,41 \bar{\jmath}$ & 75.242 & 91.439 & .518 & 1.389 \\
\hline 0.70 & $88^{\circ} 51^{\prime}$ & $63^{\circ} 31^{\prime}$ & $54 \quad 50^{\prime}$ & $6 \pi, 48 \pi$ & 73.1522 & 88,899 & .490 & 1.429 \\
\hline 0. (is & $85^{\circ} 41^{\prime}$ & $61^{\circ} 30^{\prime}$ & 53 9 & 6.5 .559 & 71062 & $86,35.9$ & $.46 i 2$ & 1. 471 \\
\hline 0.196 & $82^{\circ} 36^{\prime}$ & $59^{\circ} 30^{\prime}$ & $51^{\circ} 28^{\prime}$ & $63,6: 31$ & 68,972 & $8: 3,819$ & .436 & 1.515 \\
\hline 0.61 & $79^{\circ} 36^{\prime}$ & $57^{\circ} 31$ & $49 \quad 48$ & 61.702 & $66,8 \times 2$ & 81,279 & .410 & 1.562 \\
\hline 0.62 & $76^{\circ} 38^{\prime}$ & $55^{\circ} \quad 34^{\prime}$ & $\begin{array}{ll}48^{\circ} & 9\end{array}$ & 59.74 & 64,792 & 78,739 & .384 & 1. 613 \\
\hline 0.60 & $73^{\circ} 44^{\prime}$ & $53 \quad 38^{\prime}$ & $46^{\circ} 30^{\prime}$ & 57.846 & 62,702 & 76,199 & .360 & $1.66 \%$ \\
\hline $0.5 \mathrm{~s}$ & $70^{\circ} 54^{\prime}$ & $51^{\circ} \quad 42^{\prime}$ & $44^{\circ} 51$ & 55,918 & 60,612 & 73,659 & .336 & 1. $\tau 24$ \\
\hline $0 . \overline{3} 6$ & $68^{\circ} \quad 6^{\prime}$ & $49^{\circ} \quad 48^{\prime}$ & $43^{\circ} 14^{\prime}$ & 53,990 & 58.522 & $\tau 1,119$ & .314 & 1.786 \\
\hline 0.54 & $\left(65^{\circ} 22^{\prime}\right.$ & $47^{\circ} 5 t^{\prime}$ & $41^{\circ} 3 \tau^{\prime}$ & 52,061 & 56,432 & 68,579 & .292 & 1.852 \\
\hline 0.52 & $62^{\circ} 40^{\prime}$ & $46^{\circ} \quad 2^{\prime}$ & $\begin{array}{lll}40^{\circ} & 0^{\prime}\end{array}$ & 50,133 & 54,342 & 66,039 & .270 & 1. 923 \\
\hline 0.50 & $60^{\circ} \quad 0^{\prime}$ & $44^{\circ} 10^{\prime}$ & $38^{\circ} 24^{\prime}$ & 48.205 & 52,252 & 63,499 & .250 & 2.000 \\
\hline 0.45 & $53^{\circ} 30^{\prime}$ & $39^{\circ} 33^{\prime}$ & $34^{\circ} 27^{\prime}$ & 43,385 & 47,026 & 57.149 & .203 & 2.222 \\
\hline 0.40 & $47^{\circ} \quad 9^{\prime}$ & $35^{\circ} \quad 0^{\prime}$ & $30^{\circ} 31^{\prime}$ & 38,564 & 41,801 & 50.799 & .160 & 2.500 \\
\hline 0.355 & $40^{\circ} 58^{\prime}$ & $30^{\circ} 30^{\prime}$ & $26^{\circ} 38^{\prime}$ & 33,744 & 36,576 & 44,449 & .123 & $2.85 \%$ \\
\hline 0.30 & $34^{\circ} 56^{\prime}$ & $26^{\circ} 4^{\prime}$ & $22^{\circ} 46$ & 28,923 & 31.351 & 38,099 & .090 & 3.333 \\
\hline 0.25 & $28^{\circ} 58^{\prime}$ & $21^{\circ} 40^{\prime}$ & $18^{\circ} 56$ & 24,103 & 26,126 & $31, \tau 49$ & .063 & 4.000 \\
\hline 0.20 & $23^{\circ} \quad 4^{\prime}$ & $17^{\circ} 18^{\prime}$ & $15 \quad \tau^{\prime}$ & 19282 & 20,901 & 25,400 & .040 & 5.000 \\
\hline 0.15 & $17^{\circ} 14^{\prime}$ & $12^{\circ} 58^{\prime}$ & $11^{\circ} 19^{\prime}$ & 14,462 & 15,6 i。 & 19,050 & .023 & $6.66 \pi$ \\
\hline 0.10 & $11^{\circ} 29^{\prime}$ & $8^{\circ} 38^{\prime}$ & \% 34 & 9,641 & 10.450 & 12,700 & .010 & 10.000 \\
\hline 005 & 544 & $4^{\circ} 18^{\prime}$ & 346 & 4.821 & 5.252 & 6.350 & .003 & 20.000 \\
\hline
\end{tabular}




\section{LINEAR MAGNIFYING POWERS OF OBJECTIVES AND EYEPIECES.}

\begin{tabular}{|c|c|c|c|c|c|c|c|c|c|c|c|c|}
\hline \multicolumn{13}{|c|}{ STANDARD TUBE LENGTH, 8.5 in., $216 \mathrm{~mm}$. } \\
\hline \multicolumn{6}{|c|}{ OBjectives. } & 3 in. & 2 in. & $1 \frac{1}{2}$ in. & $1 \mathrm{in.}$ & $\frac{3}{4}$ in. & $\frac{1}{2} \mathrm{in}$. & tin. \\
\hline \multicolumn{6}{|c|}{2 in. $(\mathrm{A})$} & 15 & 25 & 33 & 40 & 50 & 70 & $1 \% 6$ \\
\hline \multirow{4}{*}{\multicolumn{2}{|c|}{ EYEPIECES }} & \multicolumn{4}{|c|}{$1 \frac{1}{2}$ in. (B) } & 21 & 35 & 42 & $5 \pi$ & \%0 & 102 & 247 \\
\hline & & \multirow{3}{*}{\multicolumn{4}{|c|}{$\begin{array}{cc}1 \text { in. } & (\mathbf{C}) \\
\frac{3}{4} \text { in. } & (\mathbf{1 0}) \\
\frac{1}{2} \text { in. } & (\mathbf{E})\end{array}$}} & 30 & 50 & 66 & 80 & 100 & 140 & 353 \\
\hline & & & & & & 42 & $\tau 0$ & 84 & 110 & 140 & $20 \pi$ & 495 \\
\hline & & & & & & 60 & 100 & 132 & 160 & 200 & 280 & 705 \\
\hline \multicolumn{9}{|c|}{ STANDARD TUBE LENGTH, 8.5 in., $216 \mathrm{~mm}$. } & \multicolumn{4}{|c|}{$\|$ TUBE LENGTH, $160 \mathrm{~mm}$. } \\
\hline \multicolumn{3}{|c|}{ OBjectives. } & $\frac{1}{5}$ in. & $\frac{1}{6}$ in. & $\frac{1}{8}$ in. & $\frac{3}{10}$ in. & $\frac{1}{12}$ in & $\frac{1}{16} \mathrm{in}$. & 2 in. & $\frac{9}{3}$ in. & $f$ in. & $\frac{1}{12} \mathrm{in}$. \\
\hline & 2 in. & (A) & 210 & 265 & 360 & 450 & $5 \% 0$ & 690 & 18 & 29 & 135 & 460 \\
\hline & $1 \frac{1}{2}$ in. & & 295 & 385 & 540 & 660 & 845 & 1025 & 26 & 42 & 260 & 675 \\
\hline & 1 in. & (C) & 420 & 530 & $\approx 20$ & 900 & 1140 & 1380 & $3 \tilde{r}$ & 58 & $3 \% 0$ & 920 \\
\hline & $\frac{8}{4}$ in. & (D) & 590 & $\pi \% 0$ & 1080 & 1320 & 1690 & 2050 & 52 & 84 & 520 & 1350 \\
\hline & $\frac{1}{2}$ in. & (E) & 840 & 1060 & 1440 & 1800 & 2280 & 2760 & $\pi 4$ & 116 & 740 & 1840 \\
\hline
\end{tabular}

\section{INSTRUCTIONS FOR USING EYEPIECE MICROMETER.}

As the eyepiece micrometer is not compared directly with the object itself, but only with the image of it formed in the focus of the eyepiece, it is only when the exact proportion between the size of the object and that of its image is known, that measurements of the object can be readily determined by the eyepiece micrometer.

This proportion depends upon: 1st, the focus of the objective; $2 \mathrm{~d}$, the distance of the image from the object; $3 \mathrm{~d}$, the focus and the place of the field-lens when the latter is situated between the objective and the image.

As these relative conditions are not of equal value in all microscopes, and consequently the relative sizes of the 1mages, as formed by different objectives of the same rating, are not always the same, these sizes have to be ascertained for each microscope and objective separately.

To reach this result, a reliable stage micrometer should be used as an object, and its image accurately measured with the eyepiece micrometer.

The figures designate the proportion of the linear measure of the object, the latter being taken as 1 .

The actual size of any object is therefore obtained when the size of its image, which is obtained by direct measurement by means of the eyepiece micrometer, is divided by the figures so obtained.

For adjustable objectives, the figures are intended for close adjustment.

In instruments having draw-tube, make measurements when tube is at standard length.

$25.4 \mathrm{~mm} .=1 \mathrm{in}$ 


\title{
OBJECTIVES--SERIES I.
}

\author{
(Old Biological Series.)
}

These objectives were specially designed for the Continental Microscopes, and are corrected for the short tube length of $160.0 \mathrm{~mm}$. They are therefore not suited for use with our other instruments unless the length of tube is decreased to the proper point by means of the draw-tube. They are intended for biological investigations and give results which are unsurpassed by any European productions. The $\frac{2}{3}$ in. has an unusual flatness of field with excellent definition; the $\frac{1}{6}$ in. has an excellent resolving power, resolving P. Angulatum easily with central light and good working distance; the $\frac{1}{1^{2}}$ in. oil immersion is mounted in non-adjustable mounting, and so perfectly corrected that it will resolve $\mathrm{A}$. Pellucida in balsam; it is well suited to the study of Bacteriology and all work requiring a higher power than the dry objective.

\begin{tabular}{|c|c|c|c|}
\hline NUMBER. & Focus. & NUMERICAL AP. & PRICE. \\
\hline 1000 & 2 in. & 0.10 & $\$ 6.00$ \\
\hline 1002 & $\frac{2}{3}$ in. & 0.25 & 7.00 \\
\hline 1004 & $\frac{1}{6}$ in. & 0.85 & 15.00 \\
\hline 1006 & $\frac{1}{1}$ in. Immersion. & 1.25 & 45.00 \\
\hline
\end{tabular}




\section{OBJECTIVES-SERIES II.}

(Old Student Series).

These objectives possess qualities which fit them excellently for the requirements of every-day work. They are unexcelled by any objectives of approximate price, and indeed by many which are higher in cost and more pretentious. We use them in making up our outfits.

The lower powers of this Selies up to $1 \frac{1}{2}$ in. are composed of a single system triplet; they give good definition. The 1 in., $\frac{3}{4}$ in. and $\frac{1}{2}$ in. are two system, of excellent definition and exceptionally flat field. The remainder of the Series are three system and offer various advantages. The $\frac{1}{4}$ in. N. A. 0.62 and $\frac{1}{5}$ in. N. A. 0.62 are especially designed lenses, having extra ordinary long working distance, sufficient to illuminate opaque objects, and they resolve $P$. Angulatum by oblique light ; their resolving power, however, does not equal that of the $\frac{1}{4}$ in., N. A. 0.77 , and $\frac{1}{5}$ in., N. A. 0.82, which both resolve P. Angulatum easily by central light. Unless it is expressly stated which objectives are desired, we always send the $\frac{3}{4}$ in. and $\frac{1}{5}$ in., $N$ A. 0.82 , with our instruments. The $\frac{1}{8}$ in. is good for general histological work where higher power is desired, although on account of the unavoidable loss of light, we recommend objectives of higher numerical aperture when these powers are required.

\begin{tabular}{|c|c|c|c|c|}
\hline NUMBER. & Focus. & NUMERICAL AP. & ADJUSTMENT. & PRICE. \\
\hline 1020 & 3 in. & 0.8 & Non-Adjustable. & $\$ 6.00$ \\
\hline 1022 & 2 in. & 0.10 & ". & 6.00 \\
\hline 1024 & $1 \frac{1}{2}$ in. & 0.14 & ." & 6.00 \\
\hline 1026 & 1 in. & 0.18 & “" & 6.00 \\
\hline 1028 & $\frac{8}{4}$ in. & 0.24 & “ & 8.00 \\
\hline 1030 & $\frac{1}{2}$ in. & 0.36 & “" & 9.00 \\
\hline 1032 & $\frac{1}{4}$ in. & 0.62 & “" & 14.00 \\
\hline 1034 & $\frac{1}{4}$ in. & 0.77 & “" & 14.00 \\
\hline 1036 & $\frac{1}{5}$ in. & 0.62 & ، & 15.00 \\
\hline 1038 & $\frac{1}{5} \mathrm{in}$. & 0.82 & “" & 15.00 \\
\hline 1040 & $\frac{1}{8} \mathrm{in}$. & 0.85 & “" & 18.00 \\
\hline
\end{tabular}




\section{OBJECTIVES-SERIES III.}

(Old Professional Series).

These objectives have a better resolving and defining power than the preceeding, and from the fact that they have larger lenses, give better illumination under the same conditions. They are substituted for those in the outfits for the difference in price.

The 3 to 5 in. is a variable objective. The variation is obtained by a revolving collar, and when at its highest power has a working distance of $\frac{1}{2} \mathrm{in}$,, and at its lowest power about 2 in. 'The lower powers from 3 in. to $\frac{3}{4}$ in. are composed of two systems, each in itself achromatic and of such a combination as will give the highest attainable results. The $3 \mathrm{in}, 2 \mathrm{in}$. and $1 \frac{1}{2} \mathrm{in}$. have a particularly flat field. In the immersion objectives the front is not affected by fluids. The $\frac{1}{2}$ in. resolves $\mathrm{P}$. Angulatum with oblique light. The $\frac{1}{4}$ in., $\frac{1}{5} \mathrm{in}$. and $\frac{1}{8} \mathrm{in}$. are newly constructed objectives of excellent capacity, resolving No. 17 of Moeller's test plate, and possess such working distance that no difficulty is experienced in comfortably working through any cover glass thickness. They are well suited to biological investigations, giving results closely approaching immersion objectives.

The water immersion objectives are notable for their long working distance and clearness of definition.

'The oil immersion are mounted in both fixed and adjustable mountings. They are admirable objectives, adapted to close work of every day occurrence, in which very large working distance and excellent resolving power are required. They will resolve $A$. Pellucida in balsam.

A phial of immersion fluid accompanies each objective.

The oil immersion $\frac{1}{12}$ in. referred to in all microscope outfits is the one in non-adjustable mounting.

\begin{tabular}{|c|c|c|c|c|c|c|}
\hline NUMBER. & & cus. & NUMERICAL AP. & & ADJUSTMENT, & PRICE. \\
\hline 1060 & $3 \mathrm{t}$ & o 5 in. & & Dry. & Variable. & $\$ 18.00$ \\
\hline 1062 & 3 & ". & 0.10 & “ & Non-Adjustable. & 13.00 \\
\hline 1064 & 2 & “ & 0.14 & “ & . & 13.00 \\
\hline 1066 & $1 \frac{1}{2}$ & “. & 0.20 & “" & “. & 15.00 \\
\hline 1068 & 1 & “ & 0.31 & “" & “. & 15.00 \\
\hline $10 \% 0$ & $\frac{3}{4}$ & “ & 0.35 & “" & “ & 15.00 \\
\hline 1072 & $\frac{1}{2}$ & “" & 0.54 & “" & “ & 18.00 \\
\hline 1074 & $\frac{1}{4}$ & “" & 0.88 & “" & Adjustable. & 24.00 \\
\hline 1076 & $\frac{1}{5}$ & “" & 0.90 & “" & ، & 28.00 \\
\hline 1078 & $\frac{1}{8}$ & “" & 0.92 & “ & “" & 30.00 \\
\hline 1090 & $\frac{1}{8}$ & “. & 0.99 & Water Im. & “" & 25.00 \\
\hline 1092 & $\frac{1}{10}$ & “" & 0.99 & “ & “" & 28.00 \\
\hline 1094 & $\frac{1}{12}$ & “ & 0.99 & “ & “ & 30.00 \\
\hline 1096 & $\frac{1}{16}$ & “. & 0.99 & ". & “ & 35.00 \\
\hline 1100 & $\frac{1}{8}$ & " & 1.18 & Oil Im. & Non-Adjustable. & 40.00 \\
\hline 1102 & $\frac{1}{10}$ & “ & 1.18 & “" & “ & 40.00 \\
\hline 1104 & $\frac{1}{12}$ & “" & 1.18 & “ & "“ & 45.00 \\
\hline 1106 & $\frac{1}{16}$ & “" & 1.18 & “" & “ & 55.00 \\
\hline
\end{tabular}

Nos. 1100, 1102, 1104, 1106 in adjustable mounting with graduated silvered collar, extra, 


\title{
OBJECTIVES-SERIES IV.
}

\author{
(Old First-Class Series.)
}

These objectives are of the highest attainable perfection, and we believe stand unrivaled. They will bear almost any amount of amplification. The $\frac{1}{6}$ in. stands pre-eminent as a dry objective, and is particularly valuable on account of its freedom from inconvenience of immersion fluids. It resolves No. 18 of Moeller's balsam plate; its adjustment is by rectilinear movement of the posterior system, and it has graduated and silvered collar.

The oil immersion objectives are four system, and we believe are unequalled in those qualities which are necessary in objectives of this class-extreme angular aperture with large working distance, resolution and flatness of field. Their numerical aperture is not less than 1.40, and the resolving power is commensurate with it.

After considering the fact that the slightest variation in immersion fluid and length of tube, change of eyepieces, cover-glasses of different refraction, in a word, circumstances differing in the slightest degree from those under which the objective was corrected, seriously affect its utility; and believing that the highest grade immersion objective should work equally well under any of these conditions, we have decided to make the above series in adjustable mountings only.

A phial of immersion fluid accompanies each objective.

\begin{tabular}{|c|c|c|c|c|c|}
\hline NUMBER. & Focus. & NUMERICAL AP. & & ADJUSTMENT. & PRICE. \\
\hline 1120 & $\frac{1}{6}$ in. & 0.94 & Dry. & Adjustable. & $\$ 40.00$ \\
\hline 1122 & $\frac{1}{8} \quad \cdots$ & 1.40 & Oil Immersion, & “. & $\pi 5.00$ \\
\hline 1124 & $\frac{1}{10} \quad$ “ & 1.40 & “ & “" & 80.00 \\
\hline 1126 & $\frac{1}{12} \quad \cdot$ & 1.40 & “ & “" & 90.00 \\
\hline 1128 & $\frac{1}{16} \quad 4$ & 1.40 & “ & “. & 125.00 \\
\hline
\end{tabular}




\section{Evgepieges.}

Our regular eyepieces are all provided with adjustable cap on eye lens; they give the largest and flattest possible field. We have adopted the par-focal plan and nomenclature as recommended by the committee of the American Society of Microscopists on eyepieces, which is the same as that used on objectives, and designates them according to the equivalent foci of the lenses. This method gives an approximate idea of the amplification.

All of these eyepieces, except when they vary from our standards, are so constructed that the neck or small tube, flange with milled edge, and large tube, are made of continuous metal, which insures not only extreme rigidity, but enables us to make the various parts exactly true with one another.

In addition to the above regular eyepieces, we make a series after the so-called Continental pattern, which consists of a straight tube, with the eye-lens and field-lens attached at each respective end. They are entirely contained in the tube of the microscope with the exception of the mounting for eye-lens and are intended to be used particularly with the Continental microscopes

The solid eyepieces consist of one piece of homogeneous glass. They are fixed in a standard size mounting which slips into an adapter for microscope tube.

The tubes of our microscopes take eyepieces of the following sizes:

$\mathrm{A}, \mathrm{B}, \mathrm{C}, \mathrm{D}, \mathrm{E}, \mathrm{F}, \mathrm{G}, \mathrm{L}, \mathrm{M}$ and $\mathrm{N}, 26.3 \mathrm{~mm}$. diam.

$\mathrm{H}$ and $\mathrm{I}$, - $\quad$ - $\quad$ - $30.5 \mathrm{~mm}$. diam.

K, - $\quad$ - $\quad$ - $\quad-38.6 \mathrm{~mm}$. diam. 


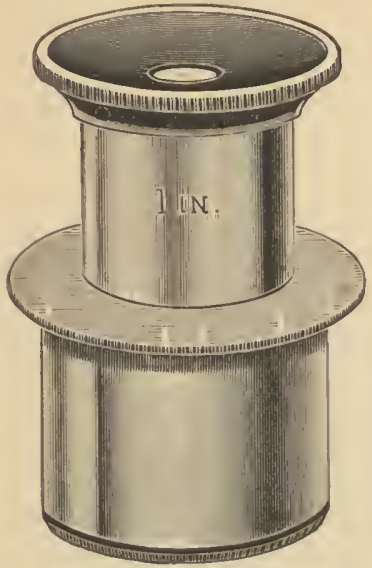

HUYGHENIAN.

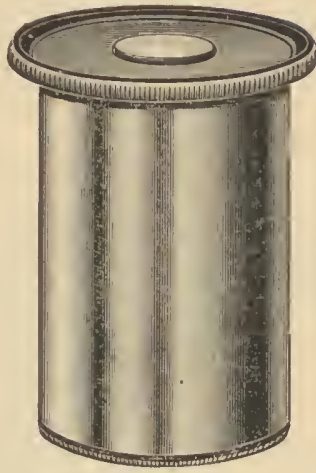

CONTINENTAL.

\section{HUYGHENIAN EYEPIECES.}

No.

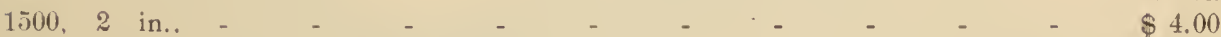

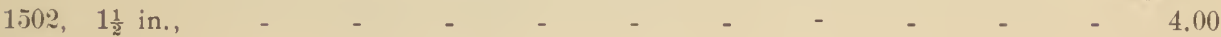

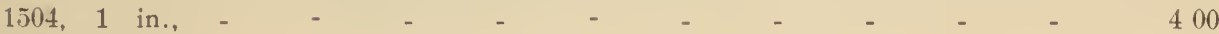

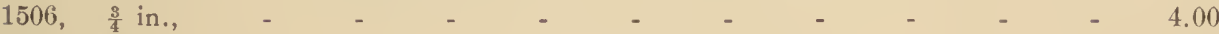

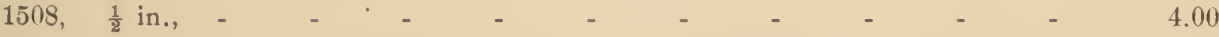

1504,1506 and 1508 can be arranged with slot to receive micrometer No. 1734; covered by cap to exclude light, eye-lens being adjustable for focus with micrometer No. 1734, extra,

1500 and 1502 can only be used with micrometer No. I736,

\section{CONTINENTAL EYEPIECES.}

No.

1520,2 in.,

$1522,1 \frac{1}{2}$ in.,

1524,1 in.,

$1526, \quad \frac{3}{4}$ in.,

$1528, \quad \frac{1}{2}$ in.,

Micrometer No. 1736 can only be used with the above.

\section{SOLID EYEPIECES.}

No.

$1540, \frac{1}{2}$ in., with adapter for any size tube, 1542 , $\frac{1}{3}$ in., with adapter for any size tube,

$1514, \frac{1}{4}$ in., with adapter for any size tube,

$1546, \frac{1}{6}$ in., with adapter for any size tube,

1548, $\frac{1}{8}$ in., with adapter for any size tube,

6.00

6.00

6.00

6.00

\section{DIRECTIONS FOR ORDERING EYEPIECES.}

When orders for eyepieces are given by measurement for other instruments than our own, we follow them exactly; but our experience has shown that this method is unreliable from the fact that the ordinary means of measuring are not sufficiently accurate. We would suggest that the best method of informing us of the size desired, is to send us a strip of good paper, of such a length that when wound around the eyepiece, the two ends will just meet. 


\section{গ2iตคอเอmes.}

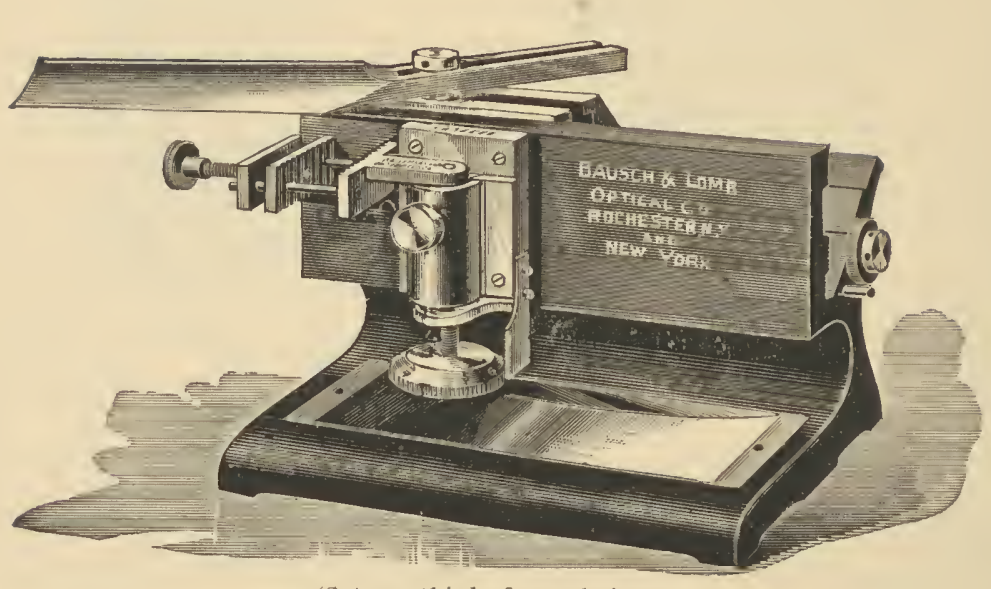

(Cut one-third of actual size.)

STUDENT MICROTOME.

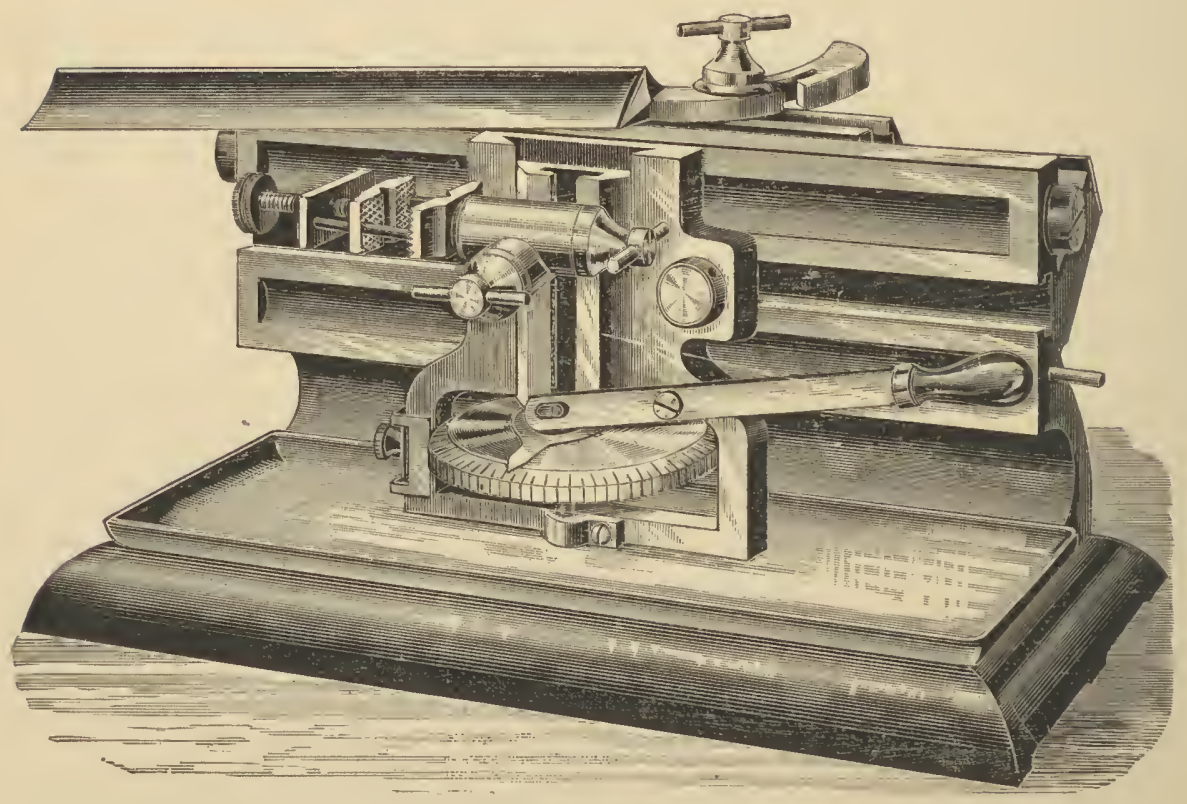

(Pat. September 8, 1885.)

(Cut one-third of actual size.)

LABORATORY MICROTOME. 


\section{MICROTOMES.}

In the Laboratory, the base, curved arm, upright and $\mathrm{V}^{\mathrm{T}}$-shaped beds are made of one continuous casting, thus insuring extreme rigidity, without excessive weight. The knife carrying block is fitted in the angular way in such a manner that the knife moves steadily through it without deviating from its plane and without requiring any extra pressure. Stop-screws with soft rubber cushions are fastened at the ends of the way, which serve to overcome any sudden concussion, and thus prevent a vibration of the knife. The upper surface of the block is provided on its entire length with a grooved slot, to which is fitted a sliding thumb-screw, so that the knife may be fastened at any point upon it."

The front vertical bed is planed and polished, and is arranged with a grooved slot its full length. The adjustable carriage is fitted to it, and may be securely fastened at any point upon it by means of two heavy screws. The tightening pin for these, when not in use, has a receptacle in the solid bed. It will thus be seen that whether it is desired to make a straight or very oblique cut, the carriage with object may be placed at such a point where it is the most convenient in its relation to the cutting edge.

To the carriage are directly fitted the micrometer screw with graduated disk and a slide which is acted upon by the former. A provision is made for taking up the possible wear on the screw. At one side of the carriage a spring is attached which works in the grooves on the edge of the disk with a pronounced click, so that the feed may be controlled without watching it ; this may be loosened so that it will not act when it is desired to use the index only. A lever with ivory handle is connected with the slide in the large size, so that this may be returned after the screw has come to the limit of its motion.

The slide is provided with a grooved slot, which admits of the quick vertical adjustment of the universal joint and clamp for specimens of different lengths. The universal joint permits inclination in any direction, and the clamp is arranged in such a manner that it swings on an axis and may be independently adjusted for height, thus giving five different adjustments for the specimens.

The Student is of smaller dimensions, but the construction of bed, curved arm, V-shaped bed and knife carrying block is the same. The feed-screw attachment is placed at one end of the bed, and for all ordinary work the best position of clamp is as shown in cut.

A drip-pan is countersunk in the upper surface of the bed, and is easily removable for the purpose of cleaning.

It is impossible to use a knife with a thin edge for all kinds of work, it will invariably nick or be otherwise damaged when such a one is used on hard substances; a knife with an edge not ground as thin as they usually are, should be used expressly for cutting hard substances. The knives we furnish are made of the very finest English steel and carefully tempered.

1600 , Student Microtome (no case), with knife in cherry case, _ _ _ _ $\quad \$ 18.00$

1602, Laboratory Microtome, small size, with knife in morocco case, the whole packed in polished case with lock and key,

1604, Laboratory Microtome, large size, with knife in morocco case, the whole

packed in polished case with lock and key, - - - $\quad-\quad 50.00$

1610, Microtome Knife, cutting edge $3 \frac{1}{4}$ in., in cherry case, each, _ _ - $\quad$ - 3.00

1612, Microtome Knife, cutting edge 4 in., in morocco case, each, _ _ $\quad$ - $\quad 8.00$

1614, Microtome Knife, cutting edge 6 in., in morocco case, each, _ _ _ _ $\quad-10.00$ 


\section{DIMENSIONS OF MICROTOMES.}

STUDENT.

Length of bed,

'Total height,

Limit of adjustment by micrometer screw,

Limit of adjustment for clamp,

Diameter of graduated disk,

Pitch of screw,

Length of cutting edge of knife,

Graduation on disk, 10.

\section{LABORATORY, SMALL SIZE.}

Length of bed,

Total height,

Limit of adjustment by micrometer screw, - " -

Limit of adjustment for clamp, - - - - $1 \frac{1}{4}$ "

Diameter of graduated disk, - - - - $\quad$ - 3 "

Pitch of screw,

Finest degree of feed, by click,

Length of cutting edge of knife,

Graduation on disk, 40 .

\section{LABORATORY, LARGE SIZE.}

Length of bed,

Total height,

Limit of adjustment by micrometer screw, - _ - 3 "

Limit of adjustment for clamp, - _ _ _ _ _ $\quad$ - 13

Diameter of graduated disk,

Pitch of screw,

Finest degree of feed, by click,

Length of cutting edge of knife,

Graduation on disk, 80 . 


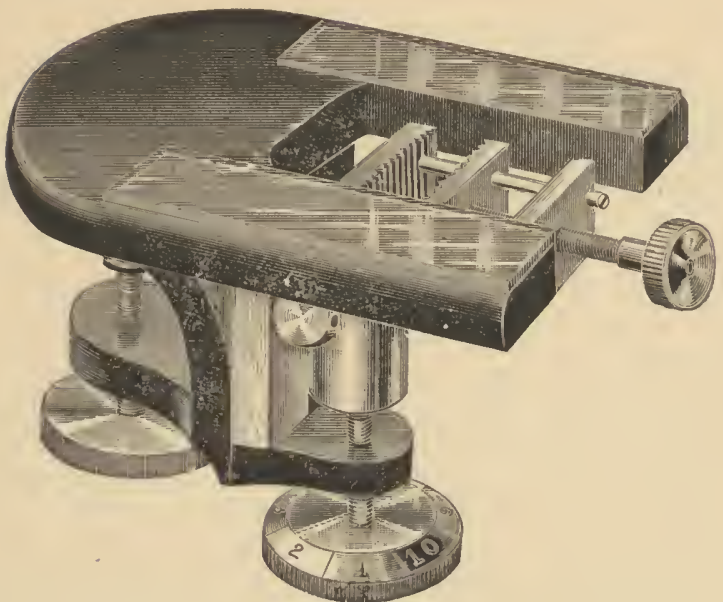

No. 1620 .

No.

1620, Microtome,

This instrument is dissimilar from the foregoing in not having a mechanical movement for the knife. It is intended to be fastened to the table-top by means of the thumb-screw. The clamp for this specimen, slide and feed-screw are the same as in the Student Microtome. Two glass plates are fastened on the top and will permit a long sweep of knife.

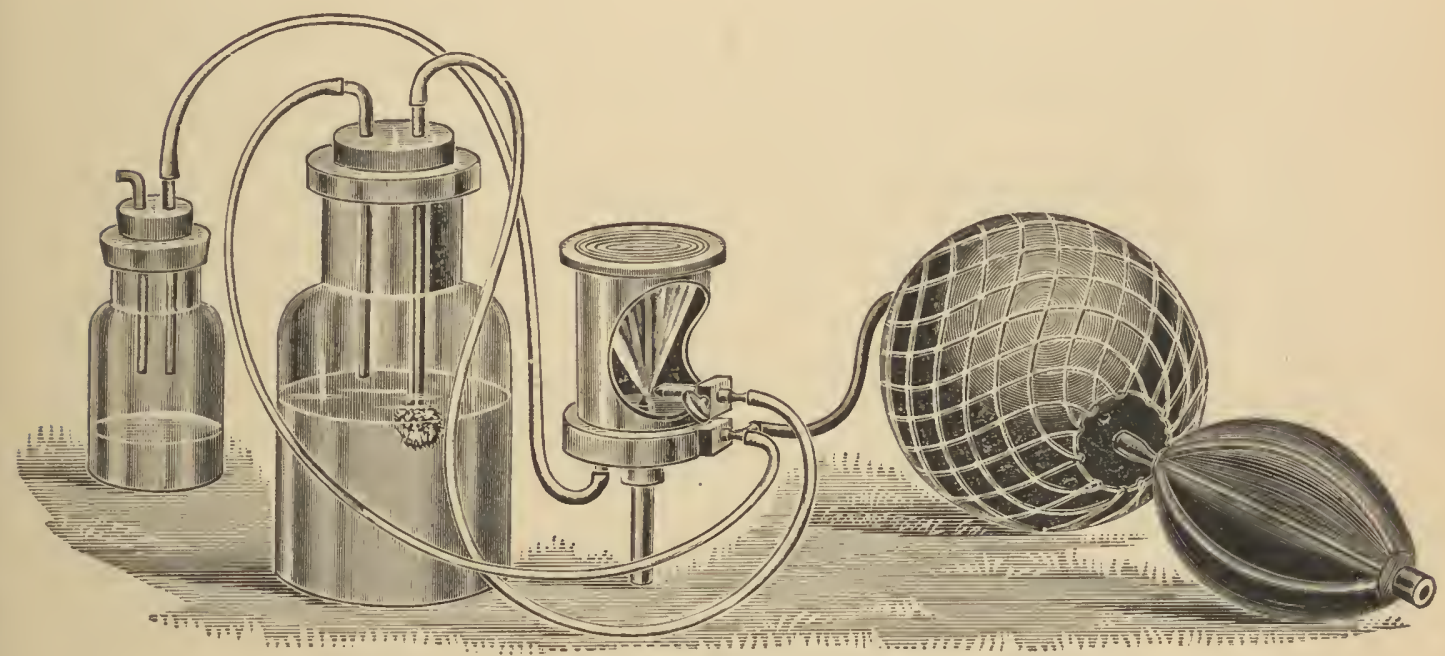

No. 1692.

1622, Freezing Attachment,

This attachment consists of nickel-plated cylinder with atomizer, and is fastened in the place of the clamp. The object to be frozen is placed upon it. The bottle for fluid is connected on one side with the atomizer, on the other with the pressure regulating bladder and hand-bulb. Objects may be frozen with it in from one to three minutes, and may be easily kept in this condition. This method of freezing commends itself for effectiveness, cleanlines and economy in time. Ether or Khigolene may be used.

(Adaptable to our Student and Laboratory Microtomes, but as fittings vary, state when ordering, for which instrument it is intended.) 


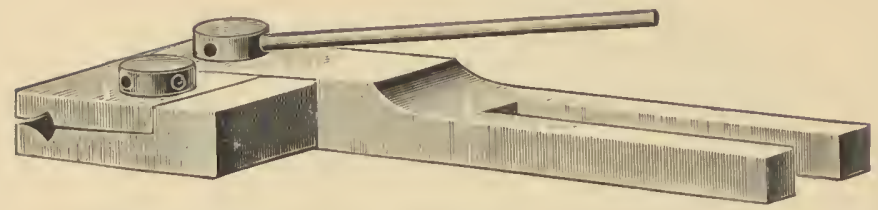

No. 1624 .

No

1624, Knife-Holder,

This attachment has been devised for holding other knives than those which are especially made for the microtomes. It is provided with a slot, so that it may be adjusted upon the block, and with set-screws, so that the angle of the cutting edge of the knife may be varied. The knife is firmly fixed by the thumb-screws.

1626, Section Flattener,

This is an exceedingly simple and effective device for preventing the curling of thin sections as they are cut. We must have the knife in order to fit it, however. 


\section{Agressepies.}

The following list of accessories is very complete, and a selection suitable to every field of investigation may be made therefrom. Many of the articles are original with us, and are only found in this catalogue, and all are carefully constructed with a view to their practical application and fully covering the purpose for which they are intended. Many articles which within the past few years have been found unsuited to modern requirements, have been entirely dropped, while others of great utility have been added. Thus many of the sub-stage condensers listed in former catalogues have become obsolete and are replaced by several new devices for effectually controlling sub-stage illumination.

It will be observed that we have made a reduction in price in many of our accessories. This is in the line of the policy we have followed from the outset, and is productive of good results in two directions. By placing a reasonable price on a new article, we bring it within the means of many who could not otherwise purchase, which again, on account of the increased quantity, enables us to work more economically and make a corresponding reduction. While practical utility and workmanship are always the first considerations, an opportunity is also given to improve in these directions under this policy.

All the sub-stage accessories are made to one uniform standard, and will fit our instruments as well as others constructed on this basis, so that they may be ordered separately.

It is often found that certain accessories are absolutely necessary for certain classes of work, whereas the instruments on which they are to be used (and as a general thing foreign instruments) are not suited to receive them. In such instances we make the required changes and give estimates of cost on inquiry. 


\section{ACCESSORIES.}

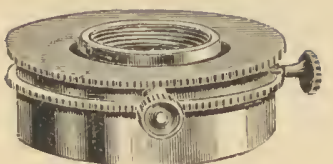

No. 1644 .

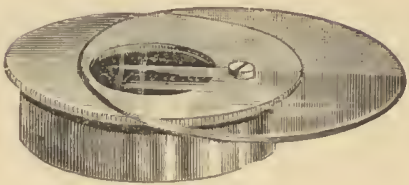

No. 1645.

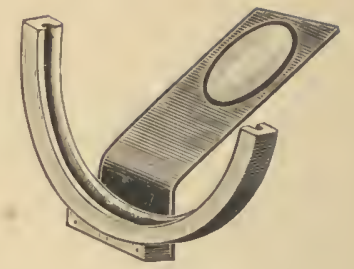

No. 1650 .

1640 , Adapter for foreign objectives, (as there is no standard among foreign objectives,

all those to be fitted to adapters should be sent us), _ - _ - $\quad \$ 1.00$

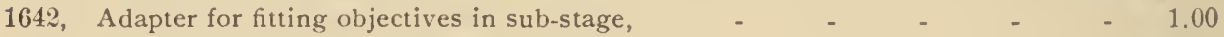

1644, Adapter, same, with centering adjustment, $\quad$ - $\quad$ - $\quad$ - $\quad$ - $\quad$ - 500

1646, Amplifier, achromatic, with society screw, in brass box, - _ _ $\quad$ - 7.50

1648, Blue Glass, Hopkins', graduated, _ _ _ _ _ _ _ _ $\quad 3.50$

This glass is in the form of a disk. It revolves upon the adapter and gives intermediate shades between white and dark blue, both transparent and translucent.

1650, Camera Lucida. in brass mounting,
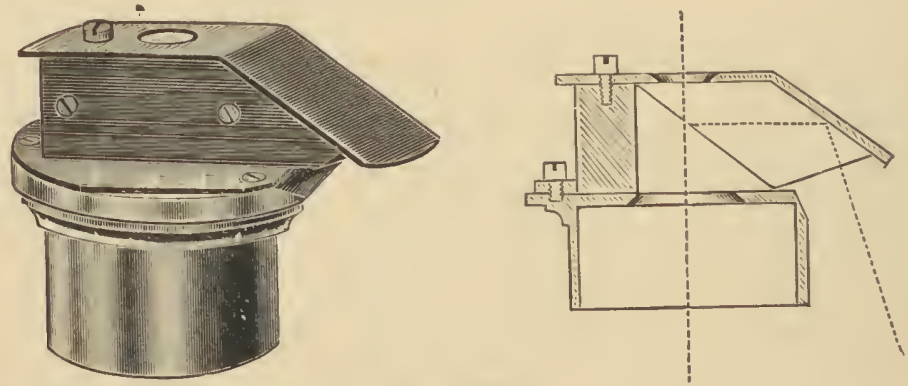

No. $165 \%$.

1652, Camera Lucida, Double Prism,

It may be used with the instrument in an upright or inclined position, and shows the image and pencil point clearly at the same time. It is far superior to the Wollaston in size of field and non-distortion of image.

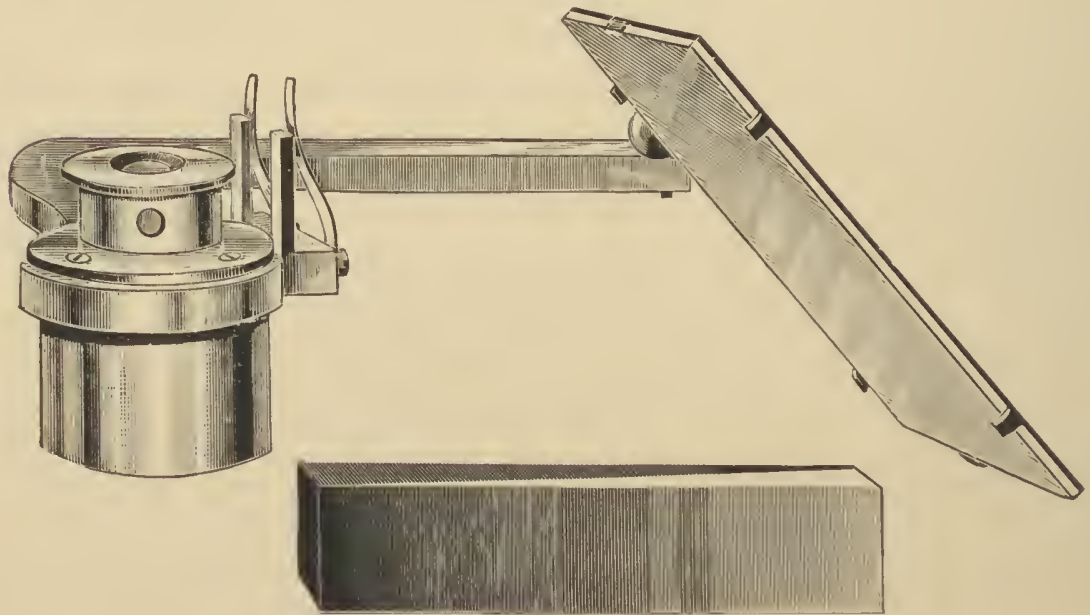

No. 1654 . 
No.

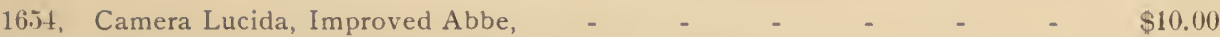

This form of Camera Lucida is without question the best form in giving distinct inage of the object and pencil point. To obtain distinct pencil point, a series of different colored smoke glasses have been required in the Abbe form, which have been inconvenient. Our mounting is improved to take a smoke glass wedge, counterbalanced by a transparent wedge to avoid the prism effect, which is interposed between the prism and mirror and held by spring clips. Any degree of modulation is thus easily obtained. This Camera Lucida is provided with adapter to fit the neck of our eyepieces.

1656, Camera Lucida, Improved Abbe,

Same as above, but provided with binding and centering screws, to attach to our or other eyepieces as well as microscope tubes.

In ordering, the outside diameter of tube to be fitted should be given us, preferably as in eyepieces.

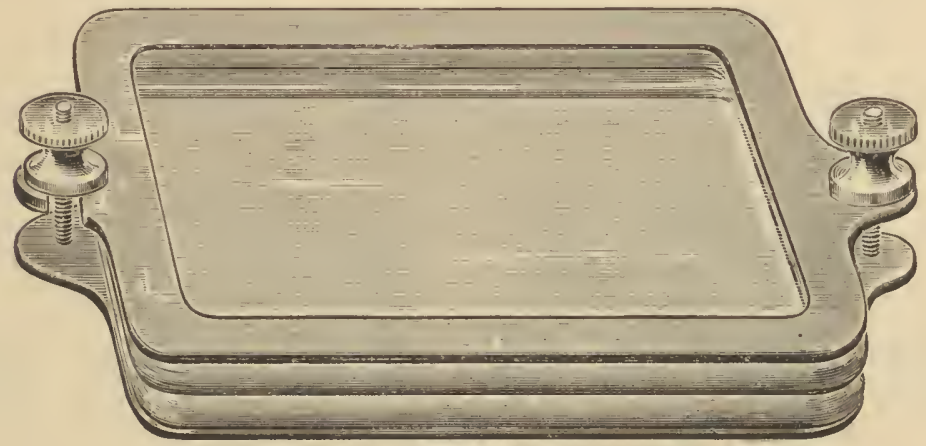

No. 1662 .

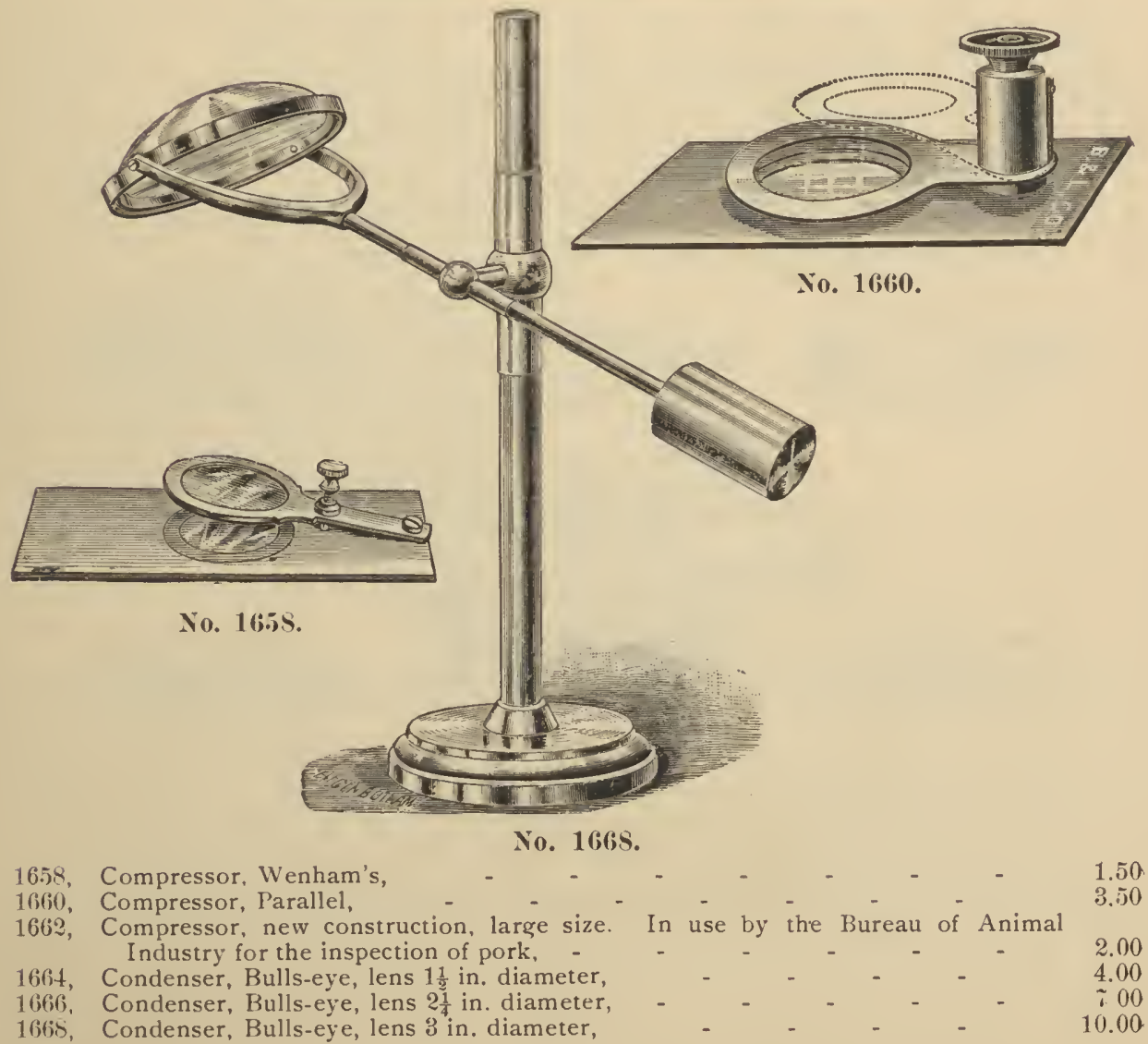




\section{SUB-STAGE CONDENSERS, ABBE.}

The lenses composing these condensers are of such a size that they will utilize almost all the rays which may pass through the sub stage ring. Their numerical aperture are about 1.20 and 1.42 ; the former suited for objectives of medium angular aperture, the latter will do justice to objectives of the largest angular aperture; its volume of light is sufficient with the highest amplification, and although it gives an intense light at the focal point, it may be distributed over a larger space, or its volume decreased by varying its distance from the object. It will work both dry and immersion. The pin-hole cap provides means for exactly centering the condenser.

These condensers can be fitted to mountings No. 1676 and 1678 , as desired. The condensers are reversible and adjustable in the adapters, thus they can be used on any stand having standard size of sub-stage.

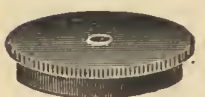

Optical part of Condenser $1.20 \mathrm{~N}$. A.

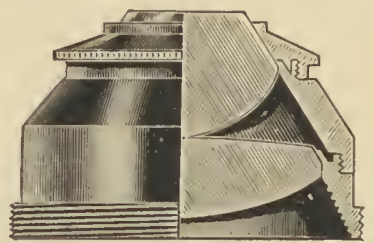

No.

16\%0, Sub-stage Condenser, Abbe, 1.20 N. A., in plain sub-stage adapter, without means for regulating light, with pin hole cap, in morocco case, _ _ _ _ $\$$

1672, Sub-stage Condenser, Abbe, $1.42 \mathrm{~N}$. A., same as above, in morocco case,

1674, Sub-stage Condenser, Abbe, achromatic 1.0 N. A, with pin hole cap, in morocco case,

This condenser gives a colorless image of the source of light. While desirable for general work, it is particularly useful in photo-micrography. It is specially adapted to mountings No. $16 \% 6$ and $16 \% 8$, and when so used the mounting is placed between the systems of the condenser.
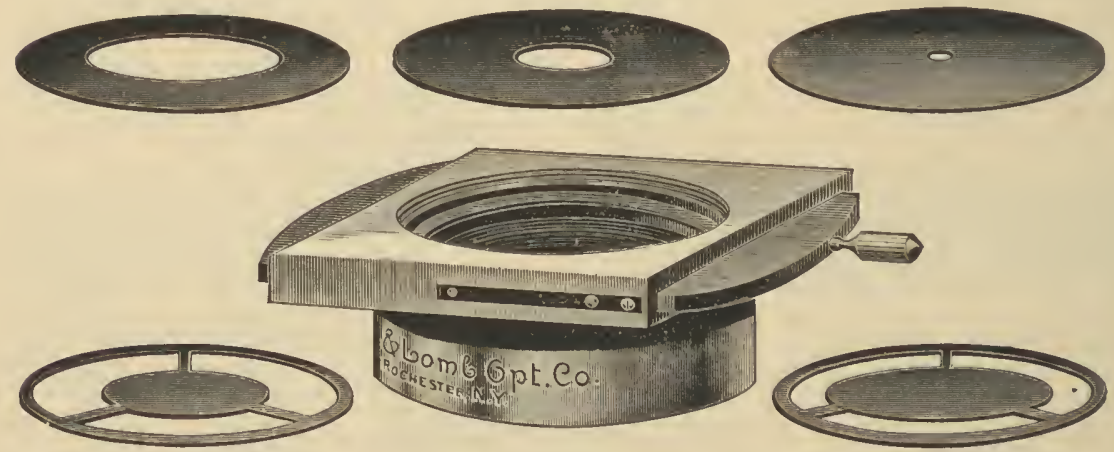

No. 1676.

16\%6, Condenser Mounting with five stops and diaphragms and blue glass,

The mounting is simplified to the greatest extent. It is reversible, adjustable and can be used on any sub-stage. The diaphragms are separate, and may be used so or in conjunction with a blue glass, by dropping into the slide, which passes diametrically below the condenser. A click is provided when it in central position. It can be used with Condensers No. 16\%0, $16 \% 2$ and $16 \% 4$. 


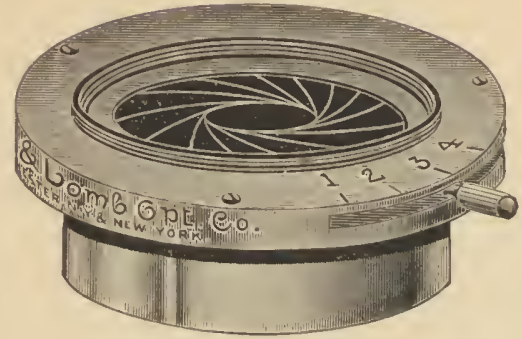

Ni1. 1678.

No,

16:8, Condenser Mounting, with Iris diaphragm,

This mounting offers a ready means for controlling the volume of light, and is well suited to the ordinary needs of the physician and student. The diaphragm may be decreased from full opening to a pin hole by means of a lever, and a graduated scale is provided for making record of the aperture used ; central stops and blue glass accompany same. The mounting is reversible and can be attached to any sub-stage and may be used with Condensers No. 1670, $16 \% 2$ and $16 \% 4$. For bacteriological work it is to be preferred to mounting No. $16 \pi 6$.

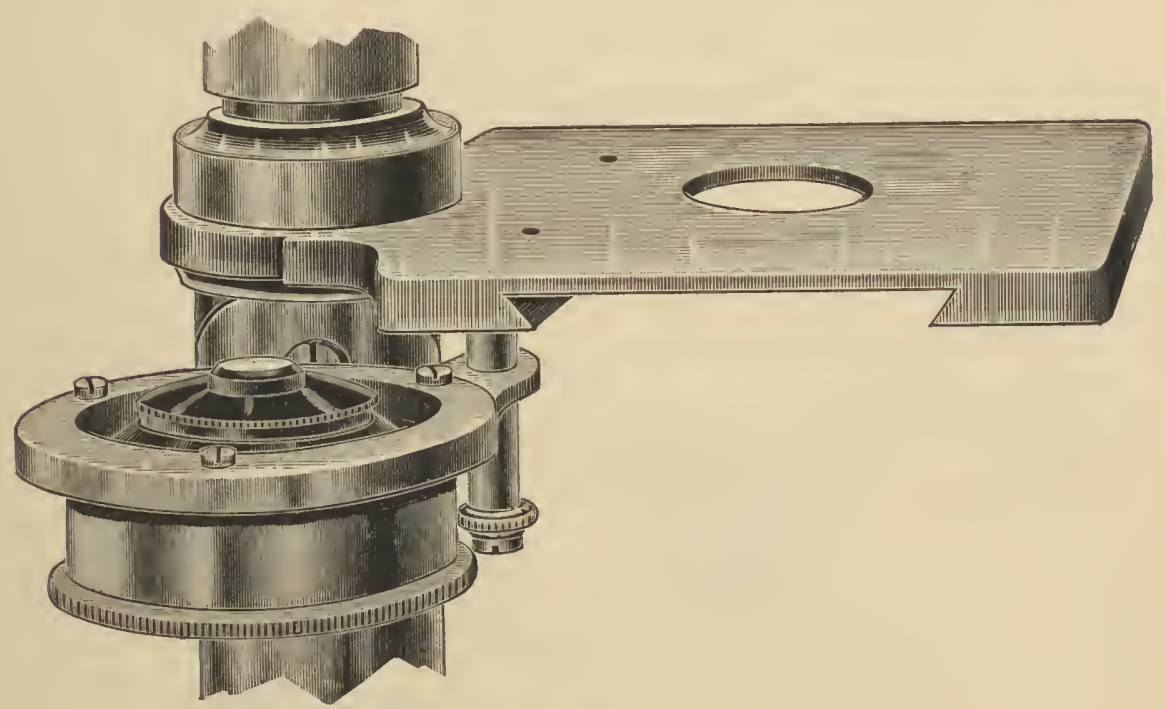

No. 1682.

(Showing the swinging sub-stage with Condenser attached as applied to the stage of $\mathbf{B}$ Continental stand.)

1682, Swinging Sub-stage Attachment (exclusive of Condenser), _ _ _ _ _ 6.00

This is adaptable to the stages of all of the Continental, as well as Harvard and Model stands. It is simple in construction, yet a very serviceable accessory, being adjustable; a Condenser attached to the same can be readily focused; centering arrangement is also provided. 


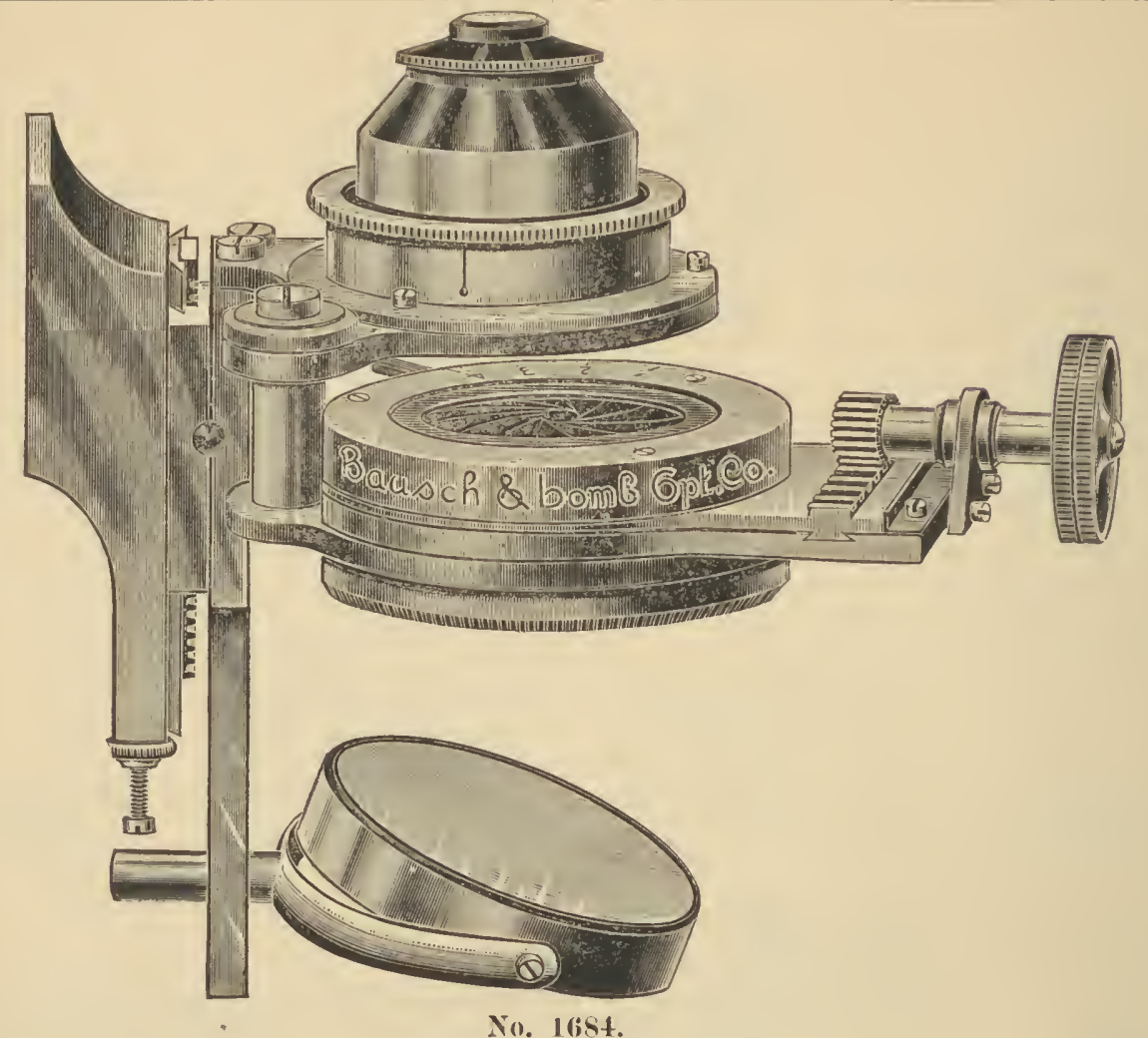

No.

No. $16 S t$.

1684, Sub-stage Attachment complete with mirror, (exclusive of Condenser),

This complete sub-stage arrangement can be used on any of our microscopes, excepting the less expensive forms. It is unquestionably the most perfect of any heretofore introduced. Adjustment to the sub-stage is by rack and pinion, the Condenser mounting provides a movement similar to No. 16i6, but by rack and pinion, it also swings on its axis, leaving the Condenser stationary; it has in addition the Iris diaghragm and recess for receiving diaphragms with central stops and blue glass, which are furnished with it Mirror is plane and concave and of large size.

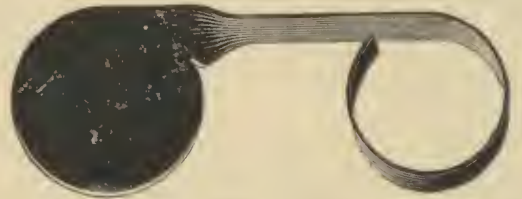

No. $1(694$.
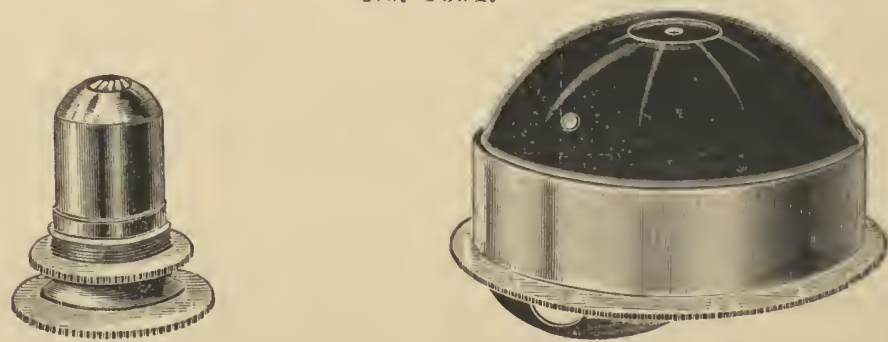

No. 1686.

No. 16 SS.

1686, Diaphragm, Iris, with sub-stage adapter, having society screw,

1688, Diaphragm Dome, can be used on any substage. -

State when ordering, whether it is to be inserted in the substage from above or below. 
1690, Draw-tube, graduated for any instrument,

1692 Micrometer Screw, graduated and silvered, for fine adjustment, with any of our instruments in place of those accompanying them,

1694, Eyeshade, Ward's,

The construction of this shade was first suggested by Dr. R. H. Ward. By its use both eyes may be kept open, which is less fatiguing than using only one eye. It has the advantage over similar devices in price, and that the eyepieces may be changed without removing the shade. In ordering, it is necessary to send approximately the size of the tube to which it is to be attached.
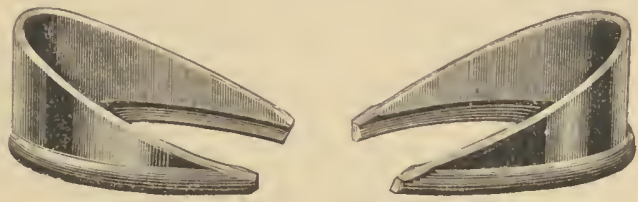

No. 1696.

1696, Eyeshades. Aubert's Binocular,

These eyeshades effectually overcome the reflections which often occur 7 in the eyepieces of binocular microscopes. In ordering the diameter of milled edge of eyepiece cap should be given.

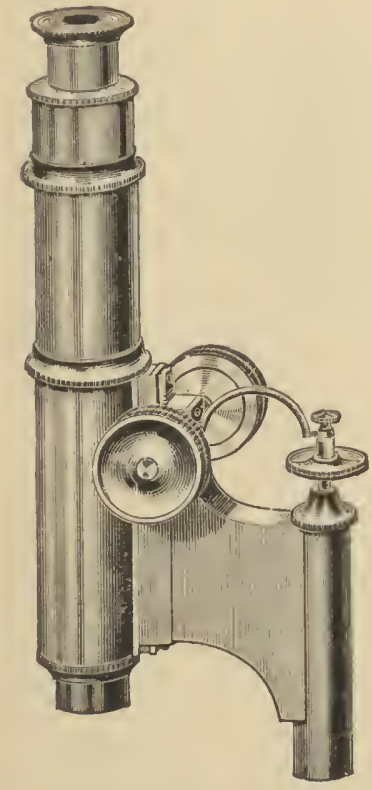

(Patented Aug. 15, 1882).

No. 1695 .

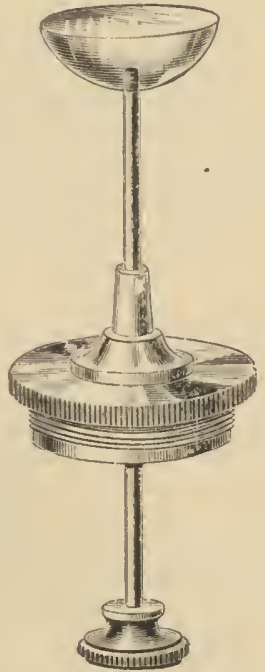

No. 1704.

1698, Fine adjustment, Differential Screw, applied to any of our instruments,

As high-power objectives are in more common use than was formerly the case, particularly in biological research, it has been found that a more delicate movement than the ordinary fine adjustments is desirable, and the one we now offer is the most simple as well as efficient, and particularly valuable inasmuch as it can be applied to almost every existing instrument in which the micrometer screw is attached to the arm. It is put in connection with the micrometer screw, and comes into play at will by tightening the thumb-screw at the top. The one milled head operates one or the other. It can be made to almost any degree of fineness, but that which we have found most desirable is the $\frac{1}{75}$ in. for the fine, and $\frac{1}{300}$ in. for the Differential Screw fine adjustment, for one revolution of the milled head. 
No.

1700, Fish Trough, for retaining life in fish while examining circulation of blood in its

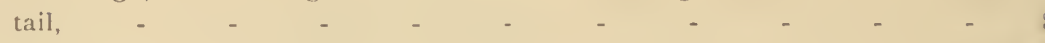

1702, Illuminator, Hemispherical, an excellent accessory in the resolution of difficult

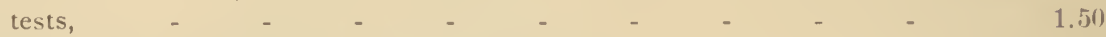

1\%04, Same as above, adjustable, with sub-stage adapter, $\quad$ - $\quad$ - $\quad$ - $\quad$ - $\quad 5.00$

1706, Illuminator, Vertical, with rotating diaphragm, in neat brass box, _ $\quad 4.50$

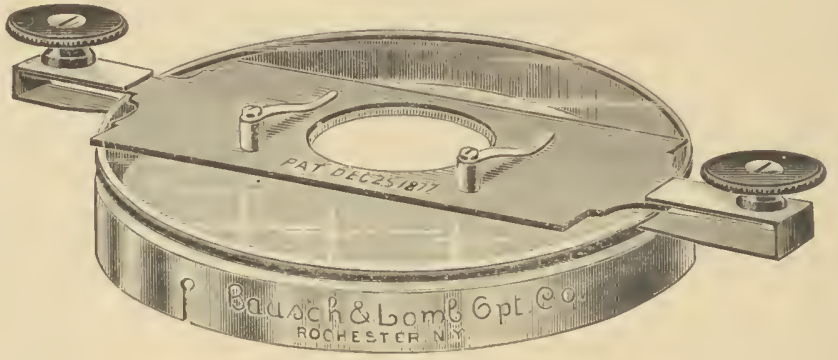

No. 1 ios.

1705, Glass Stage and Slide Carrier, for stages $3 \frac{1}{2}$ in. diameter, - _ _. $\quad$ - .00 1710, Holman's Current-Slide, with cover, in box, $\quad \ldots \quad \ldots \quad \ldots$

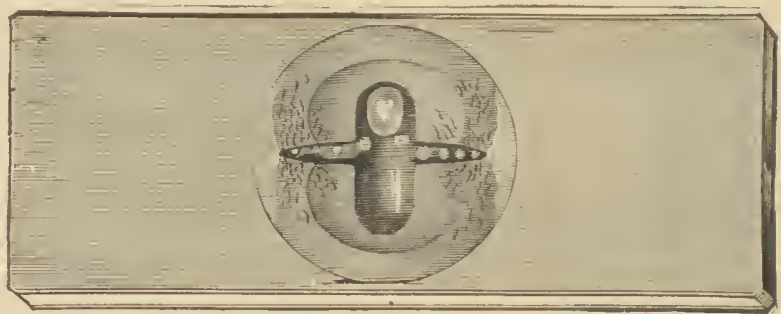

No. 1712.

1712, Holman's Life Slide, with cover, in box, $\quad$ - $\quad$ - $\quad$ - $\quad$ - $\quad$ - $\quad 1.50$

1714, Holman's Syphon Slice, cover and flexible tubes, no bottles, _ _ _ $\quad 4.00$

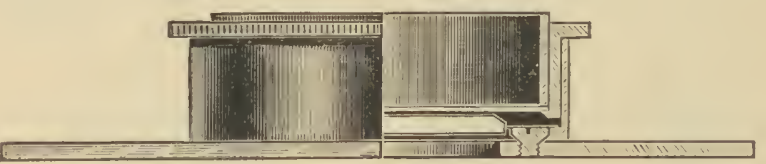

Ni. 1711.

1716, Life Box, new construction,

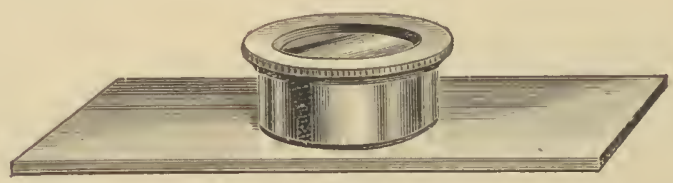

No. 1718.

1718, Life Box,

1722, Life Box, with spiral open slot for obtaining close adjus'ment, _ _ _ 3.50

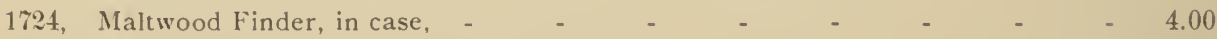

1i26, Mechanical Finger, Dr. W. B. Rezners's, $\quad-\quad$ - $\quad$ - $\quad$ - $\quad-\quad 6.00$ 


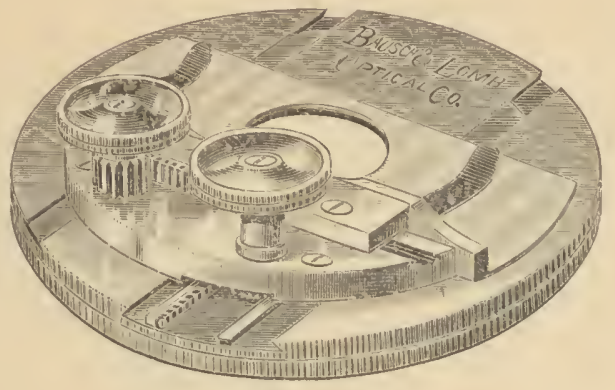

Ni. 172x.

Price.

No.

1028, Mechanical Stage,

130, Mechanical Stage, graduated and silvered on edge with vernier and with silvered graduations for the rectangular movements, otherwise same as above,

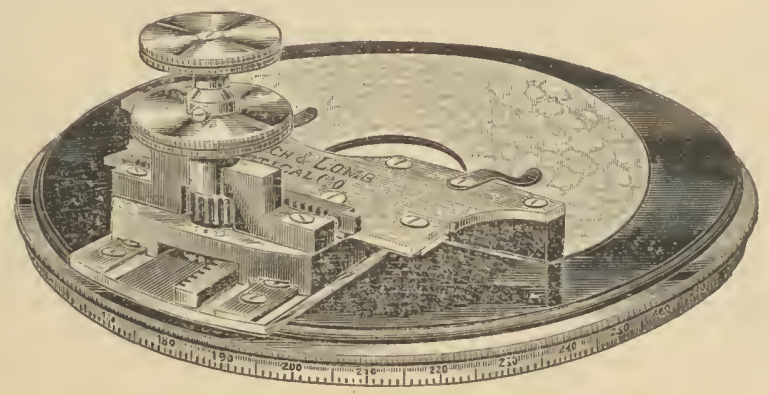

No. 1732.

1732. Mechanical Stage, as above, with vernier and with silvered graduations provided for the rectangular movements,

The advantages of mechanical stages for every variety of work, now generally conceded and particularly in original research, are as follows: The ability to systematically examine the entire surface of an object; the easy manipulation of an object. especially with high powers; the ability to count objects within a given space; its use as a finder after repeated examinations Further than this there is nothing in their construction which would prevent their use as ordinary stages. The mechanical movements are entirely contained in the upper surface of the stage, and this being revolving, may be completely rotated on its axis. They are of the same thickness as our ordinary stages, and therefore offer no obstruction to extreme oblique illumination. The movements are all extremely delicate.

No. 1728 can be adapted to cur microscopes, or any other instrument which will admit of a stage $3 \frac{1}{2}$ in. diameter. The slide-carrier is provided with clips and stop for maltwood finder.

No. 1732 is of more elaborate design and workmanship than the preceding one, and of larger size, its diameter being $4 \frac{1}{2} \mathrm{in.}$ It is intended to be used on our Professional Microscope. The rectangular movements are actuated by the two milled heads, placed one above the other. The slide-carrier is provided with clips and stop for maltwood finder on a hinge, so that it may be swung out of position. The stage is graduated to degrees and silvered. 
No.

1734, Micrometer, Eyepiece, oblong, to fit slotted eyepieces,

1736, Micrometer, Eyepiece, disk fitted to any eyepiece,

1738, Micrometer, Eyepiece, Jackson, with screw for adjusting, (can be fitted to Huyghenian eyepieces only),

1740, Micrometer, Filar, small size, adapted to any tube,
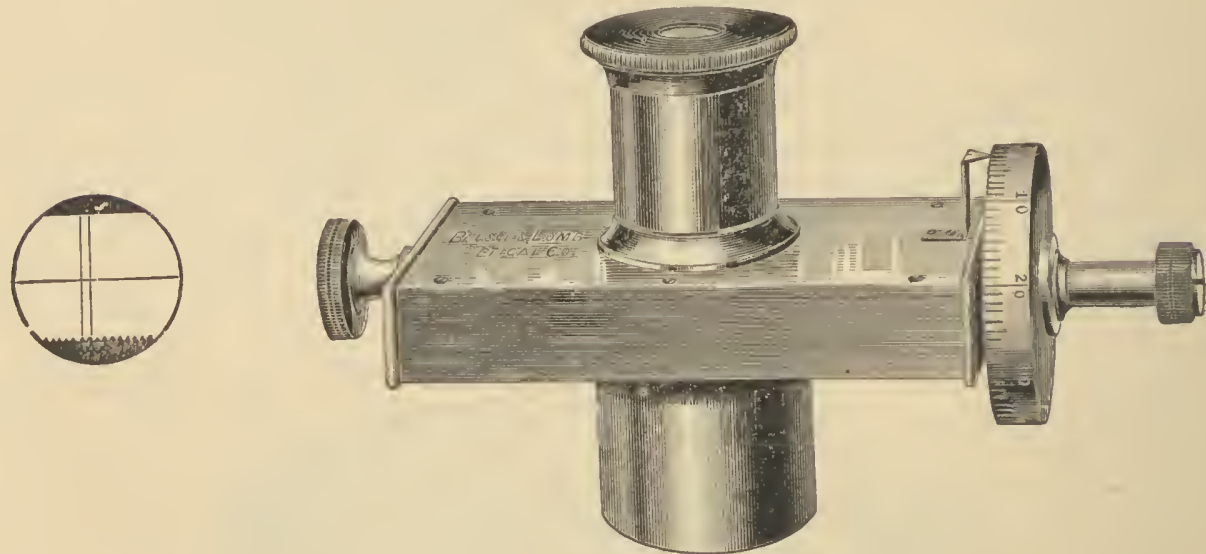

No. 1742.

1742, Micrometer, Filar, large size, adapted to any tube,

An internal frame is provided with a longitudinal, and transverse cross hair which is adjustable within a limited range for position, by a milled head at one end. The micrometer screw, which is cut either to one-half millimeter or onefiftieth inch, is adjustable by graduated disk, and carries the cross hair across the fie'd. The graduation is in 100 parts on a silver ring, and the reading is made from a stationary index. The graduated disk may be revolved on its axis. A comb is in the field corresponding exactly with the pitch of the screw, thus enabling the deternination of the number of revolutions. A Ramsden eyepiece is used which is stationary in the optical axis but adjustable for focus.

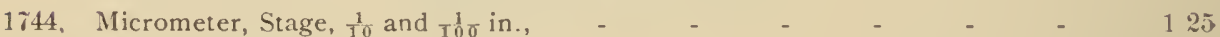

1746, Micrometer, Stage, $\frac{1}{100}$ and $\operatorname{rog}^{2}$ in., - _ _ - - - - 1.50

1748, Micrometer, Stage, $\frac{1}{10}, \frac{1}{20}$ and $\frac{1}{50} \mathrm{~mm}$., _ $\quad$ - $\quad$ - $\quad 2.00$

1750, Nicrometer, Stage, $\frac{1}{10}$ and $\frac{1}{100} \mathrm{~mm}$., _ _ _ _ _ $\quad$ - $\quad$ - 2.00

1752, Micrometer, Stage, $\frac{1}{10}, \frac{1}{10}, \frac{1}{1000}$ in. and $\frac{1}{10}$ and $\frac{1}{100} \mathrm{~mm}$., . $\quad . \quad 4.00$ 


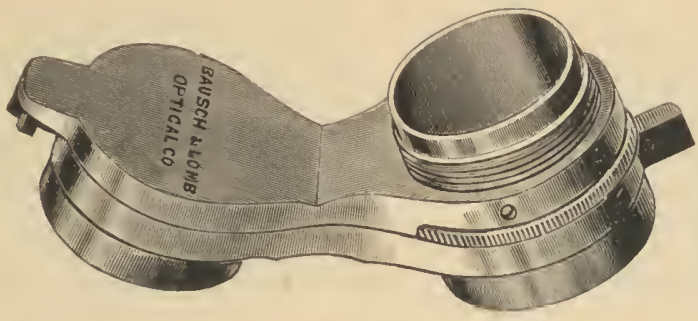

No. 17.54 .

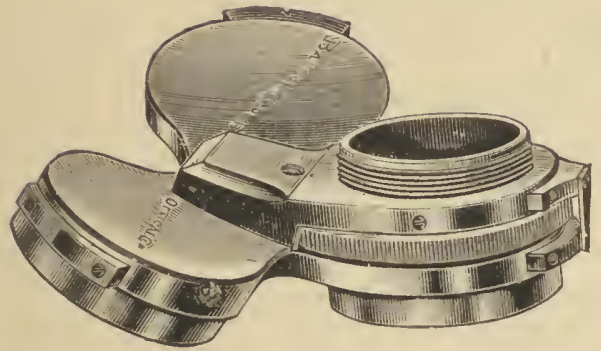

No. 1758.

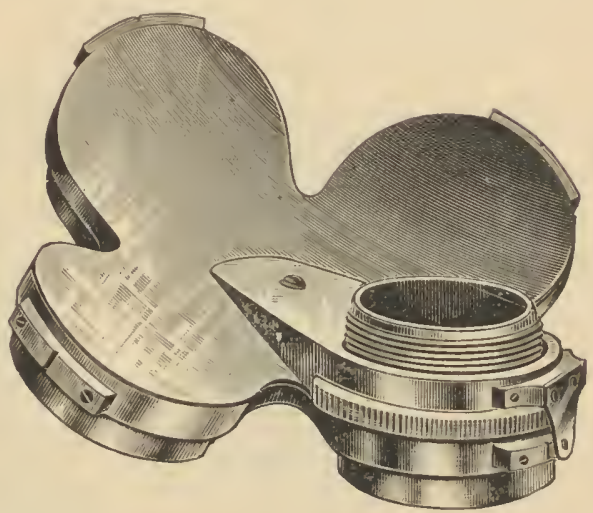

No. 1762.

No.

1754, Nosepiece, double, brass finish,

1756, Nosepiece, double, aluminum,

1758, Nosepiece, triple, brass finish,

1760, Nosepiece, triple, aluminum,

1762, Nosepiece, quadruple, brass finish,

1764, Nosepiece, quadruple, aluminum,

Since the introduction of our various nosepieces, they have become very popular and are now in general use. This is no doubt due to the perfection of their construction and practical adaptation in the first place, and then to the low price at which they are offered. The advantages of using two, three, or four objectives on an instrument, either of which can be used without the removal of one and attachment of the other, are so apparent that they need no argument. Further than this, when objectives are ordered with the apparatus, they are exactly centered, which is ordinarily not the case even in objectives of the same manufacture. We also adjust objectives to correspond exactly in focus with a certain eyepiece, so that they require no adjustment except with the micrometer screw. On account of the work involved to obtain this convenience, we make an extra charge of $\$ 1.00$ for each objective, except in pairs, No. 1028 and No. 1038, which are constructed with this object in view.

1766, Paraboloid, for dark ground illumination,

1768. Paraboloid, same with adjustable stop, 

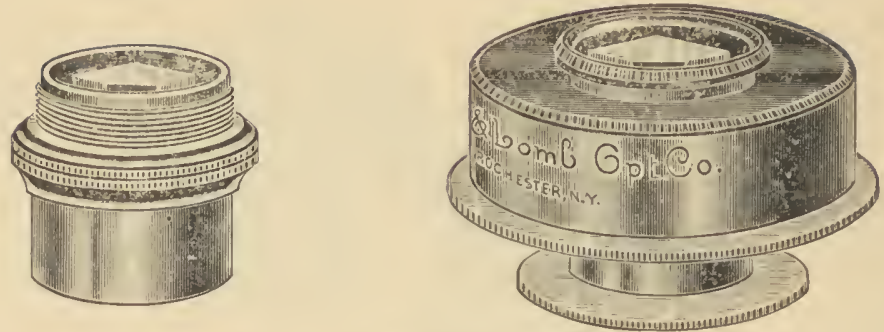

No. 1700.

No.

Price.

1770, Polariscope with 1 selenite in morocco case, . $\quad$ - $\quad$ - $\quad$ - $\quad$ - $\$ 12.00$

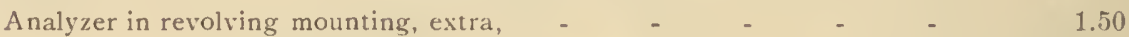
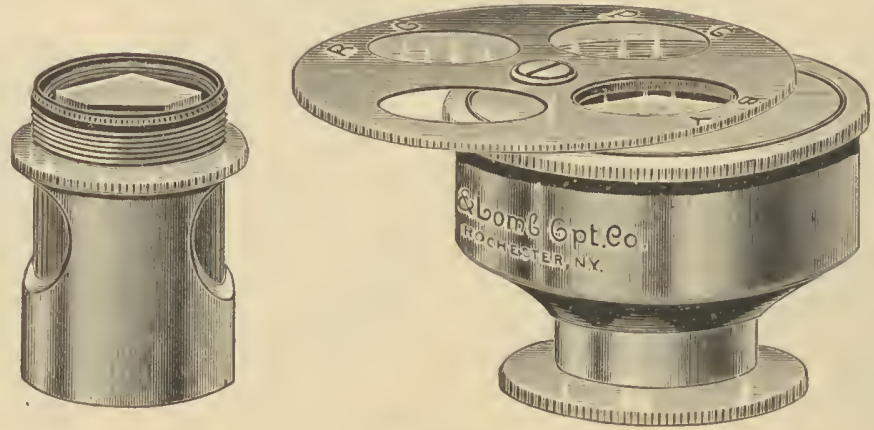

No. 1772.

1772, Polariscope, with large prisms, polarizer has 3 selenites mounted in a revolving disk, having one clear aperture, analyzer is arranged to revolve, in morocco case,

17\%4, Polariscope with large prisms, polarizer is provided with 3 selenites mounted in revolving disk, analyzer is mounted in graduated disk, arranged to set over the neck of eyepiece and revolves thereon. Indicator is provided as well as cross hairs in eyepiece,

1776, Polariscope, with extra large prisms and 3 selenites, the analyzer is connected with goniometer and separate eyepiece, provided with cross hairs, $\quad-\quad 4000$

1778, Prism. Woodward, for extreme oblique illumination, $\quad$ - $\quad$ - $\quad$ - $\quad 1.25$

1780, I'rism, Woodward, mounted with sub-stage fitting, _ $\quad$ - $\quad$ - $\quad 5.50$

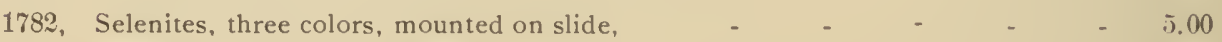

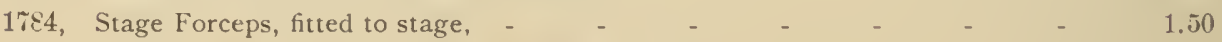

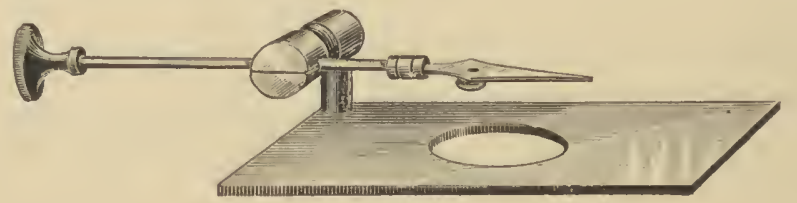

No. 1786.

1786, Stage Forceps, on slide, - 


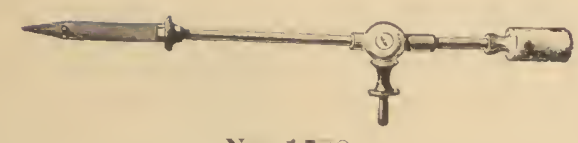

No. 1iss.

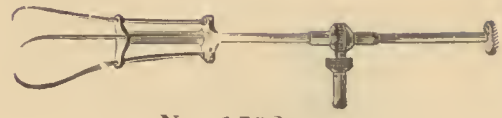

No. 1792.

Price.

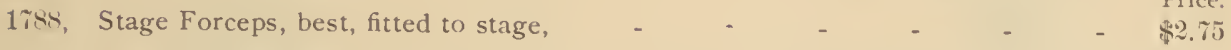

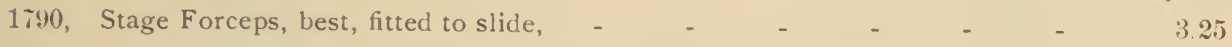

1792, Stage Forceps, three-pronged, for holding minerals, etc., _ _ $\quad$ - 5.00

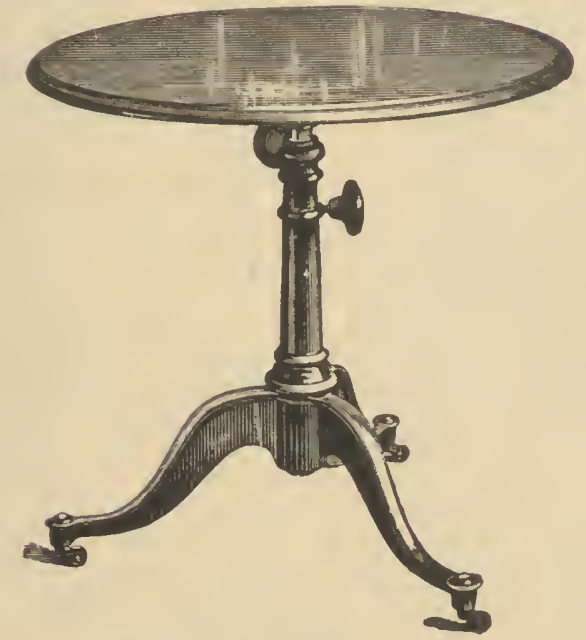

No. 1704.

1794, Table, revolving, black walnut, adjustable for height,

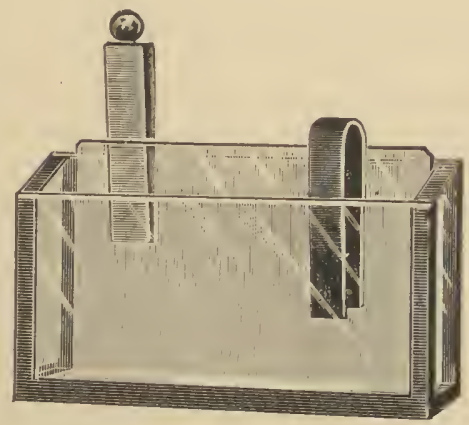

No. 1800 .

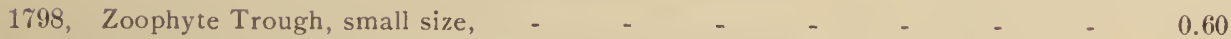

1800, Zoophyte Trough, with wedge and spring, _ _ _ _ _ _ _ $\quad$ _ $\quad 2.50$ 

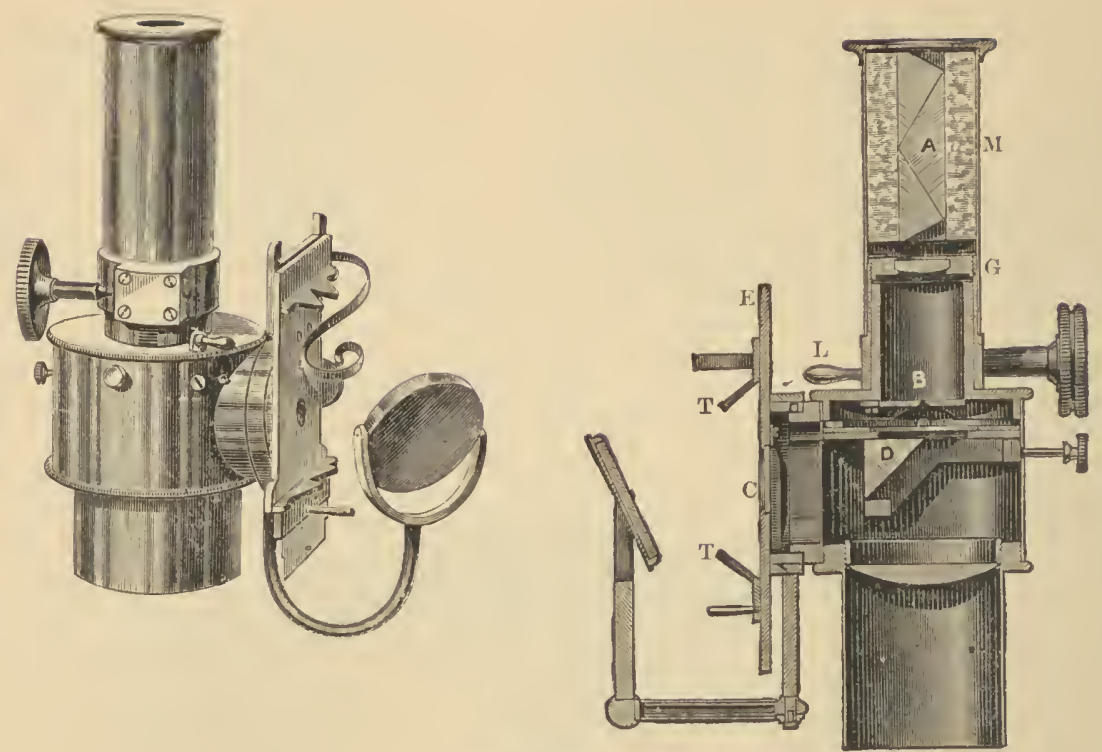

No. 1504 .

No.

1804, Sorby's Spectroscope Eyepiece, for the microscope, in mahogany case,

Price.

1806, Abbe's Spectroscope Eyepiece, for the microscope, in mahogany case,

(Can supply No. 1806 to those entitled to duty free entry, at European prices.) 


\section{APPARATUS FOR THE INVESTIGATION OF MICRO- ORGANISMS.}

No.

2800, Steam Sterilization Apparatus, as designed by Dr. R. Koch. Large size, felt covered, with stop-cock and gauge,

With thermometer,

Directions for using: Fill the apparatus with water to point indicated on gauge, place the helmet on, having previously inserted in it a thermometer; apply heat, and when the thermometer has reached $100^{\circ} \mathrm{C}$. (which will be indicated by escaping steam) then the material should be put in, but no sooner. The hooks on the side serve as supports for the material, or the latter is placed in the inner vessel.

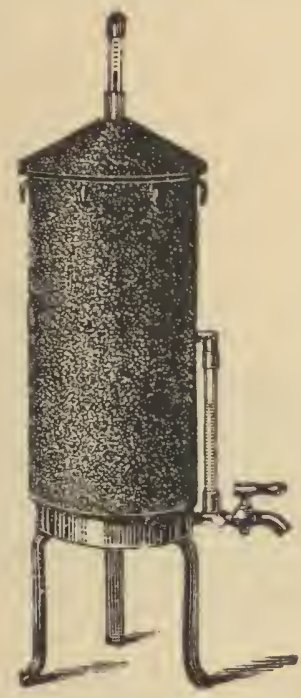

No. 2800 .

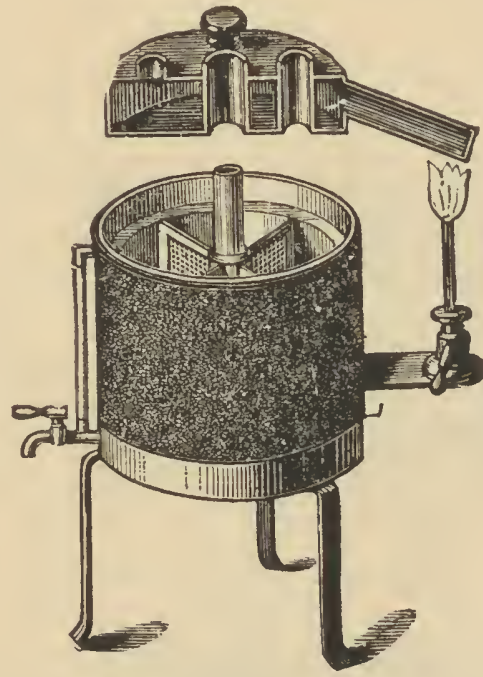

No. 2802.

2802, Steam Sterilization Apparatus, for Blood Serum, with gauge, stop-cock and felt covering,

Directions for using: Fill both cover and apparatus with water, being careful to keep the inner space perfectly dry. By means of two burners raise the temperature to $60^{\circ} \mathrm{C}$, , the blood serum contained in the sterilization glasses, which have been sterilized in apparatus No. 2806 is placed in the hollow space of the apparatus, the helmet placed on, and the inner temperature raised as quickly as possible to $58^{\circ} \mathrm{C}$. (consequently it is not advisable to place too many tubes in at one time). The blood serum must remain perfectly liquid, therefore the temperature must not be raised above $60^{\circ} \mathrm{C}$.

2804, Apparatus for Solidifying Blood Serum, to take 50 or 100 tubes, the whole appar. atus covered with felt, having glass cover and movable legs. Large,

Directions for using: The blood serum having been sterilized in apparatus No. 2802 is put in this apparatus (laying the tube in a slanting position) and heated from $65^{\circ}$ to $75^{\circ} \mathrm{C}$. The serum, as a result of this treatment, must become a transparent solid, therefore the heating has to be continued, and the tubes frequently examined, until this result has been attained. The small quantity of water which forms is allowed to remain, as it serves as Nutritive (Nährboden).

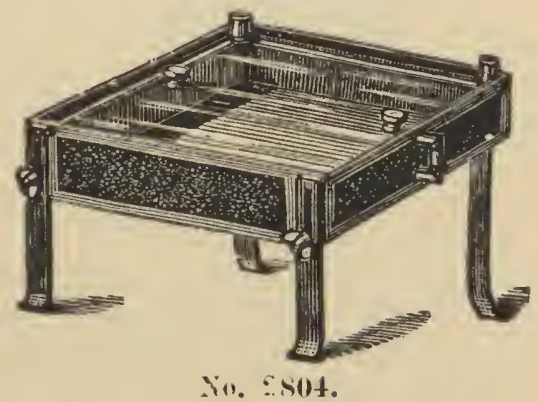


No.

2806, Double Wall Sterilization Apparatus, for sterilizing at higher temperatures.

Large size, with 3 shelves, iron rod and fork to support burner, hooks to fasten against the wall, and 4 legs to set on table, complete. Large.

This apparatus is used to sterilize the vessels, intended to receive the matter to be worked with, viz: The receivers for the blood serum, Erlenmeyer's flasks, glass plates for the nutritive gelatine supports, etc. The sterilization tubes, closed by a stopper of pure cotton, are placed in the galvanized frame (see No. 2808), the frame is put into the apparatus and heated for one hour to $140 \mathrm{C}$. ; (the cotton will carbonize slightly). The glass plates for the water investigations are placed into the covered iron box (see No. 2810 ), and heated as above.

The Erlenmeyer's flasks closed with cotton stoppers, are heated directly in the apparatus to $140^{\circ} \mathrm{C}$.

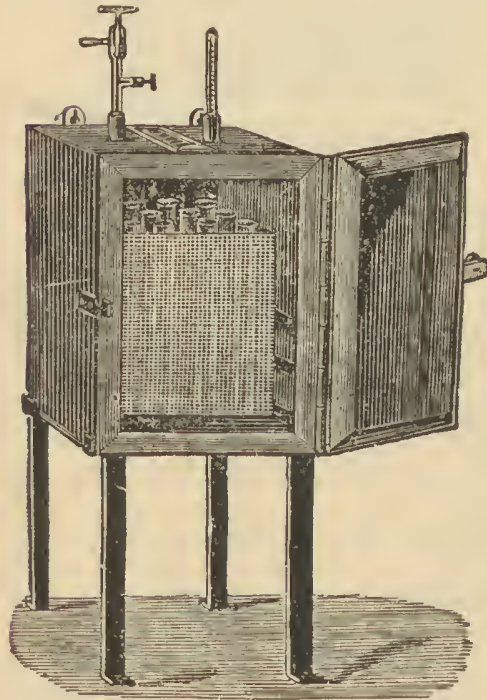

No. 2506 .

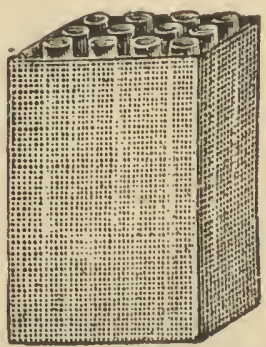

No. 280s.

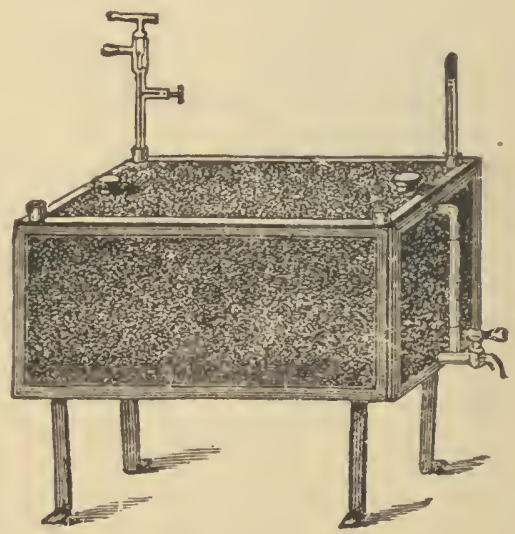

No. 2S1․

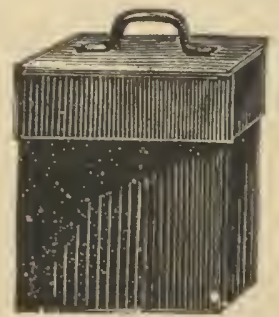

No. 2810 .

2808, Basket of tinned metal for receiving the sterilization tubes, (as described in No 2806), each,

2810, Metal Box to receive the glass plates to be sterilized, (see No, 2806), each, $\quad-\quad 2.50$

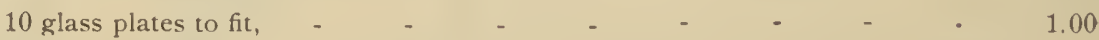

2812, Vegetation Apparatus of lead-lined metal, with glass and felt covering on legs, large size, complete, with water gauge and stop-cock, (Thermostat and Thermometer shown in cut, extra), 


\section{THE ARNOLD STEAM STERILIZER.}

This is the only inexpensive apparatus which maintains an unvarying temperature of $100 \mathrm{C} .(212 \mathrm{~F}$.) in all parts of the sterilizing chamber, without needing any care or attention. For this reason they are rapidly displacing all other methods heretofore employed by prominent institutions throughout the country. They are also extensively used by physicians in their offices.

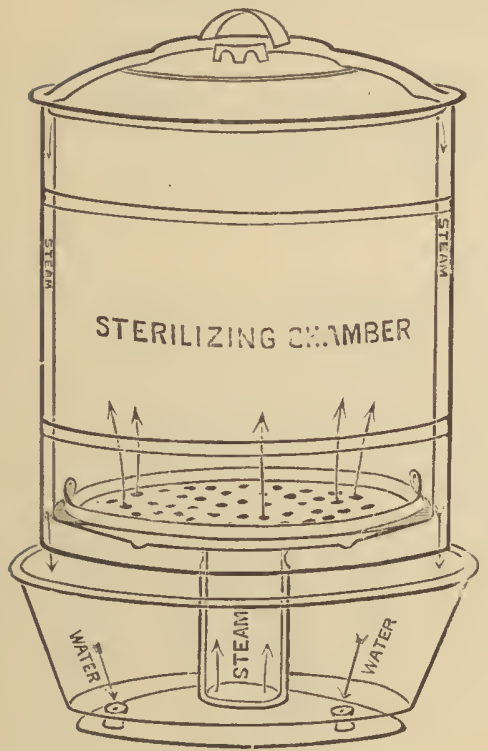

No. 2820.

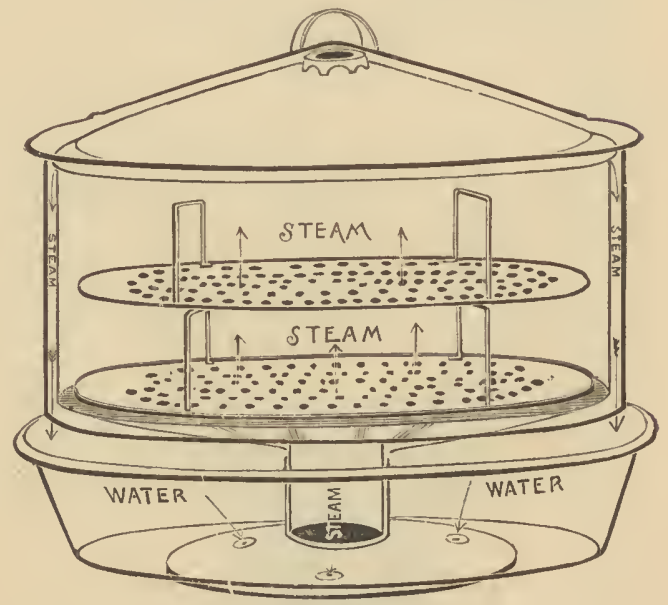

No. 28:36.

Description: Water is poured into the pan or reservoir whence it passes slowly through three small apertures into the shallow copper vessel beneath, becomes converted into steam and rises through the funnel in the center to the sterilizing chamber above. Here it accumulates under moderate pressure at a temperature of $212 \mathrm{~F}$. The excess of steam escapes about the cover, becomes imprisoned under the hood and serves to form a steam jacket between the wall of the sterilizing chamber of the hood. As the steam is forced down from above and meets the air it condenses and drips back into the reservoir.

No.

24:20, Height, $i \frac{1}{4}$ in. ; diameter, $8 \frac{1}{2}$ in. ; heavy tin, copper bottom,

Price.

$2 \& 24$, Height, $10 \frac{1}{8}$ in. ; diameter, $9 \frac{3}{8}$ in.; heavy tin, copper bottom, _ $\quad$ - $\quad 3.00$

2826, The same, all copper,

282\%. Height, $11 \frac{1}{2}$ in.; diameter, $10 \frac{1}{2}$ in.; heavy tin, copper bottom, ' - $\quad$ - $\quad 3.50$

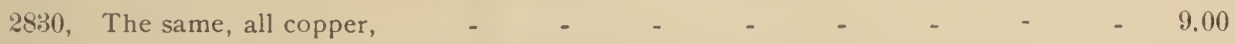

2832, Height, $12 \frac{1}{2}$ in.; diameter, $11 \frac{1}{4}$ in.; heavy tin, copper bottom, - - $\quad 4,00$

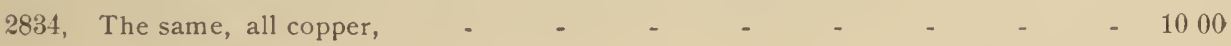

\section{SPECIAL INSTRUMENT STERILIZER.}

Oval in shape. Size of chamber, 14 in. long, $9 \frac{1}{2}$ in. wide, 6 in. deep, with two racks for instruments.

28:36, Heavy tin, copper bottom, _ _ _ _ _ _ _ _ _ _ $\quad$ _ 5.00

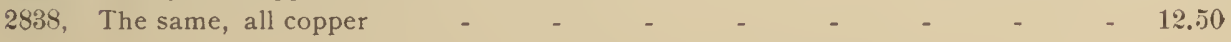




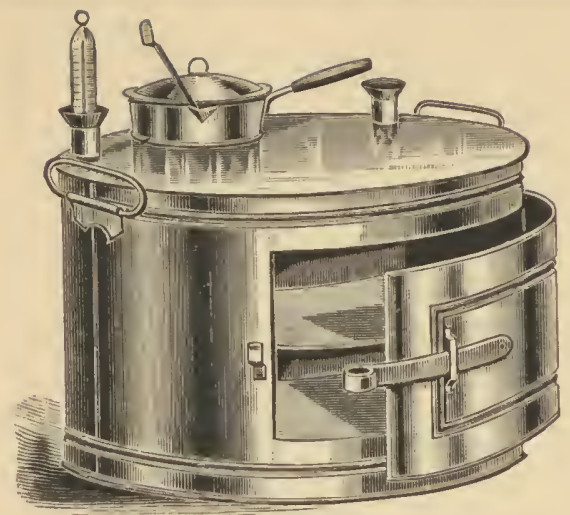

No. 2540 .

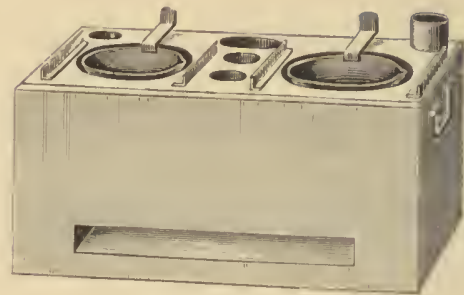

No. 2842.

2840, Water Bath and Oven, with thermometer,

Price. $\$ 12.50$

This convenient and really valuable addition to the armamentarium of the working microscopist, has won from those competent to judge its merits, many expressions of approval. Indeed, it is impossible to do good and fine work in mounting without such aid. To heat the bath and oven, it may be connected by means of rubber tubing, with a gas burner, or placed over a coal oil flame, the temperature being easily regulated by the thermometer.

2842, Paraffine Bath, polished copper, tin lined, with nickel plated copper cups ; size

$3 \frac{1}{2} \times 7$ in.,

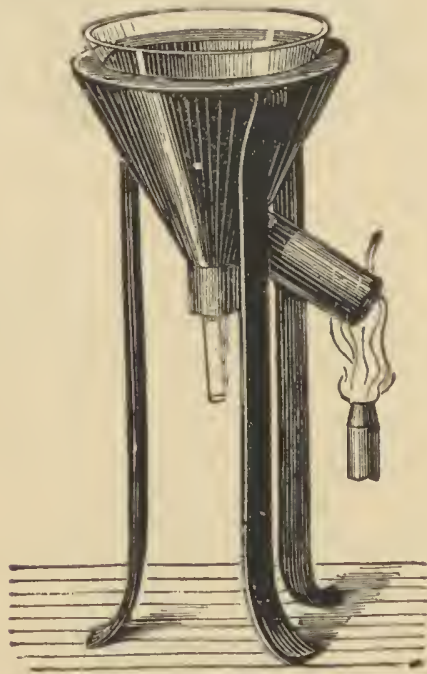

No. 2850 .

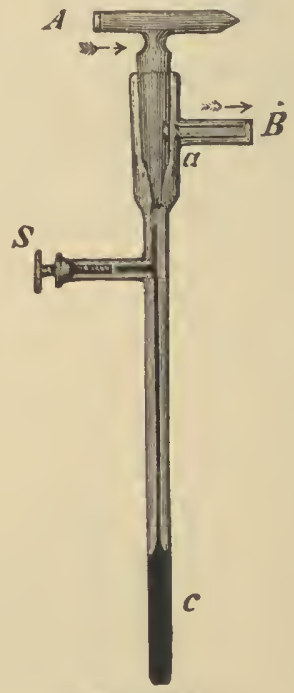

No. 28.52.

2850, Hot Water Funnel, on legs, with rubber stopper and funnel made of heavy copper, -

2852, Thermostat (temperature regulator) after Prof. Reichert,

\section{APPARATUS FOR NUMERATION OF BLOOD CORPUSCLES.}

2900, Haemacytometer (Dr. Gowers), in case, containing: Pipette for measuring the diluting solution: Capillary tube for measuring the blood: Cell with divisions on the floor mounted on a slide, to which springs are fixed to secure cover glass ; Vessel, in which the solution is made; Spud for mixing the blood and solution ; Guarded spear, pointed needle,

2902. Haemaglobinometer (Dr. Gowers), in case, containing: Bottle with pippette stopper for holding the diluting solution; capillary pipette for measuring the blood; Graduated tube for measuring the amount of Haemaglobin; Standard tint of normal blood; Support for graduated tube and standard; Puncturing needle,

2904, Both of the above in one case,

(Instruction circular accompanies each instrument.) 


\section{DISSECTING AND MOUNTING INSTRUMENTS.}

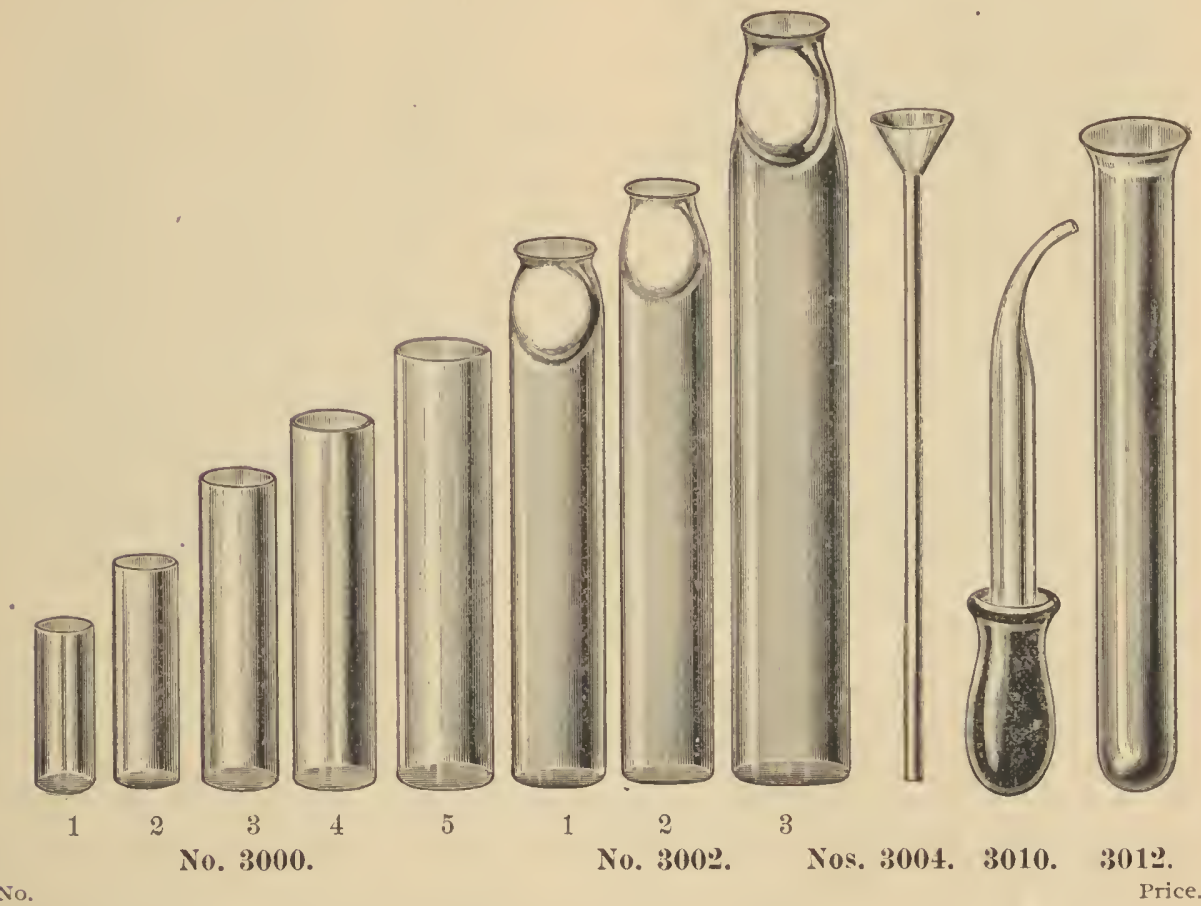

3000 , Collecting Bottles, round, number, $\begin{array}{llllll}1 & 2 & 3 & 4 & 5\end{array}$

each, $\quad \begin{array}{lllll}.02 & .03 & .03 & .04 & .05\end{array}$

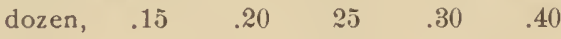

3002, Collecting Bottles, flat, number,

$\begin{array}{lrr}\text { each, } \$ .10 & .12 & .15 \\ \text { dozen, } 1.00 & 125 & 1.50\end{array}$

3004, Glass Pipettes, funnel shaped top, straight, each, $\quad$ - $\quad$ - $\quad$ - $\quad$ - $\quad .0 .5$

3006, Glass Pipettes, funnel shaped top, bent, each, - $\quad$ - $\quad$ - $\quad$ - $\quad$ - . . 0 .5

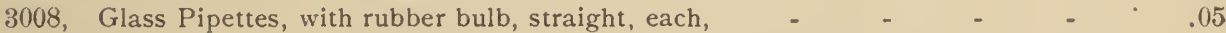

3010, Glass Pipettes, with rubber bulb, bent, each, _ _ _ _ $\quad$ - $\quad$ - .05 3012, Test Tubes,

length, $3 \mathrm{in.} \quad 4 \mathrm{in.} 5 \mathrm{in} .6 \mathrm{in.} \quad 7$ in. $8 \mathrm{in.} 9 \mathrm{in.} 10 \mathrm{in.} 11 \mathrm{in.} 12 . \mathrm{in}$. $\begin{array}{llllllllll}\text { each, } \$ .03 & .04 & .05 & .06 & .07 & .08 & .12 & .15 & .20 & .25\end{array}$

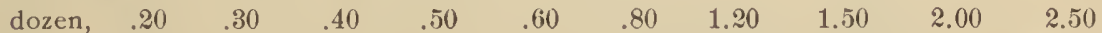

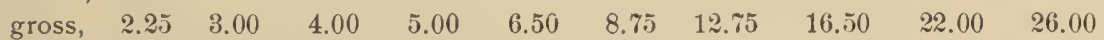

3014, Test Tubes, nested, length, $\quad 4$ to 6 in. $\quad 3$ to 6 in. $\quad 3$ to $7 \mathrm{in.} \quad 3$ to $9 \mathrm{in.}$

$\begin{array}{lrrr}\text { each, } \$ .10 & . \text { I5 } & .20 & .40 \\ \text { dozen, } \quad 1.00 & 1.25 & 1.75 & 3.50\end{array}$

3016, Bell Glasses, for preserving objects from dust during preparation.

$$
\begin{array}{lccc}
\text { diameter, } & 3 \mathrm{in.} & 3 \frac{1}{2} \mathrm{in.} & 4 \mathrm{in} . \\
\text { each, } & \$ .40 & .50 & .60
\end{array}
$$

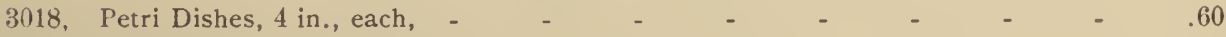

3020, Glass Stirrers, with platinnm wire fused in, - $\quad . \quad+\quad-\quad$ - $\quad .50$ 


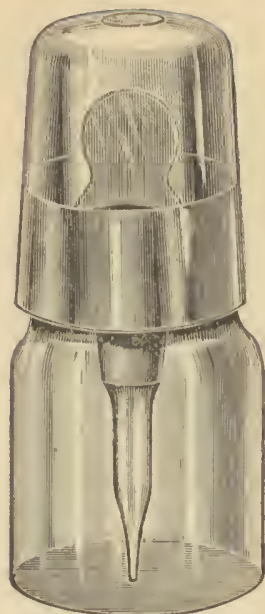

No. 302:.

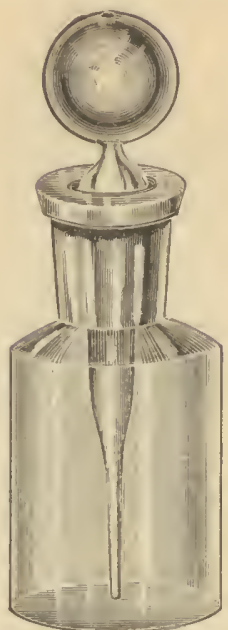

No. 3026 .

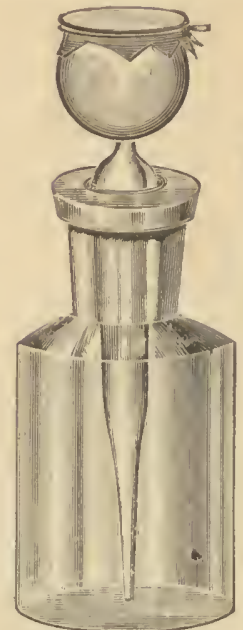

No. 302s.

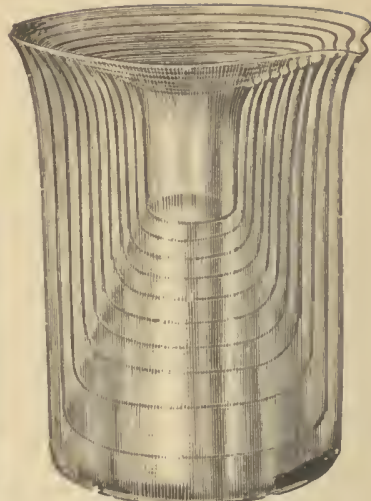

No. $30: 34$.

302:. Capped Bottles, with triangular stopper, to prevent gumming, 1 oz. capacity, each, $\$ .35$

3021. Capped liottles, with triangular stopper, to prevent gumming, $2 \mathrm{oz}$. capacity, each, .50)

3026, Dropping Bottles, with glass bulb, each,

3028 , Dropping Bottles, with rubber top, each,

3030 , Beaker Glasses, wide, with pour-out,

Capacity. $\quad 1 \mathrm{oz} . \quad 2 \mathrm{oz}-20 \mathrm{oz}$

Size,

Each,

Dozen,

Capacity,

Size,

Each,

Dozen, $2 \times 1 \frac{8}{8}$ in. $2 \frac{1}{4} \times 1 \frac{5}{8}$ $2 \frac{1}{4} \times 1 \frac{7}{8}$

$\$ .15$

1.60

.15

1.60

.18

1.75

$12 \mathrm{oz}$. $4 \times 3$ in.

$\$ .25$

2.50

$16 \mathrm{oz}$
$4 \frac{1}{4} \times 3 \frac{1}{4}$
.30

3.00

-
$4 \mathrm{oz}$.
$2 \frac{3}{4} \times 2$
.18
1.80
$24 \mathrm{oz}$
$5 \times 35$
35
3.50

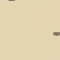

3032, Beaker Glasses, wide, without pour-out, (same prices as No. 3030.)

3034, Beaker Glasses, nested, wide.

$1,2,3,4$ and $6 \mathrm{oz}$, each,

$1,2,3,4,6$ and 8 oz., each,

$1,2,3,4,6,8,10,12$ and $16 \mathrm{oz}$., each, - _ _ _ _ _ - 1.75

$1,2,3,4,6,8,10,12,16,24$ and $32 \mathrm{oz}$, each, _ $\quad \ldots \quad \ldots \quad \ldots$

$1,2,3,4,6,8,10,12,16,24,32$ and 48 oz.. each, _ _ _ _ $\quad$ - 3.00

$1,2,3,4,6,8,10,12,16,24,32,48$ and $64 \mathrm{oz}$, each, _ _ _ _ _ 3. i.

3036, F.vaporating Dishes Glass, plain.

$\begin{array}{lrrrrr}\text { Diameter, } 2 \text { in } & 3 \mathrm{in} . & 4 \mathrm{in.} & 5 \mathrm{in} . & 6 \mathrm{in} . \\ \text { Each, } & \$ .25 & .30 & .35 & .40 & .50 \\ \text { Dozen, } & 2.00 & 250 & 3.00 & 3.50 & 4.50\end{array}$

3033, Evaporating Dishes, Glass, plain, nested.
Diameter,
2 to 4 in.
Each,
$\$ .75$

4 to $6 \mathrm{in}$.

1.00

2 to 6 in. 1.25

3040, Evaporating Dishes, Glass, with lips.

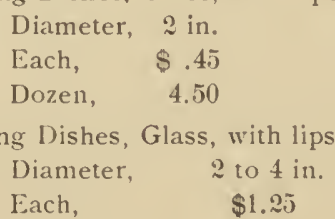

3 in.

.50

4 in.

.60

4.75

6.00

5 in

6 in.

.80

7.50

3042, Evaporating Dishes, Glass, with lips, nested.

$$
\text { Each, \$1.25 }
$$

4 to 6 in.

1.75

2 to 6 in.

2.50 


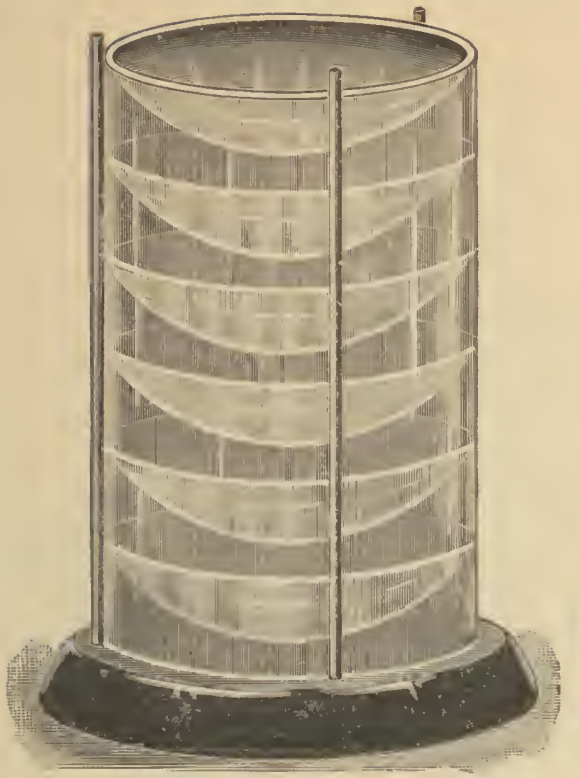

No. :3045.

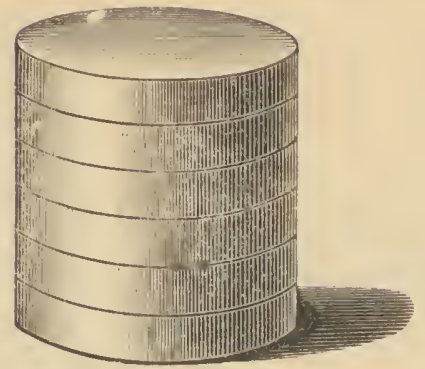

No. :30.5).

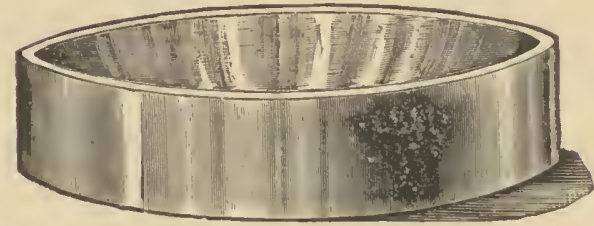

No.\$304(i.

Price.

No.

3044, Watch-Glasses, per dozen, $\$ .40$

3046, Watch-Glasses, Syracuse solid

No. 1, Unground edges, each $10 \mathrm{cts}$.; in set of six, - _ _ _ $\quad .50$

No. 2, Ground and polished edges, each $15 \mathrm{cts}$.; in set of six, - _ _ _ $\quad .75$

No. 3, Ground and polished edges and concaves, each, $50 \mathrm{cts}$; ; in set of six,

The Syracuse solid watch glass rests solidly upon the table or microscope stage, and is not liable to be overturned and its contents spilled. In it on the microscope stage, can be examined from time to time, or dissected and studied, transparent tissues while in water, alcohol, oil of cloves or other bath. When the edges are cut and the top covered, specimens may remain for long staining or soaking, without becoming dirty and without loss of fluid by evaporation.

We have secured the exclusive selling right for the American market.

3048. Standard for the above, adapted for a nest of six or less,

30.00, Porcelain Saucers, 28 in. diameter, in nest of five, with cover, _ _ _ $\quad .60$

305:, Porcelain Saucers, 23 in. diameter, in nest of five, with cover, - _ _ $\quad .70$

30:4, Porcelain Saucers, 31 in. diameter, in nest of five, with cover, - $\quad$ - $\quad .80$

30.56, Porcelain Saucers, $3 \frac{3}{4}$ in. diameter, in nest of five, with cover, - _ $\quad 1.00$

30:5, Porcelain Saucers, deep, $2 \frac{5}{\%}$ in. diameter, in nest of three, with cover, _ $\quad 1.25$

3060 , Porcelain Saucers, deep, $3 \frac{1}{1}$ in. diameter, in nest of three, with cover, - $\quad 1.50$

3062 , Porcelain Saucers, deep, $3 \frac{3}{4}$ in. diameter, in nest of three, with cover, _ $\quad 1.75$

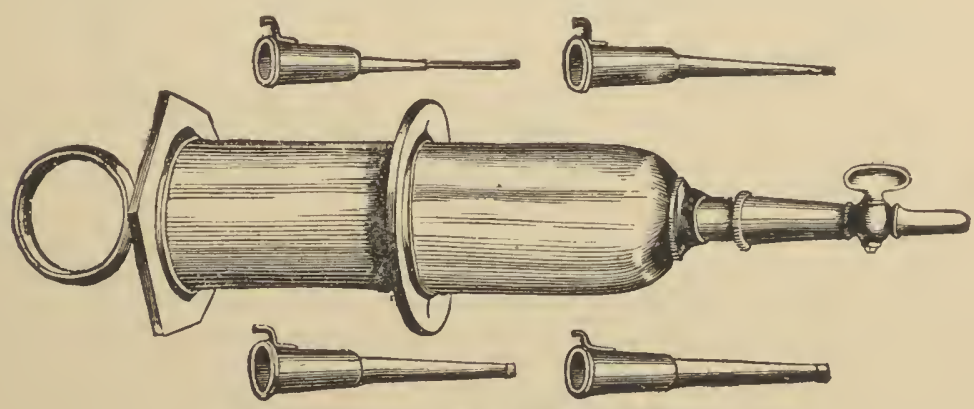

No. B064.

3064, Injecting Syringe, $\frac{1}{3}$ oz. capacity, lacquered brass, with four canulas and stop-cock,

3066, Injecting Syringe, 1 oz capacity, lacquered brass, with four canulas and stop-cock, in case, 


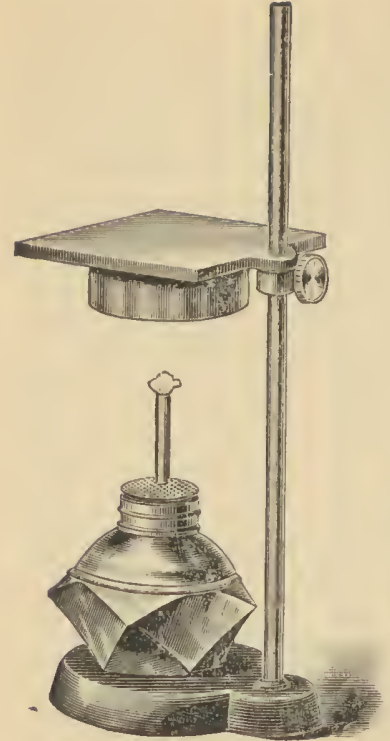

No. 3070.

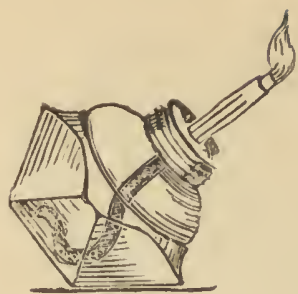

No. 3074 .

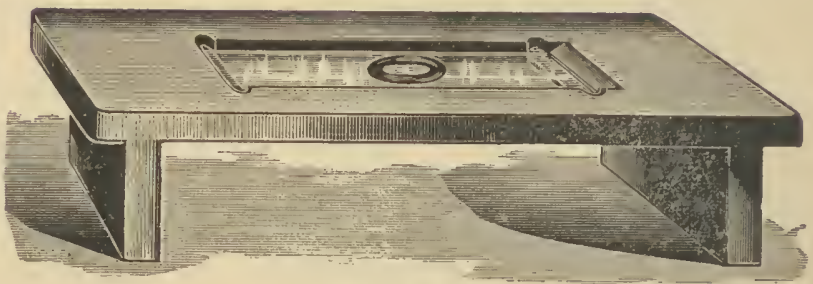

No. 3072.

No.

3068, Brass Table, with lamp for heating slides,,

Price.

3070, Mounting Stand, with lamp and separating sand bath, _ _ _ _ _ _ 2.00

3072, Mounting Table, for the preparation of mounted slides, $\quad$ - $\quad .80$

This mounting table was devised by J. M. Van Cott, Jr., adjunct Professor of Histology and Pathology at Long Island College Hospital, Brooklyn, N. Y. Its value lies in the greater facility it affords for the accurate preparation of mounted slides, and above all, the opportunity it gives for the study of stained sections in gross. The elevation of the section on the slide from the table admits of the greater certainty of its being thoroughly "cleared," and also gives opportunity for the study of the localized action of differential stains.

3074, Glass Spirit-Lamp, No. 1, with extinguisher, $\frac{3}{16}$ in. burner, - - - - .75

30\%6, Glass Spirit-Lamp, No. 2, with extinguisher, $\frac{1}{4}$ in, burner, - _ $\quad .90$

3078, Glass Spirit-Lamp, No, 3, with extinguisher, $\frac{1}{2}$ in. burner, _ _ _ $\quad$ - 1.10

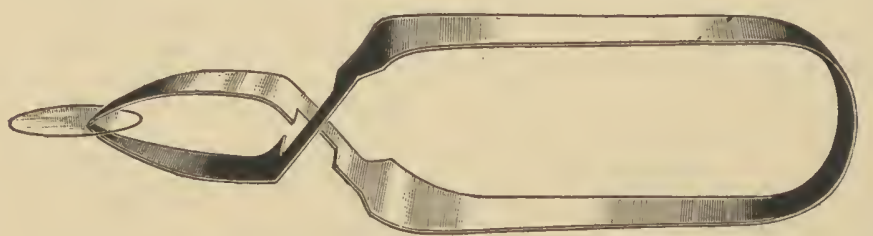

No. 30 s.

3080, Cover-Glass Forceps,

This forcep is a pattern suggested by Dr. J. H. Linsley and is a modification of a forcep for similar use generally employed in the German laboratories. The merits are these: It holds the cover-glass firmly without any danger of breaking it, the upper surface of the cover-glass is level and the forcep is laid upon its flat surface on the table. Its advantages for the purpose of staining preparations of Bacteria (Tubercle Bacillus, etc.,) is manifestly apparent.

3082, Spring Compressors, nickeled, for holding down thin covers, per dozen, 


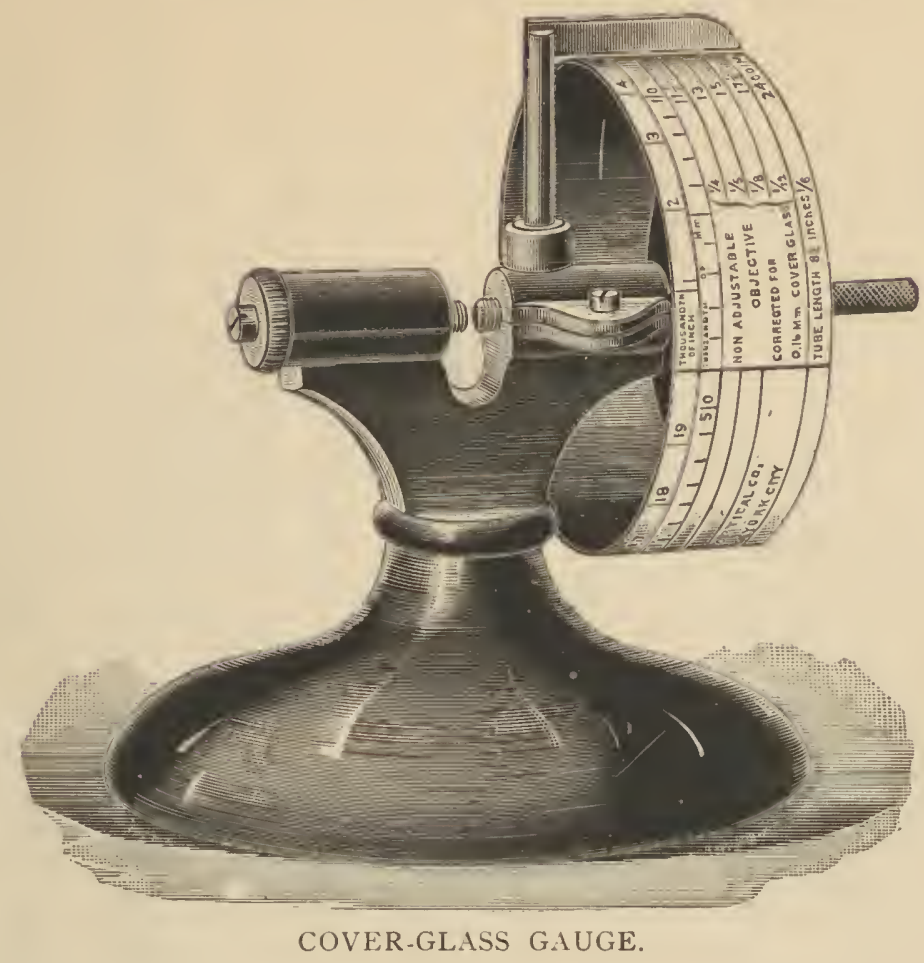

No.

3086, Cover-Glass Gauge,

While the first purpose of this apparatus is to determine the thickness of cover-glass, it goes further in introducing a new system of cover-glass correction by means of the draw-tube. In devising it, the object has been to provide a mechanical means for obtaining the best optical results without any possibility of doubt, and it is conceded by prominent workers that it accomplishes its purpose admirably.

This instrument is provided with a stand of japanned iron, cut horizontally through the top is a thread $\frac{1}{50} \mathrm{in}$. pitch and $\frac{8}{16} \mathrm{in}$. outside diameter. A recess is cut in the top below the line of the screw and at right angle to it, for placing the covers. The one-half of the top of the stand, which receives the micrometer screw, is sletted longitudinally to the depth of the screw, and is provided with a set-screw to take up wear; the other half has the fixed screw, adjustable, however, for final adjustment. The end of the miciometer screw is milled, but of a smaller diameter, so that no force can be exerted so as to endanger the cover-glass. Fixed on the screw, between two nuts, is a brass drum with a $\frac{1}{2} \mathrm{in}$. face. A knife-edge index finger is fixed to the top of the stand and projects over the top of the drum.

To the outside diameter of the drum is fixed a strip of glazed paper provided with a series of divisions. The first gives the thickness of cover-glass in one thousandth inches, the second one-hundredth millimeter. The third indicates the proper tube length with various thickness of cover-glass with a non-adjustable $\frac{1}{4}$ corrected under a tube length of $8 \frac{1}{2}$ in. and cover thickness of $0.16 \mathrm{~mm}$.: the fourth gives the tube length of a $\frac{1}{5} \mathrm{in}$, objective under the same conditions; the fifth for a $\frac{1}{8}$, and the sixth for a $\frac{1}{12}$ for same conditions of tube length and cover; the seventh is for a $\frac{1}{6}$, with the same cover and tube length of $160.0 \mathrm{~mm}$.

In objectives provided with cover-correction, the graduation is so arranged as to read to $1-100 \mathrm{~mm}$. No matter what the power of objective or whether dry or water immersion, the number gives proper correction for a thickness corresponding to it.

Its price has been reduced to a minimum, so as to put it in the power of every microscopist to have one in his possession. It should be found on the work-tuble of every one possessing a microscope. 


\section{DISSECTING AND SECTION KNIVES.}

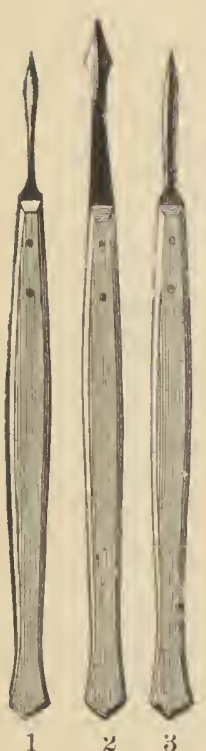

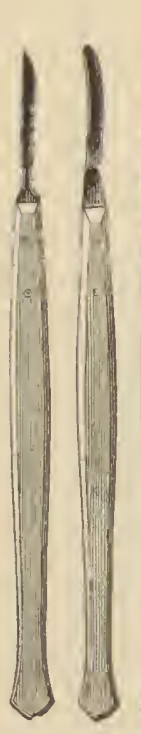

5

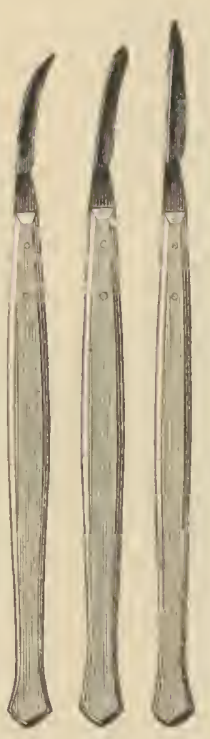

No. 30 s.

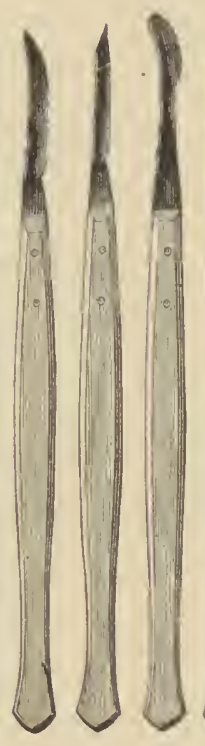

$11 \quad 12$

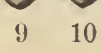

\section{1}
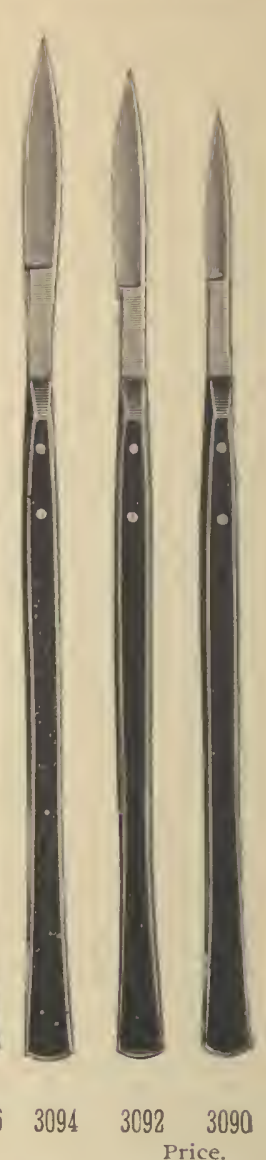

No.

\section{KNIVES.}

3088, Dissecting Knives, ebony handles, each,

3090, Dissecting Scalpels, ebony handles, $\frac{7}{8}$ in. cutting edge of blade, each, - $\quad .50$

3092, Dissecting Scalpels, ebony handies, $1 \frac{3}{16}$ in. cutting edge of blade, each, - $\quad .50$

3094, Dissecting Scalpels, ebony handles, $1 \frac{1}{4}$ in. cutting edge of blade, each, - $\quad .50$

3096, Dissecting Scalpels, ebony handles, $1 \frac{1}{2}$ in. cutting edge of bla le, each, - .50

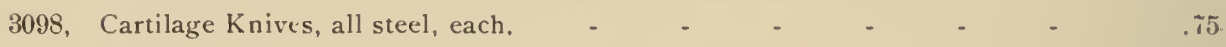

3100, Cartilage Knives, large, stout, ebony handles, each, $\quad$ - $\quad$ - $\quad$ - $\quad 1.50$

3102, Cartilage Knives, extra large, stout, each, - $\quad$ - $\quad$ - $\quad$ - $\quad 2.00$

3104, Brain Knives, each, - $\quad$ - $\quad$ - $\quad$ - $\quad 2.00$

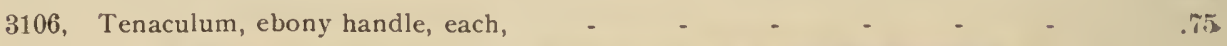

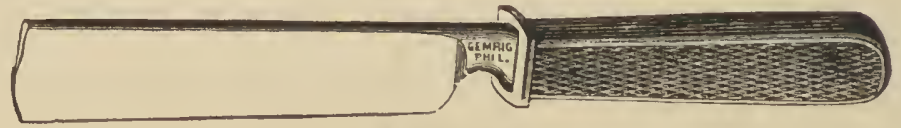

Niv. 3110.

3108, Section Knives, ebony handles, in morocco case, each, - - $\quad$ - 3.25 -

3110, Section Knives, ebony handles, large size, in morocco case, each, - $\quad$ - $\quad \mathbf{5 . 0 0}$.

Ho!ding knife in right hand with concave side uppermost, and drawing towards the bodv, we consider right-handed.

3112, Valentine Knives, for making thin sections of soft substances, each, - - $\quad 6.00$.

3114. Fritsch's Knives, for making thin sections of soft substances, each, _ $\quad \quad 6.00$ 


\section{DISSECTING NEEDLES AND SCISSORS.}

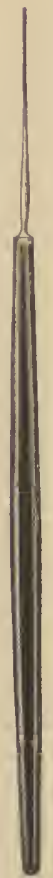

Nos. 3116
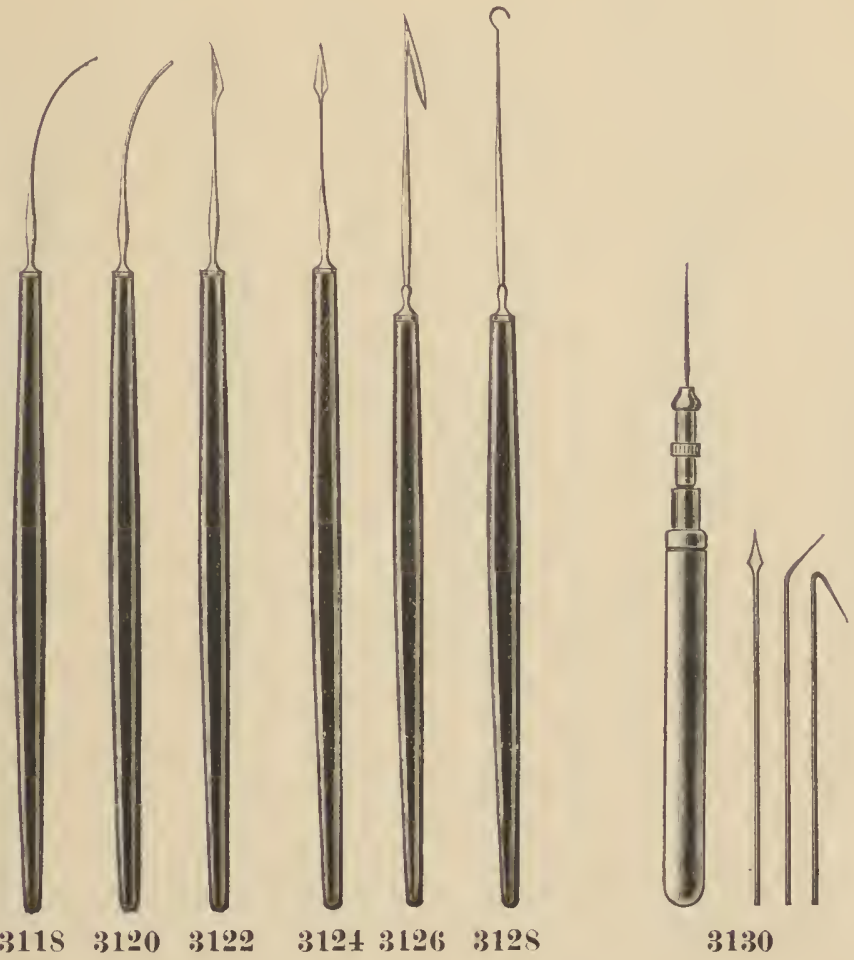

No

3116. Dissecting Needles, ebony handles, round, each,

Price.

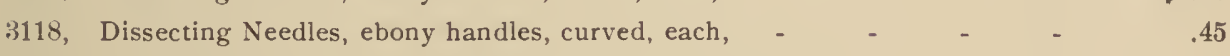

3120, Dissecting Needles, ebony handles, curved, blunt, each, $\quad$ - $\quad$ - $\quad .45$

3122, Dissecting Needles, ebony handles, spear pointed. each, $\quad$ - $\quad$ - $\quad .50$

3124, Dissecting Needles, ebony handles, triangular pointed, each, - $\quad$ - $\quad .50$

3126, Dissecting Needles, ebony handles, harpoon shaped, each, - $\quad$ - $\quad$ - 1.00

3128, Dissecting Needles, ebony handles, hook shaped, each, - _ $\quad$ - $\quad$ - $\quad .75$

3130, Dissecting Needle Holder, with clamp and four needles, each, _ $\quad$ - $\quad .20$

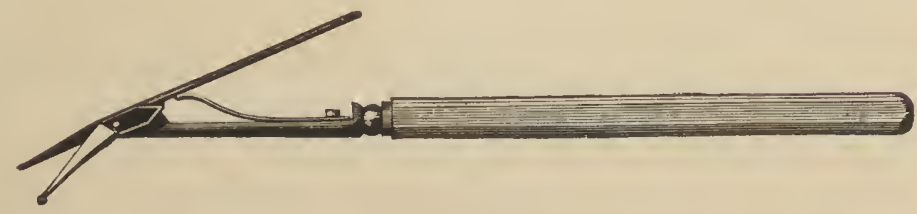

No. 3132.

3132, Dissecting Scissors, ivory handle, with spring, 


\section{DISSECTING SCISSORS AND FORCEPS.}

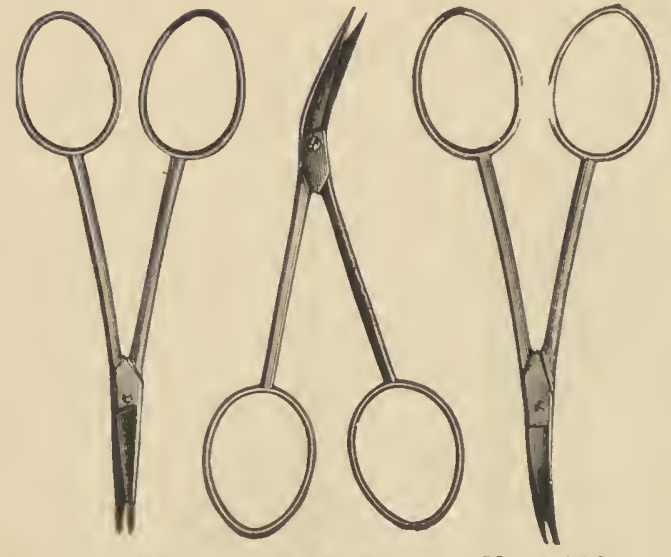

No. 3134 .

No. :3136.

No. :3135. No.

3134, Scissors, Dissecting, very delicate, $4 \frac{1}{2}$ in. long, straight, each, -

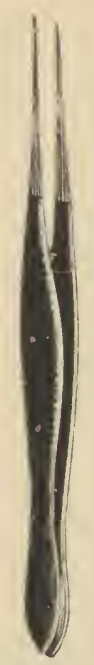

No. 31.58 .

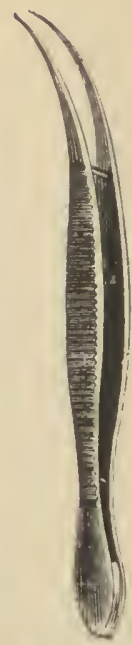

No. $\$ 160$.

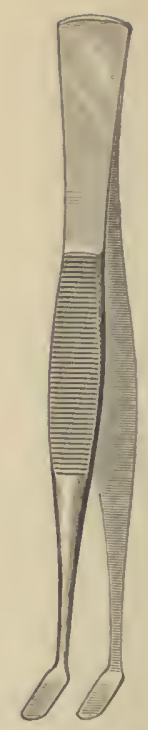

No. 3174 .

Price.

$\$ 1.00$

1.25

1.50

.90

1.00

1.25

.75

1.00

1.75

.15

.40

.60

1.00

1.25

.75

1.00

.60

.55

1.00

1.50

1.00

3174, Cover-Glass or Slide Forcep, steel, nickeled, 4 in. long, each, 


\section{SECTION LIFTERS AND CAMEL'S HAIR PENCILS.}

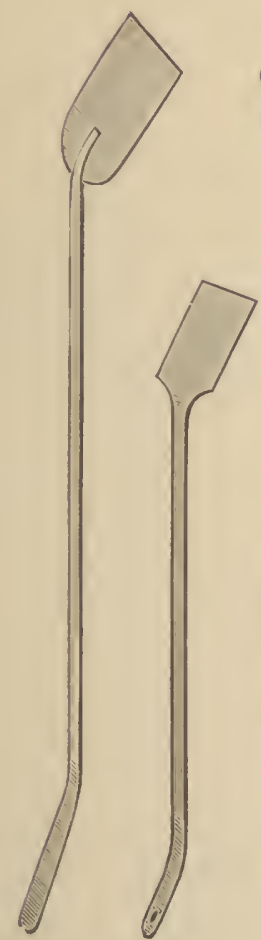

Nos. 31 is 3176
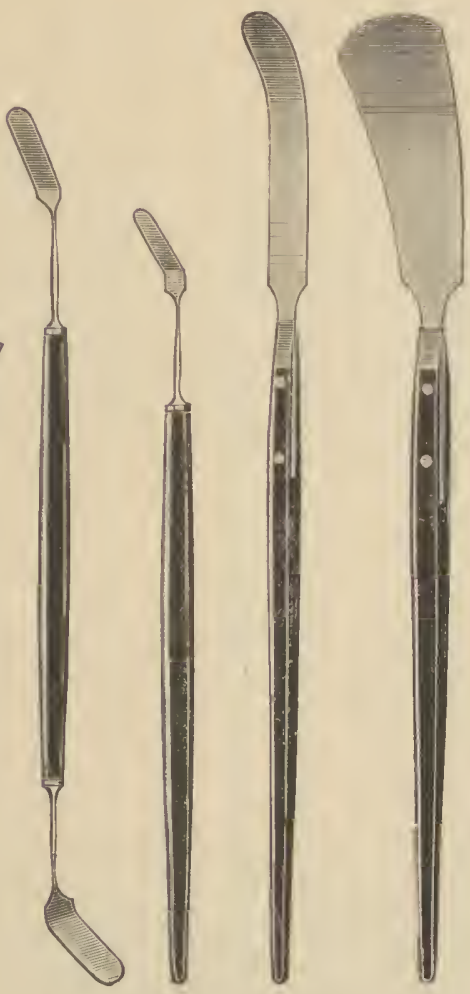

\$150 \$152 3154

3186

\section{CAMELS H}
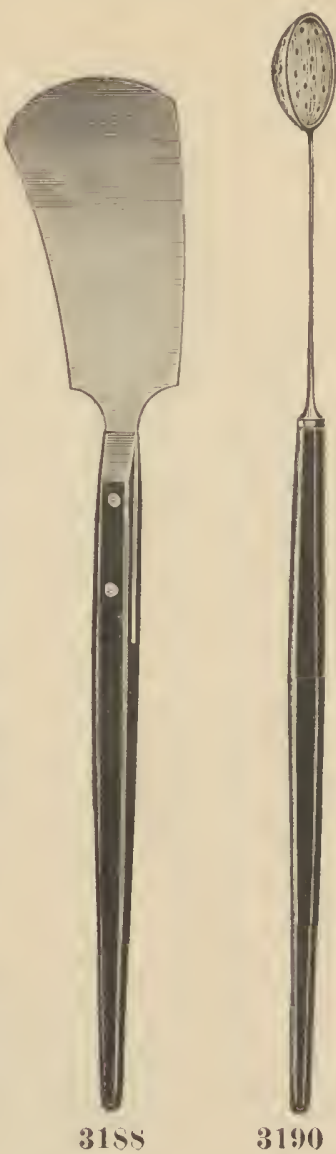

Yo.

31 ss

3190

$31 \% 6$, Section Lifters, brass, nickeled, single, $\frac{5}{8}$ in. wide, each,

$31 ; 8$, Section Lifters, brass, nickeled, (better finish), single. $\frac{3}{4}$ in, wide, each,

3180 , Section Lifters, brass, nickeled, ebony handles, double ended, $\frac{1}{4}$ and $\frac{3}{8}$ in wide, each, .60

3182, Section Lifters, brass, nickeled, ebony handles, single, $\frac{1}{8}$ in, wide, each, - $\quad .40$

3184, Section lifters, brass, nickeled, ebony handles, single, $\frac{1}{2}$ in. wide, each, _ $\quad .45$

31 $\$ 6$, Section Lifters, brass, nickeled, ebony handles, single, $\frac{3}{4}$ in. wide, each, - $\quad .50$

3188, Section Lifters, brass, nickeled, ebony handles, single, $1 \frac{1}{2}$ in. wide, each, - $\quad$.60

3190 , Section Lifters, brass, nickeled, ebony handles, spoon, perforated, each, - $\quad 1.00$

\section{No. 3194.}

3192, Camel's Hair Pencils, miniature, in quills, red silk and gold thread binding.

$\begin{array}{lrrrrrrrrr}\text { Number } & 1 & 2 & 3 & 4 & 5 & 6 & 7 & 8 & \begin{array}{c}\text { Assorted } \\ \text { Length, }\end{array} \\ \text { Each, } & \$ .05 & .06 & .07 & .08 & .09 & .10 & .12 & .15 & .65 \\ \text { Dozen, } & .50 & .60 & .70 & .80 & .90 & 1.00 & 1.25 & 1.50 & \end{array}$

3194, Camel Hair Swan Quill Pencils, pointed, $\frac{3}{4}, \frac{7}{8}$ or $1 \mathrm{in.}$ long, red silk and gold thread binding, each, 


\section{ANATOMICAL, BOTANICAL AND MICROSCOPICAL SETS OF DISSECTING INSTRUMENTS.}

No.

3200, Anatomical Set No. 1. Contains

Price.

2 Scalpels, (No. 3092 and 3096); 1 Tenaculum, (No. 3106); 1 Cartilage Knife, (No. 3098); 1 Scissors, (No. 3146); 1 Forceps, (No. 3166); 1 Blow-I'ipe and 1 Pair Chain Hooks, in cherry case,

3202, Anatomical Set No. 2, Contains

3 Scalpels, (No. 3092 to 3096); 1 Tenaculun, (No. 3106); 1 Cartilage Knife, (No. 3098); 1 Scissors, (No. 3146); 1 Forceps, (No. 3166); 1 Blow-l'ipe and 1 Pair Chain Hooks, in cherry case,

3204, Anatomical Set No. 3, Contains,

4 Scalpels, (No. 3090 to 3096); 1 Tenaculum, (No. 3106); 1 Cartilage K nife. (No. 3098); 2 Scissors, (No. 3146 and 3148); 1 Forceps, (No. 3166); 1 Blow-Pipe and 1 Pair Chain Hooks, in cherry case,

3206, Botanical Set No, 1, Contains

1 Knife, (No. 3092); 1 Needle Holder and Needles, (No. 3130): 1 Forceps, (No. 31.54); 1 scissors, (No. 3140); 1 Magnifier, (No. 112); in cherry case, -

3208 , Botanical Set No. 2, Contains

2 Knives, (No. 3092 and 3096); 1 Needle Holder and Needles, (No. 3130); 1 Forceps, (No. 3154), 1 Forceps, (No.-3164); 1 Scissors,(No. 3140), 1 Scissors, (No. 3142); 1 Magnifier, (No. 112), in cherry case,

3210, Microscopical Set No. 1, Contains

1 Knife, (No. 3085); 1 Needle Holder and Needles, (No. 3130); 1 Scissors, (No. 3140); 1 Forceps, (No. 31.it), in cherry case,

3212, Microscopical Set No. 2, Contains

3 Knives, (No. 3088); 1 Needle Holder and Needles, (No. 3130); 1 Scissors, (No. 3140), 1 Scissors, (No. 3142): 1 Forceps, (No. 316?), 1 Forceps, (No. 3164), in cherry case, 


\section{RE-AGENT CASES.}

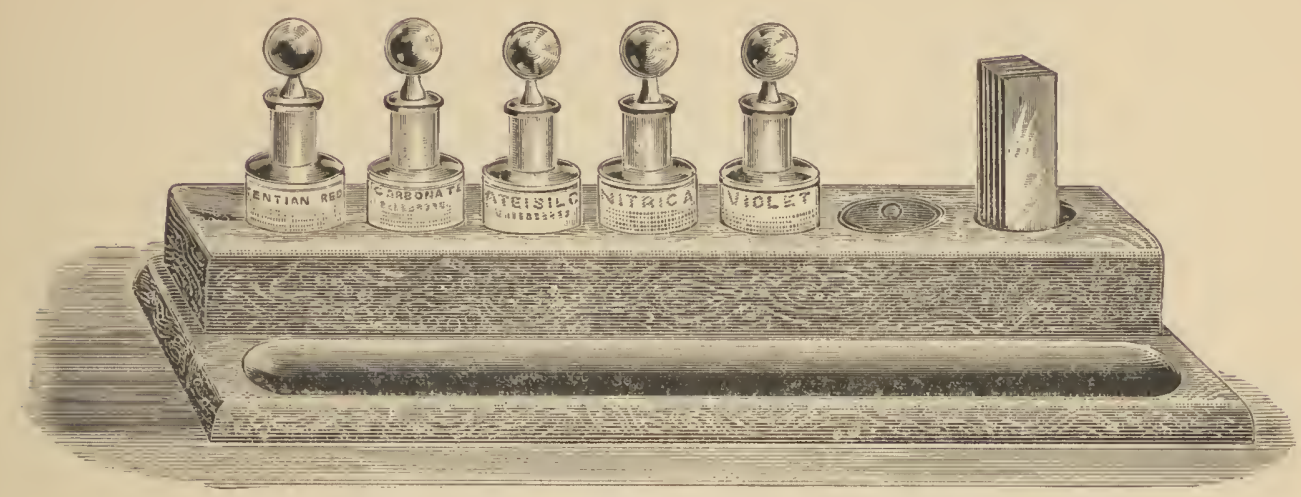

No. 3220.

No. Price.

3220 , Block of wood (bird's-eye maple), polished, fitted for and with five re-agent bottles, No. 3026 , labeled, and receptacles for cover-glass, glass slips and groove to receive dissecting instruments; $1 \mathrm{oz}$. each of the following media, in separate bottles: Gentian Violet, Bismarck Brown, Absolute Alcohol, Turpentine and 3 per cent. solution Nitric Acid in Alcohol, (Other media may be selected.) Each,

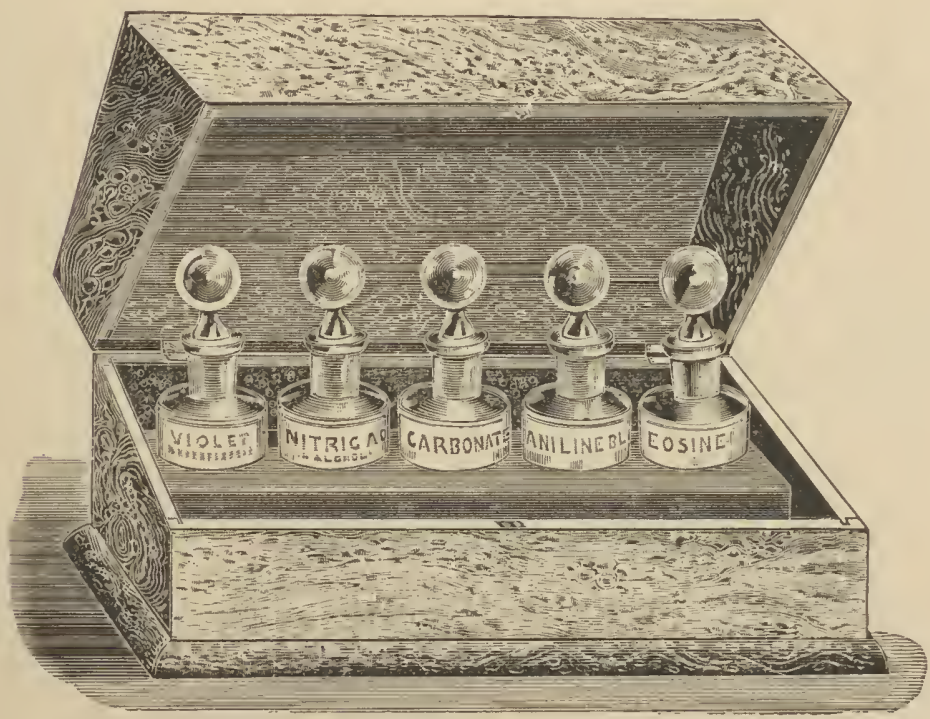

No. 3220.

3222, Re-Agent Case, of highly polished bird's-eye maple wood, with cover and lock, containing five bottles, No. 3026, labeled, and arranged with receptacle for dissecting instruments. The same media as No. 3220 accompany this case. (Other media may be selected). Each, . 


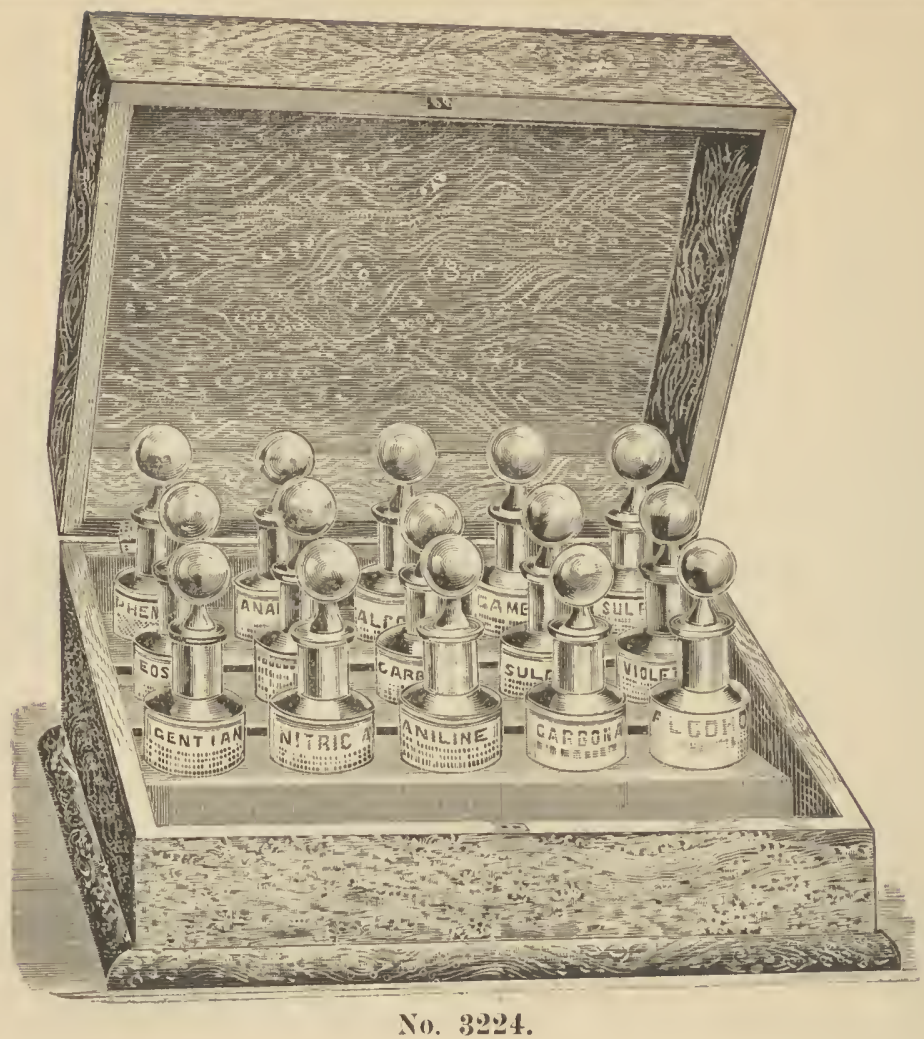

; No.

3224, Re-agent case of highly polished bird's-eye maple, with cover and lock, containing 15 bottles. No. 3026. labeled, and having groove provided for knives, scissors, forceps, etc. The following media (1 oz. of each in separate bottles) accompany each case: Gentian Violet, Bismarck Brown. Fuchsine, Aniline l3lue, Eosine, 0.3 per cent. solution, Nitric Acid in Alcohol, 0.3 per cent. Iodo-Iodide l'otassa, 0.5 per cent. solution Caustic Potassa, 0.3 per cent. solution Carbonate Potash, Phenolphtaline, Pot. Ferro-Cyanide, with 0.1 per cent. Acetic Acid, Absolute Alcohol. Turpentine, each,

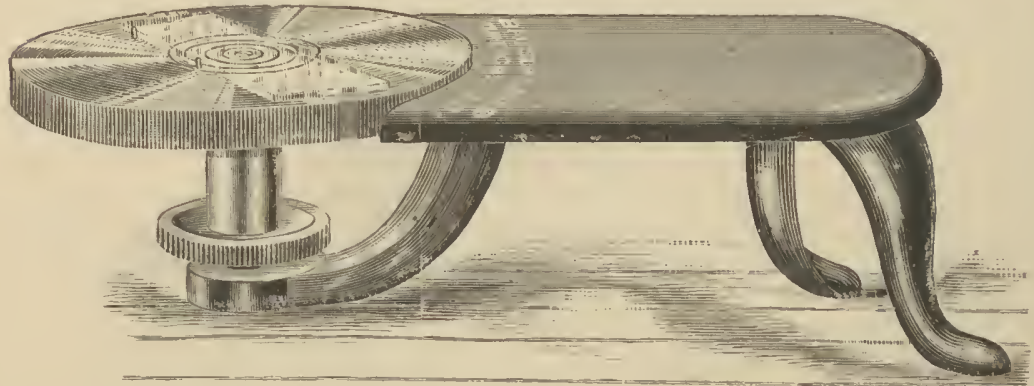

No. 3244 .

$3240, \quad$ Turn-Table, "National,"
$324 \%, \quad$ Turn-Table, same, with detachable hand-rests,

3244, Turn-Table, “National," centering,

The centering arrangement of this turn-table consists of three stops, against which the slide is placed and is held in position by the spring clips Although not strictly centering, it is approximately so on the usual slide, and, for all ordinary purposes, quite efficient.

3246, Same, with detachable hand-rests, -
3248 , Turn-Table, self-centering with hand-rests. The advantage which this turn-table

3248, Turn-Table, self-centering with hand-rests. The advantage which this turn-table
has over others, is, that glass slips of the various standard sizes used, can be centered thereon, 


\section{GLASS SLIPS.}

No.

3400 ,

3404, Crown, 3 $x 1$ in., ground edges, square, extra white,

:340. Crown, $3 \times 1$ in., thin, ground edges, square. extra white, - .18

3410 , Crown, $1 \frac{3}{4} \times 1$ in., ground edges, rounded, extra white, - . $\quad .20$

3412 , Crown, $2 \times 1$ in., ground edges, rounded, extra white, _ . .20

3414, Crown, $3 \times 2$ in., ground edges, rounded, extra white, - . $\quad .40$

3416, Crown. 5 x 4 in., cut edges, extra white, _ _ _ . . . _

3418, Crown, 5 $\mathrm{x} 4$ in., ground edges, extra white, - $\quad$ - . .5

3420 , Crown or Plate, $3 \times 1$ in., ground bevels, _ _ _ $\quad .40$

3422, Crown or Plate, $3 \times 1$ in., polished bevels, $\quad$ - $\quad .50$

3424 , Crown, $3 \times 1$ in., with ground edges and concave centres,

\section{THIN GLASS COVERS.}

3440, In sheets, No. 1, $\frac{1}{15}$ to $\frac{1}{2} 00$ in. thick,

$\begin{array}{ccc}\text { Per } & \begin{array}{c}\text { Per } \\ \text { In to oz. }\end{array} \\ \text { Dozen. Ounce. } & \text { lots. } \\ \text { Each oz. }\end{array}$

$\$ 1.00$

3442 , In sheets, No. $2, \frac{1}{100}$ to $\frac{1}{150}$ in. thick,

344 , In sheets, No. $3, \frac{1}{50}$ to $\frac{1}{100}$ in. thick,

3446 , In squares, No. $1, \frac{1}{2}, \frac{5}{8}, \frac{3}{4}, \frac{7}{8}$ or 1 in. diameter, -

3448 , In squares, No. 2,

3450 , In squares, No. 3 ,

34,2 , In circles, No. 1, “ “ “ “ ,

34.j4, In circles, No. 2, “ “ “ “

3456 , In circles, No.

3458 , Oblong sizes, $\frac{1}{100}$ to $\frac{1}{150}$ in. thick, $10 \times 15 \mathrm{~mm}$,

$15 \times 20 \mathrm{~mm}$.

$18 \mathrm{x} 25 \mathrm{~mm}$,

$18 \mathrm{x} 27 \mathrm{~mm}$,

$20 \times 25 \mathrm{~mm}$.

$21 \times 24 \mathrm{~mm}$.

2:) $x$ 50 mm.,

$24 \mathrm{x} 32 \mathrm{~mm}$.,

$26 \times 34 \mathrm{~mm}$.,

$30 \times 40 \mathrm{~mm}$.,

$40 \times 50 \mathrm{~mm}$.,

$50 \times 60 \mathrm{~mm}$.,
$1.80 \$ 1.60$

$\begin{array}{lll}.16 & 140 & 1.20\end{array}$

$.14 \quad 100 \quad .80$

$.20 \quad 2.25 \quad 2.00$

$\begin{array}{lll}18 & 1.80 & 1.60\end{array}$

$16 \quad 1.40 \quad 1.20$

\section{LABELS AND COVERS FOR SLIDES.}

34i0, Adhesive Labels, white, round or oval, per 100 in box, $\quad$ - $\quad$ - $\quad .10$

$34 \pi$, Adhesive Labels, white, square with black border, per 100 in box, $\quad .15$

3474 , Adhesive Labels, square with fancy border,assorted colors, per 100 in box, $\quad .25$

3476 , Adhesive Labels, same as No. 34it, with imprint of two lines on each label, per 1000 uncut,

3478. Adhesive Labels, gilt fronts, for covering slides, per 100, 2.00

3480 , Adhesive Labels, backs, per 100, _ _ _ _ _ _ _ _ _ $\quad{ }_{-} \quad 25$

Backs and Fronts, if with holes punched, per 100, extra, _ _ _ $\quad .15$. 


\section{MOUNTING AND STAINING MEDIA.}

No.

3i) 00 , Xylol, pure.

3.502, Absolute Alcohol, Dr. Squibb's,

3504 Benzole, pure,

3506

3508 ,

3.510 ,

3512,

3514

3516 .

3518 ,

3520 ,

$35: 2$,

3524 ,

3.526 .

3.28 ,

$35: 30$,

$353:$

$35: 34$

3536 ,

$35: 38$,

3540 .

3542

3546

3548

3550

3552

35.56

$35 \overline{5} 8$

3560

3502 ,

3564

3566

3568 ,

$35 \% 0$,

3)ิข

$35 i$

$35 \%$

3.50,

3582

3584

3586

$358 s$,

3590

3592

359

3596,

3600 ,

3602 ,

3604

3606 ,

3608

3610 ,

3612

3616

3618

$36: 0$

$36: 2$

Aniline, green,

Aniline, red,

Aniline, violet,

Methyl, blue,

Methyl, violet,

Methyl, green,

Eosine,

Haematoxylin,

Bismarck Brown

Fuchsine,

Saffranine,

Vesuvin.

Canada Balsam, paper filtered, in flexible tubes, _ _ _

\begin{tabular}{|c|c|c|}
\hline $\begin{array}{c}\mathrm{Czz}_{\text {. }} \\
\text { Bottle } \\
\text { Solution. }\end{array}$ & $\begin{array}{c}\text { Pint } \\
\text { Bottle } \\
\text { Solution }\end{array}$ & $\begin{array}{l}\text { 1)ry } \\
\text { per oz. }\end{array}$ \\
\hline$\$ .20$ & $\$ 1.50$ & \\
\hline .20 & 1.50 & \\
\hline 20 & 1.00 & \\
\hline .25 & 2.7 .5 & .30 \\
\hline .50 & 4.25 & \\
\hline .50 & 5.00 & \\
\hline .50 & 5.00 & \\
\hline .50 & 3.50 & \\
\hline
\end{tabular}

llamar, in benzole. $\quad$ - $\quad$. $\quad$ - $\quad .50$

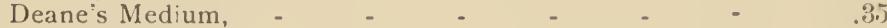

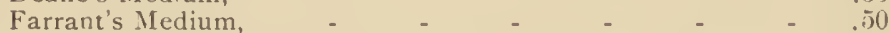

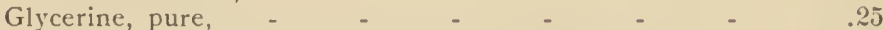

Glycerine, camphorated, for delicate vegetable tissues, _ $\quad .25$

Glycerine, jelly, _ $\quad$ - $\quad$ - $\quad$ - $\quad$ -

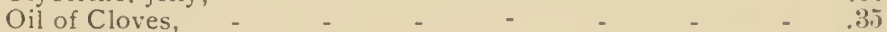

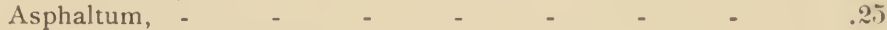

Aspha'tum, quick drying, _ $\quad \ldots \quad \ldots \quad \ldots$

Turpentine, - $\quad-\quad$ - $\quad$ - $\quad$ -

Brown's Transparent Rubber Cement, _ _ _ _ _ _ $\quad .35$

Brunswick Black, - $\quad$ - $\quad$ - $\quad$ _

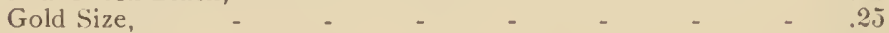

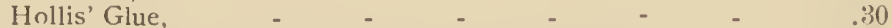

King's Amber Cement, transparent, with directions, _ - .2.

King's White Cement, transparent, with directions, -

King's Lacquer Cell and Finish, scarlet, with directions, - .50

King's Lacquer Cell and Finish, blue, with directions, -

Marine Glue, hard, melting point $250^{\circ} \mathrm{F}$, box, _ - _ . 35

Marine Glue, fluid, - $\quad$ - $\quad$ - $\quad$ - $\quad$ -

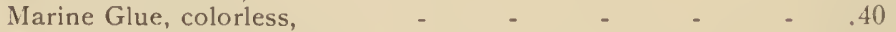

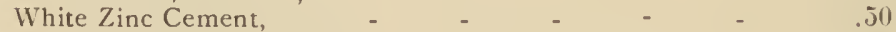

Ammonia, Carmine, Beale's, _ _ _ _ _ _ $\quad$ - .25

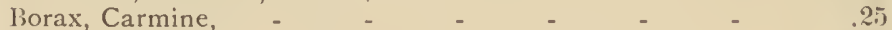

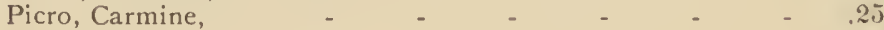

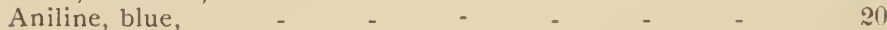

Burril's Stain for Bacillus Tuberculosis, with directions, -

Gentian Violet, - _ - _ _ _ _ . 20

Osmic Acid, $\frac{1}{32} \mathrm{Oz}$ or 1 gramme, - _ _ _ $\quad 200$

Carmine Injecting Gelatine, Dr Seiler's, _ _ 1.00

Aniline Oil, pure, for use in preparation of Bacillus Tuberculosis, . 20

Paraffine, pure, soft, melting point $109^{\circ} \mathrm{F}$., pound. _. .

Paraffine pure, hard, melting point 1:29 F., pound, - _ $\quad .50$

Celloidine, $1 \mathrm{oz}$. box, - - _ - $\quad$ -

Cedar Oil, for microscopic purposes, - _ _ _ _

Dr. Gibbes Double Stain for Bacillus Tuberculosis, _. $\quad .50$

Nitric Acid in Alcohol, 3 per cent. Solution,

2.00

2.00

$2.00^{\frac{1}{8} \text { oz. }} .75$

$2.00 \quad .40$

$2.00 \quad .35$

$2.00 \quad .60$

$2.00 \quad 1.00$

$2.00 \quad 1.00$

$2.00 \quad .50$

$200 \quad .50$

$2.00 \frac{1}{8}$ Oz. . . 55

$2.00 \frac{1}{8}$ oz. . 25

2.00

.60

2.00

.30

Iodo-Iodide Potassa, 0.3 per cent, Solution, -

Caustic Potassa, 0.5 per cent. Solution, - _ _ _ _ _ _

Carbonate of Potash, 0.3 per cent. Solution, - _ _ _ . 25

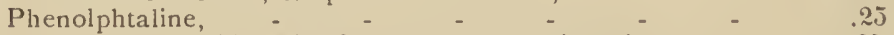

Pot. Ferro-Cyanide, with 0.1 per cent. Acetic Acid, - $\quad .25$ 


\section{CELLS.}

No.

3640, Glass cells, various sizes and depths, per dozen,

Price.

$364 \%$, Rubber cells, various sizes and depths, per dozen,

3644, Block tin cells, various sizes and depths, per dozen,

3646, Zylonite cells, various sizes and depths, transparent, per dozen,

No. 36.50 .

3650, Atwood Rubber Cells, for mounting opaque objects, per dozen,

These celis are made by us They are exceedingly neat, require but little time in mounting, and have the advantage that objects can be mounted and preserved independent of the slip. They are made for one-half in. covers.

\section{BOXES AND CABINETS FOR OBJECTS.}

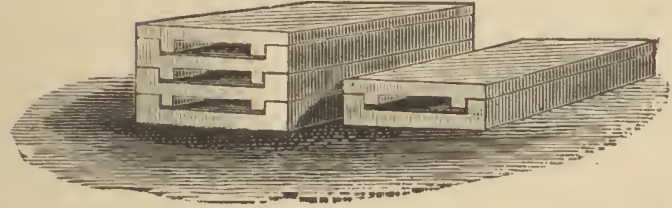

A.
No. 3660 .

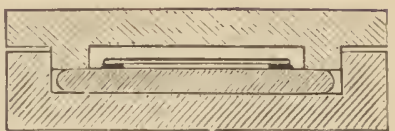

13.

3660, Mailing Cases, Bradley's, per dozen tops, $\quad$ - $\quad \ldots \quad-\quad$ - $\quad$ - $\quad$ - $\quad .06$ Mailing Cases, Bradley's, per dozen bottoms, $\quad$ - $\quad \ldots \quad \ldots \quad$ - $\quad . \quad 06$ Mailing Cases, Bradley's, per dozen centers, _ _ _ _ $\quad$ - $\quad$ - $\quad .06$

The new mailing case here illustrated is designed to supply a demand for some safe and cheap means of packing one or more microscope slides for mailing. The entire device comprises three differently shaped pieces of wood so formed that two, three or more may be put together, as shown in the cut, figure $\mathbf{A}$. For one slide two pieces are used, for two slides three pieces, and so on to any convenient number.

The cross section, figure $\mathbf{B}$, shows the relation of the parts of the case to the slide. The pinching of the wooden lips on the margin of the glass, outside the mounting, serves to hold the slide securely in place, and to protect the mounting from possible injury. The three pieces are designated as tops, bottoms and centers.

3662, Mailing Boxes, wood, to hold 3 objects, $3 \times 1$ in., per dozen, - $\$ .80$, each, $\$ .07$

3664, Mailing Boxes, wood, to hold 6 objects, 3 x 1 in., per dozen, - .85, each, .08

3666, Mailing Boxes, wood, to hold 12 objects, $3 \times 1$ in., per dozen, - .90 , each, .09

3668, Mailing Boxes, wood, to hold 25 objects, 3 x 1 in., per dozen, - 1.00 , each, .10

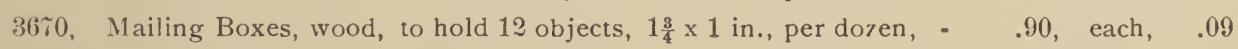

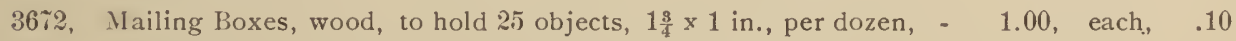

36i4, Mailing Boxes, wood, to hold 50 objects, $1 \frac{3}{4} \times 1$ in., per dozen, - 1.50, each, .15

36 6, Mailing lioxes, wood, to hold 25 objects, $3 \times 2$ in., per dozen, - $\quad 9.00$, each, .20

$36 \% 8$, Clnth covered slide box, with lid and sliding cover and numbered index to hold,

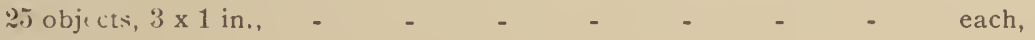




\section{CABINETS.}

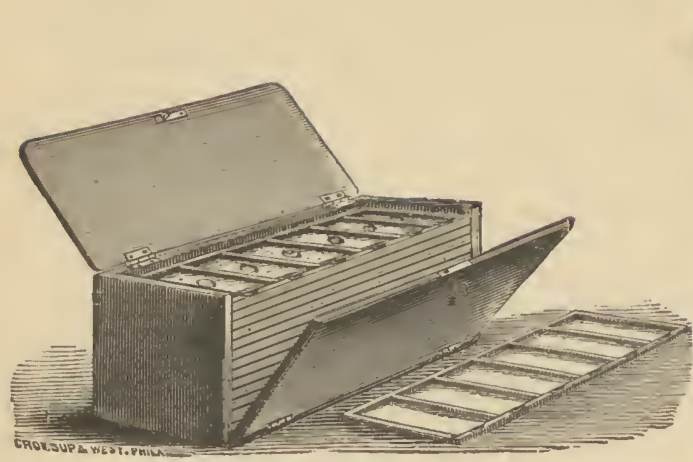

No. 3694.

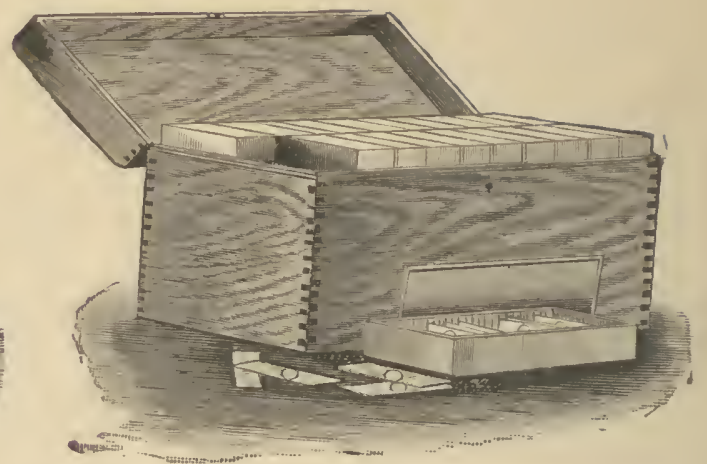

No. $\$ 300$.

No.

3650 , Cabinet, portable, white wood, 4 trays, holding 24 objects,

I'rice.

$36 \times 2$. Cabinet, portable, white wood, 6 trays, holding : 0 (j objects,

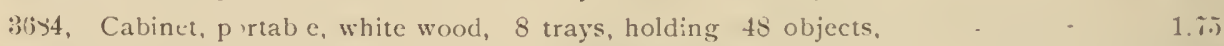

3686. Cabinet, portable, white wood, 10 trays, holding 60 objects, . _ 200

3688 , Cabinet, portable, white wood, 12 trays, holding $i 2$ objects, $\quad$ - 2.50

3090, Cabinet, portable, white wood, 12 trays, holding 144 objects, - 3..50

3692, Cabinet, portable, mahogany, 6 trays, holding 36 objects, _ _ $\quad 2.00$

3694, Cabinct, portable, mahogany, 12 trays, holding 22 objects, - _ _.2.)

3696, Cabin t, portible, mahogany, 12 trays, holding 144 objects, _ _ _. 50

3698, Cabinet, portable, Pillsbury`s, containing 10 boxes for 2.50 slides. _ _ $\quad 3.00$

3700, Cabinet, portable, l'illsbury's, containing 20 boxes for 500 slides, - $\quad 400$.

The Pillsbury Cabinet consists of a finely polished cherry case, containing ten or twenty bnxes, grooved on the inside, to receive twenty-five slides each, and provided w th a lock. When the boxes are in place in the cabinet, the slides lie hurizontally, ti, us avoiding all liability of damage to slides in top.

The top of each box as placed in the cabinet, is provided with an index, and on the bottom of the box. inside, is a corresponding number to show the proper location of each slide. If a cabinet is not required the boxes may be used singly, as a simple rubber band serves to hold the cover securely in place. They are of plain white-wood, neatly finisher. (See No. 31i6s.)

3r0:2. Cabinets, mahogany, solid door, for 500 objects, _ _ _ _ _ _ 3.j 00

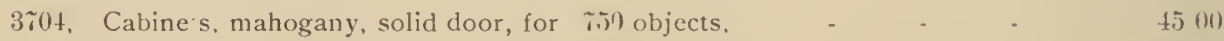

3\%0i, Cabinets, mahogany, solid door, for 1000 objects, _ $\quad$ - $\quad$ - ji.00

3\%0s. Cabinets, mahogany, glass panel door, for 500 objects, _ _ $\quad 40.00$

3710. Cabinets, mahogany, glass panel door, for 7.50 objects, . _ _ . 50.00

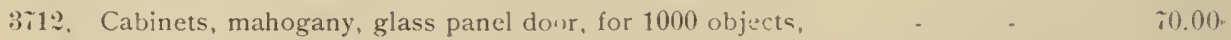

Olijects in all above cabinets lie flat. In cabinets Nos. 3702 to 3712 the knobs are numbered, and porcelain tablets are inlaid into the fronts of the drawers. they are made to order only. 


\title{
IMPROVED PHOTO-MICROGRAPHIC GAMERA.
}

\author{
SMALL SIZE.
}

The camera portion of this apparatus is in general construction the same as the large size described on parge 9.5 , except that the size is $4 \frac{1}{4} \times 5 \frac{1}{2}$ in., and that the front is so arranged that $\mathrm{a}+\mathrm{x} .5$ plate in kit can be adjusted directly to the same, which in the case of the large size, using $6 \frac{1}{2} \times 8 \frac{1}{2}$ in. plate would require the use of the plate holder. Kits : $3 \frac{1}{4} x+\frac{1}{4}$ and $+x ;$ accompany this outfit. The microscope attachment is simple; the tube to receive objective is fastened directly to the front board, and is arranged with draw-tube to receive eyepiece if such is required to be used. The coarse adjustment is effected by sliding the stage of mirror-bar upon a solid base and is focused at any point by a screw with pin. The fine adj stment is contained in the base plate, and is acted upon by a micrometer screw at the back and the connecting rod as shown.

The camera bellows when drawn out have an extension of 2 feet 6 in. Microscope attachment the same as No. $376+$ can also be applied to this camera.

3750, Improved Photo-Micro Camera, small size, (no microscope attachment), - $\$ 30.00$

3752, Improved Photo-Micro Camera, as described above and as shown in cut, $\quad-\quad 42.00$

3754, Improved Photo-Micro Camera, with microscope attachment, same as No. 3764, $\quad 65.00$

New rectangular tube with prism, can be fitted to any microscope or camera,

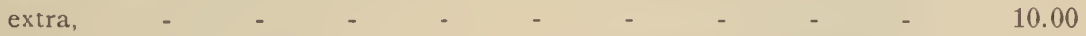

Fitting other microscopes than our own to camera, extra, according to the amount of work involved,

Revolving stage, with removable spring clips, extra, _ $\quad$ - $\quad$ _ 5.00

Glass stage with slide carrier, which slips over either plain or revolving stages, extra, -

Mechanical stage No. 1728, in place of the regular, extra,

Graduated mirror bar, with mirror and sub-stage (both adjustable), same as used on Investigator, in place of one accompanying stand, extra, $\quad 5.00$

Abbe Condenser, $1.20 \mathrm{~N}$. A., in mounting No. 1678 , extra, - $\quad$ - 14.00

Abbe Condenser, 1.49 N. A., in mounting No. 1678, extra, : - - - 16.00

Abbe Condenser, Achromatic, 1.0 N. A, , in mountıng No. 16\%8, extra, $\quad 26.00$ 

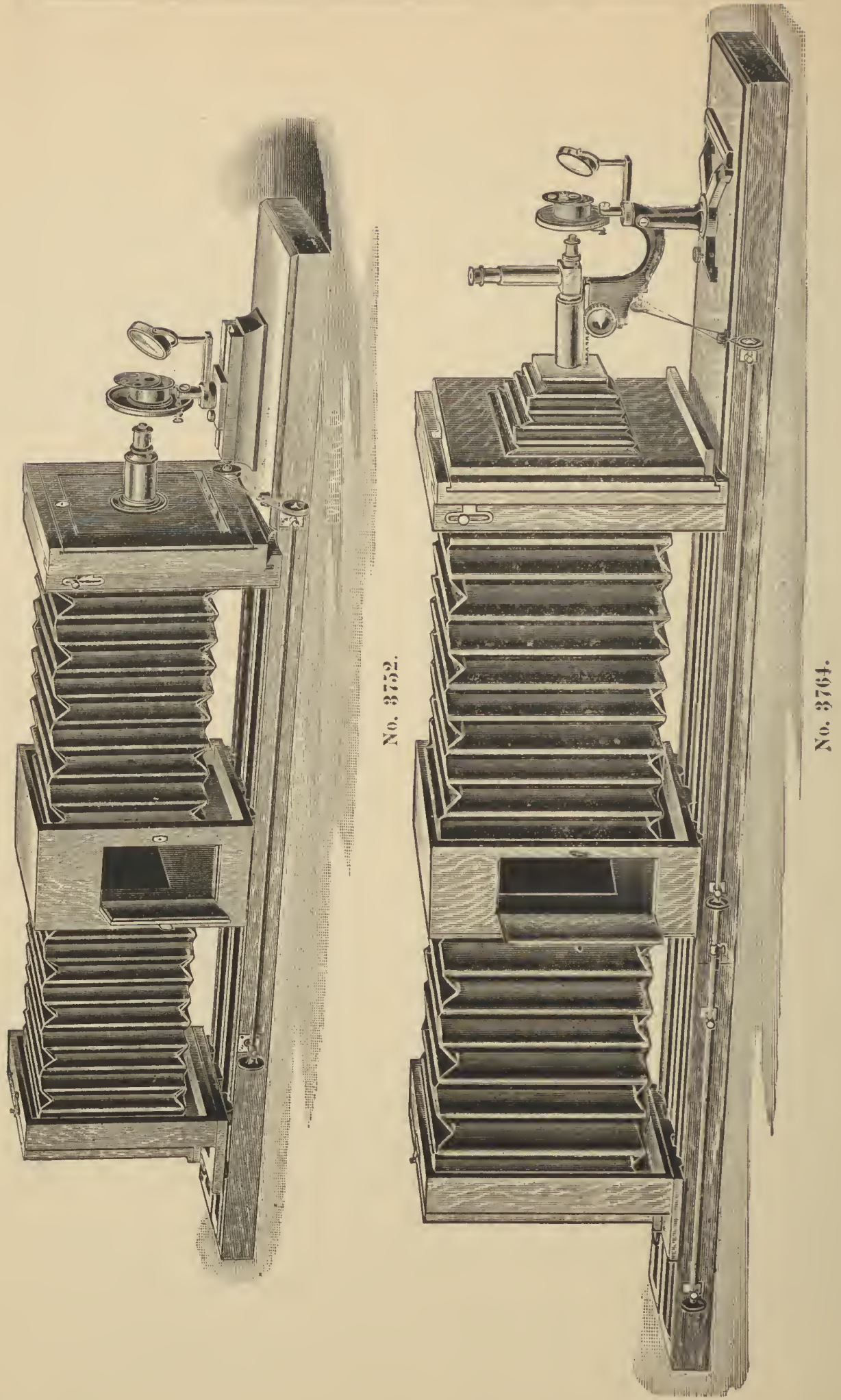


\title{
IMPROVED PHOTO-MICROGRAPHIC CAMERA.
}

\author{
LARGE SIZE.
}

This camera is designed for photo-micrographic, copying, enlarging and reducing work. The camera sections are made of mahogany highly finished, bellows of rubber and well made. The camera slides on $V$ shaped ways; the sections have clamps, thus allowing each to be fastened at any point upon the bed and insuring extreme firmness. The center section is arranged to receive front board for rectilinear lens. The front of the camera has adjustment in two directions (rising and falling front and side movements); plate-holder can either be used in the front or the back of the camera, as the case may require. The ground glass is removable and cover glass is cemented to the matted surface of the same to allow of more delicate focusing. Alongside of the bed the focusing rod is attached, which is separable at the junction of the two sections of the bed; by means of a clamping screw the connection of the rod can easily be made.

The size of plate is $6 \frac{1}{2} \times 8 \frac{1}{8}$ in. Kits $3 \frac{1}{4} \times 4 \frac{1}{4}, 4 \times 5$ and $4 \frac{1}{4} \times 5 \frac{1}{2}$ accompany the outfit. The plate-holder is single and reversible.

The microscope attachment consists of our Model stand (see description page 21) having draw-tube, thus giving short and long standard of tube length in cases were eyepieces are used. A valuable feature in connection with the microscope is our new rectangular tube carrying a prism in mounting, which is attached to the nosepiece. By raising or lowering the latter, the prism is. brought in or out of the field of the image circle. In the case of the former the object is plainly visible in the eyepiece, and may be centered at will and light. adjusted, by withdrawing the tube all light is excluded and the object can be focused on the ground glass of the camera. The microscope is fastened to the bed by cleats and thumb-screw, and is easily removable when the attachment. is not required. The camera bellows when drawn out have an extension of 3 feet 6 in.

Microscope attachment as No. 3752 can also be applied to this camera. No.

3760, Improved Photo-Micro Camera, large size, (no microscope attachment), _ 3762. Improved Photo-Micro Camera, with microscope attachment, same as No. 3752. 52.00 3764, Improved Photo-Micro Camera, with microscope attachment as described above, and shown in cut, including Continental eyepiece (any power),

New Rectangular Tube with prism, can be fitted to any microscope or camera, extra,

Fitting other microscopes than our own to camera, extra, according to the amount of work involved,

Revolving stage, with removable spring clips, extra,

Glass stage with slide carrier, which slips over either plain or revolving stages, extra,

Mechanical stage No. 1728, in place of the regular, extra,

Graduated mirror bar, with mirror and sub-stage (both adjustable), same as used on Investigator, in place of one accompanying stand, extra, $\quad$ - $\quad 5.00$. Abbe Condenser, 1.20 N. A., in mounting, No. 1678, extra, - _ $\quad$ - 14.00 Abbe Condenser, 1.42 N. A., in mounting, No. 1678, extra, - $\quad$ - $\quad 16.00$. Abbe Condenser, Achromatic, 1.0 N. A , in mounting No. 1678, extra, - $\quad 26.00$ 


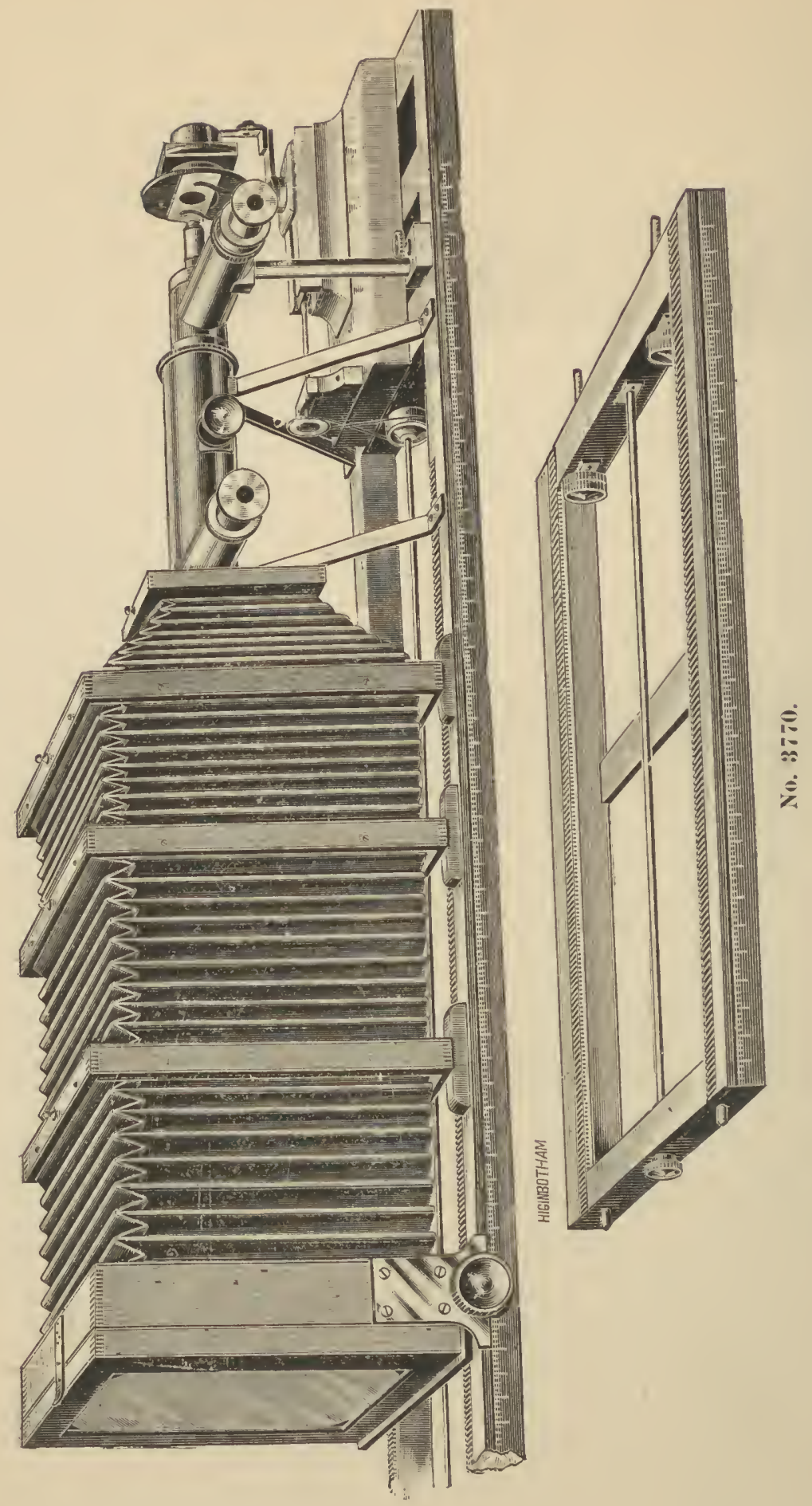




\section{THE PROFESSIONAL PHOTO-MICRO CAMERA.}

This instrument has been designed by Mr. George W. Rafter, with special reference to doing photo-micrographic work of a high character with the greatest possible economy of time. It is provicled with a number of new and important features, which enable work to be done with the utmost facility and certainty. The work which has been done on this instrument is of the highest order, and is in the greatest measure owing to the perfection of the instrument, and to the new features involved.

The base of the instrument consists of a wooden frame in which are inlaid two racks. On one side of the base is a graduation in feet, tenths and hundreds of a foot, which forms a record of the positions of the screen for producing given magnifications. The length of the frame may be extended to eight feet by the addition of supplementary frame, which are easily attached and automatically form connection of the adjusting rod. The bellows rest and slide upon the frame, and the ground glass is adjusted by pinions. The bellows are made in sections and may thus be extended to the length of the bed. The plate holder is for $6 \frac{1}{3} \times 8 \frac{1}{3}$ plate, but so arranged that smaller plates may be used. The fine adjustment is effected by a micrometer screw, which is acted upon by the adjusting rod, and works with promptness with any amplification. The stage is round and provided with spring clips, and may be fastened at any point upon the bed for approximate focus. The sub-stage bar has adjustable sub-stage and swings to any obliquity on a center in line with the stage.

The tubes rest upon two brass supports and are connected with the tapering front of the camera. The main tube is provided with two inner tubes, the smaller of which is graduated and intended to carry the amplifier, or when desired, an eye-piece. Both tubes are adjusted by means of a rack and pinion, and arranged with pulley for cord. The main tube has at its posterior end a rectangular tube provided with draw-tube, eyepiece with cross hairs, and rectangular prism by which the image may be viewed and centered upon the ground glass. At the front is a similar rectangular tube intended for use with high powers.

The new features which we claim make it the efficient instrument it is, are :

1. The application of specific appliances for moving the amplifier, in order to find by trial, for any given extension of the camera, the best position of the amplifier.

2. The application of two horizontal prism-tubes, one for use with high powers and the amplifier, and the other for use with low powers without the amplifier.

:3. The cross wires in the eyepieces for centering.

4. The making of bellows in sections to admit of their ready extension or removal

5. The making of the base in sections in connection with the coupling focussing rod.

6. The plate holder, which admits of all sizes of plates up to $6 \frac{1}{2} \times 8 \frac{1}{2}$ in.

7. The ability to use an eyepiece in place of the amplifier.

To those interested in the subject, we will send a pamphlet giving complete description on application.

37\%0, Professional Photo-Micro Camera. with tapering bellows and one section with ground glass, posterior and anterior rectangular tubes, one frame section, complete adjustments, one $6 \frac{1}{2} \times 8 \frac{1}{2}$ plate holder, one achromatic amplifier,

One additional sectional Bellows and Frame extra,

125.00

Mechanical stage \o. 1 \%28, with grooved pulleys for cords in place of plain stage, extra,

Plane and Concave Mirror with Attachments, extra,

Apparatus for instantaneous exposures, extra,

Sub-stage, with rack and pinion, extra,
Abbe Condenser, $1.20 \mathrm{~N}$. A., in mounting No. $16 \% 8$, extra,

“ $\quad 1.42 \mathrm{~N} . \mathrm{A}$.

Achromatic, 1.0 N. A., in mounting No. $16 \% \overline{8}$, extra, 


\section{PLANO OR DOUBLE CONVEX AND CONCAVE LENSES.} BEST QUALITY.

\begin{tabular}{|c|c|c|c|c|c|c|c|c|c|c|c|}
\hline N & & & & & & & & & & $\begin{array}{c}\text { Ground } \\
\text { edges } \\
\text { (not ceitered.) }\end{array}$ & $\begin{array}{l}\text { Perfectly } \\
\text { centered. }\end{array}$ \\
\hline 850 & $\frac{1}{16}$ in. diameter. & 1 in, foc & & - $\quad-$ & & - & & & - & $\$ .65$ & $\$ .90$ \\
\hline $5 ?$ & & $\frac{1}{4}$ in. to & & in. focus, & - & & - & - & & .65 & .90 \\
\hline 54 & $\frac{8}{16}$ in & $\frac{3}{8}$ in. to & & ocus, & & - & - & & - & 6.5 & .90 \\
\hline 56 & $\frac{1}{4}$ in. & $\frac{1}{2}$ in. to & & in. $f$ & - & & - & - & & .75 & 1.00 \\
\hline 358 & $\frac{3}{8}$ in. $d$ & $\frac{3}{4}$ in. to & & in. & & - & - & & - & .75 & 100 \\
\hline 60 & $\frac{1}{2}$ in. diameter, 1 & 1 in. to & & in. focus, & - & & - & - & & .75 & 1.00 \\
\hline 862, & $\frac{5}{8}$ in. diameter, 1 & $1 \frac{1}{4}$ in. to & & in. focus, & & - & & & - & .85 & 1.10 \\
\hline 364, & $\frac{3}{4}$ in. diameter, 1 & $1 \frac{1}{2}$ in. to & 1 & in. focus, & - & & - & - & & .85 & 1.10 \\
\hline 866, & 1 in. diameter, & 2 in. to & $1 \frac{1}{2}$ & in. focus, & & - & & & - & .85 & 1.10 \\
\hline 368 , & in. diameter, & in. to & 72 & in. focus, & - & & - & - & & .50 & .85 \\
\hline 370 & in. diameter, & in. to & 72 & in. foc & & - & & - & - & .60 & .95 \\
\hline 178 & in. diameter, 6 & in. to & 72 & in, foc & - & & - & - & & .75 & 1.25 \\
\hline & $\mathrm{r}, 12$ & in. to & 72 & in. $f$ & & - & & - & - & 1.25 & 1.75 \\
\hline &, 18 & in. to & 72 & & - & & - & - & & 1.75 & 2.25 \\
\hline &, 24 & in. to & 72 & & & - & & - & - & 2.50 & 3.00 \\
\hline &, 30 & & 72 & & & & - & - & & 3.0 & \\
\hline & in. diameter, 30 & in. to & 72 & in. focus, & & & & & & 4.00 & 4.75 \\
\hline
\end{tabular}

\section{DEMONSTRATION LENSES.}

No.

3890, Demonstration Lenses. A set of six $1 \frac{1}{2}$ in. diameter, showing the forms of the various kinds of lenses, viz: Double convex, double concave, plano convex, plano concave, Meniscus convex and Meniscus concave, in box,

3892, Demonstration Lenses. A set of ten, $1 \frac{1}{2} \mathrm{in}$. diameter, as above, in addition one lens each, cylindrical convex, cylindrical concave, spherical-cylindrical and prismatic, in box,

CONDENSING LENSES-PLANO CONVEX, GROUND EDGES.

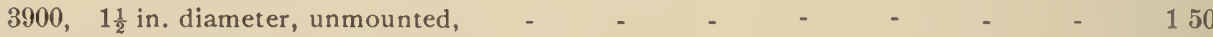

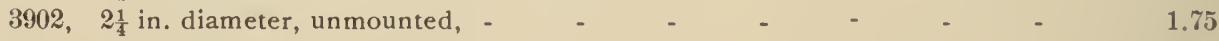
3904,3 in. diameter, unmounted, $\quad$ - $\quad$ - $\quad$ - $\quad$ - $\quad$ - $\quad$ - $\quad$ - 2.00 $3906, \quad 3 \frac{1}{2}$ in. diameter, unmounted, - $\quad \ldots \quad \ldots \quad \ldots \quad \ldots \quad \ldots$

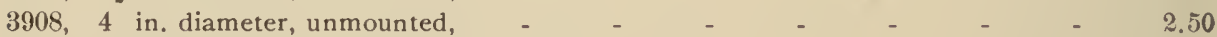

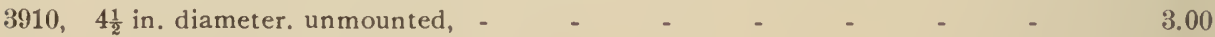

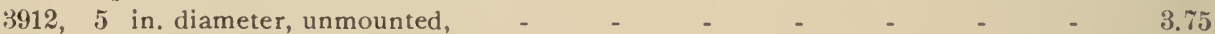

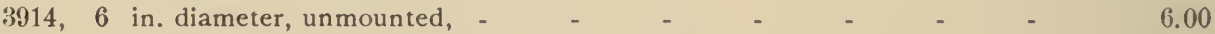

3916, 7 in. diameter, unmounted, $\quad$ - $\quad$ - $\quad$ - $\quad$ - $\quad$ - $\quad$ - $\quad$ - 10.00

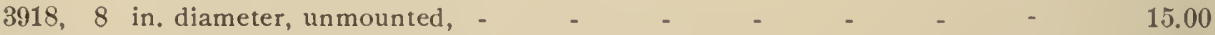

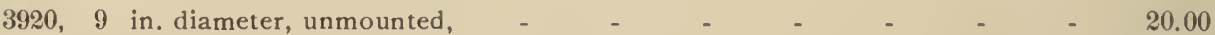

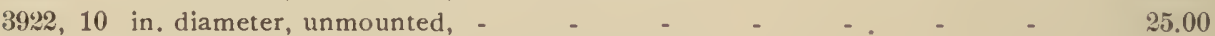

$3924,3 \frac{1}{2}$ in. diameter, one pair, mounted in brass cell, _ _ _ _ _ $\quad$ _ 7.00

3926, 4 in. diameter, one pair, mounted in brass cell, _ _ _ _ $\quad$ - 8.00

$3928,4 \frac{1}{2}$ in. diameter, one pair, mounted in brass cell, _ _ _ $\quad$ - 10.00

3930,5 in. diameter, one pair, mounted in brass cell, _ $\quad$ - $\quad$ - $\quad$ - $\quad 11.50$

3932, 6 in. diameter, one pair, mounted in brass cell, _ _ _ _ _ 1 - 1 . _.00 


\title{
CALCSPAR, QUARTZ, SELENITE AND MICA PREPARATIONS.
}

\author{
GUARANTEED OF THE BEST QUALITY.
}

\section{NICOL'S PRISMS, DIAGONAL FACE.}

No.

Price.

$3940,6 \mathrm{~mm}$, , opening angle $31^{\circ} 16^{\prime}$, each, $\$ 1.50$

$3942, \quad 7 \mathrm{~mm}$, opening angle $31^{\circ} 16$, each,

$3944,8 \mathrm{~mm}$, opening angle $31^{\circ} 16^{\prime}$, each,

3946, $9 \mathrm{~mm}$., opening angle $31^{\circ} 16$, each,

$3948,10 \mathrm{~mm}$. , opening angle $31^{\circ} 16^{\prime}$, each,

$3950,11 \mathrm{~mm}$, opening angle $31^{\circ} 16^{\prime}$, each,

$3952,12 \mathrm{~mm}$, opening angle $31^{\circ} 16^{\prime}$, each,

$3954,13 \mathrm{~mm}$, opening angle $31^{\circ} 16^{\prime}$, each,

\section{NICOL'S PRISMS, SQUARE FACE, WIDE FIELD.}

39.58, $6 \mathrm{~mm}$, opening angle $31^{\circ} 16^{\prime}$, each, - $\quad$ - $\quad$ - $\quad$ - $\quad$ - 1.75

$3960,7 \mathrm{~mm}$., opening angle $31^{\circ} 16$, each, _ _ $\quad$ - $\quad$ - $\quad 2.00$

$3962,8 \mathrm{~mm}$, opening angle $31^{\circ} 16^{\prime}$, earh, - _ _ _ _ $\quad$ - 2.50

3964, $9 \mathrm{~mm}$., opening angle $31^{\circ} 16^{\prime}$, each, _ _ _ $\quad$ - $\quad 3.00$

$3966,10 \mathrm{~mm}$.. opening angle $31^{\circ} 16^{\prime}$, each, _ _ _ _ _ _ $\quad 3.75$

$3968,11 \mathrm{~mm}$, opening angle $31^{\circ} 16^{\prime}$, each. $\quad$ - $\quad$ - $\quad$ - $\quad$ - $\quad$ - 4.50

$3970,12 \mathrm{~mm}$., opening angle $31^{\circ} 16^{\prime}$, each, - _ _ _ _ $\quad 5.00$

$3972,13 \mathrm{~mm}$, opening angle $31^{\circ} 16^{\prime}$, each, _ $\quad$ - $\quad$ - $\quad$ - $\quad$ - $\quad 6.00$

39ז4, $14 \mathrm{~mm}$., opening angle $31^{\circ} 16^{\prime}$, each, _ _ _ _ _ $\quad$ - 7.00

3976, Quartz Wedge Compensator mounted on glass plate, $55 \times 14 \mathrm{~mm}$., each, $\quad 6.00$

3978 , Quartz Wedge, $12 \mathrm{~mm}$. wide, $32 \mathrm{~mm}$. long, colors 1 to 3 order, _ _ $\quad 6.00$

3980, Quartz Wedge, $12 \mathrm{~mm}$. wide, $32 \mathrm{~mm}$. long, colors 3 to 5 order, _ _ $\quad 6.00$

3982, Quartz Wedge, $12 \mathrm{~mm}$. wide, $32 \mathrm{~mm}$. long, colors 1 to 6 order, _ _ $\quad 6.00$

3984, Quartz Wedge, $12 \mathrm{~mm}$. wide, $45 \mathrm{~mm}$. long, colors 1 to 3 order, - $\quad$ - $\quad 8.00$

3986, Quartz Wedge, $12 \mathrm{~mm}$, wide, $45 \mathrm{~mm}$. long, colors 3 to 5 order, . - _ $\quad 6.00$

3988, Quartz Wedge, $12 \mathrm{~mm}$. wide, $45 \mathrm{~mm}$. long, colors 1 to 4 order, - $\quad$ - $\quad 6.00$

Number 3978 to 3988 are made to order only.)

3990, Quartz Plate, Bertrand's quadrant, $24 \mathrm{~mm}$. diameter, mounted, each, $\quad-\quad 10.00$

3992, Gypsum Plate, red of the first order, $12 \mathrm{~mm}$. diameter, unmounted, each, $\quad 2.00$

3994, Bertrand's Lens, for magnifying the interference figure, mounted, - $\quad 2.50$

3996, Selenite films, $18 \mathrm{~mm}$. diameter, unmounted, red and green, - _ _ $\quad 1.50$

3998. Selenite films, $18 \mathrm{~mm}$. diameter, unmounted, blue and yellow, _ _ $\quad 1.50$

4000, Selenite films, $18 \mathrm{~mm}$. diameter, unmounted, purple and green, _ _ $\quad 1.50$

4002, Quarter Undulation mica plate, $12 \mathrm{~mm}$. diameter, unmounted, - $\quad$ - $\quad 2.00$ 


\section{TELESCOPE OBJECTIVES, GUARANTEED OF FINEST QUALITY.}

No.

4010, 1 in. diameter, $5 \frac{1}{4}$ in. focus, mounted in cell,

$4012,1 \frac{3}{16} \mathrm{in}$. diameter, $T$ in. focus, mounted in cell,

4014, $1 \frac{3}{16}$ in diameter, 8 in. focus, mounted in cell,

4016, $1 \frac{3}{8}$ in. diameter, 11$\}$ in. focus, mounted in $c \cdot 11$,

4018, $1 \frac{3}{s}$ in. diameter, $14 \stackrel{1}{1}$ in. focus, mounted in cell,

$402 \prime, 1 \frac{3}{8}$ in. diameter, $16 \frac{1}{2} \mathrm{in}$. focus, mounted in cell.

$4022, \quad 1 \frac{1}{2}$ in. diameter, 20 in. focus, mounted in cell,

4024,2 in. diameter, 24 in. focus, mounted in cell,

4026, $2 \frac{1}{2}$ in. diameter, 30 in. focus, mounted in cell,

4028,3 in. diameter, 42 in. focus, mounted in cell,

4030, $3 \frac{1}{2}$ in. diameter, 48 in. focus, mounted in cell,

4032,4 in diameter, (io) in. focus, mounted in cell,

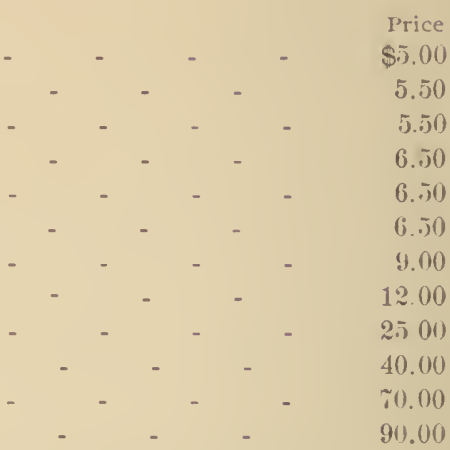

All of the above objectives of $1 \frac{1}{2} \mathrm{in}$. and larger diameter we make to order, and are of a quality which will equal the best extant. The foci for the different sizes are in our opinion the most desirable, but may be changed according to the wish of the purchaser.

\section{ACCESSORIES FOR TELESCOPES.}

4040, Celestial Eyepieces, Huyghenian, any power, $\quad$ - $\quad$ - $\quad$ - $\quad$ - 4.00

4042, Celestial Eyepieces, Periscopic, any power, _ - $\quad$ - $\quad$ - $\quad$ - 10.00

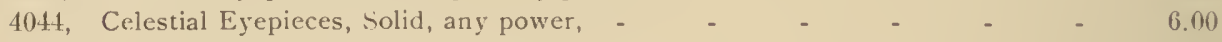

4046, Comet Eyepieces, Periscopic, large field, _ _ _ $\quad$ - $\quad$ - $\quad$ - $\quad 15.00$

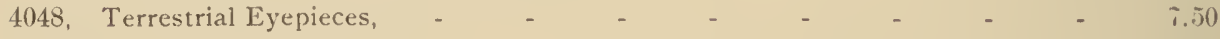

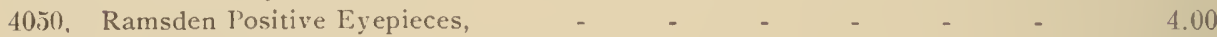

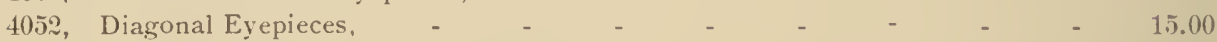

4054 , Sun-shade, fitted to either of the above, $\quad$ - $\quad \ldots \quad$ _ $\quad \ldots$

4056 , Sun-shade, wedge shape, giving intermediate tints between light and very dark, 4.50

4058, Finder, with objective $1 \frac{8}{16}$ in. diameter, with cap, in lacquered tube, with draw-

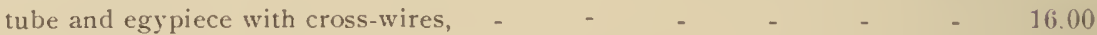

4060, Same as 4058 , with the addition of centering standards, $\quad$ - $\quad$ - $\quad 20.00$

We also make to order tubes with and without rack and pinion adjustment suitable for any size objectives : also portable and fixed equatorial mountings in iron or brass, which are adapted to objectives up to $6 \mathrm{in}$. aperture. They are from new patterns of exceedingly neat design. It will give us pleasure to furnish estimates on application.

\section{RECTANGULAR PRISMS-CROWN GLASS.}

$40 \% 0, \frac{1}{4}$ in. square, face $90^{\circ}$,

$40 \% 2, \frac{1}{2}$ in. square, face $90^{\circ}$,

$4074, \frac{3}{4}$ in. square, face 90 ,

4076,1 in. square, face 90 ,

$40 \% 8,1 \frac{1}{4}$ in. square, face 90 ,

$4080,1 \frac{1}{2}$ in. square, face 90 ,

$4082,1 \frac{3}{4}$ in. square, face $90^{\circ}$. 


\section{ACHROMATIC TRIPLETS AND CODDINGTON MAGNIFIERS.}
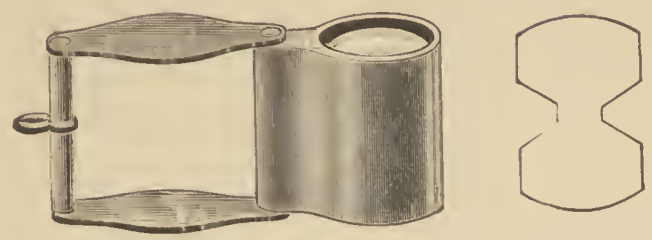

No. 345.
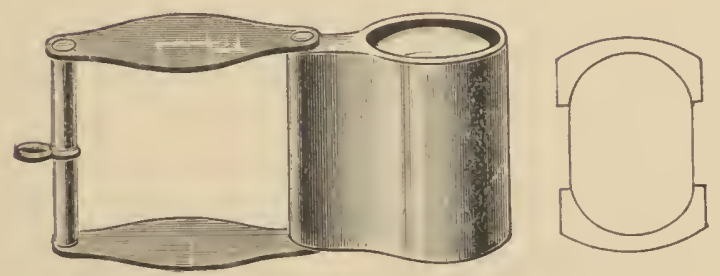

No. 350.

No.

340, Coddington Magnifier, $\frac{1}{2}$ in. focus, in German silver mounting,

345 , Coddington Magnifier, $\frac{3}{4}$ in. focus, in German silver mounting,

350 , Coddington Magnifier, 1 in. focus, in German silver mounting,

35̃, Coddington Magnifier, 2 in. focus, in German silver mounting,

360 , Doublet Magnifier, new construction, giving large and flat field,

370, Achromatic Triplet, $\frac{1}{2}$ in. focus, in German silver mounting,

375, Achromatic Triplet, $\frac{3}{4}$ in. focus, in German silver mounting,

3s0, Achromatic Triplet, 1 in. focus, in German silver mounting,

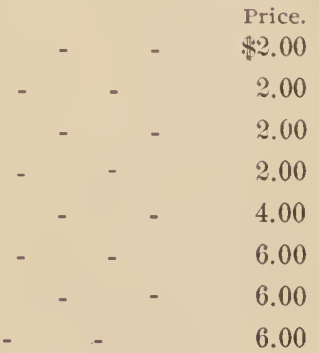

The above Coddington Magnifiers are of the best possible construction, and are made with great care throughout. Although the size of the field is limited, it is flat and the definition excellent.

The Achromatic Triplets are, as their name implies, thoroughly achromatic systems composed of one crown and two flint glass lenses cemented together. The image given by them is the nearest approach to that given by the compound microscope, and for preliminary examinations where powers up to twenty diameters are required, will well take the place of low-power objectives. They give a very large and flat fleld, have great depth of focus, and give perfect definition even when the optical axis is held at great obliquity. 


\section{MA G N I F I ERS.}

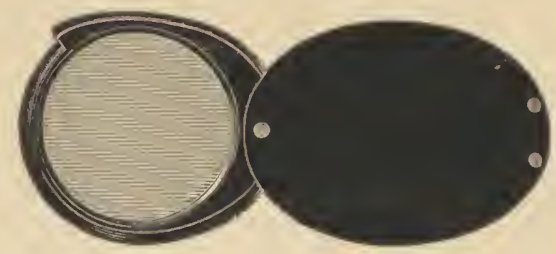

No. jo.

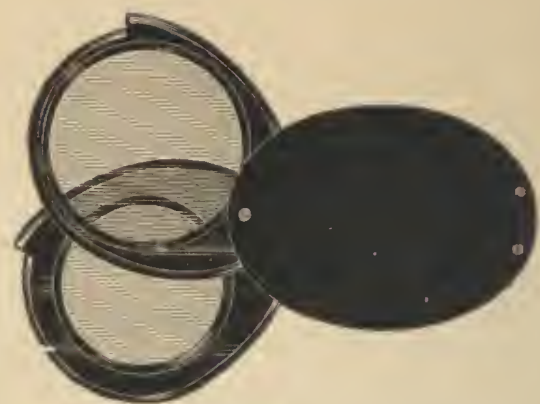

Ni1. 51.

No.

50, Rubber Case,

size of glass, $\frac{5}{4}$ in. diameter,

Price.

56, Rubber Case, same as No 50, size of glass, 1 in. diameter,

$\$ .30$

62, Rubber Case. same as No. 50 , size of glass, $1 \frac{1}{4}$ in. diameter,

.40

68, Rubber Case, same as No. 50, size of glass, $1 \frac{1}{2}$ in. diameter,

74, Rubber Case, same as No. 50, size of glass, $1 \frac{3}{4}$ in. diameter,

78, Rubber Case, same as No. 50, size of glass, 2 in. diameter,

51, Rubber Case,

size of glasses, $\frac{5}{8}$ and $\frac{3}{4} \mathrm{in}$. diameter,

57. Rubber Case, same as No. 51, size of glasses, $\frac{z}{8}$ and 1 in. diameter.

63, Rubber Case, same as No. 51, size of glasses, $1 \frac{1}{8}$ and $1 \frac{1}{4}$ in. diameter,

69, Rubber Case, same as No. 51, size of glasses, $1 \frac{1}{4}$ and $1 \frac{1}{2}$ in. diameter,

75. Rubber Case, same as No. 51, size of glasses, $1 \frac{1}{2}$ and $1 \frac{3}{4}$ in. diameter,

79, Rubber Case, same as No. 51. size of glasses, $1 \frac{3}{4}$ and 2 in. diameter,

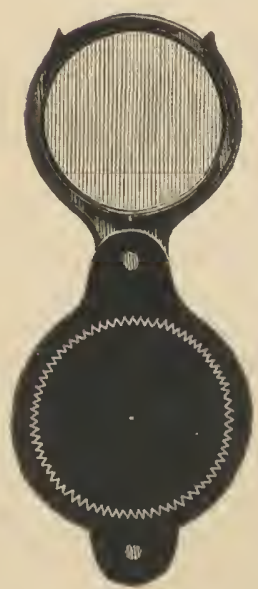

No. 101.

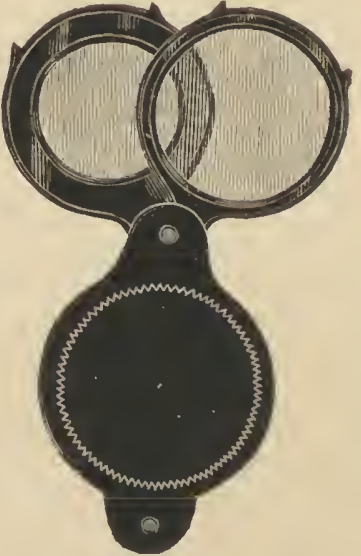

No. 102.

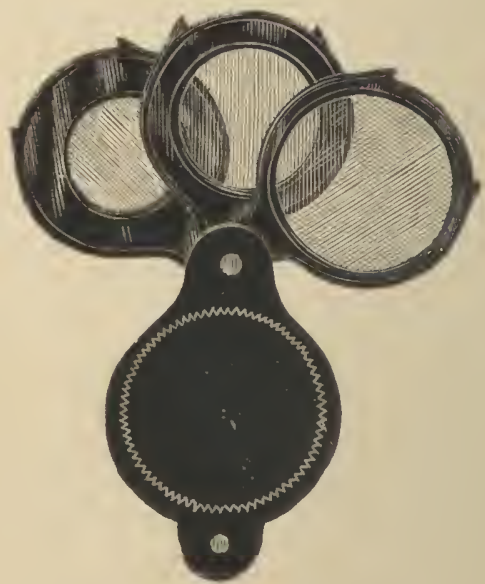

No. 103 .

101. Rubber Case, size of glass, $\frac{3}{4}$ in. diameter,

110, Rubber Case, same as 101 , size of glass, $\frac{\tau}{8}$ in. diameter,

119. Rubber Case. same as 101 , size of glass, 1 in. diameter,

102, Rubber Case,

size of glasses, $\frac{5}{8}$ and $\frac{3}{4}$ in. diameter,

111, Rubber Case, same as 102 , size of glasses, $\frac{3}{4}$ and $\frac{7}{8}$ in. diameter

120. Rubber Case, same as 102 , size of glasses, $\frac{7}{8}$ and 1 in. diameter,

11):3, Rubber Case, size of glasses, $\frac{1}{2}, \frac{5}{8}$ and $\frac{3}{4}$ in. diameter,

1I 2 , Rubber Case, same as 103 , size of glasses, $\frac{5}{8}, \frac{3}{4}$ and $\frac{7}{8}$ in. diameter,

121, Rubber Case, same as 103 , size of glasses, $\frac{3}{4}, \frac{7}{5}$ and 1 in. diameter, 


\section{A G N I FI ERS.}

No. Price. 56 A, Aluminum Case, (shape and size of No. 56), - $\quad$ - $\quad-\quad$ - $\quad$ - $\$ .60$ $101 \mathrm{~A}, \mathrm{Aluminum} \mathrm{Case,} \mathrm{(shape} \mathrm{and} \mathrm{size} \mathrm{of} \mathrm{No.} \mathrm{101),} \quad$ - $\quad$ - $\quad$ - $\quad$ - 60 $110 \mathrm{~A}$, Aluminum Case, (shape and size of No.110), - $\quad$ - $\quad$ - $\quad$ - $\quad .75$ 102 A, Aluminum Case, (shape and size of No. 102), $\quad$ - $\quad-\quad$ - $\quad$ - $\quad .90$ $111 \mathrm{~A}$, Aluminum Case, (shape and size of No. 111), _ _ _ _ _ $\quad$ - 1.10

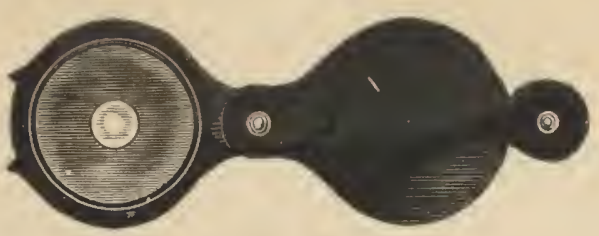

No. 125 .

128, Rubber Case, with diaphragm ; single lens,

129, Rubber Case, with diaphragm, size of No. 128 ; two lenses,

130, Rubber Case, with diaphragm, size of No. 128; three lenses,

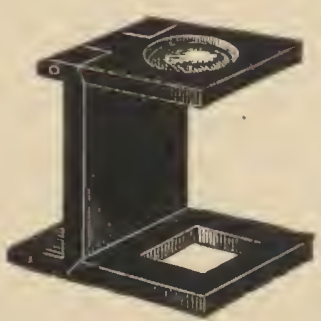

No. 143.

141. Linen-Prover, Brass, with 1 in. open square,

142, Linen-Prover, Brass, with $\frac{1}{4} \times \frac{1}{2}$ in. open square,

143, Linen-Prover, Brass, with $\frac{1}{4}$ in. open square, $143 \frac{1}{2}$, Linen-Prover, Brass, with round openings,

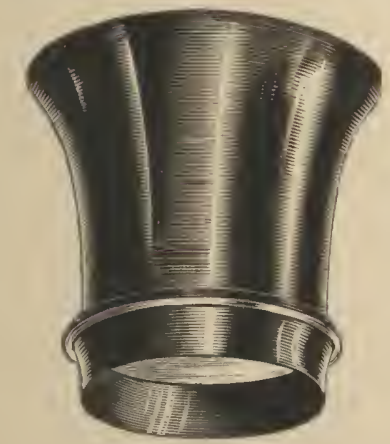

No. 144 .

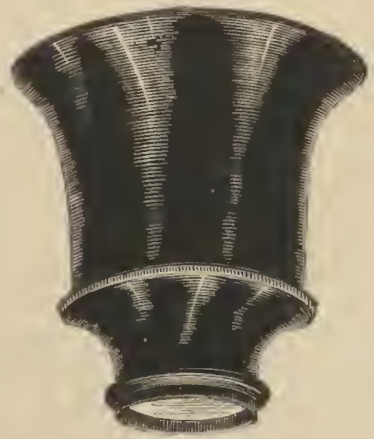

Yo. 144 A.

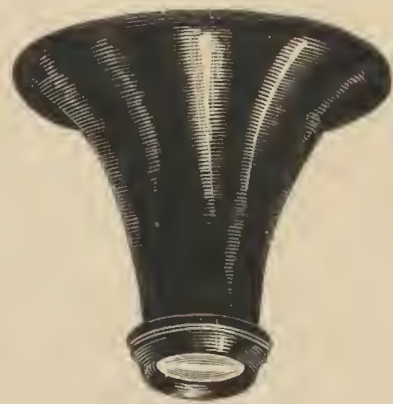

No. $1441 / 2$.

144, Watchmaker Glasses, assorted (three sizes and different focus), each, _ $\quad .40$

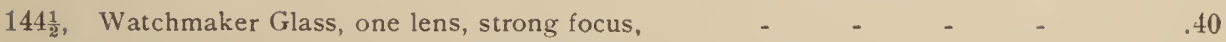

144A, Watchmaker Glass, with two lenses, giving two powers, _ - _ - $\quad .75$

144 L. P., Watchmaker Glasses, with springs, (three sizes and different focus), each, $\quad .60$ 


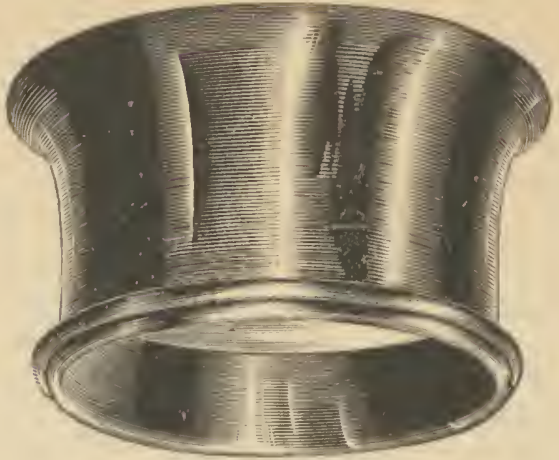

No. 146 .

No.

14.5, Engraver Glass, with double plano-convex lenses, $1 \frac{3}{8}$ in. diameter,

146, Engraver Glass, with double plano-convex lenses, $1 \frac{5}{5}$ in. diameter,

147, Engraver Glass, with double plano-convex lenses, $1 \frac{\tau}{8}$ in. diameter,

148, Engraver Glass, with double plano-convex lenses $2 \frac{1}{\%} \mathrm{in}$. diameter,

145A, Engraver Glass, with single double-convex lens, $1 \frac{3}{8}$ in, diameter.

146A, Engraver Glass, with single double-convex lens, 15 in. diameter.

14iA, Engraver Glass, with single double-convex lens, $1 \frac{\tau}{6}$ in. diameter.

148A, Engraver Glass, with single double-convex lens, $2 \frac{1}{8}$ in. diameter,

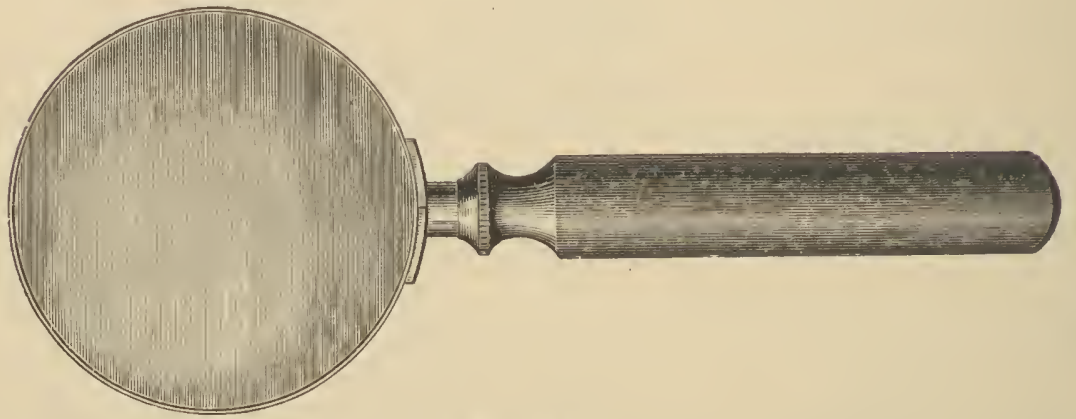

No. 25.).

Metal Frame, size of glass, 2 in. diameter, Black enamcled No Price

Metal Frame, size of glass, $2 \frac{1}{4}$ in. diameter $252, \$ .80$ lvory Zilonite
handle io. risce Metal Frame, size of glass, $2 \frac{1}{4}$ in. diameter, $253, \quad .90$ $2 \% 0, \quad \$ 120$

Metal Frame, size of glass, $2 \frac{1}{2}$ in. diameter, 254. $\quad 1.00$

$2 \approx 1, \quad 1.30$

Metal Frame, size of glass, $2 \frac{3}{4}$ in. diameter,

Metal Frame, size of glass, 3 in. diameter,

$255, \quad 1.25$

2\%2, 1.41"

Metal Frame, size of glass, $3 \frac{1}{4}$ in. diameter,

$256, \quad 1.50$

$273, \quad 1.75$

Metal Frame, size of glass, $3 \frac{1}{2}$ in. diameter,

$25 \%, \quad 1.55$

$2 \pi 4, \quad 2.00$

$2.58, \quad 2.00$

$275, \quad 2.35$

Metal Frame, size of glass, $3 \frac{3}{4}$ in. diameter,

$259, \quad 2.25$

$2 \% 6, \geqslant \tau$

Metal Frame, size of glass, 4 in. diameter,

$260, \quad 2.50$

$2 \because, \quad 3.00$

Metal Frame, size of glass, $4 \frac{1}{2}$ in. diameter,

$261, \quad 3.25$

2ะ8, 325

Metal Frame, size of glass, 5 in. diameter,

$262, \quad 4.00$

2ร9, 4.00

Metal Frame, size of glass, $5 \frac{1}{2}$ in. diameter,

$263, \quad 5.00$

$280, \quad 5.00$

Metal Frame, size of glass, 6 in. diameter.

$264, \quad 6.00$

$281, \quad 6.00$

$2 \$ 2, \quad \div .00$ 


\section{A Glassified List of}

\section{Fipst-Glass Iligrosgope Objegts.}

In revising this list and classifying the subjects and studies represented, we have been guided altogether by the demand of the past years, and only enumerate such preparations as are most generally called for by the busy microscopist who has not the time to prepare them himself. We have made arrangements with reliable and, in their line of study, representative parties to prepare these objects for us, and we offer only the very best obtainable in quality and finish of mount. It shall be our endeavor to carry the stock as complete as possible, and thus avoid all vexatious delays in the filling of orders. It will give us pleasure to send out a reasonable number of objects for examination and selection to any person known to us, giving good references, with the understanding that he bear the cost of transportation and loss of breakage.

We preface the Educational Series with remarks, to which we beg to call your attention. In many instances these preparations will fill all need fully as well for demonstration purposes as some of the best quality, and we can recommend them to give good satisfaction.

Where so stated, we will put up sets of preparations according to the number given, in a neatly finished wooden case with trays, and in such cases will leave the selection entirely to the purchaser. All subjects classified are considered typical slides in their respective series. 


\section{HISTOLOGICAL SERIES.}

No. 4.500. Each, 75 cents ; per dozen, $\$ 7.50$; set of 24 in case with trays, $\$ 15.00$.

Aorta, Normal, Human.

Bladder, Human.

Bone, Adult, Longitudinal,

$$
\text { “ “ Transverse. }
$$

“ Developing.

Brain, Cerebellum, Normal, Human.

“ Cerebrum, " "

" Medulla, “ “

Cartilage, Elastic.

. Hyaline.

Compound Lymphatic Gland.

Crystalline Lens, Human, showing ultimate fibre.

Endothelimn.

Epithelium, Columinal. " Squamous.

Finger-Nail.

Heart, Normal, Human.

Ileum, Human.

Intestine, Injected, Cat.

$$
\text { “ Normal, Human. }
$$

Kidney, Injected, Human.

$$
\text { “ Normal, “ }
$$

Liver, Bile Ducts, Injected.

$$
\text { “ Normal, Human. }
$$

Lung, “ “

Mammary Gland, Normal, Human.

Membrane, Mucous.

$$
\text { “ Serous. }
$$

Muscle, Striated.
Muscle, Unstriated.

Nerve Cells.

Nerve Fibres.

Nerve, T. S. Normal, Human.

Oesophagus.

Optic Nerve, Trans. Sect.

Ovary, Normal, Human.

Pancreas, “ ‘

Pigment Cells.

Scalp, Human, Caucasian.

$$
\text { " " Negro. }
$$

Skin, Human, African

$$
\text { “ " Caucasian. }
$$

Spinal Cord, Trans. Sec., Normal, Human.

$$
\text { " " Long. Sec., " " }
$$

Spleen.

Stomach.

Supra-Renal Body, Normal Human.

Tendon Cut, Transverse.

$$
\text { “ “" (Teased). }
$$

Testicle, Normal, Human.

Thyroid Lymphatic Gland.

Tissue, Adipose.

“ Adult, Connective,

“ Embryonal, Connetive.

“ Growing,

“Yellow, Elastic.

Tooth, Longitudinal.

“Transverse.

Uterus, Normal, Human.

\section{PATHOLOGICAL SERIES.}

No. 4502 . Each, 75 cents ; per dozen, $\$ 7.50$; set of 24 in case with trays, $\$ 15.00$.

Brain, Cerebrum, General Paralysis.

“ " Softening.

“ Medulla Oblongata, Locomotor A taxia.

“ Pons Varolii, Diabetes.

Heart, Fatty Degeneration.

" Fatty Infiltration.

Intestine, Enlarged Peyers Patch.

" Tubercular.

Kidney, Acute Catarrhal Nephritis.

“ Amyloid.

“ Chronic, Bright's Disease.

“ Chronic Catarrhal Nephritis.

“ Interstital Nephritis.

Liver, Amyloid Degeneration.

" Carcinoma.

“ Cirrhosis.

" Fatty Degeneration.

“ " Infiltration.

Lung, Acute Catarrhal Pneumonia.
Lung, Acute Miliary Tuberculosis.

“ Catarrhal Pneumonia and Tuberculosis.

“ Croupous Pneumonia, 1st stage.

" " “

" " " 3 3rd stage.

" Fibroid Phthisis.

“ Haemorrhagic Infarction.

“ Solitary Tubercle.

“ Nailer's Consumption.

Muscle, Trichinous.

Skin, Lupus Vulgaris.

" Scarlet Fever.

Spinal Cord, General Paralysis.

“ “ Hydrophobia.

Spleen, Amyloid.

" Leukaemia.

Thyroid Glands, Colloid Degeneration.

Tongue, Epithelioma.

Tonsil, Hypertrophy. 


\section{TUMOR SERIES.}

No. 4504 . Each 75 cents; per dozen, $\$ 7.50$; in set of 24 in wooden case, $\$ 15.00$.

Adenoma, Breast.

$$
\text { “ Cystic, Ovary. }
$$

Carcinoma, Encephaloid, Breast.

“ Endothelial. “"

" Scirrhus,

Chondroma, Testicle.

Epithelioma, Cylindrical, Rectum.

$$
\text { " Squamous, Lip. }
$$

Fibroma, hard, Palm of hand.

$$
\text { . soft, Back of Neck. }
$$

Glioma, Cerebrum.

Myoma, Leio., Uterus.
Myoma, Rhabdo., Kidney.

Neuroma, Thigh after Amputation.

Osteoma, Left Frontal Region.

Papilloma, hard, Face.

$$
\text { " soft, Bladder. }
$$

Sarcoma, Giant Cell, Head of Humerus.

“ Large Spindle Cell, Elbow.

“ Melanotic, Eye.

“ Osteo, Knee Joint.

“ Small Round Alveolar, Neck.

" Small Round Cell, Arm.

“ Small Spindle Cell, Jaw.

\section{BACTERIOLOGICAL SERIES.}

No. 4506. Each, 85 cents; per dozen, $\$ 9.00$ : set of 24 in case with trays, $\$ 18.00$.

Anthrax, Bacillus.

“ Blood of Guinea-Pig(Gram's method).

“ Colonies.

“ Liver, (section).

“ Spleen, “

" Threads and Spores.

Bacillus Anthracis in Kidney.

“ of Chicken Cholera.

“ of Glanders.

“ of Green Pus.

“ of Hog Erysipelas.

“ of Malignant Oldema.

“ of Swine-Plague (Am.)

، of Symptomatic Anthrax.

" of Tetanus.

“ Leprosy in Ear.

. Leprosy in Skin.

“ Tuberculosis.

“ Tuberculosis in Human Lung, (sec.)
Bacillus Tuberculosis from Lung Cavity. “ Tuberculosis, Pure Culture. " " in Sputum.

Comma Bacillus.

Comma Bacillus with Flagella.

Deneke's Bacillus.

Eberth's Bacillus of Typhoid Fever.

Emmerich's Bacillus.

Finkler-Prior's Bacillus.

Fraenkel's Pneumococcus.

Friedlander's Pneumobacillus.

Gonococcus.

Löffler's Diphtheria Bacillus.

Micrococcus Tetragenus.

Prudden's Diphtheria Streptococcus.

Spirilla and Vibriones.

Staphylococcus pyog. Aureus.

Streptococcus Erysipelatis.

Vibrio Metschinkoff.

\section{BLOOD, SPERMATOZOA AND URINARY DEPOSITS.}

No. 4.)0S. Each, 60 cents ; per dozen, $\$ 6.00$.

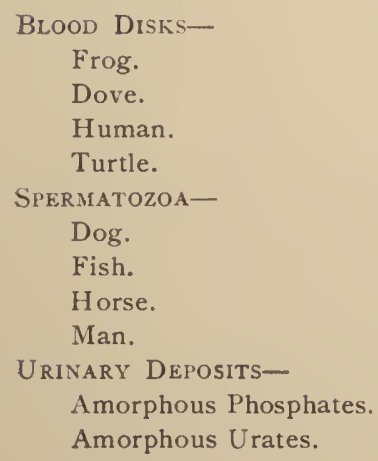

\section{URINARY DEPOSITS-}

Chlopide of Sodium.

Carbonate of Lime.

Cystirue.

Epithelium.

Glucose.

Leusine.

Mucus.

Murexide.

Nitrate of Urea.

Oil Globules.

Oxalate of Lime, Dum-bell.

Oxalate of Lime, Octahedral.
URINARY DEPOSITS. Phosphate of Lime. Phosphate of Calcium. Phosphate of Soda.

Pus.

Sugar in Diabetes.

Triple Phosphate.

Tube Casts.

Tyrosine.

Urate of Ammonia.

Urate of Soda.

Urea.

Uric Acid. 


\section{PARASITIC I NSECTS.}

No. 4510. Each, 50 cents ; per dozen, \$5.00.

Bed-I3ug, Cimex lectularius, Male.

$$
\text { " " " Female. }
$$

Body Louse, Pediculus vestimenti.

Crab Louse, I'ediculus pubis, Male.

$$
\text { " " " " Female. }
$$

Face Insect, Demodex folliculorum.

Flea of Cat, Pulex felis.

Flea of Dog, Pulex canis.

Flea of Man, Pulex irritans, Male.

Flea of Man, I'ulex irritans, Female.
Head Louse, Pediculus capitis, Male.

$$
\text { " } \text { " }
$$$$
\text { “ ‘ “ “ “ Figg. }
$$

Itch Insect, Sarcoptes scabiei, $\$ 1.00$.

$$
\text { “ " " " Male, Female }
$$
and Iarva, (\$2 50).

Itch. Insect, Sarcoptes scabiei, Male, Female, Male, Female, Egg and Larva, $(\$ 3.0(1)$.

I'arasite of Bee.

Sheep Thick, Melophagus ovinus.

\section{PARTS OF INSECTS.}

No. 4512. Each, 50 cents; per dozen, \$5.00.

Antennae, Blow Fly.

Eggs, Butterfly.

Eyes, Beetle.

“ Green Head Fly.

“ House Fly.

Foot, Green Head Fly.

“Water lieetle.

Gizzard, Cockroach.

“ Cricket.

Head, Blow Fly.

“ Mosquito, Male, (showing Antennae).

“ " Female, (showing Lancets).

Lancets, Green Head Fly.

Leg and Foot, Blow Fly.

“، “" Honey Bee.

“ " " " Spider.

Mouth Parts, Honey Bee.

Proboscis, Blow Fly, ( 75 cents).

“ Bumble Bee.
Proboscis, Honey Bee. House Fly.

Scales, Butterfly.

“ Mosquito.

“ Lipisma saccharina, (60 cents).

“ l'odura Plumbea, ( 15 cents).

Spinnerets, Spider.

Spiracle, Blow Fly.

“ Cricket.

“ Tomato Worm.

Sting, Bumble Bee.

“Honey Bee.

Trachea, Potato Bug, showing hairs.

“ Water Beetle.

Wing, Bee, showing hooklets.

“ Butterfly,

“ Honey Bee.

“Mosquito.

\section{SECTIONS OF AMERICAN WOODS.}

No. 4514. Each, 60 cents; per dozen. $\$ 6.00$.

Apple, Pyrus Malus.

Ash, Fraxinus Americana.

Asp, Populus tremuloides.

Balm of Gilead, Populus Balsamifera.

Basswood, Tilia Americana.

Bay, Magnolia glauca.

Beech, Fagus ferrugniea.

Birch. Betula, papyracea.

Box, Buxus, sempervirens.

Buckwheat Tree, Cliftonia ligustrina.

Cedar, Torreya taxifolia.

Cherry, Prunus Pennsylvanica.

Chestnut, Castanea vesca.

Cottonwood, Populus monolifera.

Cucumber Tree, Magnolia acuminata.

Cypress, Taxodium distichum.

Dogwood, Cornus florida.

Elder, Negundo aceroides.

Elm, Ulmus Americana.
Fir, Abies Balsamea.

Hickory, Carya alba.

Holly, Ilex Opaca.

Ironwood, Carpinus Caroliniana.

Laurel, Magnolia Grandiflora.

Lime, Nyssa Capitata,

Linden, Tilia Europaea.

Locust, Robinia Pseudacacia.

Maple, Acer saccharinum.

Oak, Quercus alba.

Persimmon, Diospyros Virginiana.

l'ine, Pinus resinosa.

Poplar. Populus alba.

Sassafras, Sassafras officinale.

Spruce, Abies nigra.

Sycamore, Platanus occidentalis.

Tamarack, I arix Americana.

IValnut, Juglans nigra.

Willow, Salix alba. 


\section{VEGETABLE KINGDOM.}

No. \$̋16. In two Series of 24 preparations each, illustrating the structure of the higher order of plants. Each, 60 cents; set of $2 t$ in case with trays, \$12.00.

Series I on structure, illustrating plant anatomy. This shows the most important features of plant structure, from the simple cell and its contents, to the most elaborate tissue formations. The student starts with the cell, studies its structure and contents, then takes up iell aggregates or tissues, and finally tissue systems. 'The arrangement being according to Prof. Bessey's Botanies. The practical studies given in his books have been followed where possible, so as to make the set fit the text and work there given. The "mounts" have been prepared to show some special feature plainly and correctly, but at the same time care has been taken to make the "mounts" comprehensive, so that each one is valuable for a number of practical studies, at the same time showing the relation of the various tissues and tissue systems to each other in the plant body.

THF CELL ANI) ITS PROIICTS.

1. Protoplasm and nucleus, stained, showing chromation threads, Long. sec. of Pine Cone.

2. Cell-Walls. Black rust spores of wheat. (See also 4.)

3. Cell-formation by budding. Ferment of Wine (yeast) stained.

4. Chlorophyll. Leaf of Moss.

j. Starch and Aleurone in cross section of Pea. Stained.

6. Crystals of Cactus fruit (aggregate) and prisms in scale of Onion bulb. Tissuly.

^ Parenchyma (soft tissue), sunflower pith.

8. Collenchyma (thick angled), cross section of stem of white water lilly.

9. Sclerenchyma (stony tissue, long. and cross section of hickory-nut shell.)

10. Fibrous tissue, cross and long. section of maple, showing bast and wood, (stained).

11. Laticiferous (milk tissue), Euphorbia.

12. Sireve tissue, cross and long. section of squash stem.

TRACIIEARY.

13. Spiral ringed, etc., in longitudinal section of Impattens sp.
14. Scalariform vessels, cross and long. section of Pteris aquilena (underground stem).

15. l'itted vessels Nicotinna glaucer. (See also 16 and 12.$)$

16. Tracheids in Douglas Spruce. PRIMARY MERISTEM.

17. Growing point; long. section from tip of corn root.

SYSTENS OF TISSTES-EPIDERMAL.

18. Epidermis of "Liveforever" leaf ; top view showing stomata and cells, also cross section showing guard cells of stomata.

19. Epidermis of Fiens elastica, showing thickened epidermal walls and stomata in cross section. Many of these sections show fine cystoliths.

20. Hairs, various kinds on one slide. FIBR? VASCULAR SYSTEM.

21. Bundle of corn, cross and long. section.

22. Bundle of "ground-pine," Lycopodium dendroideum.

INTERCELLULAR SI'ACES.

23. Star-shaped cells and spaces, cross section yellow pond lily. (See also 8 ).

24. Turpentine canals in leaf of pine.

*The fundamental system may be studied from $1,3,7,8$ and others, 


\section{VEGETABLE KINGDOM-Continued.}

Series II illustrating "The Vegetable Kingdom." Starts with the lowest plants and shows typical representatives of the various classes throughout the Kingdom. Great care has been taken to make each specimen complete.

CYANOPHYCEAE.

1. C'scillaria.

2. Bacteria.

CHLOROPHYCEAE.

3. Protococcus viridis.

4. Desmids.

5. Spirogyra sp.

6. Rhizopus nigricaus.

7. Euteromorpha intestinallis.

8. Vaucheria sessilis.

9. Peronospora parasitica.

PHAEOPHYCEAE.

10. Lauimaria, (cross sectic $\mathbf{n}$ ).

11. Fucus vesiculosis, (cross section).

FLORIDEAE.

12. Coleochaete sp.

13. Ectocarpus littorales, (red sea-weed).

14. Chara, in fruit.

$$
\text { CIIARACEAE. }
$$

ASCOMYCETES.

15. Lichen, vertical section of fruit of Physcia stellaris.
BASIDIOMYCETES.

16. Cross section of gills of Ayaricus sp. showing spores, etc.

\section{HEPATICAE.}

17. Marchantia polymorpha.

MUSCI.

18. A moss showing leaves and fruit EQUISETINAE.

19. Equisetum arvense, long. section of cone.

\section{FILICINAE.}

21. Prothallium of fern.

21. Sori of fern.

LYCOPODINAE.

22. Selaginella sp.

GYMNOSPERMAE,

23. Pine cones, male and female, long. section.

\section{ANGIOSPERMAE.}

24. Long. section of flower and fruit of sunflower.

\section{MINERAL SERIES.}

No. 4518. Each, $\$ 1.00$; set of 15 in box, $\$ 1450$.

Selected preparations constituting a small set of typical mineral slides.

Serift Granite (Graphic Granite).

Melitite Basalt.

Noseau Phenolite.

Eustalite diabase.

Harzburgite.

Hypersthene Anderite.

Pitchstone.

Uralite Porphyrite.
Perlite.

Syenite.

Andalusite Schist.

Ottrelite Schist.

Cyanite granulite.

Cordierite Gneiss.

Topaz Tourmaline rock.

Mounted on glass slips $45 \times 26 \mathrm{~mm}$.

We can also supply the complete "Standard Collections" as recommended by Prof. C. Klein and H. Rosenbusch, upon import order, however, only. These comprise :

4520, 1st Collection-115 thin sections of the must important petrographical minerals, mounted on glass slips $45 \times 26 \mathrm{~mm}$.

4522, 2nd Collection-314 thin sections of igneous rocks, mounted on glass slips $45 \times 26 \mathrm{~mm}$.

To institutions of learning and others entitled to "duty free importation," we can furnish the above at European prices, which we will quote upon request. 
CHEMICAL SERIES.

No. 4524. Each, 50 cenis ; per dozen, $\$ 5,50$.

Aloin.

Boracic Acid.

Bromine (Bromide of lead).

Caffeine.

Carbonate of Cerium.

Chronium (Potassium Chromate).

Hydrastine.

Iodide of Lead.

Iodide of Mercury.

Manganese (Potassium Permanganate.)

Molybdate of Ammonium.

Hippuric Acid.

Nitrate of Nickel.

Nitrate of Strontium.

Oxalate of Calcium.
Oxide of Arsenic.

Phosphate of Magnesium.

Silver (Reduced).

Sulphate of Atropia.

Sulphate of Chinchonidia.

Sulphate of Iron.

Sulphate of Lithium.

Sulphate of Morphia.

Sulphate of Quinia.

Sulphate of Quinidia.

Sulphate of Strychnia.

Sulphate of Zinc.

Sulphide of Tin.

Sulphur.

Tartrate of Antimony.

\section{PREPARATIONS SPECIALLY SELECTED FOR USE WITH THE POLARISCOPE.}

No. 4526. Each, 50 cents; per dozen $\$ 5.50$.

Borate of Sodium.

Chloride of Barium.

Chloride of, Cobalt.

Eikonogen.

Ethyl Gallate.

Hydroquinone.

Kinate of Quinia.

Murexide (Dichromatic).

Phenacitin.

Pyro.Gallic Acid.
Pyrogallol.

Quinidine.

Salicin.

Saccharine (Benzoic sulfinine).

Santonin.

Sulphate of Brucia.

Sulphate of Cadmium.

Sulphate of Codia.

Sulphate of Copper.

Triple Phosphate.

\section{MISCELLANEOUS.}

No.

Price.

4525, WORMS-

Ascarides and Ova from Child, _ _ _ _ _ _ $\quad \ldots \quad \ldots \quad$ Each, \$ $\$$ _ 75

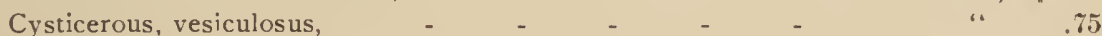

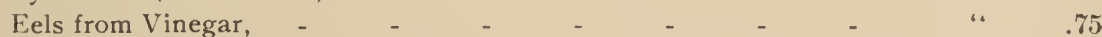

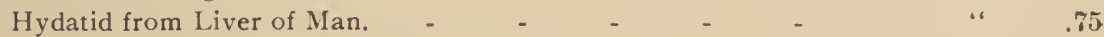

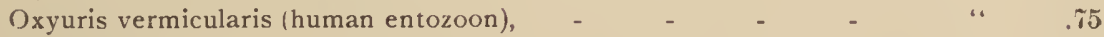

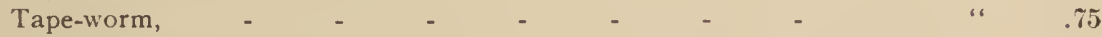

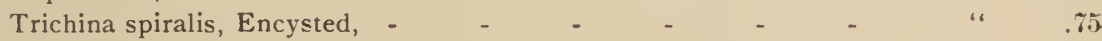

“ “

4.3.30, Mollusca-

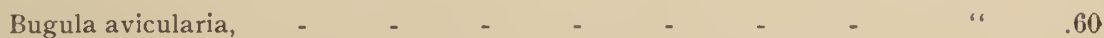

Embryo oysters, in fluid moving, _ _ _ _ _ _ _ _ $\quad$ " $\quad 1.00$

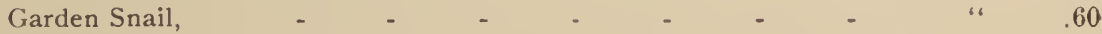

4532, RADIATA-

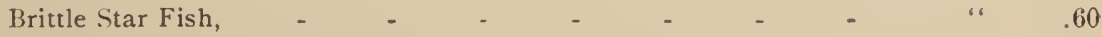

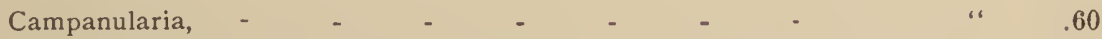

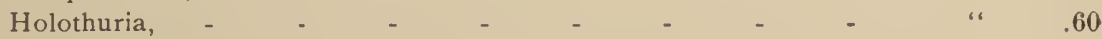

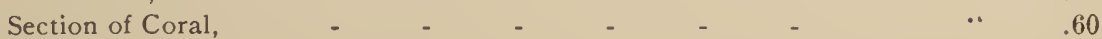

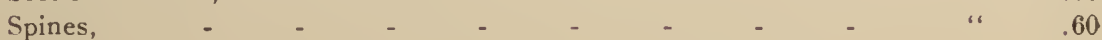

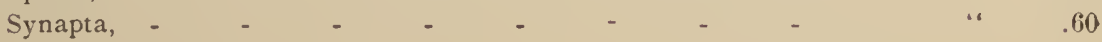




\section{MISCELLLA NEOUS.-CONTINUED.}

4.5:34, PROTOZOA-

Sponge,

Spiculae,

Foraminifera,

I'olycystina,

4.):6, VEGETABLE KINGDOM-

Frond of Fern,

Spores of Fern,

Corn Simat,

Ilould, mucor mucedo,

Potato Mould,

Red Rust,

Simut in Ear and Grain of Wheat

Spores of Yeast Plar.t,

Volvox Glotator,

Edible Earth from Java,

Sea Soundings, Atlantic Ocean,

Sea Soundings, Indian Ocean, .

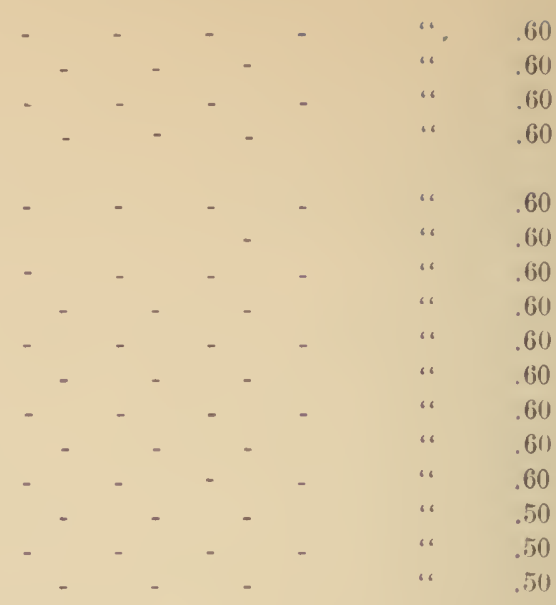

TEST OBJECTS.

No. 453S. Each, 60 cents; per dozen, $\$ 6.00$.

DIATOMS, DRY OR IN STYRAX.

Amphipleura Pellucida.

Frustulia, saxonica,

Grammathophora Marina.

$$
\text { “ subtilisima. }
$$

Navicula Rhomboides.

Nitzschia Sigmoides.

Pleurosigma, Angulatum.

$\begin{array}{cl}\text { “ } & \text { Acuminatum. } \\ \text { “ } & \text { Balticum. } \\ \text {. } & \text { Elongatum. } \\ & \text { Fasciola. }\end{array}$

Surirella Gemma.

\section{MOELLER'S ARRANGED DIATOMS.}

45.52, Diatomaceen Probe Platte, 60 diatoms arranged in line according to their value

$$
\text { . Dry, }
$$

$$
\begin{array}{ccc}
\text {. } & \text { “ } & 25 \\
\text { ، } & \text { “ } & 40 \\
\text { ، } & \text { “. } & 55 \\
& \text { “ } & 70
\end{array}
$$

tomaceen Probe Platte, 20 diatoms arranged in line according to their value as test objects, in case with printed list. as test objects, in case with printed list.
Prepared in styrax
" Dry,

Hair of American Bat.

Hair of Indian Bat.

Foot of Water Beetle.

l'roboscis of Blow Fly ( 15 cents).

Scales of Lipisma saccharina.

" of l'odura I'lumbea.

“ of Hipparchia Janira.

.. of Morpho-Menelaus.

Hair of Dermestes, larva.

Hair of Indian Mouse.

Pygidium, Flea.
60

4554, Diatomaceen Typen P'latte, systematically arranged, prepared in balsam with name of diatoms photographed beneath it, in case with printed catalogue.

100 diatoms,

Styrax has been substituted for balsam, as objects mounted in it are better 


\title{
ARTIFICIAL MICROSCOPIC OBJECTS.
}

\author{
No. Hijti. Micro-P'hotographs. Each, 50 cents ; per dozen, \$5.00.
}

Iddress to Light, by Milton.

I Glimpse at an English llomestead.

Apollo and Daphne.

A lortrait badly paid for.

Apostrophe to the Ocean, Byron.

"Bab Ballads", Captain Keece, K. N.

IBenjamin Franklin.

Cupid and I'syche.

Dignity and Impudence.

Dr. Carpenter, (W. B )

Ecce Homo.

Fingal's Cave.

Genesis, Chap. I. (New Version after Darwin). George Washington.

Gladstone.

Gray's Elegy.

Group of Elephants, from life.

II amlet's Soliloquy.

Happy as a King.

Jesus bearing the Cross.

Laying down the Law.

Map of North America.

Morning Hymn, Milton.

Niagara Falls.

Origin of Species, macle easy.

l'anoramic View of Paris.

Paul I'reaching at Athens, (Raphael).

Planet Jupiter, Belts and Moons.
Planet Saturn, Rings and Moons.

President Lincoln and ten Union Statesmen.

Psalm of Life, by Longfellow.

Pyramid of Ghizeh.

Rustic Felicity.

Sermon on the Mount.

Signing of the Declaration, 1\% 6 .

Song of the Shirt.

"Suffer Little Chilkren to come unto Me."

Taking Down from the Cross.

The liashful Lover and the Maiden Coy.

The Bower of Idam and Eve, Milton.

The Creed.

The Crucifixion, (M. Angelo).

The Death of the Stag.

The Gardener's Daughter.

The Great Rosse Telescope.

'The Lord's I'rayer.

The Moon.

The Moon, two l'hases, Full and Gibbous (75c.)

The stag at Bay.

The Ten Conmandments.

The Three Graces.

The Village Blacksmith, by I,ongfellow.

Title-page of Punch.

Venus.

Yarn of the Nancy liell.

windsor Castle.

\section{EDUCATIONAL SERIES.}

Each 30 cents ; per dozen, \$3.00.

For the use of schools, students and investigators who often find the need of special-microscopic preparations, we offer the following line of objects. They are neatly mounted on the usual $3 \times 1$ in. slides, and securely finished with a plain ring of transparent cement ; they are, however, less elaborately prepared and finished than the preceeding. We recommend them as thoroughly reliable for use, whether in the laboratory or class-room. For teachers desiring to illustrate widely different lines of study, at small cost, they are particularly well adapted.

No.

Blood of man, dog, cat, ox, frog, fish, snake, fowl, etc.

Human. Sections of finger, eye-lid, chin, nose, liver, lung, kidney, bone, ear, skin, scalp, spinal cord, brain, etc.

Bird. Sections of brain, spinal cord, trachea, stomach, intestine, skin, lung, etc.

Calf. Sections of ear, retina, skin, spinal cord, artery, vein, stomach, kidney, lung, etc.

Cat. Sections of tongue, nose, lip, trachea, stomach, duodenum, ileum, kidney, lung, liver, pancreas, spleen, foot, skin,'etc.

l.izard. Sections of stomach, and other organs in situ.

Rabbit. Sections of brain, medulla, spinal cord, ear, tongue, lip, nose, foot, stomach, duodenum, ileum, kidney, lung, liver, pancreas, ecc. 


\section{EDUCATIONAL, SERIES-CONTINUED.}

No.

Rat. Sections of tongue, nose, lip, jaw, stomach, duodenum, ileum, kidncy, lung, liver, pancreas, foot, skin, etc.

Snake. Sections of brain, stomach, kidney, intestine, etc.

4560 ,

Actinolite, asbestos, amygdalin, berberine, bi-chromate of potassa, caffeine, chloride of strontium, chrome alum, hippuric acid, limonite in muscovite, nitra-prusside of sodium, oxalate of ammonia, picrate of ammonia, palminitic acid, sulphate of copper, stearic acid, salicin, satin spar, theine, etc.

4562 ,

ILANT TISSLES.

Epidermis with stomata of grass, Indian corn, aloe, apple, iris, yucca, equisetum, deutzia, etc.

leaves. Sections of aloe, ricinus, India rubber tree, iris. lily, etc.

l'ollen of mallow, Hibiscus, Althea, Coboea, passion flower, pine, morning glory, Oenothera, etc.

Seeds opaque, of Silene, Lychnis, Stellaria, l'ortulaca, Drosera, Oxalis, Cerardia, l'enstemon, etc.

Spirals (dissected) of ricinus, lotus, etc, and scalariform ducts of fern.

Stems. Sections of burdock, clematis, maple, mahogany, cane, sedge, lily, fern, equisetum, etc.

4564 ,

Antennae of butterfly, moth, beetle, cricket, bee, cockroach, centipede, etc.

Corner of house fly, meat fly, horse fly, bumble bee, honey bee, wasp, hornet, moth, butterfly, beetle, grasshopper, cricket, cockroach, dragon fly, etc.

Feathers of fowl, guinea fowl, bobolink, humming bird, parrot, peacock, sparrow, canary, blue jay, etc

Fibres of cotton, flax, ramie, hemp, jute, manilla hemp, pine-apple, merino wool, Lincoln wool, Cotswold wool, Donskoi wool, liagdad wool, Cashmere goat hair, camel's hair, alpaca, vicuna; silk of Chinese, Italian and French silkworm ; silk of Cecropia silk-worm, etc.

Gizzard of field cricket, mole cricket, cockroach, katydid, beetle, etc.

Hairs of cat, dog, mouse, rat, mole, ground mouse, goat, cow, horse, bat, caterpillar, dermestes, rabbit, squirrel, man, etc.

Head of small bee, house fly, meat fly, male mosquito, female mosquito, bug, grasshopper, etc.

Legs and feet of spider, honey bee, beetle, cricket, house fly, meat fly, centipede, mosquito, gyrinus, notonecta, etc.

Ovipositor of house fly, meat fly, cricket, grasshopper, katydicl, etc.

Parasites. Flea of cat, dog and man ; bed-bug, head louse, wood tick, sheep tick; lice of fowl, pigeon, swallow, beetle, house fly, grasshopper, etc.

Proboscis of butterfly, moth, honey bee. bumble bee, fly, etc.

Scales (opaque) of diamond beetle, wings of moth, silkworm moths, butterfly, etc.

Scales of azure blue butterfly, silkworm moths, various butterflies, dermestes, lepisma, etc. Scales of trout, shad, eel, perch, sole, pike, herring. shark, etc.

Spicules of sponge, gorgonia, etc. ; foraminifera, polycystina, etc.

Spiracles of blow fly, house fly, silk worm, tolacco worm, honey hee, grasshopper, spicler, etc.

Wings of honey bee, bumble bee, crane $13 y$, mosquito, house fly, meat fly, butterfly. moth, lace-wing fly, dragon-fly, etc.

\section{STUDENT SERIES.}

rach 10 cents; per dozen, $\$ 1.00$.

4566, Imported objects, on slides $23_{8}^{3} \times \frac{3}{4} \mathrm{in}$. paper covered, comprising parts of insects, hair, feathers, starch, fibres, etc, 


\section{BOOKS ON OPTICS AND OPTICAL INSTRUMENTS.}

No.

4800, ALIING, CHAS. E. Microscopical Records. It is based on a form prepared by Prof. S. H. Gage, 13. S. of Cornell University, and fills a want for which nothing has heretofore been provided.

j00 objects. Postage 16 cents. Net, 1000 objects. Postage 16 cents. Net,

$480^{\circ}$, BAILEY, W. W. liotanical Collector's Handbook, with many illustrations, 12no., cloth. Postage ! cents. Net,

4804, BAI,LARD, J. P. Among the Moths and Butterflies. A revised and enlarged edition of "Insect Lives," 8vo. Illustrated. l'ostage 15 cents. Net,

430), B.IUSCH, EDWARD. Manipulation of the Microscope. Second Edition. Bound in cloth. Postage 5 cents,

4808, BEALE, LIONEL, S. How to work with the Microscope. Fourth Edition. Postage 24 cents. Net,

4810, BEALE, I.IONEL, S. The Microscope in Medicine. Fifth Edition. Postage 26 cents. Net,

4812, BEllRENS, J. W. A Guide for the Microscopical Investigation of Vegetable Substances Translated from the German of Dr. Julius Wilhelm Behrens. By Rev. A. B. Hervey. 475 pages, profusely illustrated. Postage 27 cents. Net,

4814, BEHRENS, J. W. Guide to the Microscope in Botany. Translated and revised by Rev. A. B. Hervey, A. M. Postage 24 cents. Net,

4\$16, BESSEY, CHARLES E., Ph. D. Advanced Course, liotany for High Schools and Colleges. Postage 24 cents. Net, - - - - -

4818, BESSEY, CHARLES E, 1'h. D. Briefer Course. The Essentials of Botany. I'ostage 11 cents. Net,

4820, BLACKHAM, DR. GEO. E. Angular Aperture of Microscope Objectives. Postage 8 cents. Net,

4822, CARPENTER, WM. B. The Microscope and its Revelations. Seventh Edition. Revised by the Rev. W. H. Dallinger, I.. L. D., F. R. S., etc. Postage 36 cents. Net,

48:4, COOKE, M. C. 1000 Objects for the Microscope, with 400 engravings. Post

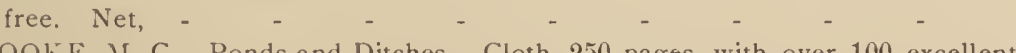

48:6, COOKE, M. C. Ponds and Ditches. Cloth, 250 pages, with over 100 excellent illustrations, especially referring to microscopical objects. Postage $6 \mathrm{cts}$. Net,

4828, COOKE, M. C. Microscopic Fungi; an introduction to the study of Rust, Smut, Mildew and Mould. Illustrated by nearly 300 figures, colored. Postage 8 cents. Net,

4\$30, CROOKSHANK, EDW. M., M. B. A Manual of Bacteriology. New Edition. Postage 20 cents. Net,

4832, CROOKSIIANK, EDW. M., M. B. Photography of Bacteria. Illustrated by 86 photographs, reproduced in autotype, and 6 wood cuts. R. 8vo., Cloth. Postage 14 cents. Net,

4834, DAVIES, THOMAS. The l'reparation and Mounting of Microscope Objects. New Edition. Post free. Net, - $\quad$ - $\quad$ - $\quad$ - $\quad$ - $\quad$ -

4\$36, DAVIS, GEO. E. Practical Microscopy. Illustrated with 310 illustrations and a colored frontispiece. New and revised Edition. Postage 16 cents. Net,

4838, DOLLEY, CHAS. S., M. D. The Technology of Bacteria Investigations. Explicit directions for the study of Bacteria. Postage 10 cents. Net, - 


\section{BOOKS ON OPTICS AND OPTICAL INSTRUMENTS-CONTINUED.}

No.

4\$40, FREY, H. The Microscope and Microscopic Technology, A text-book for physicians and students. Illustrated by :384 engravings on wood. Octavo, (66i) pages, cloth. Post free. Net,

4842, FRIEDLANDER, CARL. Microscopical Technology. For use in the Investigations of Medicine and Pathological Anatomy. Translated from the second enlarged and corrected edition by Stephen Yates Howell, M. A., M. D. Post free. Net,

484.4, GAGE, SIMI)N HENRY. The Microscope and Histology. Part 1., 5 full page plates and 8 figures in the text, heavy manilla. I'ostage 7 cents, - 1.0

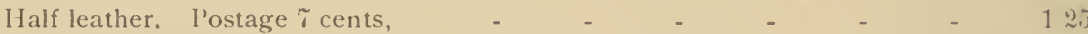

4846, GIBBES, HIENEAGL. Practical II istology and l'athology. Third Edition.

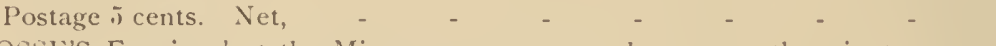

4818, GOSSE'S Evenings' at the Microscope, or researches among the minute organs and forms of animal life. 12mo. Postage 1:3 cents. Net,

4xiñ, HEITZ.MANN, C., M. D. Microscopical Morphology of the animal Body in Health and Disease. $3 \$ 0$ original engravings, made expressly for this work from Irawings by the Author. Bvo.. cloth. Postage 30 cents. Net,

4 Si2, JAMlES, FRANK L., PII. D., II. D. Elementary Microscopical Technology, Part 1. The Technical History of a Slicle from the crude Material to the finished mount. Cloth, stiff cover. P'ost free. Net,

Flexible cover.

Paper cover,

Price. (6.)0

4854, HOGG, JABEZ. The Nicroscope; its IHistory, Construction and Application. Illustrated with upwards of 500 engravings and colored illustrations. 750 pages. Seventh Edition. Postage 1\% cents. Net,

4856, KINGSI_EY, J. S. The Naturalists Assistant. With many lllustrations. A perfect Guide. 12mo., cloth. Postage 12 cents. Net,

4Ais, IANCASTER; EDIVIN. Ilalf Hours with the Microscope; being a popular guide to its use. New Edition. P'rofusely illustrated. Postage j cents. Net,

4860, L.EL. Vade Mecum. Second Edition. l'ostage 1.) cents. Net, - - 4.00

4N62, MACIONALD, Examination of Water. Postage 10 cents. Net, - - 2.it

4\&(it, MARSH, SYLVESTER. Section Cutting; a Practical Guide to the Preparation and Mounting of Sections for the Microscope, special prominence being given to the subject of Animal Sections. American Edition, 1879, cloth. Postage 4 cents. Net,

4866, MATILEWS, CHAS. GEO. and LOTT, FRANCIS E. The Microscope in the lirewery and Malt IIouse. Illustrated Svo, cloth. Postage 13 cents. Net,

4R68, MICROGRAPIIIC DICTIONARY. 13y J. W. Griffiths and Arthur Ilenfrey. 8 iij pages, illustrated by 53 plates and 800 wood engravings. Fourth Edition, Postage :3i cents. Net,

48\%, MILLER, MAURICE N. Practical Microscopy Illustrated with 126 photographical reproductions of the author's pen drawings Postage 13) cents. Net,

4872, NAVE, JOLANN. Handy-Book to the Collection and Preparation of FreshWater and Marine Algre, Diatoms, Desmids, Fungi, I,ichens, Mosses and other of the Lower Cryptogamia. Translated by Rev. W". W. Sipicer, A. M., I.ondon, 1 vol., $16 \mathrm{mo}$. l'ostage 5 cents,

48i.4, PEYER, ALEX, M. D. An Atlas of Clinical Microscopy. Translated by A. C. Girard, M. D. 8vo, cloth. Post free. Net, - - - -

4Si(i, I'ENIIALLOW, D. P. Vegetable II istology Tables for the use of Students. Svo., cloth. l'ostage $\boldsymbol{i}$ cents. Net,

48is, PIIIN, JOIIN. P'ractical Hints on the Selection and Use of the Microscope. New Edition, 231 pages, highly recommenled. P'ostage 8 cents. Net,

4\$80, I'RINGLE, ANDREW. P'ractical Photo-Mirrography. Fully illustraterl. Cloth bound. Post free. Net 


\section{BOOKS ON OPTICS ANI) OPTICAL INSTRUMENTS-CONTINUED.}

No.

4S4: IROCTOR, RICIIARD A. Half IIours with the Telescope. With numerous

illustrations on stone and wood Postage 4 cents. Net,

4884, SLACK, HINRY J. Marvels of Pond Life. Second Edition. With colored plates and numerous wood-cuts. P'ost free. Net, - _ _ _ .

4R86, S.IITII, J. EDW.IRDS. II ow to see with the Microscope. 400 pages, illustrated. Postage 14 cents. Net,

4S4, STOKES, ALFRED C., M. D. Microscopy for leginners, or common objects

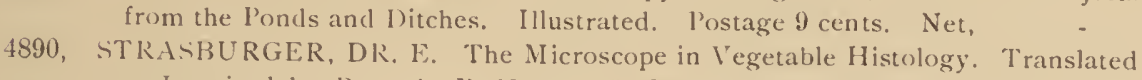
and revised by Rev. A. B Ilervey, A. M. Illustrated, \&ro., cloth. l'ostage 17 cents, Net,

4892. TRELEASE, WM. Botanical Micro-Chenistry. From the original of $V$. $\Lambda$. Poulsen. 12mo, cloth. I'ostage 5 cents. Net, - _ _ $\quad$ - 100

4N.9, WHITMAN, C. O. Methods of Microscopical Investigations in Anatomy and Embryology. Illustrated, Sro., cloth. Postage $1+$ cents. Net, - -

4\$96, WOUD. J. ( . Common ()bjects of the Microscope. With upwards of 400 illus. trations, printed in colors. I'ostage 3 cents. Net,

I'lain plates. Postage :3 cents Net, _ _ _ _ _

4R.S, WORMLEY, THEODORE G., M. D., PH. D., I.L. D. Micro-Chemistry of

I'oisons. Including their l'hysiological, Pathological and I.egal Relations. With an Appendix on the Detection and Microscopic Discrimination of the Blood. Adapted to the Use of the Medical Jurist, Physician, and General Chemist. By Theodore G. Wormley, M. D., I'h. D., LL. D., Professor of Chemistry and Toxicology in the Medical Department of the University of Pennsylvania. A new revised and enlarged Edition, with new Illustrations. Large 8vo. Extra cloth. I'ostage :35 cents Net, 
Abbe Condensers. Sub-stage.

Abbe Improved, Camera Lucida,

Absolute Alcohol, Dr Squibbs,

Accessorics,

Accessories for Telescopes,

Achromatic Amplifiers,

Achromatic Triplets,

Icid. Nitric,

Idapters,

Alcohol, Absolute, Dr. Squibbs,

Amber Cement.

Ammonia Carmine,

Amplifier, achromatic

Analyzer.

Anatomical Instruments-Dissecting,

Anatomical Scissors

Anatomical Sets, Diss. Inst.

Aniline Oil.

Aniline Stains,

Aperture, numerical table of,

Apparatus.

A pparatus for Numeration of Blond Corp. w

Apparatus for Solidifving lilood Serum, 76

Apparatus for Steam Sterilization, - 73

Ipparatus for Vegetation,

Asphaltum,

Atwood Rubber Ceils,

Arnold's Steam Sterilizer,

Bacillus Tuberculosis Stain,

Balsam, Canada,

Basket, Sterilization,

Bath, Paraffine.

Bath, Water ar

Beaker Glasses,

Bell Glasses, $\quad$ - $\quad$ - $\quad$ -

Benzole,

Binocular Microscopes, _ _ _ $\quad 36,37$

Bismarck Brown _ _ _ _ 90

lilock Tin Cells, - $\quad$ - $\quad$ - $\quad 91$

Blue Glass, Hopkins.

Books on Optics and Optical Instruments,

Borax Carmine,

lotanical and Microscopical sets Dissecting Instruments,

Botanical Instruments, Dissecting,

Bottles, Capped,

Bottles, Collecting.

linttles, Dropping,

Ijox metal sterilization,

Box Slide, cloth covered,

Boxes, Mailing.

Bradley's Mailing Cases,

Brain Knives,

Brass Table,

Brown's Transparent Rubber Cement, Brunswick Black,

liulls Eye Condensers,

Cabinets, Pillsbury's,

Cabinets, Portable.

Calspar, Quartz Selenite and Mica Preparations,

Camel's Ilair Pencils,

Camel's 11 air l'encils, Swan quill,

Camera Lucida,

Camera Photo-Micro, small,

Camera I'hoto-Micro, large.

Camera I'hoto-Micro, professional,

Canada Balsam,

Capped Bottles,

Carbonate of Potash,

Carmine Gelatine, Injecting,

60, 61

93. 94

94,95

96,92

is

$! 0$
Page.

62) ('arrier Slide and Glass Stage,

90 Cases, Mailing, Bradley's, -

1)-92 Cases, Ke-agent, _ _ _ _

100 Caustic l'otassa. $\quad$ _ $\quad \ldots \quad \ldots$

60 Cedar Oil, $\quad$ - _ _ _

101 Celloidine, - $\quad$ -

90 Cells, Atwood, Rubber, _ _ $\quad$ !

60 Cells, Block, Tin, _ _ _ 91

90 Cells, Glass, - $\quad$ - $\quad$ _

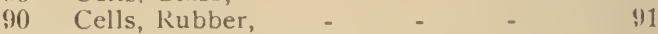

90 Cells, Zylonite, - $\quad$ - $\quad$ - 91

60 Cement, Brown's Transp. liubber, $\quad 90$

70 Cement, Kings, - _ _ _ - 90

86 C'ement, White Zinc, - $\quad$ - 9

84 Cloth Covered Slide Box, _ _ _ !

86 Cloves, Oil of, - _ _ $\quad$ - 90

90 Collecting Bottles, - $\quad$ -

90 Combined, Inverted and V'ertical Mi-

46 croscope, $\quad$ - $\quad$ - $\quad$ - 32-3i

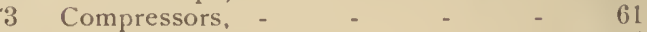

Compressors, Springs, - _ $\quad-\quad+60$

Concave and Convex l.enses, $\quad$ - 98

Condenser, Mounting, _ _ $\quad$ - $\quad 62,6 ; 3$

Condensers, bulls Eye, _ _ $\quad 61$

Condensers, Sub-stage, Abbe, - $\quad 62$

Continental Eyepieces, - $\quad 53$

Continental Microscopes, - $\quad$ - $\quad 9-13$

Continental Microscope, (small) A, 8,?)

Continental Microscope, (medium) 1;, 10, 11

Continental Microscope, (large) C, 12,13

Convex and Concave Lenses, - 18

Convex Condensing I enses, -

Cover Glass Forceps, $\quad$ - 80

Cover Glass or Slide Forcep, _ $\quad 84$

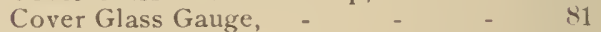

Covers, Thin Glass. $\quad$ - $\quad$ - $\quad 89$

Covers and Labels for tilides, $\quad$ - $\quad 89$

Crown Glass Slips.

Current Slide, Holman's, _ _ _ $\quad 66$

Damar - $\quad$ - $\quad$ - $\quad$ - $\quad 90$

Deane's Medium, $\quad$ - $\quad$ - $\quad 90$

90 Demonstration Lenses, - $\quad$ - 98

Diaphragm, Dome, - $\quad$ - 64

Diaphragm, Iris, - $\quad$ - $\quad$ - $\quad 64$

86 Differential screw, Fine adjustment,

i8 Dimensions of Microtomes, - 56

i⿱ Directions for ordering Fyepieces,

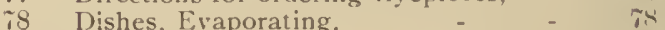

74 Dissecting Forceps, - -

91 Dissecting Instruments, Anatomical,

91 Botanical and Microscopical, - 86

91 Dissecting Knives, _ _

82 Dissecting and Section Knives, - 82

80 Dissecting Microscopes, - $34-43$

90 Dissecting . Iicroscope, (Educational) [C, 40, 41

90 Dissecting Microscope, (Excelsior

90

90 pocket). S,

Dissecting . Vicroscope, (Folding) $\mathrm{V}, \quad 42,43$

I)issecting Microscope, (1 Handy) R, ;3, 3!)

Dissecting Microscope, (Primary) T, 40, 41

Dissecting Microscope and Mounting Instruments, - $\quad$ - $\quad$ -

Dissecting Needle llolder, _ _ _ 83

Dissecting Needles, - _ n

Dissecting Scissors, - _ _ _ $\quad$ - 83,84

Dome Diaphragm, $\quad$ - $\quad$ - $\quad 64$

Double or Plano Convex and Concave Lenses,

Double P'rism Camera Lucida, -

Double IVall Sterilization Apparatus,

Draw-tube, graduated, _ _ _ 
l'age.

Dropping Bottles,

Educational Microscope, Dissecting, ${ }^{\circ}, 40,41$

Engraver Glass,

104

Eosine,

Fvaporating Dishes,

Excelsior I'ocket and Dissecting .licroscopes, $\mathrm{S}$,

Eyepiece Micrometer,

Eyepiece Micrometer, how to use,

Eyepieces,

Eyepieces, power of,

liyepieces, spectroscopic,

Eye Shades,

Farrant's Medium,

Ferro-Cyanide l'otassa.

Filar Micrometer,

Finder, Maitwood,

Fine Adjustment, Differential Screw,

Finger, Mechanical,

Fish Trough,

Folding Dissecting Microscope, $\mathrm{I}$,

Forceps, Cover Glass,

Forceps, Dissecting.

Forcep Slides or Cover Glass,

Forcep Stage,

Freezing Attachment,

Fritsch's Knives,

Fuchsine

Funnel, Hot Water.

Gauge, Cover Glass,

Gentian, Violet,

Glass, Cells,

Glass Covers, Thin,

Glass. Engraver,

Glass Pipettes,

Glass Slips, Crown,

Glass Slips, Plate,

Glass Spirit Lamps.

Glass Stage and Slide Carrier,

Glass Stirrers.

Glasses, Beaker,

Glasses, Watch,

Glasses, Watch, Sy racuse, _ _ _

Glasses, Watchmaker, _ _ _ 10 :

Glue, Hollis, - $\quad$ - $\quad$ - $\quad$ - 99

Glue, Vlarine,

Glycerine,

Gold Size.

Gradluated blue Glass,

Graduated Draw-tube,

Haemacy tometer,

I Jaemaglobinometer,

Haematoxylin,

Half Button, Wenham's

II ancly Dissecting Microscope, R, 34, 39

Harvard Microscope, E,

Hemispherical Illuminator,

Holder, Insecting, Needle,

llolder, linife,

Hollis, Glue,

IIolman's Current Slice,

Holman's Life-Slide.

Holman's Syphon-Slicle, - _ - 66

Hopkins Blue Glass,

IIot Water Funnel,

Huyghenian Eyepieces,

Illuminator, Hemispherical,

11 uminator, Vertical,

Improved Photo-Micro Camera (large) 94

Improved Photo-Micro Camera (small), 93, !)

Injecting Gelatine, Carmine,

Injecting Syringe,

Instructions for using Micrometer,
Instrument, Sterilizer, Special,

Instruments, Anatomical,

Instruments, Botanical,

Instruments, I )issecting,

Instruments, Microscopical,

Instruments, Mounting and Dissecting, if

Inverted and Vertical Xicroscopes, $32-35$

Investigator Microscope, 11, - _ 24, 25

Iodo-Iodide I'otassa, $\quad$ - $\quad \ldots \quad 90$

Iris Diaphragm, - $\quad$ - $\quad$ (j-t

Iris Diaphragm, Condenser Mounting, (i;

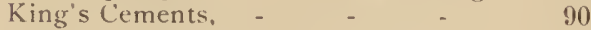

King's Lacquer Cell, _ _ _ _ $\quad$ - 90

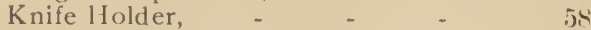

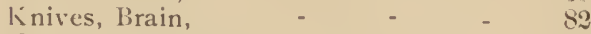

Knives, Cartilage, _ - $\quad 82$

Knives, Dissecting, - $\quad$ - _ $\quad$ -

Knives, Dissecting and tiection, -

Knives, Fritch's, - _ _ _ _

Kinives. Microtome, - $\quad 5$ - 5 -

Knives, Section, _ $\quad$ - $\quad$ - $\quad 82$

Kinives, Valentine, _ _ 82

Labels and Covers for Slides, _ $\quad$ - 9

Laboratory Microscope, M, _ $\quad 32,33$

1.aboratory Microtomes, - _ $\quad 54,55$

lacquer, Cell, King's, - _ $\quad 30$

Lamps, Spirit, Glass. $\quad$ - $\quad 80$

Large Continental Microscope, - $\quad 12,13$

Large Photo-Micro Camera, - _ 94, 95)

1.enses, Concave and Convex, - $\quad 98$

lenses, Condensing l'lano Convex, $\quad 98$

lenses, Demonstration, - . - 98

Library Microscope, D, - _ $\quad$ - 16,17

Life Box, - $\quad$ - $\quad$ - $\quad$ - 66

1.ife Slide, Holman's, _ $\quad$ - $\quad 66 ;$

lifter's, Section, - _ _ 85

I.inear Magnifying l'owers of Objectives and Eyepieces, $\quad$ - $\quad 4 \quad 47$

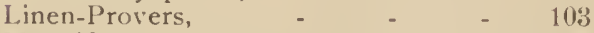

Magnifiers, - _ _ 101-104

Magnifiers, Coddington, _ _ $\quad$ - 101

Iagnifying Powers, Tube of, - 47

Mailing Boxes, _ $\quad$ - $\quad$ -

Mailing Cases, Bradley's, $\quad$ - $\quad 91$

Maltwood Finder, _ $\quad$ - $\quad$ - $\quad 0 \quad 66$

Marine Glue, $\quad$ - $\quad$ - $\quad$ - $\quad 9$

Mechanical Finger, - $\quad$ - $\quad 66$

Mechanical Stages, $\quad$ - $\quad$ - $\quad 67$

Medium, Continental Microscope, $\quad 10,11$

Metal Sterilization Box, - it

Methyl Stains, - $\quad$ - $\quad$ - 90

Mica, Calcspar, Quartz and Selenite Preparations,

Micrometers,

99

Micrometer, Instructions for using,

Mcroscopes, Binocular, - _ _ 36,37

Vlicroscopes for Special Purposes, $\quad 30-3 i$ )

Microscopical Instruments, Dissecting, $\quad 86$

Microscopic Objects, - - 105-114

Nicrotomes, - - - - $\quad$ - 54-57

Microtome Freezing Attachment, 57

Microtome linives, - $\quad$ - $\quad$ - 55

Microtome with clamp for Table Top, $\quad 5^{\text {r }}$

Model Microscope, F, - _ 20, 21

Mounting and Dissecting Instruments, 77

Mountings for Sub-stage Condensers, $\quad 62,63$

Mounting Stand, - $\quad$ - $\quad$ - 80

Mounting and Staining Media, - $\quad 90$

Mounting Table, _ _ _ 80

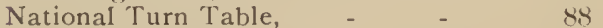

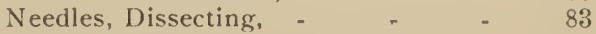

Needle-Holder, Dissecting, - 83 
. 

JUN 51946 
